\title{
/ Stories I Must Tell: \\ An Architectural Exploration
}

\author{
Thesis by: \\ Bobby Ilg \\ Thesis Supervisor: \\ Yves Gosselin \\ Secondary Advisors: \\ Bret Cardinal \\ Derek G. Smith
}

A thesis submitted to the Faculty of Graduate Studies and Research in partial fulfillment of the requirements for the degree of

\section{Professional Masters of Architecture}

\author{
School of Architecture \\ Carleton University \\ Ottawa, Ontario \\ May 2, 2005 \\ (C) copyright 2005 \\ Bobby Ilg
}




\section{Abstract:}

This thesis explores the potential of using multiple perspectives during the design process. This includes potential users of an architectural project, professionals in related fields, and various advisors. How does the designer respect his/her discipline while maintaining the views of the peoples integrated into the design process? What do the designer and potential users, when associated together during the design process, achieve?

This thesis uses architectural tools, for communication and of representation, to structure a clear understanding of the process to the multiple audiences. This resulted in a written and documented thesis structured around the narrative. The act of reading allows the audience to experience the exploration, both the architectural and cultural process, as one inseparable entity. The architectural process was the exploration of the thesis and the design project offered a context to explore this process. This is emphasized by the written structure of the thesis. 


\section{Table of Contents:}

Introduction --

pg 1

Let me introduce myself... --

pg 9

Part 1: Resurfacing Aboriginal Stories in Urban Saskatchewan --

pg 10

Part 2: In the Land of Stories /

Program, Urban Design, and Architecture --

pg 56

Part 3: Thunderbird House --

pg 183

Dave Thomas --

pg 187

Kyle Kennedy --

pg 192

Part 4: Approaching a Place for Gathering --

pg 195

A Place for Urban Gathering and the Sharing of Stories --

pg 199

Conclusion --

pg 217

Primary Bibliography --

pg 222

Secondary Bibliography --

pg 225

Appendix A: Letter of Information and Consent --

pg 229 


\section{List of Illustrations:}

Illus I - 1: Saskatoon Indian and Metis Friendship Centre --

pg 19

Illus I - 2: SIMFC front sign --

pg 20

Illus I - 3: White Buffalo Youth Lodge --

pg 20

Illus I - 4: Central Business District (CBD) of Saskatoon --

pg 24

Illus I - 5: Gathering site elevation (Kiwanis Park) --

pg 25

Illus I $-6: 360^{\circ}$ view of site context --

pg 25

Illus I- 7: Gathering site elevation $\left(21^{\text {st }}\right.$ street $)$--

pg 25

Illus I - 8: Bacon, "Principle of the Second Man," Design of Cities, 108-109. Addition to the piazza -pg 28

Illus I - 9: Bacon, "Principle of the Second Man," Design of Cities, 108-109. Sangallo's arcade --

Illus I - 10: Henderson, personal photograph. Aboriginal Day -pg 33

Illus I - 11: Henderson, personal photograph. Aboriginal Day -pg 33

Illus I - 12: Henderson, personal photograph. Aboriginal Day -pg 33

Illus I - 13: Henderson, personal photograph. Aboriginal Day -pg 34

Illus I - 14: Henderson, personal photograph. Aboriginal Day -pg 34

Illus I - 15: Henderson, personal photograph. Aboriginal Day -pg 34

Illus I - 16: Urban Documentation (Land Use Patterns) -pg 46

Illus I - 17: Urban Documentation (Entry Points) -pg 46

Illus I - 18: Urban Documentation (Public Parks) -pg 47

Illus I - 19: Urban Documentation (Important Views) -pg 47 
Illus II - 1: (C) DJC "Design Philosophies" (Collective Approach) -pg 58

Illus II - 2: (C) DJC “Design Philosophies” (Living Cell) -pg 58

Illus II - 3: (C) DJC “Design Philosophies” (Related Cells) -pg 58

Illus II - 4: (C) DJC “Design Philosophies” (Breathe Life) -pg 59

Illus II - 5: (C DJC “Design Philosophies” (Vision and Function) -pg 59

Illus II - 6: C DJC “Design Philosophies” (Grand Prairie R.C.) -pg 59

Illus II - 7: Gathering of programs -pg 73

Illus II - 8: Narrative through parti -pg 78

Illus II - 9: Breathing life into the program (Entrance from East) -pg 91

Illus II - 10: Breathing life into the program (Storytelling space) -pg 92

Illus II - 11: Breathing life into the program (Healing area) -pg 93

Illus II - 12: Precedent - First Nations Gardens Pavilion, Montreal. Saucier and Perrotte Architects (Pavilion Detail) -pg 95

Illus II - 13: Precedent - First Nations Gardens Pavilion, Montreal. Saucier and Perrotte Architects (Pavilion Detail) -pg 95

Illus II - 14: Precedent - First Nations Gardens Pavilion, Montreal. Saucier and Perrotte Architects (Panel Display) -pg 95

Illus II - 15: Breathing life into the program (Bed and Breakfast) -pg 96 Illus II - 16: Breathing life into the program (Bed and Breakfast) -- $\quad$ pg 96 Illus II - 17: Breathing life into the program (Bed and Breakfast) -pg 96 Illus II - 18: Repetition and Hyperbole (Entry from the East) -pg 110 Illus II - 19: Repetition and Hyperbole (Entry from the East) -pg 110 Illus II - 20: Repetition and Hyperbole (Entry from the East) -pg 111 Illus II - 21: Bus stop in Saskatoon's CBD -pg 122 
Illus II - 22: $21^{\text {st }}$ Street Promenade with the Bessborough Hotel -pg 122

Illus II - 23: Kiwanis Park on Aboriginal Day --

pg 123

Illus II - 24: Aboriginal Day at Friendship Park (2004) --

pg 125

Illus II - 25: Aboriginal Day celebrations (2004) --

pg 125

Illus II - 26: Alleyway observations --

pg 128

Illus II - 27: Alleyway observations --

pg 128

Illus II - 28: Alleyway observations --

pg 129

Illus II - 29: Alleyway observations --

pg 129

Illus II - 30: SCYAP and low-income housing --

pg 130

Illus II - 31: Interior of the SCYAP art gallery --

pg 130

Illus II - 32: Multi-use Learning environments --

pg 131

Illus II - 33: Saskatchewan Indian Institute of Technologies --

pg 132

Illus II - 34: The Gallery - art store --

pg 132

Illus II - 35: The First Nations Bank with the site behind it --

pg 133

Illus II - 36: Urban Design: Entrance from the alleyways --

pg 134

Illus II - 37: Urban Design: Aboriginal Gardens --

pg 134

Illus II - 38: Urban Design: Aboriginal Gardens --

pg 134

Illus II - 39: Urban Design: Aboriginal Gardens --

pg 135

Illus II - 40: Precedent - First Nations Gardens Pavilion, Montreal.

Saucier and Perrotte Architects (Panel Display) --

pg 135

Illus II - 41: Precedent - First Nations Gardens Pavilion, Montreal.

Saucier and Perrotte Architects (Birch Bark Tree) --

pg 135

Illus II - 42: Precedent - First Nations Gardens Pavilion, Montreal.

Saucier and Perrotte Architects (Panel Display) --

pg 135 
Illus II - 43: Precedent - First Nations Gardens Pavilion, Montreal.

$$
\text { Saucier and Perrotte Architects (Ash Tree) -- }
$$

pg 135

Illus II - 44: Urban Design: Aboriginal Gardens --

pg 136

Illus II - 45: Urban Design: Kiwanis Park --

pg 136

Illus II - 46: Urban Design: Aboriginal Day stage --

pg 136

Illus II - 47: Urban Design: Entrance from the Parkways --

pg 137

Illus II - 48: Urban Design: Entrance from $21^{\text {st }}$ Street --

pg 137

Illus II - 49: Urban Design: Entrance from the Alleyway --

pg 137

Illus II - 50: Repetition and Hyperbole: Entrance --

pg 140

Illus II - 51: Introduction to project: Leaf massing model --

pg 150

Illus II - 52: Introduction to project: Leaf massing model --

pg 150

Illus II - 53: Exterior/Interior --

pg 154

Illus II - 54: Exterior/Interior --

pg 154

Illus II - 55: Exterior/Interior --

pg 154

Illus II - 56: Keeping spaces open: Fire in the Healing rooms --

pg 155

Illus II - 57: Keeping spaces open: Translucent concrete

$$
\text { (C) http://www.litracon.hu -- }
$$

pg 155

Illus II - 58: Street level: Ground --

pg 156

Illus II - 59: Urban Gathering in Saskatchewan (1898)

(C) Saskatchewan Archives Board No. S-B4021 --

pg 157

Illus II - 60: Resurfacing gatherings in urban Saskatchewan --

pg 157

Illus II - 61: Parti: Narrative --

pg 161

Illus II - 62: 'Belonging' --

pg 162

Illus II - 63: Inverse of the Ground Materials --

pg 165 
Illus II - 64: Inverse of the Ground Materials -pg 165

Illus II - 65: Standing, Rising, and Opening -pg 166

Illus II - 66: Standing, Rising, and Opening -pg 166

Illus II - 67: Standing, Rising, and Opening -pg 166

Illus II - 68: Standing, Rising, and Opening -pg 167

Illus II - 69: Standing, Rising, and Opening -pg 167

Illus II - 70: Youth and Good Diet -pg 176

Illus II - 71: Youth and Good Diet -pg 176

Illus II - 72: Elders and Youth -pg 176

Illus II - 73: Elders and Youth -pg 177

Illus II - 74: Elders and Youth -pg 177

Illus II - 75: Concrete Detailing -pg 179

Illus II - 76: Concrete Detailing -pg 179

Illus II - 77: Window Detail -pg 179 
Illus IV - 1: Saskatoon, Saskatchewan: CBD --

pg 195

Illus IV - 2: Bird's-eye view of CBD --

pg 195

Illus IV - 3: $21^{\text {st }}$ Street Promenade --

pg 196

Illus IV - 4: $21^{\text {st }}$ Street entrance to Gathering site --

pg 196

Illus IV - 5: Alleyway leading to the Gathering site --

pg 197

Illus IV - 6: Alleyway extends into Gathering site --

pg 197

Illus IV - 7: The SCYAP and low-income housing --

pg 197

Illus IV - 8: The Saskatchewan Indian Institute of Technologies --

pg 197

Illus IV - 9: The First Nations Bank --

pg 197

Illus IV - 10: Introduction of Aboriginal Gardens to Meewasin --

pg 198

Illus IV - 11: Entrance from to Gathering site from Kiwanis Park --

pg 198

Illus IV - 12: $21^{\text {st }}$ Street Elevation with site context --

pg 199

Illus IV - 13: $21^{\text {st }}$ Street Elevation --

$\operatorname{pg} 200$

Illus IV - 14: Kiwanis Park Elevation with site context --

pg 201

Illus IV - 15: Kiwanis Park Elevation --

pg 202

Illus IV - 16: Alleyway Entrance Elevation --

pg 203

Illus IV - 17: South Elevation --

pg 204

Illus IV - 18: Below Grade Floor Plan --

pg 205

Illus IV - 19: Ground Floor Plan --

pg 206

Illus IV - 20: Second Floor Plan --

pg 207

Illus IV - 21: Third Floor Plan --

pg 208

Illus IV - 22: Fourth Floor Plan --

pg 209

Illus IV - 23: Fifth Floor Plan --

pg 210

Illus IV - 24: Approaching the Gathering centre --

pg 211 
Illus IV - 25: Precedent - First Nations Gardens Pavilion, Montreal.

$$
\text { Saucier and Perrotte Architects (Pavilion Detail) -- }
$$

Illus IV - 26: Precedent - First Nations Gardens Pavilion, Montreal.

$$
\text { Saucier and Perrotte Architects (Pavilion Detail) -- }
$$

Illus IV - 27: Entrance from $21^{\text {st }}$ Street --

Illus IV - 28: Bed and Breakfast room window details -pg 211

Illus IV - 29: Urban Entrance -pg 212

Illus IV - 30: Translucent concrete in the Storytelling area

$$
\text { (C) http://www.litracon.hu -- }
$$

Illus IV - 31: Precedent - Eberswalde Technical School

Herzog and de Meuron Architects (Concrete detail) -pg 212

Illus IV - 32: Interior Section/Perspective -pg 213

Illus IV - 33: East Entrance Detailed Perspective -pg 214

Illus IV - 34: Ground Plane/Dance Floor Detailed Perspective -$\operatorname{Pg} 215$ Illus IV - 35: Rooftop Garden Perspective: sharing familiar stories -$\operatorname{Pg} 216$

* All illustrations by author unless otherwise noted. 
Table of Appendices:

Appendix A: Letter of Information and Consent

Outline of methodology and authorization form for conversations -- $\quad$ pg 229 


\section{Introduction:}

$\underline{\text { Thesis Statement }}$

The exploration of the thesis is to examine the potential of obtaining multiple perspectives of a particular clientele or subject during the architectural process. Alvar Aalto addressed the principal inspiration for this exploration when he wrote,

"Architecture is a synthetic phenomenon covering practically all fields of human activity ... since architecture covers the entire field of human life, real functional architecture must be functional mainly from the human point of view." ${ }^{1}$ Through the rigorous process of understanding the people who will potentially use a space, how is the designer to maintain a clear design methodology and still respect the people for whom he/she is designing? In other words, what can the potential clients and experts in a particular field contribute to an architectural investigation? Finally, how can the tools for architectural communication, verbal, graphic, and written, be adapted and become part of this translation; conversations turned into a physical concretization?

The Plains Aboriginal peoples are the specific peoples chosen for this exploration. In Saskatchewan, the urban Aboriginal population is consistently growing, ${ }^{2}$ causing urban centres to react to this growing population. This transition also creates a circumstance where the culture struggles with an unfamiliar environment. NorbergSchultz describes, "Urban gathering may be understood as an interpretation of the local genius, in accordance with the values and need of the actual society." 3 The design

\footnotetext{
${ }^{1}$ Alvar Aalto, In his Own Words, 102.

${ }^{2} 2001$ Canadian Census conducted by Statistics Canada.

${ }^{3}$ Norberg-Schultz, Genius Loci, 170.
} 
objective of the project is to create a space that 'belongs' to the city of Saskatoon, while offering a 'familiar' and recognizable environment to Aboriginal peoples.

Recurring conversations with potential users, professionals associated with the culture, and academic ethnographic methodologies will establish an understanding of the Aboriginal culture. The advisors were chosen in regards to their understanding of the culture and design problem, while providing different perspectives of the same project. The cultural understanding (stories) is interpreted into the architectural process using an appropriate design tool, for communication and of representation, the narrative. The architectural project exists as the context that the societal explorations could be explored in and how they would be represented. In response, the thesis examined methods for communicating these findings and explorations, both graphically and written, to the people it brought into the project. This includes the people from the academic profession of architecture, professionals associated with Aboriginal culture, and potential users of the architectural project.

In addition, the exploration of the thesis is an opportunity to reflect upon personal questions regarding the architectural process and establishing an understanding toward a society of peoples. These are personal concerns that had to be attended to. The thesis allowed for one issue to stimulate questions and resolutions about the other, and vice versa. The context of a thesis, the final academic exploration in the architectural education, is an appropriate situation to investigate such personal issues. These issues were dealt with for future reference and understanding, both personally and professionally. 
Stories - The Narrative Structure

"The truth about stories is that that's all we are," explains Thomas King, an Aboriginal writer and storyteller, referring to his culture's relationship with stories. Ethnographic methodologies, research, and Aboriginal literature led to a cultural understanding of stories and narratives. Aboriginal peoples live their lives through stories by making reference to these stories to describe life events. ${ }^{5}$

Stories are recognized in the places Aboriginal peoples live. Margaret Bruchac is an Aboriginal anthropologist who portrays the relationship Aboriginal peoples have with the stories initiated in their environment. She quotes Keith Basso:

Landscapes are always available to their seasoned inhabitants in other than material terms. Landscapes are available in symbolic terms as well, and so, chiefly through the manifold agencies of speech, they can be 'detached' from their fixed spatial moorings and transformed into instruments of thought and vehicles of purposive behaviour. Thus transformed, landscapes and the places that fill them become tools for the imagination, expressive means for accomplishing verbal deeds, and also, of course, eminently portable possessions to which individuals can maintain deep and abiding attachments, regardless of where they travel. ${ }^{6}$

Aboriginal peoples recognize stories embedded in the landscape throughout North America. $^{7}$ The landscape and environment initiate stories. These stories are Indigenous, being of a place, ${ }^{8}$ and are embedded in the people who live there. Native peoples believe this; therefore the narrative, or story, is used as the primary design tool in the architectural project.

\footnotetext{
${ }^{4}$ King, Truth About Stories, 2.

${ }^{5}$ Cruikshank, Life Lived Like a Story.

${ }^{6}$ Bruchac, "Earthshapers and Placemakers," 9.

${ }^{7}$ Kyle Kennedy, interviewed in person by the author on 14 October 2004.

${ }^{8}$ Deloria and Wildcat, Power and Place, 31.
} 
Using the written thesis as a tool for communication, the thesis is written in the structure of a narrative. This narrative becomes an experiential and learning tool that initiates and assists the architectural exploration. This allows for an understanding of the narrative's role in the cultural and architectural context. The narrative reveals how it is told (rhetoric) and read (interpreted), and it communicates how the architectural discipline may use the narrative as a potential tool of representation. The narrative reads as a journal depicting the explorations, both architectural and cultural, which developed during the thesis. The written portion of the thesis signifies the cultural understanding, process and experiences investigated in the architectural project. This thesis articulates the written and design components as one entity that cannot be separated from the other.

Michael Ling is an anthropology grad from Carleton who worked on a thesis regarding narratives. How to respond to the "needs of those whose lives we inquire into, and the desires of the ethnographer, ${ }^{, 9}$ was his concern. In this circumstance, the desires of the architect or designer are of concern. He persuades the reader in his thesis to observe academic writing as a story, not so different from oral traditions. Both are rhetorical styles of communication directed at a specific audience. His thesis was structured as a prefaced examination of ethnography and its role in societies, followed by the scholarly content in the form of conversations between the participant and ethnographer.

The narrative written structure allows the reader to understand the nature of the narrative by becoming a part of the narrative itself. The result, as in Michael Ling's thesis, reveals an understanding of narrative through the act of participating and

\footnotetext{
${ }^{9}$ Ling, "Between the Tongue and the Teeth," ii.
} 
experiencing a narrative, both written and architectural. This process differs from standard scholarly practices where the author persuades the audience what a narrative is and does, without actually allowing the audience to engage in a narrative. Through experiencing and therefore, understanding the structure of a narrative, a scholarly discipline is recognized, and the participant is able to see how his/her contribution (his/her stories) directly impacted the thesis.

The voice of the narrative is written in first person for two reasons: one, to allow the voice of the teller to directly communicate with that of the reader; and two, to articulate the voices of those participating in the architectural process. All participants, both actual conversations and scholarly texts, are represented as dialogues to keep with the narrative. This signifies the equality of all participants. An elder's voice is as important to this exploration as Christian Norberg-Schultz's voice. Through the communication between the narrator and reader, it emphasizes the reader's participation in the thesis itself. There cannot be a separation between the narrator and the reader. ${ }^{10}$ The experience of the story is rhetorically presented to the reader through the actual performance of the story. By writing the thesis in the form of a narrative, the emphasis is placed on the stories; the stories told by the people participating in the thesis exploration, which eventually became the stories embedded in the urban and architectural design project.

The completed thesis document will be provided as remuneration to the people whose conversations compose the narrative. Academic cultural authorization was obtained from the participants involved in the conversations before deciding to share their

\footnotetext{
${ }^{10}$ Barthes, "Introduction to the Structural Analysis of Narratives," 56.
} 
stories (see outline in Appendix A). It is respected in the discipline of anthropology to give something in return to those lives one inquires into. With respect to architecture covering all fields of human life, the thesis is a tool for architectural communication, offered, in return, to the Aboriginal peoples and professionals partaking in the thesis. The narrative written structure reveals the understanding it obtained of the Aboriginal culture, while creating a narrative relationship to architecture and the urban environment. The narrative uses a voice 'familiar' with the chosen Aboriginal peoples, a voice originating in Saskatchewan. The 'Saskatchewan voice' is essential to the communicative qualities of the narrative, because it is recognizable and respected.

The scholarly audience is persuaded to see this methodology as a rigorous exploration that cannot remove itself from the people and the architectural process it engaged in. The Dauenhauers, who have experience transcribing oral traditions, explain, "Narrative frameworks are a preface in which the storyteller somehow identifies him- or herself, traces knowledge of the story from a reliable source, asserts the right to transmit the story, and in other ways establishes the context for and validity of the performance."11 This narrative framework is used to persuade the multiple audiences of this thesis to observe the investigation as a series of stories that construct themselves around the context of an architectural project.

Lastly, the narrative structure is used to emphasize the life of a story; a story never ends, only begins again. ${ }^{12}$ As with any story, this thesis is meant to initiate new stories; stories about the urban environment; stories about architecture; and stories to be shared between cultures.

\footnotetext{
${ }^{11}$ Dauenhauer and Dauenhauer, "The Paradox of talking on the Page," 9.

${ }^{12}$ Ling, "Between the Tongue and the Teeth," 23.
} 


\section{The Architectural and Urban Design Project}

The design project, the context for the thesis, is an Aboriginal centre for gathering. The program responded according to the site context and the associated peoples in the urban centre of Saskatoon. Both the urban and architectural process initiated conversations regarding culture. The issue of Aboriginal peoples moving into the urban centre is an urban concern, the building being one extension of this. Existing urban situations provided certain programmatic and design decisions in the building and the surrounding context.

The narrative is the design tool, for communication and of representation, used in the project. Norberg-Schultz explains, "We have to be able to 'see' the meanings of the things that surround us; be they natural or man-made. Things always tell several stories; they tell about their own making, they tell about the historical circumstances under which they were made, and if they are real things, they also reveal truth." 13 How a thing is made, determines the story that it reveals in the experiential world. This includes: program - deciding and organizing thereof; structuring urban design and building characteristics; and detailing specific experiential moments. This is the extent of the architectural project.

As stated earlier, the design project provided the context for the thesis exploration. Thus, such building characteristics as mechanical systems and specific technical and detailed resolutions will not be explored in the project. The limitations of the architectural solution, due to time restraints and the appropriateness towards the

\footnotetext{
${ }^{13}$ Norberg-Schultz - Genius Loci. Pg. 185.
} 
exploration, required focus on the most apparent narrative qualities of the building and urban design. Using vignettes, plans, elevations, and sections, the participant's narratives will be initiated in the urban and building context.

This thesis is an exploration involving potential users, experts in a specific field, and using multiple perspectives to initiate and construct an architectural process. The narrative language is the appropriate tool, for communication and of representation, in this context. It is used to connect the cultural exploration with the architectural project. Through the narrative structure, the urban environment will be treated as the new landscape, initiating cultural stories for First Nations peoples. 
Let me introduce myself...

as you make yourself comfortable. I have a story to tell. It explores the journey of a young architect who set out one sunny day on that old grid road, to learn a little about himself, his professional discipline and a culture he grew up around. It tells of his adventures and the many curious people he met along the way. These adventures led to an exploration of a culture coming to terms with their new lived-environment. One that they were unfamiliar with and felt they did not belong to. One where preconception was a normality, often lost in the winds of change, or lack thereof.

The story takes place in Saskatoon, Saskatchewan, a sleepy little city full of trees and bridges. It observes people of two cultures living amongst each other, yet divided by a river. The bridge connecting the two, is in the distance. The young architect felt a place where gathering occurred was needed, a gathering where stories between cultures could be shared, eliminating the misunderstandings that currently existed. And misunderstandings were all they were.

By running into several kind people, who enjoyed sharing stories about stories, the young architect began to understand the truth about stories. This is his story, his journey, his numerous conversations, and the things he discovered along the way. I also want to say a special thanks to you, for taking the time to listen to this story, for it is through you that this story now has a life, exists in the real world, and I hope will be shared for time to come. Let us begin... 


\section{Part 1:}

\section{$\underline{\text { Resurfacing Aboriginal Stories in Urban Saskatchewan }}$}

Growing up in Saskatchewan wasn't particularly interesting by any means; a flat plains, a vastness of nothing covered the landscape. Imaginations tended to wander. Often the mind wandered elsewhere, to the exotic lands of the world. The surrounding landscape may not determine one's youth, but perhaps the stories told within it do. There were several stories about places afar, adventures, and interesting people who lived there. Any book would prove it so. The stories embedded in Saskatchewan were monotonous by comparison. However, actually experiencing the stories about skies seemed exciting; stories about clear starry nights; the northern lights; the electrical storms; or simply watching clouds form two-three days in the distance. How would anyone ever realize the significance of this, if they never left Saskatchewan to compare those stories?

This was the case for the stories regarding the Aboriginal peoples living nearby.

Why would one think differently of the culture if the only exposure came from an outside perspective? History, as far as young Bobby could acknowledge, painted vivid stories of his cultural neighbours. Stories of abuse, violence, self-destruction and poverty were well-known tales in these parts; stories regarding people who were given everything, yet had nothing. The stories told from generation to generation of Saskatchewan families, each commonly expressing the outside view of the reserve. Nietzsche, ${ }^{14}$ the PrairieGerman word for Indian, revealed the view early settlers had of their cultural neighbours,

\footnotetext{
${ }^{14}$ James Exner described how early German settlers in the Prairies used the term Nietzsche, referring to the German philosopher, to refer to First Nations peoples. It is a term still used today. This was discussed in a conversation on 19 December 2003.
} 
one that is not easily erased, even though most who used the word had no idea of its origin or what it actually referred to. ${ }^{15}$ Yes, Bobby definitely had a preconceived notion of Indians

was not until much later that First Nations was commonly used and it was not always a positive one. Why would he think any differently, if those were the only stories he knew?

"So you want to hear stories about Indians," Bobby replied to the curious girl sitting attentively across from him.

She nodded eagerly.

"Well, let's call them Native Indians. There are several names used nowadays, and I'm not exactly sure which one should be used."

She smiled ever so slightly, showing that she understood.

"You want to hear stories about Native Indians? Not sure where to begin," pondered Bobby, as he thought through the numerous stories he knew about First Nations Peoples. He was trying to capture one that would not offend her, or worse, destroy the refreshing excitement she had about Native North Americans. It may have been one of the first times that he could remember, someone pursuing the subject so intensely, and in Australia of all places.

\footnotetext{
${ }^{15}$ Elizabeth Exner, upon being asked what the Prairie German word for Indian was, responded Nietzsche. She had no other recollection of what Nietzsche also referred to. She grew up in, and still lives in, rural Saskatchewan. She is the grandmother of the author, and the conversation was on 23 December 2003.
} 
Her eyes glistened, "What are Indian people like?"

Bobby really didn't know how to answer this. The only perspective he had of the culture was a jaded one. Through his short life, twenty-two at the time, he knew there was so much more to Aboriginal peoples then what he was told. He did the only thing he could do, reiterate the number of stories his university classmate, Dave, had told him.

Dave was of First Nations descent and both his parents held close ties to their reserve. They believed and lived the Native philosophy, and encouraged their children along the same path. Dave was raised in Winnipeg, and was one of those new 'urban Indians. ${ }^{16} \mathrm{He}$ was part of the new generation of Native people who now faced the growing impact this transition to the urban centre was having. The stereotypes, the preconceptions, the prejudices, and the racism would be only a few of the barriers Native people like Dave would face while growing up. This was an all too familiar scenario for Dave's urban generation.

Bobby had the opportunity to know Dave at architecture school in Winnipeg, where they became close friends. They discussed music, architecture, life, and of course, Indians, but not the stories about the Indians Bobby had grown up knowing. No, these were real Indian stories, stories about the people, stories that had never occurred to him before. Several years later Bobby would come to understand the full importance of these stories, and the power they possessed. For now though, they would entertain this curious girl that sat across from him.

\footnotetext{
${ }^{16}$ Krotz, Urban Indians, 156.
} 
"You see, I've only talked to a few Native-Indians, so my understanding of the people is not very good," explained Bobby, "although, I can tell you some of the stories my friend Dave told me."

She listened inquisitively. Bobby told her about Dave, how he knew him, and touched on their amazing conversations. The curious girl was ecstatic! As pleased as Bobby was, for he really liked the company of this girl, he couldn't help but be a bit surprised. He had not shared the stories mystified by Western culture surrounding Native legends. These were the stories he felt she wanted to hear, but all he could share with her were the stories that described Dave, the person he was, and the Native people Bobby felt others should see. Little did he know but these were the stories surrounding the culture. The stories embedded in the culture. The stories shared amongst the people of the culture. The curious girl could not have heard a more real and beautiful story.

Bobby often struggled with how to deal with those old stories, the stories that had jaded the culture for him, the stories that he grew up believing. Were these stories true? Of course they were, and Bobby knew that. He had grown up there. He had never been exposed to the other stories while growing up though. The stories that superseded the old ones. The stories that revealed the proud people. Dave's own story for example. Dave was on his way to becoming an architect. He was successful, smart, and well respected. Above all, he was close to his family and community, and often shared the numerous stories he lived by. 
Not all Native-Indians were as fortunate as Dave. Several were struggling with alcohol and drugs. Several were struggling with urban poverty. Several were not following the stories passed down to them. More often than not, several were never given the opportunity to hear these stories. As a culture there was a fear of losing their past, which had always been their present and future. There was a fear of losing their stories. A wise little man once said, "The truth about stories is that that's all we are."17 Talking to the curious girl was the first time Bobby had ever thought about this.

Australia proved to be quite the learning experience for young Bobby. He always enjoyed learning, but the things Australia and travelling taught him, allowed him to appreciate his home in the Canadian Prairies from a completely new perspective. It allowed him to appreciate the subtle beauty that was Saskatchewan. The vastness of nothing soon turned to majestic fields of folklore and tradition. It was who he was, all that he knew, and those wandering skies never looked so good. Australians and their cultural differences, or at times lack thereof, made Bobby realize the importance of his own stories.

Someone from rural Australia was not that much different from rural Saskatchewan, although the landscapes were, including all that is nature -- animals, water, land, and the way people live amongst it. The environment changed details of the stories told, but the themes remained the same. There were no attachments to the ocean, surfing, or tropical forests. Bobby enjoyed every minute of it, but mentally he was more comfortable underneath the great vast skies, which were no stranger to Australia. But,

\footnotetext{
${ }^{17}$ King, The Truth About Stories, 2.
} 
this is only one perspective. Others may feel very differently about this than he did. Never-the-less, Bobby began to recognize what he considered to be attributes of home. One striking comparison that could not be overlooked was the similarity between Australian Aboriginal peoples and Native-Indians living in the Prairies -- very similar social situations, living environments, cultural struggles, and, of course, stories. The most striking differences were often associated with being from a different place.

These observations were too apparent to overlook, so as Bobby's stay in Australia turned into months, he began socializing and observing the interaction between peoples. As he grew a small appreciation for the Aboriginal culture in Australia, primarily through conversations with Aboriginals themselves, he noticed how little the non-Aboriginal Australians knew about their neighbours. Not so different from home, he often thought.

This was the beginning of the journey, the journey that would take Bobby home to Saskatchewan. The same journey that initiated the architectural explorations a few years later at Carleton University in Ottawa. The curious girl,

$$
\text { oh, the curious girl, }
$$

the connections to land and place, and the similarities between indigenous peoples were the stories that sparked his imagination and the several stories to follow. Bobby simply didn't know it yet. 
Early January of that long year, the year that the thesis began, Bobby discovered the little Aboriginal man. Thomas King was his name, and he had decided to move into Bobby's backpack for a short while. Tom King was truly a storyteller, whisking tales about stories, tales explaining stories, and tales that were stories. Stories were his favourite thing, and seldom did he speak of much else.

"Did you know the truth about stories is that that's all we are,"18 Tom had said, creating quite a stir in Bobby. Here was a little Aboriginal man, no more than six inches tall, someone Bobby had never seen before, and who had now decided to call his backpack home.

"Who are you? What are you? And what are you doing in my backpack?" Bobby asked now quite concerned.

"I am here to help you through your thesis. You are non-Aboriginal and will need all the help you can get from people like me, if you are to ever complete such a task." Tom spoke so confidently, "This is what I know; stories are all we are."

"You already mentioned that," Bobby responded, not too sure what to do about this little Aboriginal man.

"Well it is very important," Tom explained very patiently, "sit down my friend, I'm here for a little stay."

Bobby quietly sat down next to his backpack, as Tom King hurriedly pulled himself out from inside of it. This was a curious situation, it was. Never had Bobby found himself in the presence of such an unusual character.

\footnotetext{
${ }^{18}$ King, The Truth About Stories, 2.
} 
"Are you a trickster or transformer? ${ }^{19}$ I've heard a little about you if you are," Bobby needed to cure his confused, uncomfortable mind.

"I am whatever you want me to be," Tom replied. "I would like so much to share the truth about stories with you, if I could. Oh, and how I have stories to tell. I never tire of telling stories. There are six stories I think you need to hear, with several smaller stories inside each one of those. Do you know the story about Coyote and the Ducks? Or, the one about Porcupines and China Dolls? They are such lovely stories, they are, and you will be all too familiar with them soon enough., ${ }^{20}$

What was Bobby to say? He was more intrigued by the size of the little Aboriginal man than anything else.

"Perhaps you have heard this one," continued Tom, now well atop the backpack, sitting cross-legged and enjoying an even smaller pipe, a common sight Bobby would grow accustom to. "It's about the earth and how it floats in space on the back of a turtle. I've heard this story many times, and each time someone tells the story, it changes." Tom paused, slowly inhaling from his little pipe. "Sometimes the change is simply in the voice of the storyteller. Sometimes the change is simply in the details. Sometimes in the order of events. Other times it's the dialogue or the responses of the audience. But in all the tellings of all the tellers, the world never leaves the turtle's back. And the turtle never swims away. $" 21$

\footnotetext{
${ }^{19}$ The Trickster and Transformer are characters in Aboriginal oral traditions often used to refer to life lessons. For reference see: King, The Truth About Stories, 111.

${ }^{20}$ King, The Truth About Stories.

${ }^{21}$ King, The Truth About Stories, 1.
} 
To 'belong,' to sense something 'familiar,' and to cope with 'preconception,' were the puzzling little themes that continuously swam around Bobby's mind, struggling desperately not to become tangled among the swarms of indecision and unrestraint. Thesis was a fantastic swimmer and would not tire if no boundaries were made. These themes would clarify themselves, Bobby was sure, but one had to keep some focus.

The Indian and Metis Friendship Centre in Saskatoon was one of several nonprofit organizations set-up throughout urban Canada. They welcomed Aboriginal peoples of all descent into the unfamiliar urban scenario, a foundation where people gather, begin, and familiarize themselves within the urban centre. A place that 'belongs' to Saskatoon, yet is 'familiar' to Aboriginal peoples, while making a common place where Native culture is shared with all. This seemed as good a place to start as any.

May Henderson and Ashley Kayseas were the center's director and program coordinator, respectively. It was early January when Bobby made his first visit to the outskirts of downtown Saskatoon, where the centre snuggled itself amongst the surrounding businesses. The Friendship Centre focused on several urban social issues that rose due to the transition of Aboriginal peoples into Saskatoon. Historically, Friendship Centres were established in the 1960's when a large number of Aboriginal peoples began the transition from the reserve to the urban city. ${ }^{22}$ Programming consisted of job searches, cultural programs, celebratory events (directed at bringing all peoples in the urban centre together to celebrate Aboriginal culture), and an opportunity for

\footnotetext{
${ }^{22}$ May Henderson described on 7 January 2004 a brief history of her understanding of Friendship Centres in Saskatchewan.
} 
segregated families to make connections back to the community. In all, it offered a familiar place in an unfamiliar landscape, easing that ever difficult journey into the city.

The program had evolved since then, establishing itself as a drop-in and youth centre as well. It continued to create gatherings, celebrating Aboriginal cultures (including Metis), with the rest of Saskatoon. This was important to Bobby, since an objective of his thesis was to create a place where all peoples would come to celebrate First Nations' culture. Ashley provided Bobby's first conversation that cold January day, as he entered the modest building, only recognizable by a sign outside.

During the course of the narrative, I will interrupt with the architectural story and explain how it relates to the narrative. The architectural story, for the most part, existed after the narrative, however the narrative led to architectural decisions. These connections are very important to the understanding of my interpretation of the voyage. Treat this as a type of foreshadowing. This is my story, my interpretation, and my abstraction of the voyage I engaged on:

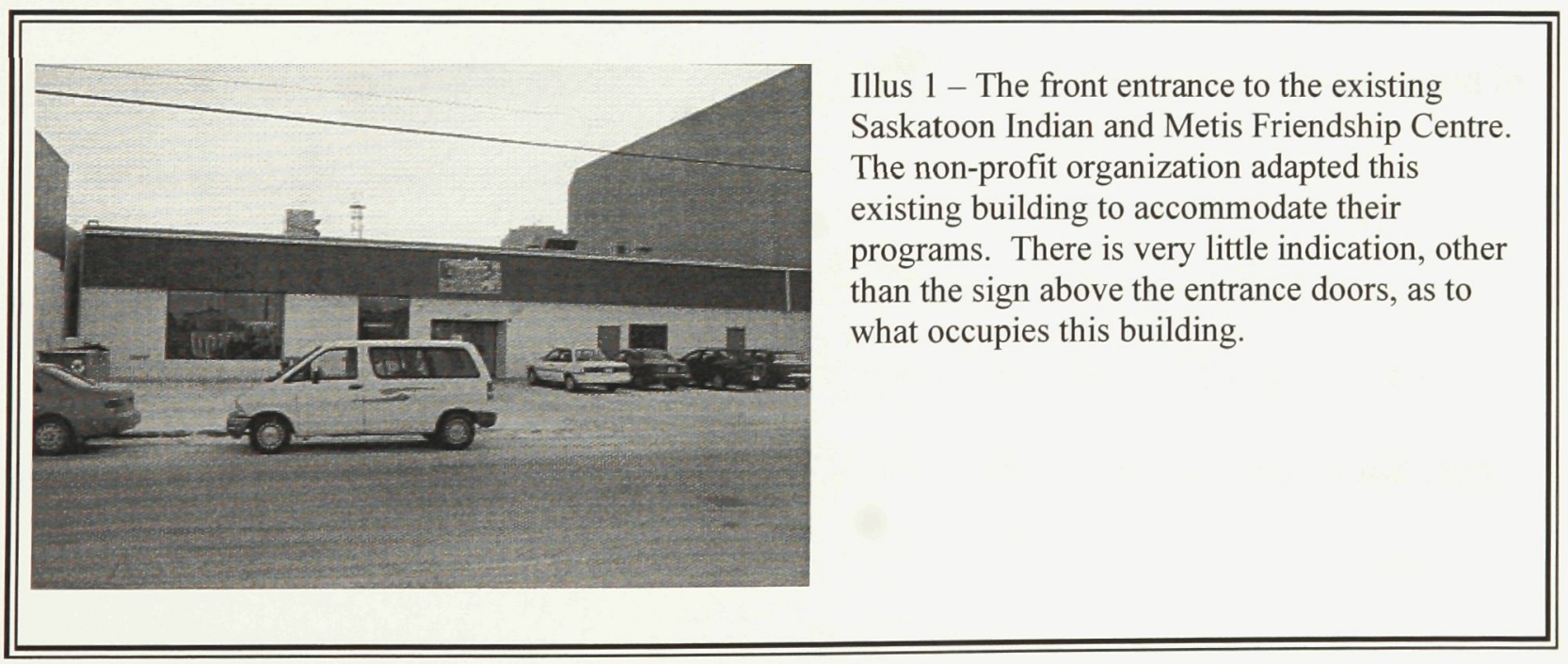




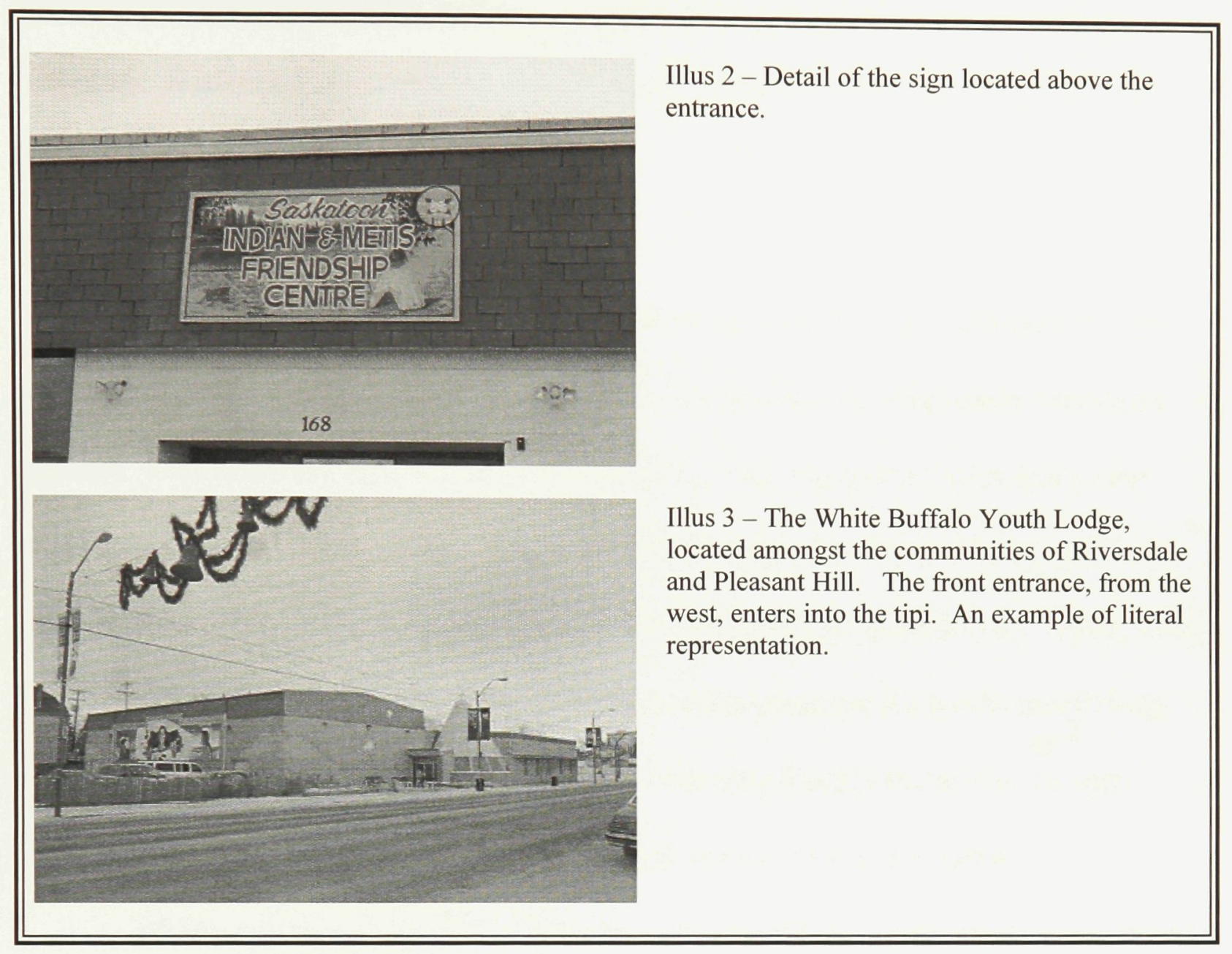

Back to our conversation Ashley,

"Before we start," Bobby began, "I have a letter of consent to go over with you." Bobby explained the purpose of his visit, what he planned to do with the conversation, and Ashley's involvement in the thesis. He also explained that all conversations used in the thesis would be paraphrased.

This was explained to all who participated in the thesis (Appendix A).

"The programs we focus on are primarily youth oriented," Ashley answered Bobby's question regarding programming, as he toured Bobby through the quaint little 
facility. ${ }^{23}$ "This includes both cultural or traditional practices, and non-traditional

activities. Basketball is as important to the youth of today as any traditional activity.

There has to be a balance between the two."

Bobby nodded attentively.

Ashley had his long black hair tied back, as so many Native Canadians do. He spoke sensitively, yet confidently, as only years of exposure to youth could have done. A friendly, understanding face was inviting to Bobby, who was rather intimidated even coming to the Friendship Centre. It is never easy being an outsider, and one could only imagine how difficult the move into the city for Aboriginal people must be. Bobby could simply walk outside and see something familiar; Aboriginal people had to search long and hard to find the little centre, and even then, the only thing cultural was the sign depicting the words "Indian" and "Metis," and of course, the people inside.

Ashley continued, "There are two culturally important events we do host. We try to maintain the connection with the community of Saskatoon, creating events where people come together to celebrate all Aboriginal cultures. You may be familiar with the annual Folkfest Aboriginal pavilion, held here at the centre, and the Aboriginal Day celebrations held at Kiwanis Park. We host a small procession, dancing, musicians, lunch, and other activities in Kiwanis Park, next to the Bess. You know."

Bobby nodded in recognition. The Bessborough hotel was the landmark of Saskatoon. One of the iconic Chateaus painted across the Canadian landscape. Yeah, Bobby knew this building well. Anyone who knew Saskatoon did.

\footnotetext{
${ }^{23}$ Ashley Kayseas, the program coordinator of the Saskatoon Indian and Metis Friendship Centre, was interviewed in person by author on 6 January 2004 at the beginning of the thesis project. He also gave a tour of the Friendship Centre facilities and described the programs offered there.
} 
"We've been hosting it there for some years now," Ashley went on. "It is in the heart of Saskatoon, in the middle of the gathering area, where all peoples come. It is the tourist hub and it allows everyone a chance to celebrate our culture."

Ashley knew what he was talking about. The heart of the city was the financial centre, the tourist destination, the dining base, and the centre of all river-paths congregating on the doorstep of that well-known hotel. It was chilling to observe the vacancy offered by the heart of the city when six o'clock came around, but during the day, it truly was the vigorous hub of Saskatoon, an ideal location for festivals.

Jazz festival is one of these events. It is held annually near and around the grounds of the Bessborough hotel and the numerous surrounding parks. Kiwanis Park is one of these. Jazz fest had grown into one of the most attended of the summer month events and attracted locals and tourists alike, an appropriate addition to the business and tourist district that existed.

"You may have heard of Jazz festival," Ashley continued, showing Bobby the gymnasium that housed both sports and festivals. "It often occurs during the same week as Aboriginal Day. Last year, the commotions competed with one another, overshadowing both events. This year, we are forced to host the celebrations in Friendship Park."

Friendship Park was a neighbouring park to Kiwanis, yet seemed across the city. It lay just south along the river parkways. The bridge that bordered the two was a major entry point to the city, distinguishing the two parks as night and day. There were no visual connections, leaving Friendship Park on its own, with little ties to the central axis 
that downtown Saskatoon was designed around. It could be a little more difficult attracting people, even though the two parks were adjacent to one another.

"It is unfortunate that a festival that could be held any week during the summer, takes priority over a specific day event. That must be a little frustrating," Bobby responded to what Ashley had just said.

Ashley didn’t know how to respond to this. Bobby had just pointed out a pretty obvious thing. Aboriginal Day was June 21, the summer solstice, and there was no changing that. This was a sacred day, one that had been celebrated by Indigenous Canadians far before Saskatoon ever existed.

May, the director of the Friendship Centre, would also comment a day later on the change of site. ${ }^{24}$ "It will probably affect the amount of spectators that attend. We held the celebrations there a few years ago, and found when we finally moved to Kiwanis Park, our attendance at least doubled. Last year we had close to 8000 spectators over the entire day."25 8000 spectators must compete with the most attended Jazz festival day, Bobby thought to himself. Bobby had also talked to Ashley and May about possible site locations and any additions to the existing program that would benefit a hypothetically new Friendship Centre.

"If it is all hypothetical," Ashley smirked to himself, "I would like to see a celebration space, a space where we could host powwows and other celebrations. An outdoor space would be ideal, but it should be accessible during the winter months. It

\footnotetext{
${ }^{24}$ May Henderson, Executive Director of the Saskatoon Indian and Metis Friendship Centre, was interviewed in person by author on 7 January 2004.

25 Other attendance references for Aboriginal Day celebration in: Jeannie Armstrong, "Kiwanis Park Site of Tomorrow's National Aboriginal Day Festivities," Saskatoon StarPhoenix, 20 June 2002: C7-8.
} 
could be an interior space that opens during the summer. Another important addition would be a space for smudges or sacred ceremonies." May added a day later, "What we are missing here, is a sacred space or storytelling area where youth could meet with elders, and smudges and smoking of the pipe could take place. It would be important exposure for the youth."

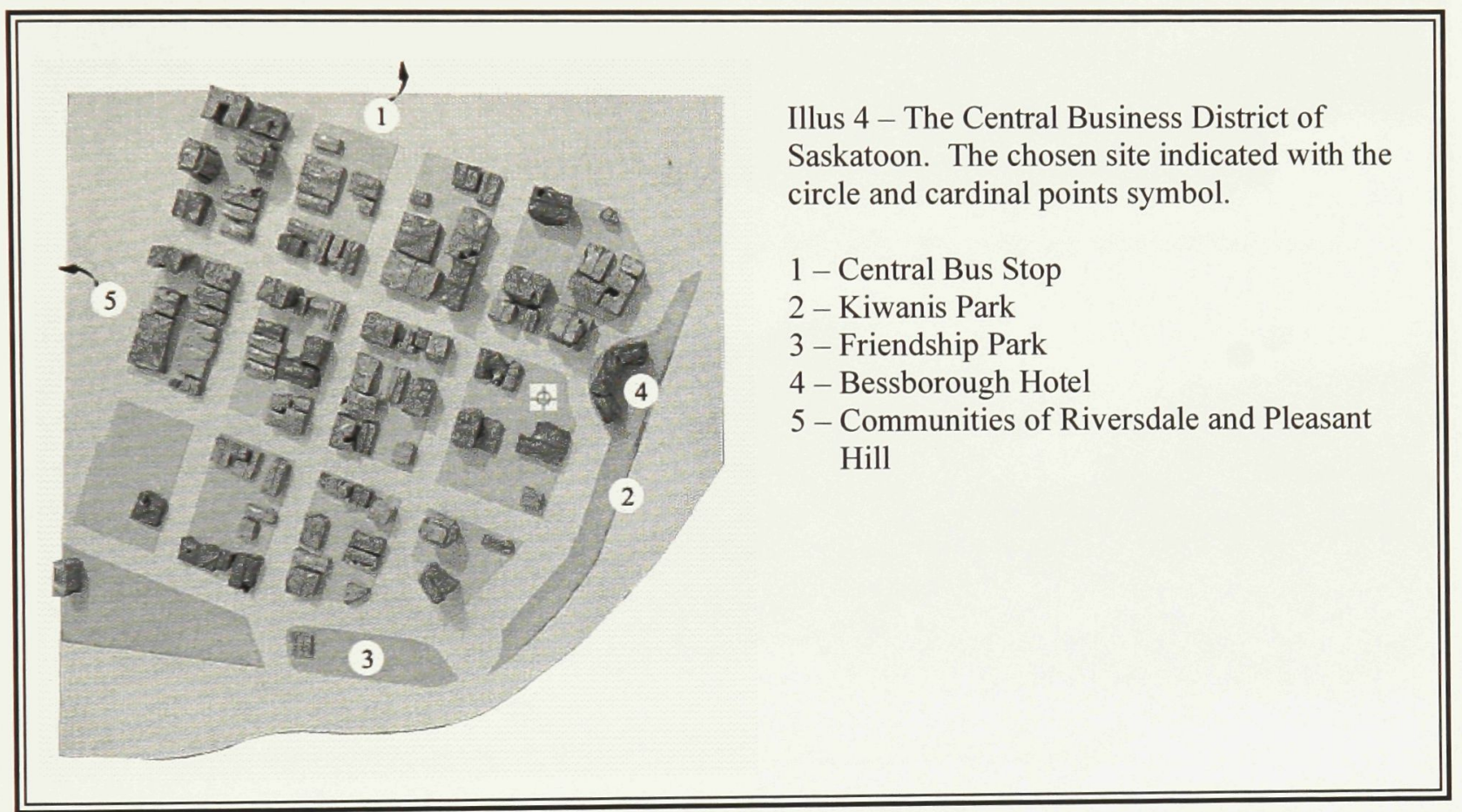

Regarding site, they both noted the importance of Kiwanis Park during Aboriginal Day, and the need to communicate their culture to others in Saskatoon. Bobby decided to choose a site near the park as a starting point and see how the choice of site evolved from there. There was a parking lot across from the Bessborough Hotel, one of the few empty lots in the surrounding area. For the time being it made sense to start there. Besides, the site looked out of place at the central meeting point of the city. With program, site and 
thesis objectives in place, it was time to return to Ottawa, find a committee and officially begin his journey.

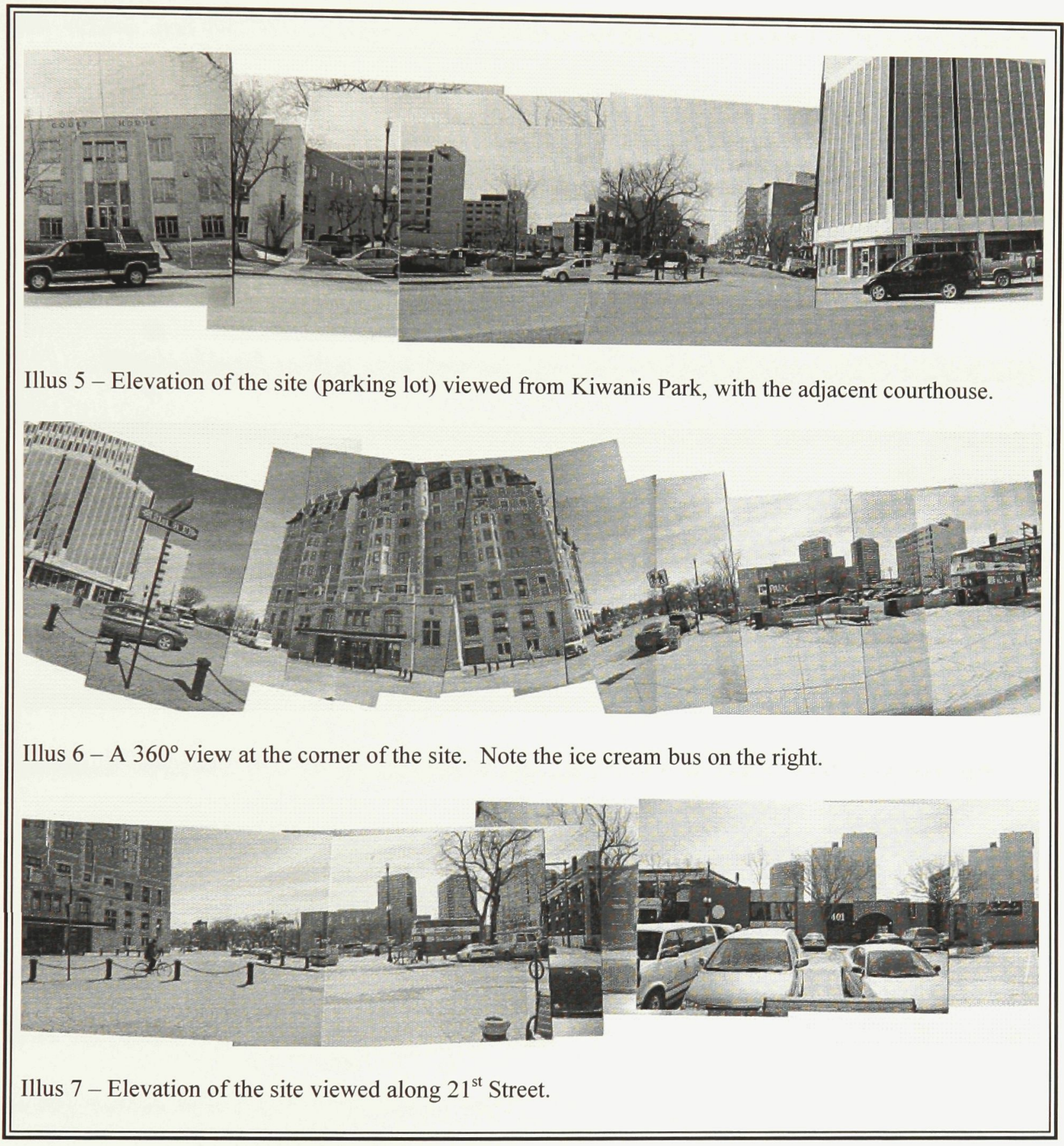


"I'm designing a Friendship Centre in Saskatoon, Saskatchewan," Bobby described his thesis project during the introductory presentation he held with his advisory committee in late February. "The program will remain the same, the site will be in the city centre, and the First Nations people will be the primary culture I'll be representing. This raised some great interest (some might call it concern!) amongst his committee members. "I believe the program will be of great importance, and may change significantly yet," cautioned Bret.

Those present on that cold February day were Yves Gosselin, Bret Cardinal, and Derek Smith. The advisory committee was chosen according to their specific expertise in Aboriginal culture and urban design. Yves was an adjunct professor at Carleton, and a director for the Public Works and Government Services of Canada. He had several years experience with urban design. Bret was an architect, of First Nations heritage, with substantial experience working with First Nations peoples. Derek was an anthropology professor currently introducing Bobby to the exploration of cultural identity, and the associated methodologies.

Bret's cautionary words served as an initial reminder of the importance of program and its role in cultural identity and the experiential environment. It was also the first indication Bret gave of the 'organic design' approach that his father had been using in his architectural explorations for decades now. Bret knew the challenge in representing or embedding First Nations culture, or any culture in the man-made environment. He could only serve as an educator, teaching through example and 
experience, telling of his past observations with the challenge. It was up to Bobby to interpret what Bret said and what could be used in the progress of the thesis.

In a meeting a month earlier with Yves, the initial meeting between the two, Yves directed Bobby toward the importance of respecting the existing urban environment. "One must acknowledge the importance of place and learn how an architect respects and designs according to it. North American cities, including Saskatoon, were designed from a Western ${ }^{26}$ perspective. I see your challenge as respecting this existing urban environment while introducing the cultural environment within. I don't know of many urban precedents for First Nations though."

Bobby knew this well. Outside of the Cardinal examples, most major First Nations buildings occurred on reserves, where the only surrounding environment was a collection of trees, sky, and vast amounts of space, but rarely other buildings. Any urban centre would tell a long tale regarding space, although likely not to include 'vast amounts.' Saskatoon consisted of several built environments, all of which had to be respected. To further his point, Yves told a story, one Edmund Bacon had told him years before. It went like this:

"Any really great work has within it seminal forces capable of influencing subsequent development around it, and often in ways unconceived of by its creator. The great beauty and elegance of Brunelleschi's arcade of the Foundling Hospital, found expression elsewhere in the Piazza della Santissima Annunziata, whether or not Brunelleschi intended this to be so.

26 'Western' refers to Judeo-Christian origins, and all its associated philosophies. 


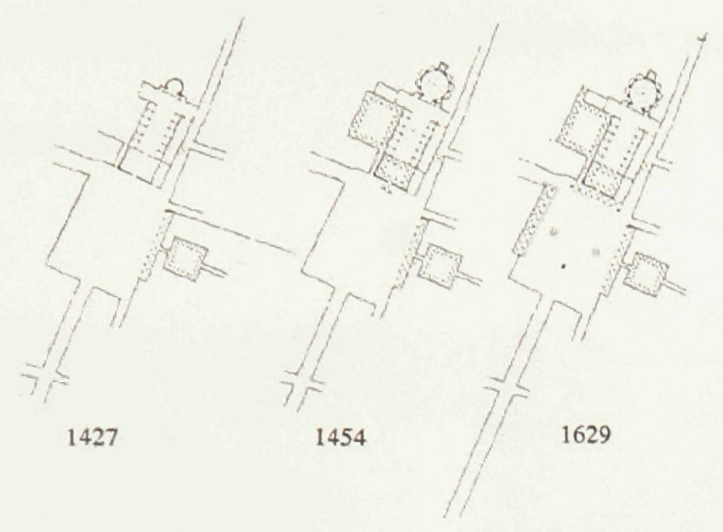

Illus 8 - Bacon, "Principle of the Second Man," Design of Cities, 108-109. The addition of the arcade to the Piazza.
"The form of the square remained in doubt until 1516, when architects Antonio da Sangallo the Elder and Baccio d'Agnolo were commissioned to design the building opposite to Brunelleschi's arcade. It was the great decision of Sangallo to overcome his urge toward self-expression and follow, almost to

the letter, the design of the then eighty-nine-year-old building of Brunelleschi. This design set the form of Piazza della Santissima Annunziata and established, in the Renaissance train of thought, the concept of a space created by several buildings designed in relation to one another. From this the 'principle of the second man' can be formulated: it is the second man who determines whether the creation of the first man will be carried forward or destroyed.

"The quality of Piazza della Santissima Annunziata is largely derived from the consummate architectural expression that Brunelleschi gave the first work, the Innocenti arcade, but it is really to Sangallo that we owe the piazza in its present form. He set the course of continuity that has been followed by the designers there ever since." 27

"This project should respect the character that exists in Saskatoon, especially the area surrounding the Bessborough hotel and your site. Saskatoon, like all Canadian cities, is young and it will take several years before any real distinct character exists there. In addition, the architectural decisions you make should be approached as if it

\footnotetext{
${ }^{27}$ Bacon, "Principle of the Second Man," Design of Cities, 108-109.
} 
could be implemented in Ottawa as much as Saskatoon," Yves ended the initial conversation.

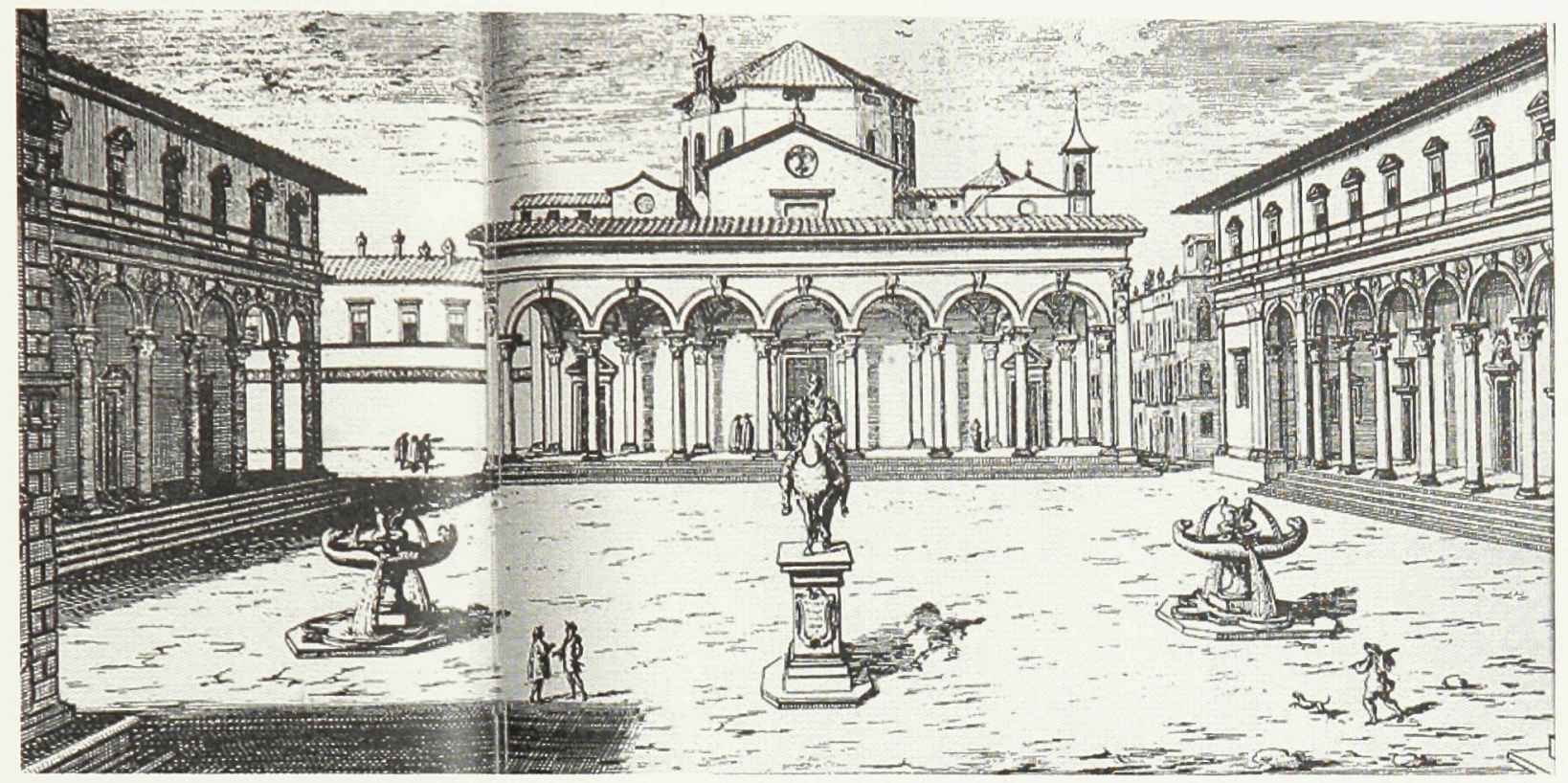

Illus 9 - Bacon, "Principle of the Second Man," Design of Cities, 108-109. Sangallo's arcade is to the left of the Piazza in this perspective.

Derek was hosting a class on problems in ethnohistory. This was where Bobby and Derek met. Bobby enlisted in the class, half as a requirement, half hoping to seek some guidance in Native North America. He wasn't disappointed. Early on, Derek would discuss methodologies in identifying cultural perspectives from storytelling, images, and journal entries, to name a few. He raised questions. Like, whose history is it? and whose perspective is it coming from? He also spoke of Pan-Indian religious, political, and cultural movements.

Pan-Indian was a term widely used within the Native urban cultural context. It referred to the characteristics that were now identified to all Aboriginal peoples in 
general. A tipi had turned into a cultural symbol, identifiable to all First Nations, whether a part of their specific heritage or not, as was the dream catcher, turtle, and totem pole. The growing number of Aboriginals moving into the city lay behind the emergence of these icons. Politically it brought these groups together, as one culture with a common background. Their education and common belief would later be identified as another Pan-Indian issue. One had to respect each tribe as a unique entity, however there were certain Pan-Indian issues that had become important ties for the new 'urban generation.'

Overall, Bobby knew he had a strong committee. They would be patient. They would be critical. Most importantly, the committee would be full of stories and be more than willing to share them.

Thanks Yves, Bret, and Derek. This story is as much yours as anyone else's.

"Tom, we are traveling to Saskatoon again," Bobby told his little friend. "I think I have to spend some time at the Friendship Centre."

It was mid-March by the time Bobby and Tom landed at the Saskatoon airport. They had two weeks to explore Saskatoon, discover a small piece of the indigenous culture and drop-in at the Friendship Centre. Bobby was also hoping to learn a bit about processions and movement. His paper with Derek depended on it. 
"May, how are you?"28 Bobby greeted on his arrival to the centre.

May invited him into her office, the private section secured away from the "free coffee' atmosphere of the drop-in centre. May wore a big smile as usual. The staff at the centre were wonderfully inviting. Bobby was still so thankful for that. It never grew any easier, this transition into culture and social issues. People like May and Ashley however, made the transition worth while.

"I know this is an Indian and Metis Friendship Centre," Bobby said as he sat down, making himself comfortable once again. "Are both cultures equally represented?" "I am Metis," May responded, definitely a little amused at Bobby's question, "and yes they are both represented. Ashley works hard to make sure both cultures are represented in our programming. Of course both cultures are very unique, however, we have youth from both participating in events. The Friendship Centre was designed for all Aboriginal peoples, not only First Nations. Today, we even encourage people of all backgrounds to come, Aboriginal and non-Aboriginal peoples."

Pan-Indian issues surfacing again. Perhaps Bret's earlier comment of using a host tribe was a good idea. It could be very difficult if Bobby decided to embed all cultures in his design. The 'familiar' environment might be too vague from any perspective to do anyone any good. Focus was a word that Bobby had to maintain and respect. He might get lost in the land of cultures if he didn't.

"I've been exploring several Plains Cree traditions and ceremonies, such as the Sun Dance and Sweat Lodge," Bobby continued after explaining his dilemma of PanIndian issues to May.

\footnotetext{
${ }^{28}$ May Henderson, conversation with author, 29 March 2004.
} 
"We actually try to avoid spiritual events such as the Sun Dance and Sweat Lodge. We've run into issues regarding smoking pipes, ${ }^{29}$ let alone the very specific guidelines and practices to be followed in those spiritual events. Besides, I don't think I have ever heard of a Sun Dance being held in the city," May replied.

"Is a powwow not sacred?"

"It is, but I have always seen it as a social gathering and celebration rather than a healing event."

"Would you say Plains Cree First Nations are the most dominant First Nations group in the Saskatoon area?"

"To my understanding."

His ethnohistory paper had led him to explore several Plains Cree ceremonies, focusing on procession and movement in and around the festival. Bobby was hoping to make links to the transformation of time and space during these events. His primary techniques however, were based around the images illustrating the history of these celebrations. Through movement and procession, perhaps Kiwanis Park would turn into the sacred site needed to host celebrations during that one unique day of the year. Bobby was hoping May had some images of past processions and celebrations held during Aboriginal Day. Luckily for him, she did.

\footnotetext{
${ }^{29}$ Newspaper article describing pipe event.
} 


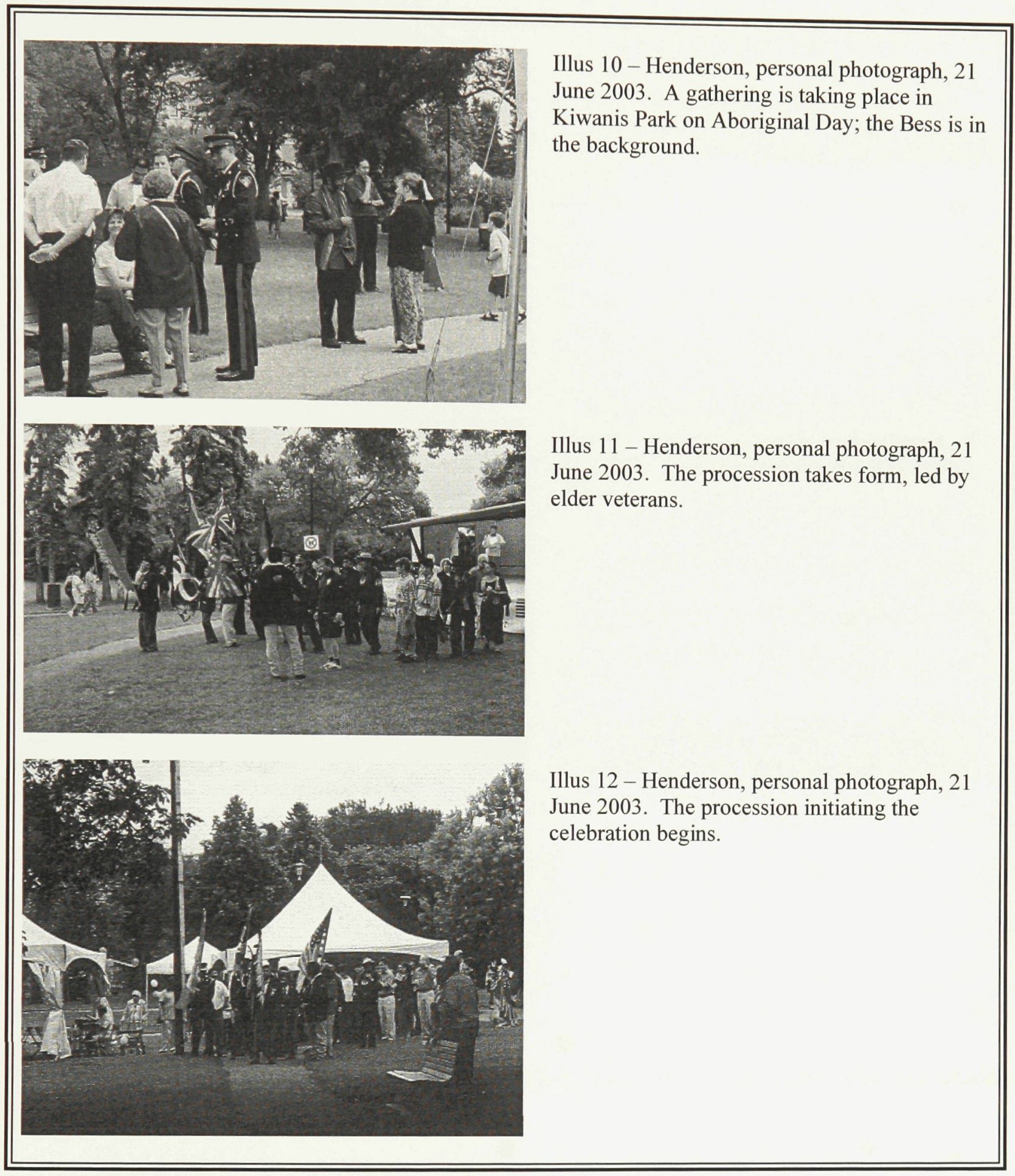




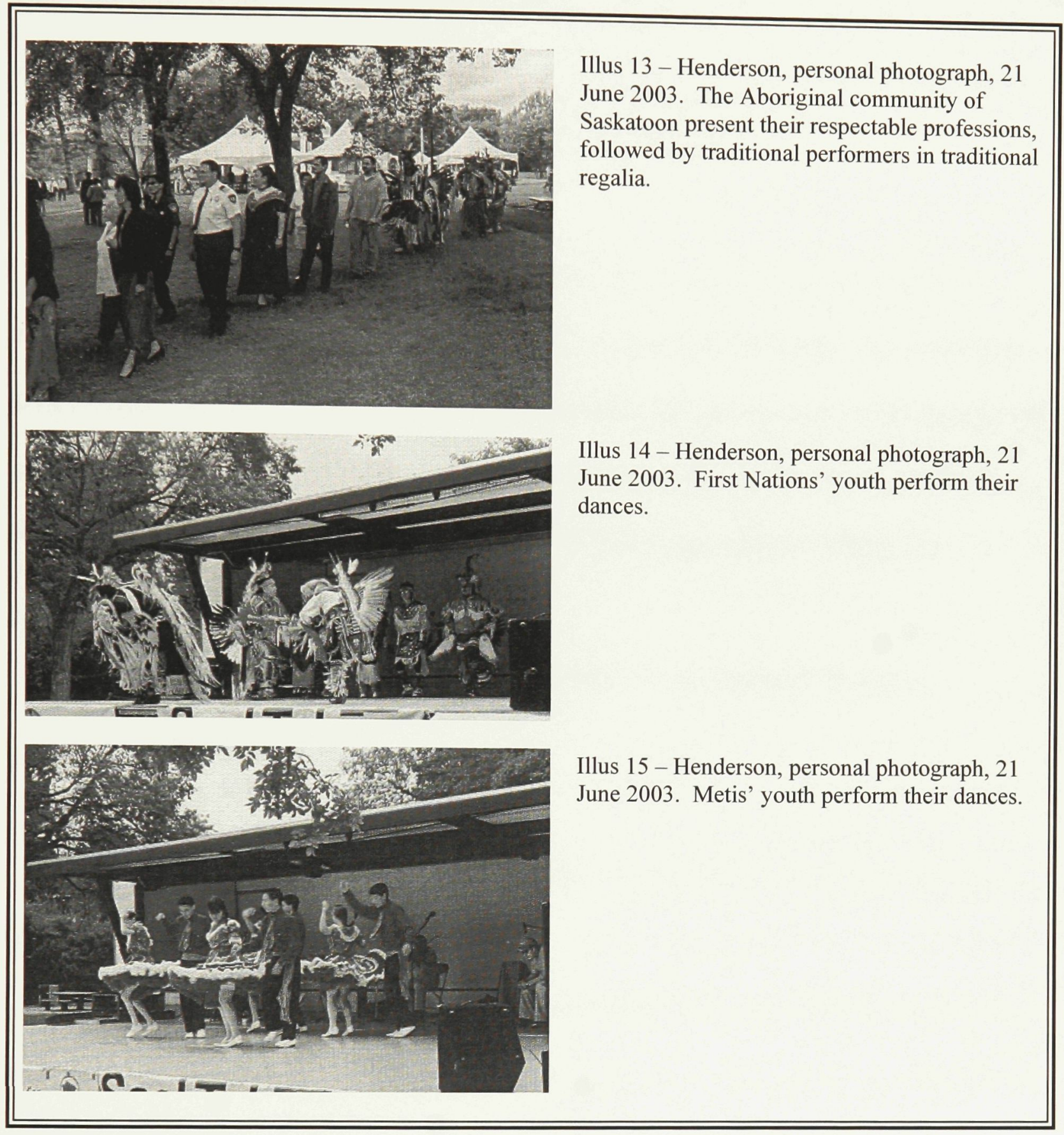

May shared several images with him. Pictures of Metis' performances. Pictures of First Nations' performances. A few photos depicting the entry procession, clothing and the participants of the event. Photos revealing the entry from the East, and movement in the clockwise direction. These were all moments when the park, or any 
other site used, would transform itself into the sacred event. Time, day of the year, sun location, site location, proximity to the natural landscape, and the cardinal points were all other attributes respecting the transformation of time and space.

Gary Gossen spent plenty of time with the Maya culture of central Mexico, describing the transformation of time and space in Maya oral tradition. ${ }^{30}$ He portrayed how certain celebrations transformed secular sites through certain sacred movements and actions, including procession. The belief or acknowledgment in these movements as transforming devices, allowed the preparation of the site for sacred celebrations.

Bobby later realized by reading Gary's book, he was actually having a conversation with him. $^{31}$

"Gary," Bobby started, "what do you mean by the transformation of time and space in Maya oral tradition?"

"Bobby, you see, by the Maya people performing certain ritualistic movements, a site would be prepared for events that would take place there, regardless of where the site existed. Orientation, procession, and movement become important features in the transition of space. Space is transformed for the duration of time that it is required for the celebration,"32 Gary extensively and thoroughly explained with several examples.

\footnotetext{
${ }^{30}$ Gossen, Chamulas in the World of the Sun: Time and Space in a Maya Oral Tradition.

${ }^{31}$ Barthes, "Introduction to the Structural Analysis of Narratives," 56.

${ }^{32}$ Gossen, Chamulas in the World of the Sun: Time and Space in a Maya Oral Tradition.
} 
"Just to be clear," Bobby strained to understand, "wouldn't it be the belief in these ritual actions, and the power they possess, that transforms the space. The people participating in the ceremony must first acknowledge and believe in the transforming power of these actions if a specific space is to be transformed for any length of time."

"That is correct," Gary told Bobby through several pages.

Stories had similar transforming powers, but Bobby didn't believe in them yet.

The conversation with May and the images she was able to provide, allowed Bobby to argue that Kiwanis Park, during that one day a year, would transform into a sacred site. Through such physical characteristics as procession, orientation, and movement, Kiwanis Park would transform for a specific time to allow celebrations to occur. At midnight of June 22, Kiwanis Park would transform itself back into the park it would remain the rest of the year. Between sunrise and sunset on the summer solstice, Kiwanis would be the site required to celebrate Aboriginal peoples throughout Canada. One site linked to several others throughout the country, where all peoples gathered to acknowledge the importance of Aboriginal culture. It truly was one of those rare moments in Saskatoon where all peoples gathered.

The March trip to Saskatoon would not have been complete without the visit to the University of Saskatchewan to meet Jim Waldram. Bobby had been introduced to 
Jim through Derek, in their ethnohistory class. Jim had worked with Aboriginal inmates and the impact of traditional healing practices in the prison system. Jim concluded that such healing practices were very important and successful amongst Aboriginal peoples. ${ }^{33}$ Considering the Friendship Centre was dealing with similar urban situations and social issues, Bobby felt it was important to meet this anthropologist.

Jim invited Bobby into his office. Jim was non-Aboriginal and it was important for Bobby to meet some non-Aboriginal people who worked with Aboriginal issues, just as he was. It revealed ways of interpreting and connecting to this culture from his Western perspective.

"I've read Way of the Pipe, and have come to the understanding that you feel quite strongly about the use of the pipe and sweat lodge ceremonies in healing situations," Bobby began the conversation. ${ }^{34}$

"I believe it is quite successful for inmates to use recognizable traditions when dealing with the healing process. However, as you are probably familiar with, there are plenty of issues regarding ceremonies," Jim replied.

Jim quickly referred to his experiences regarding some elders' sensitivity toward practicing these ceremonies in prisons. "Often elders refuse because the location is not right. Earth is needed for several ceremonies, and often prisons cannot supply this. To sit on the earth is of great importance for some ceremonies. In sweats, the ground offers the release from the intense heat inside the lodge."

\footnotetext{
${ }^{33}$ Waldram, Way of the Pipe.

${ }^{34}$ James Waldram, professor at the University of Saskatchewan, spoke of his previous experience with First Nations in the Saskatoon area. He did extensive studies on Urban Indians, and healing and ceremonial events. Interviewed in person by author on 30 March 2004.
} 
The reluctance of some elders was of concern to Bobby. This could easily determine what kind of ceremonial space may occur in this project. He had to find out. "No," Jim slightly grinned, "I cannot see a Sun Dance ever being held in the city. There is too much preparation and spiritual transformation to occur. That is one ceremony that will stay on the reserve. However, I've been to several sweats in Saskatoon. Even one held right here on campus.”

"On campus? Who organized it?" Bobby was pretty interested by this time.

"It was organized by Native Studies, and we asked an elder to perform the ceremony. There is an interesting story regarding this particular elder. He was selected from all elders in Saskatchewan by the Federation of Indians to address the Queen during the opening of Waneskewin. ${ }^{35}$ This was considered a great honour. When he chose to perform the sweat in Saskatoon, he was ridiculed. One of the most respected elders in Saskatchewan felt it was important to host sweats in the city, yet his people felt he had no right in doing so. It shows the amount of controversy about these spiritual subjects, and the significant support urban ceremonies do have. Of course you know my opinion already."

The conversation was soon directed toward site, program and the Friendship Centre. After describing the thesis premise and the importance of Aboriginal Day and gatherings, Bobby revealed his site.

"You plan to put a Friendship Centre across from the Bessborough hotel." Jim was amused, "I can't wait to hear the argument for this."

"I know, in the middle of the business district."

\footnotetext{
${ }^{35}$ Waneskewin Heritage Park is a tourist destination north of Saskatoon, representing archaeological discoveries.
} 
"You are planning to bring one side of downtown into the other." Jim quietly warned.

One must understand, in architecture, tensions in buildings, site, program, and interaction are encouraged, and make for some interesting relationships.

Bobby was more than delighted with Jim's response. Besides, one of the purposes of the thesis was to create urban moments where interaction between cultures would occur. Dramatic was often a good thing.

"Program becomes very important then," Jim added.

Where did I hear this before, Bobby thought to himself.

The scenario in downtown Saskatoon should quickly be discussed:

Downtown Saskatoon was indeed split in two, the business side and the communities of Riversdale and Pleasant Hill, each occupying a side of the highway Idylwild running North through Saskatoon. There were few routes connecting the two sides, and even if there were more, there would be little movement from either side. The division between cultures was dramatic and not easily overlooked. Drugs, prostitution, violence and poverty were all too familiar for the communities of Riversdale and Pleasant Hill. Rent was cheap and the community was identifiable. Too often, Aboriginal transitions into the city ended in these parts. 
"You are proposing to place a Friendship Centre, and all of the associated connotations, directly in the middle of the business core of Saskatoon," Jim repeated the scenario making sure he understood the peculiar proposal. "The businesses will be affected. The ice cream bus, the lively little destination it is, will need to be relocated. You will affect the major hotels and the tourist industry. This is the heart of Saskatoon, home to a majority of the city's festivals. There is a lot of money in this part of town, and where there is money, there are politics. Personally, I don't think the city would ever allow for such a program to exist there."

Bobby smiled at this.

"The clientele of the Friendship Centre will be of great concern. You are encouraging the 'ghetto' side of downtown into the business side. Like I said, this will affect businesses. This will affect tourism. There is a good chance of introducing panhandlers and homelessness to this area. I'm not saying interaction is not needed, I just think you will have to carefully build your argument, while respecting what already exists there."

Is this not what Yves warned me about, Bobby thought recognizing the relationship.

"With this in mind," Jim continued, "you may want to consider introducing other programs to combine with the Friendship Centre. For example, by adding the Cultural Centre and their associated programs, especially the learning environment and keeping house, you begin to accommodate the tourist aspect of the site." 
Had Jim stumbled upon something. It was good to talk to someone who was familiar with both, the culture and the city of Saskatoon. Jim tended to see things from both perspectives, even though he had no background in architecture,

$$
\text { or did he? }
$$

Program could serve as the initial answer to several of the questions raised so far. By adding specific programs, one begins to accommodate and even attract certain groups to the space. Jim was touching on some of the important urban and programmatic issues that Bobby had come to Saskatoon to find, and not a day too late. That evening, Tom and Bobby would make their way back to Ottawa.

Jim expressed great enthusiasm, "Both the Friendship Centre and Cultural Centre exist in poor locations at the moment. Both are barely known by the people of the city."

Bobby was soon to discover that this was true.

"The most practical place for a Friendship Centre, would be in the community. Riversdale already has one, the White Buffalo Lodge, the building with the tipi."

Yes, he knew that one. That was part of the preconceptions that Bobby wanted to avoid in his thesis. Bobby, after five years of architecture school, knew better than to represent something literally. Support for this would come from several different sources over his journey.

"The original context of the Friendship Centre, a place focusing on identity, sharing culture, and providing Aboriginal peoples with a familiar environment, will accommodate your site and project more effectively," Jim continued. 
Bobby was curious about the urban reserves ${ }^{36}$ that were located downtown, only half a block from his site. Wouldn't they supply an argument that Aboriginal people were moving into the downtown area?

"Those urban reserves are businesses."

How could Bobby argue? Jim had a good point.

"Look, I really think your thesis objectives are very interesting, and could realistically work, but I think you have to look at some of the issues that I've brought up. I still feel program will be important to your argument. I agree that both, Aboriginal and non-Aboriginal peoples, should be accommodated in urban spaces. This is something far too often overlooked in cities like Saskatoon, and will need to be looked at considering the growing urban Aboriginal population."

Urban Pan-Indian issues was the last area of discussion. Jim felt it would be important to select one group and design accordingly.

"It would be practically impossible to accommodate all Aboriginal identities in the building. Besides, urban modern scenarios are turning largely toward Pan-Indian issues, and each culture is represented within this context."

It was a growing point of discussion. These common urban struggles with identity and social issues were bringing several different Indigenous cultures together in the city. Bobby saw signs of this in his friend Dave from Winnipeg.

With an extra special thanks to Jim, Bobby found himself outside amongst the buildings of the $\mathrm{U}$ of $\mathrm{S}$ campus. He started walking toward the bus, reflecting on what

${ }^{36}$ Define Urban Reserve 
would be considered the first turning point in his project. The new developments that Jim introduced were substantial. Bobby knew the program had to now consist of much more than a Friendship Centre, and attract people who already used the site's business district. Changes to the project were already occurring. A month from now was his next review, and this felt like starting over. Jim had criticized various initial moves, and consequently there were some dramatic changes to make. However, Bobby found himself surprisingly excited.

"Urban gathering may be understood as an interpretation of the local genius, in accordance with the values and need of the actual society." ${ }^{37}$ Bobby began his review by quoting Mr. Norberg-Schultz.

Christian Norberg-Schultz lived on the transit system in Ottawa. ${ }^{38}$ His primary home was the O-train, where Bobby was introduced to him only a few weeks earlier. Christian was a thinker, often dabbling with phenomenology ${ }^{39}$ and spirit/sense of place, depending who was asking. He assembled several interpretations of culture and architecture's involvement within it. Most of his conversations with Bobby regarded

\footnotetext{
${ }^{37}$ Norberg-Schultz, Genius Loci, 170.

${ }^{38}$ The O-train in Ottawa provided the context that Genius Loci was read in, therefore the conversations with Christian Norberg-Schultz.

${ }^{39}$ Stewart, Exploring Phenomenology, is a good introduction and overview of Phenomenology.
} 
Genius Loci, a phenomenological approach to architecture. He would describe how cultures gather in one place. They respect that sense of place while accommodating their individual identity. Those past few weeks Bobby had spent plenty of time riding the train, being exposed to some intense conversations with Christian.

Such as:

"From the beginning of time man has recognized that to create a place means to express the essence of being, ${ }^{, 40}$ Christian remarked as if this statement was commonly told.

Bobby could only sit there with a baffled, yet not quite annoyed, look on his face. This was the third time this man repeated himself, do I dare ask for another. His fingers slowly caressed his temples. He knew it would take some time before this would sink in. His teeth clenched, the nerves working their impatience through him. Even his eyes hurt, straining to make sense of something. What was this man talking about?

or:

"The 'meaning' of any object consists in its relationships to other objects, that is, it consists in what the object 'gathers'. A thing is a thing by virtue of its gathering. 'Structure', instead, denotes the formal properties of a system of relationships. Structure and meaning are hence aspects of the same totality. Both are abstractions from the flux

${ }^{40}$ Norberg-Schultz, Genius Loci, 50. 
of phenomena; not in the sense of scientific classification, but as a direct recognition of 'constancies," ${ }^{41}$ Christian said as he made tea.

Bobby was dumbfounded, stiff with confusion.

It slowly began to make sense however, and soon the relationships to the thesis were apparent. Urban gathering was 'belonging' to a place, while allowing for 'familiarity.'

"One must understand the environment, or place, they are designing in. They must also understand the culture and people they are working with. Without both, there is no opportunity of expressing culture in urban gatherings," Bobby continued his presentation.

"There are three primary objectives to this thesis. Creating a place that 'belongs' to Saskatoon, creating a place that is 'familiar' to First Nations culture, and lastly, a place where all peoples gather.

“ 'Belonging' refers to respecting the urban environment, both character and place, as well as metaphorically, referring to a culture's need to belong to any unfamiliar environment. 'Familiarity' refers to the unique and recognizable characteristics of any given people or culture. The gathering place refers to the need to bring both Aboriginal and non-Aboriginal peoples together to share stories."

\footnotetext{
${ }^{41}$ Norberg-Schultz, Genius Loci, 166.
} 
Those who were present were silent, listening attentively as Bobby guided them through his project. The three committee members, a full-time professor from the faculty of architecture, and a few outside critics were in attendance. The company assembled in the pit, a large presentation area in the Architecture building on campus. As a brief description of the site's context, Bobby went through a digital presentation, giving a small overview of the site and the surrounding city centre.

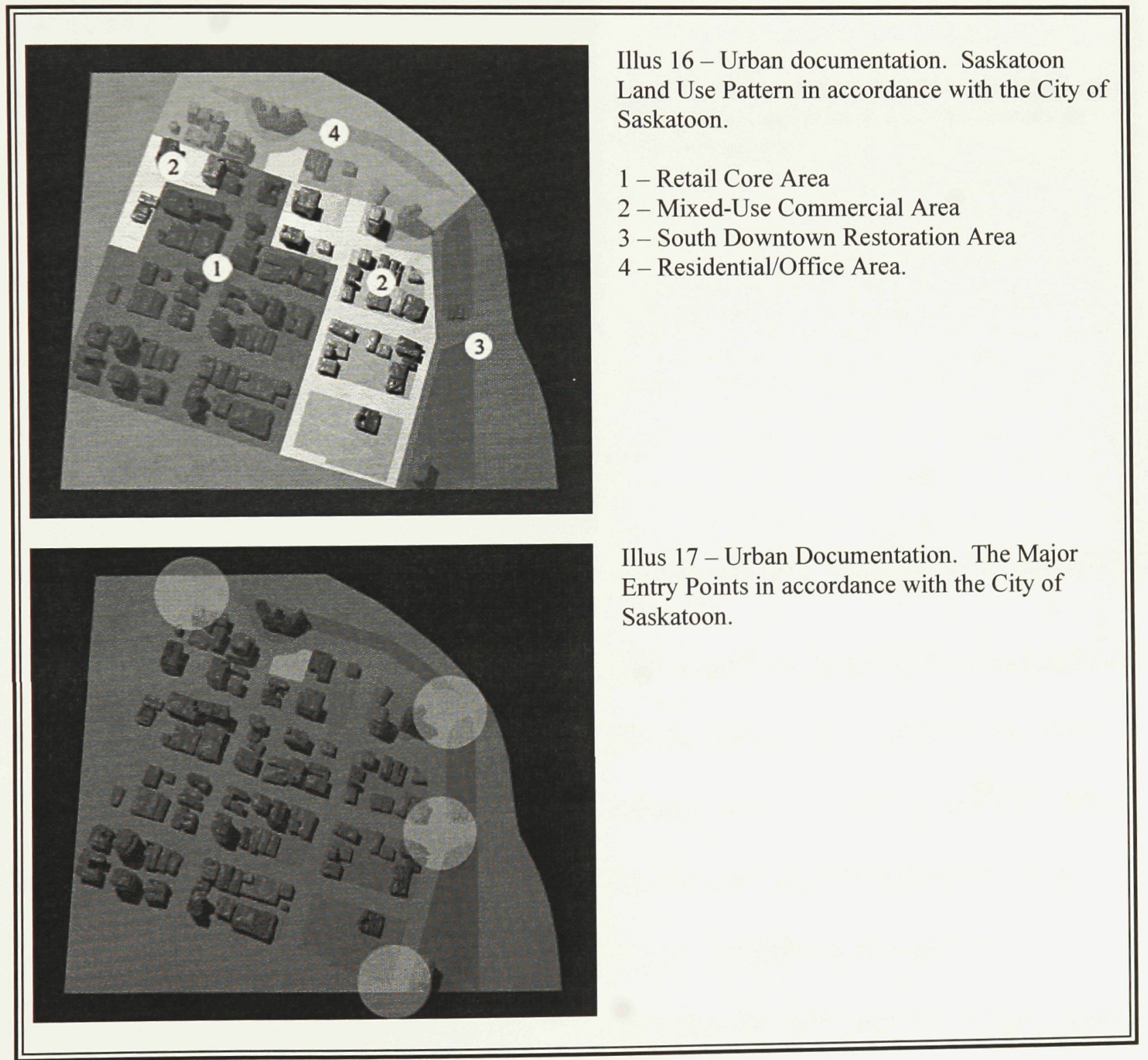




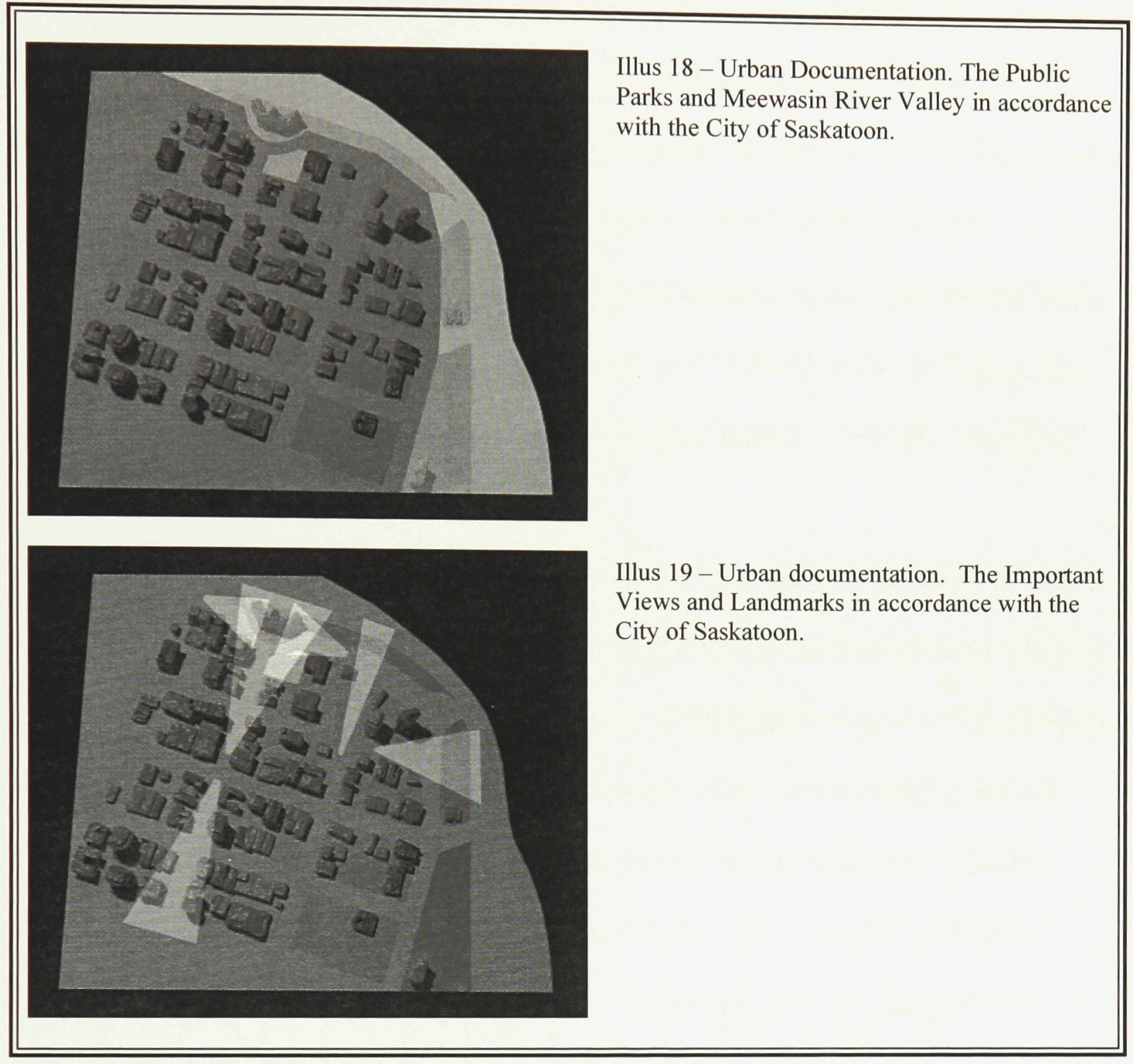

The program was introduced as Jim had left it in Bobby's mind: the collaboration of the Friendship Centre and Cultural Centre. This included the sacred space that May and Ashley suggested, and the regular program already in place at the Friendship Centre. From the Cultural Centre, it included the learning and display environments, and the library. Bobby justified his moves similar to the way Jim had a month earlier.

Bobby then went through the cultural side of his first four months of exploration. He discussed conversations he had with Bret. Bret had provided Bobby with a significant 
fundamental background depicting the difference between Aboriginal and non-Aboriginal beliefs. Bobby discussed the opinions of several social scientists that Derek had introduced him to. Bobby discussed his own discoveries of procession, orientation, and movement, and how they transform space for specific periods of time. He also introduced the committee to Tom King, the little Aboriginal man living in his backpack.

"The truth about stories is that that's all we are," ${ }^{42}$ Bobby naturally began, now glancing toward his backpack where Tom sat listening intently. "I'm told, Aboriginal peoples live through stories."

During the past four months, Bobby had begun exploring relationships between the art of writing and that of architecture. As Christian, and so many others, told Bobby, 'concretization' of the lived-world, or architecture, "is the function of the work of art, as opposed to the 'abstraction' of science." ${ }^{43}$ The relationship he was pursuing seemed appropriate in this context. During this exploration he discovered several linguistic devices that were used in oral traditions, or storytelling. Often, modern Aboriginal writers would adopt these techniques, trying to create a 'familiar' or recognizable Indigenous world in their own literature and stories. ${ }^{44}$

"Hyperbole, repetition, and orality are all rhetorical devices that are recognized, appropriately interpreted, and respected by Aboriginal peoples in storytelling." At this point, Bobby had hoped to know how to use these linguistic tools in architecture. "As with procession, orientation, and movement, the physical 'concretization' of these terms

\footnotetext{
${ }^{42}$ King, The Truth About Stories 2.

${ }^{43}$ Norberg-Schultz, Genius Loci, 23.

${ }^{44}$ King, The Truth About Stories, 115.
} 
would distinguish themselves as a 'familiar' environment, recognized, appropriately interpreted, and respected by Aboriginal peoples."

However, he did not know how he was to do this yet. It existed at this point as an idea, presented as such, and criticized respectively. All Bobby knew at the moment, was the importance stories have on Aboriginal culture, and somehow this had to transform itself into the built and experienced world.

As for a building, it had yet to be started...

Before continuing though, a quick glance at the Aboriginal and non-Aboriginal metaphysical worlds, with the help of the renowned Vine Deloria Jr., of Aboriginal metaphysical, spiritual and political fame.

Bret had given Bobby an introduction to the conversation he was about to engage in, and it was a good thing. A Western-raised mind was in no shape to tackle these terrains. Vine would take Bobby for a little journey of his own. They would start in Ottawa, touch upon the Appalachians to the east, before traveling west through the rocky landscape of the Shield. Once through, they would trek the endless Prairie Plains, abruptly trudge through the Rockies, and finally come to a stop on a beach, overpowered by towering sculpted, wood poles. It was an adventure he would pursue several times before understanding occurred, and even then the extent of the understanding was limited. It wasn't that Vine was a poor guide; no, the terrain was simply that difficult. 
"The incredible gulf between Western and indigenous metaphysics is best summed up as follows: in the Western context metaphysics became a study for philosophers; in indigenous communities metaphysics would be understood as the basis for living well - attentively, respectively, and responsibly - in this world. ${ }^{, 45}$ Daniel Wildcat, Vine's fellow metaphysical explorer, greeted Bobby. "A good place to begin Indian education in America is with the lived experiences of peoples who have resided in places long enough to know and remember what it means to be Native to a place." ${ }^{.46}$

Bobby knew this to be indigenous. Daniel would continue, "Indigenous in the sense that people historically and culturally connected to places and do draw on power located in those places. Stated simply, indigenous means 'to be of a place.',"47

Vine responded politely, yet without hesitation, to what Daniel was saying, "Traditional technology can be extremely useful because it always reminds us that we must take our cue about the world from the experiences and evidence that the world gives us. We may elicit and force secrets from nature, but nature is only answering the specific questions we ask it. It is not giving us the whole story as it would if it were specifically involved in the communication of knowledge. What is given willingly is much more valuable than what is demanded as a matter of force. ${ }^{48}$ Remember, education in the traditional setting occurs by example and not as a process of indoctrination. That is to say, elders are the best living examples of what the end product of education and life experiences should be. ${ }^{, 49}$

\footnotetext{
${ }^{45}$ Deloria and Wildcat, Power and Place, 52.

${ }^{46}$ Deloria and Wildcat, Power and Place, 39.

${ }^{47}$ Deloria and Wildcat, Power and Place, 31.

${ }^{48}$ Deloria and Wildcat, Power and Place, 65.

${ }^{49}$ Deloria and Wildcat, Power and Place, 45.
} 
"Yes, Bobby," Daniel had waited attentively to take his turn again, "You see and hear things by being in a forest, on a river, or at an ocean coastline; you gain real experiential knowledge that you cannot see by looking at the beings that live in those environments under a microscope or in a laboratory. You experience places and learn, if attentive about processes and relationships in those places."

Through observation, Bobby thought to himself. Vine replied, "The acknowledgement that power and place produce personality means not only that the natural world is personal but that its perceived relationships are always ethical. For that reason, Indian accumulation of information is directly opposed to the Western scientific method of investigation, because it is primarily observation. ${ }^{51}$

"Here power and place are dominant concepts. Power being the living energy that inhabits and/or composes the universe, and place being the relationship of things to each other. Power and place produce personality." 52

"We, human beings, in all our rich diversity, are intimately connected and related to, in fact dependent on, the other living beings, land, air, and water of the earth's biosphere."53 Daniel spoke, supporting Vine's claim. They were now preparing for another night camp, somewhere in the heart of the vast Prairie sky which Bobby knew so well. Evenings became extremely cold in these parts; Bobby knew he would be bundling up tonight.

Vine continued the stories amongst the flickering warmth of the campfire's flames, "The primary focus of creation stories of many tribes placed human beings as

\footnotetext{
${ }^{50}$ Deloria and Wildcat, Power and Place, 36.

${ }^{51}$ Deloria and Wildcat, Power and Place, 27.

${ }^{52}$ Deloria and Wildcat, Power and Place, 23.

${ }^{53}$ Deloria and Wildcat, Power and Place, 12.
} 
among the last creatures who were created and as the youngest of the living families. We were given the ability to do many things, but not specific wisdom about the world. So our job was to learn from other, older beings and to pattern ourselves after their behaviour. We were to gather knowledge, not dispense it,"

“Oren Lyons,” Daniel spoke respectfully regarding an Onadoga elder, "remarked at the twenty-fifth anniversary of Earth Day that the difference between American Indian and Western views of nature is that while European immigrants looked at nature and saw resources, we looked around and saw relatives." 55

Vine nodded in recognition.

Daniel, pausing ever so briefly to fill his pipe, inhaled a little earthly treasure, and began describing his surrounding relatives again. "Native worldviews involve consideration for the rights or we might say more accurately, following Vine, the 'personalities' of plants, animals, and the physical features of the natural world - for example, land, air, and water - as well as our relationships among our humankind. The framework for the measurement of the 'greatest good' is not human society but the ecosystem or natural environment that forms one's political and ethical community in the broadest sense. In short, the Native view advocates an understanding of the public sphere, which includes many peoples, including many other-than-human persons." Pausing for a few more small wisps of earthly delights, he continued again, "finally, nearly all indigenous North American worldviews that I am familiar with consider the world as dynamic, not static. These views acknowledge the biological and

\footnotetext{
${ }^{54}$ Deloria and Wildcat, Power and Place, 60.

${ }^{55}$ Deloria and Wildcat, Power and Place, 121.

${ }^{56}$ Deloria and Wildcat, Power and Place, 88.
} 
physical principles of emergence - especially in their accounts of creation - which on the whole are much less anthropocentric and much more ecological and evolutionary."${ }^{, 57}$

Vine made sure Daniel was finished before giving his insight into the matter, "today we have the artefacts of every tribe lining the shelves of museums and being described as great primitive art. And, indeed, if we think of these artefacts only as useful utensils and implements, apart from the tribal context, they may be simple instruments. The important part of the relationship, however, was that all things were alive, and consequently their own power and wisdom was incorporated with them wherever they were represented. Modern humans use weapons, tools, and instruments to extend the capabilities of their own selves, and they use these things mechanically. Tribal people in using their instruments did not simply extend the scope of their own capabilities, but enhanced their abilities through the addition of the powers inherent in the relationships they had with other living things. ${ }^{58}$

"Now, Indians use a peculiar way of maintaining a metaphysical stance that can best be termed as 'suspended judgment.' People did not feel it obligatory that they reach a logical conclusion or that they could summarize the world of experience in a few words and sentences. The hallmark of the true Indian philosopher was the ability to hold in suspended judgment the experiences he or she had enjoyed or was told, and to file away that bit of knowledge until the time when more data of closely related content came his or her way.", 59

\footnotetext{
${ }^{57}$ Deloria and Wildcat, Power and Place, 88.

${ }^{58}$ Deloria and Wildcat, Power and Place, 62.

${ }^{59}$ Deloria and Wildcat, Power and Place, 6.
} 
Bobby recognized this trait in his two guides early on in their voyages. Daniel was patiently waiting to share a little more insight that evening.

"Vine, maybe more than any other scholar living today, had positioned the questions about self-determination and sovereignty in the most radical context possible: the real world or, if you want a technical description, a phenomenological critical realism. Vine is correct to refer to a disorientation resulting from the conflict between cultures, not worlds; we must avoid the error of talking about life in two different worlds or realities. I find Vine's point for almost four decades has been to suggest in the broadest sense that questions about our indigenous education, and for that matter the future of humanity itself, revolve precisely around who we are and how we choose to live in the world. ${ }^{, 60}$

Bobby couldn't help but make associations back to his conversations with Christian, as he slowly dozed off into the starry night. Everyone lately was talking about place, phenomenology and how we live amongst things. How we choose to live in the world.

"Real knowledge creates politeness in the personality," Vine spoke politely, as the fire slowly shone it's final flame that evening, "this being the most precious of all the old traditional personality traits." ${ }^{, 61}$

These words stuck with Bobby as he fell asleep that night.

\footnotetext{
${ }^{60}$ Deloria and Wildcat, Power and Place, 115.

${ }^{61}$ Deloria and Wildcat, Power and Place, 130.
} 
... as for a building, it had yet to be started. Program and urban studies had to be almost complete before any real design could take place. Of course, Bobby's head was swarming with ideas, but he had to resist and be patient until some of the preliminary work was well under way. He knew he had several more voyages with Vine and Daniel before any understanding about culture would reveal itself. Obviously the culture needed to be understood to some degree if a design reflecting this culture was to exist.

"This is my project so far," Bobby finished his presentation, "I was hoping to receive some specific feedback regarding program. Any ideas?"

This sparked a commotion of conversations amongst those present. Amongst the onslaught of suggestions was a cultural restaurant, a craft centre, a resource centre instead of a library, a bed and breakfast, legal aid, a doctor's office, an elder's room, a local Aboriginal radio broadcast centre, and an Aboriginal garden (referring to the Montreal Botanic Gardens as a precedent).

The critics also felt the building had to penetrate beyond the site. It had to be responsive to, and resonate into the surrounding community. Approaching the building was as much part of the journey as the building itself.

Overall the review went well. Another stage of the project was complete. The feedback was generous, and those present were helpful. The months to follow were to be filled with two journeys, one regarding stories, and the other about architecture. How these two would collide, Bobby wasn't quite sure, but oral tradition was a strikingly interesting link to Indigenous culture. It was curious to see if storytelling could somehow translate itself into the built, lived-world. 


\section{Part 2:}

$\underline{\text { In the Land of Stories }}$

Derek was excited about exploring stories and architecture with Bobby. It was an opportunity to use his academic background in a new context. Where the explorations were to lead them, neither Derek nor Bobby were sure, but that is the exciting part about learning. Firstly though, Derek knew Bobby had to see the full spectrum of oral storytelling and how it impacts a culture.

"You must first understand, Bobby, that stories are much more than words," Derek enthusiastically taught. "The performance of oral tradition involves the enactment of, the understanding of the audience, and the context in which the story is told. It is an embodiment that consists of the verbal dialogue as well as these other aspects. It is vital to the atmosphere and understanding of the story itself."

Bobby listened as his professor described stories, or his understanding of them. The potential of stories was only beginning to reveal itself.

"In the middle of a story it is not unusual for a teller to begin singing a song or acting out a scene. It is through this acknowledgement of the performance of stories, that they are understood, experienced, and embodied," Derek continued. "I think it may be of some use to look at the embodiment of stories in festivals and how the audience experiences certain stories. How the experiential environment recreates and initiates stories often determines the audience's exposure to and embodiment within the story.

This sounded interesting. How the performance of a story involved more than verbal dialogue. This seemed like an entry point for architecture. 
"After several conversations with the little Aboriginal man, I think it is also important to look at how Aboriginal writers, which would include ethnographers, translate and represent oral traditions in the written form." Bobby expressed concern. Derek reassured this concern. "This may help you discover ways of using repetition, hyperbole, and orality architecturally."

As with most students in architecture school (or any design school), literal representation was a brutal lesson learnt. Any artist knows not to represent anything literally, whether they are a writer, a painter, or an architect. Bobby was reassured about this several months later during one of his conversations with Tom King, however that is a different story, meant for a later time. Right now, Bobby knew he had to avoid the literal representation of Aboriginal symbols. There were way too many tipi misrepresented across the Prairies already. He had to be careful not to approach stories in the same literal way as well. Yves and Bret would appropriately remind him of this over the months to come. This was important to establish, at the beginning of the journey into the land of stories.

\section{Program, Urban Design, and Architecture}

\section{Meanwhile,}

the program, urban studies, and ultimately, the architectural exploration was in progress. Initially, Bobby had wanted to add all the suggested programs to this project ('this' project, because the project belonged to so many people aside from Bobby 
already). To be used to its full potential, the site needed a few additional programs. This was understood. Including all the suggested programs seemed a bit excessive however, and Bobby did not want to create a 'one-stop mall' for Aboriginal peoples. Something else had to tie them together, allowing him to be selective. For the time being though, each program was to be explored individually. Perhaps this too would help determine the programs to be included.

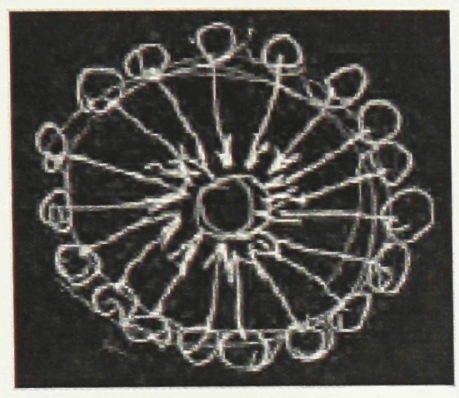

Illus 1 - The collective approach. It is in the circle we speak from our heart, our soul, our centre.

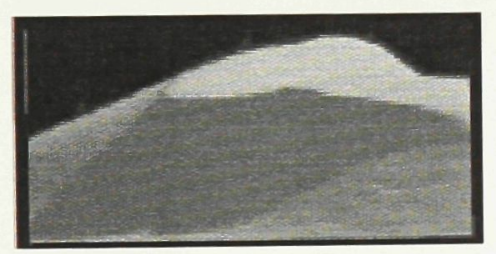

Illus 2 - Each space is like a living cell.

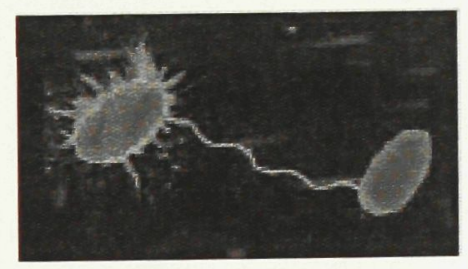

Illus 3 - In the analysis it becomes just a group of related cells.
During a meeting in May with Bret, Bobby was thoroughly introduced to the 'Cardinal Organic Design' process. Douglas Cardinal, Bret's father, had created this process out of a need to put himself and his Aboriginal heritage into his design philosophy. By using this technique, Aboriginal identity surfaced in all his buildings, regardless of the program. His process reflected his beliefs, therefore placing a little piece of himself and his culture into everything he did. There was no literal representation of symbols, only the identity he grew up knowing.

"We first determine a program, which is often very important in Native buildings, and begin to allow the programs to arrange themselves accordingly. In the most sensible way." Bret described the process he followed for several years working with his father, "In this I mean to allow the programs that have the most connections with one 


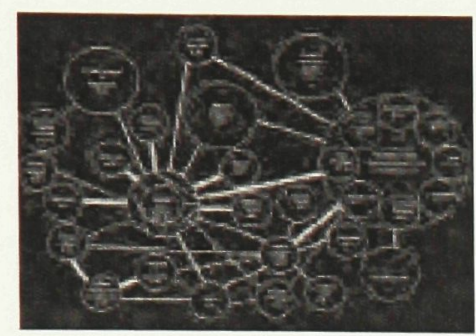

Illus 4 - Until we breathe life into this matrix, by perceiving it as a living organism with a purpose.

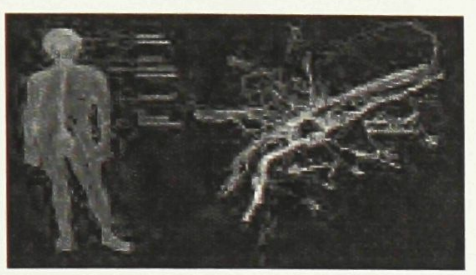

Illus 5 - We study each function forming a matrix. Vision and Function will dictate the form, not a preconceived idea.
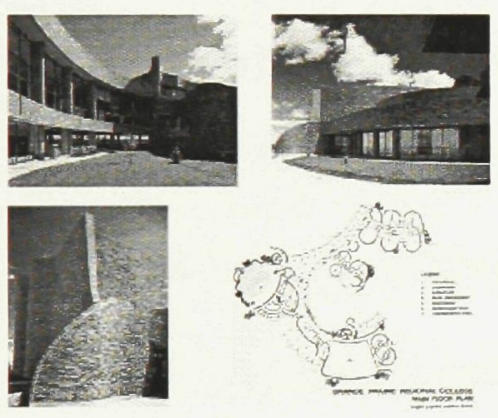

Illus 6 - Grand Prairie Regional College.

(C) DJC Architects Ltd, "Design Philosophies." These images are represented as DJC has presented them. These images show the process of the 'organic' design process. This process was interpreted and used during the design of the Gathering centre. another, to be placed amongst one other. This way, circulation occurs in the most logical and experiential way." According to Bret, this resulted in a design without preconceived form. By allowing the programs to appropriately situate themselves, form was derived accordingly.

Using the Grand Prairie Regional College as a reference, Bret explained, "buildings are living organisms. They grow, deteriorate and function as a living, organic body. The entrance is like the mouth and where wastes gather (loading, garbage disposal, ect.) is the anus.

"To back up a little though, it is important to note that the initial space required by each part of the program is determined by the 'inside-outside' process."

Bobby nodded, but wasn't quite sure what this meant.

"This means, we determine how many people will be using the space, the number of furnishings and other requirements, and the amount of circulation room. From this we are able to get an accurate estimate at how large 
each interior room will be. After determining all the 'interior' rooms, the 'exterior' becomes the suitable placement of interior pieces. The exterior is derived from the interior out."

"Shouldn't all spaces be determined this way?" Bobby asked, confused by the association of this process as being typically Indigenous.

A smile slowly revealed itself as Bret simply shrugged.

$\underline{\text { In the Land of Stories }}$

Julie $^{62}$ awaited Bobby's arrival. She knew what Bobby had come for. Something she involved herself in for years. Julie Cruikshank was an ethnographer, highly recommended by Derek, and it was at the National Art Gallery where she would reveal to Bobby what she knew about stories.

"I will start by quoting two of my colleagues, Nora and Richard Dauenhauer," Julie began, reflecting back on a conference in which she participated in a few years back. "They refer to oral traditions as 'embodied,' that is, it occurs in real time, it is performed, it always involves interaction between teller and listener, and in North America it is deeply embedded in clan and community."

These were insightful words that would forever sustain themselves in the curious journey through the land of storytelling. To embody stories, and stories being deeply

\footnotetext{
${ }^{62}$ Julie Cruikshank is an ethnographer who documented oral traditions of elders in the Yukon. She wrote Life Lived as a Story, one precedent for the narrative structure of this thesis.

${ }^{63}$ Cruikshank, "The Social Life of Texts," 98.
} 
embedded in clan and community, what did these mean? Bobby patiently awaited answers as Julie continued telling her story.

"Words have work to do: words make the world rather than merely refer to it. To really hear a story, elders have agreed, you need to know it already at some level, and if narratives told and written in English can provide today's audiences with background they would otherwise lack, so be it." ${ }^{94}$

Julie had spent several years with three elders in the Yukon, translating and recording their oral traditions. She was reflecting upon these experiences. "From this perspective, writing becomes just one more component of performance: one way of familiarizing audiences with narratives so that a storyteller can count on listeners to appreciate the really creative editing or shaping when she tells those stories again. Such a perspective enlarges the definition of performance to include the written page, so that 'editing' goes beyond the written page just as 'performance' may go beyond the physical act of telling the story." 65

Bobby recognized the similarities in Julie's tone with that of Derek's. 'Performance' being the common theme in both.

"The reason I say this," Julie continued, "is to describe how I have come to appreciate a very particular definition of 'editing' that includes carefully tailoring performances for specific audiences. In the not so distant past, a Native storyteller could always count on local listeners to be familiar with stories they were being told and hence to appreciate why these stories were being directed specifically to them."

\footnotetext{
${ }^{64}$ Cruikshank, "The Social Life of Texts," 104.

${ }^{65}$ Cruikshank, "The Social Life of Texts," 104.

${ }^{66}$ Cruikshank, "The Social Life of Texts," 104.
} 
Bobby listened attentively as the two of them left the solemn silence of the courtyard behind, the silence they had spent the early parts of that afternoon in. Julie was now working through the process, as an ethnographer and editor, she had come to realize as part of oral tradition. There were several interesting connections between architecture and the editing process, the most notable being the expansion of storytelling to include the editing process. Like editing, perhaps architecture could expand its roots and become a part of oral tradition. The initial idea was there. As Vine, that patient Aboriginal thinker, would so often mention, "the hallmark of the true Indian philosopher was the ability to hold in suspended judgment the experiences he or she had enjoyed or was told, and to file away that bit of knowledge until the time when more data of closely related content came his or her way. ${ }^{, 67}$ Bobby knew Julie's stories would resolve themselves much later in his journey. It was now time to listen.

"I want to summarize a story about stories told on the printed page," Julie continued. "However, I should briefly describe the work I was doing. I went to the Yukon to record life histories of three women elders. They wanted their narratives recorded in English so they would be accessible to younger family members. I had no difficulty with this as long as we were recording what might be called secular history, such as the narratives associated with the goldrush, the early twentieth century fur trade, and the construction of the Alaska highway. I was troubled when the women wanted me to record more foundational narratives in English because it seemed to me then that all this was taking us away from what I took to be our primary goal - the documentation of

\footnotetext{
${ }^{67}$ Deloria and Wildcat, Power and Place, 6.
} 
everyday experience. These women seemed far more interested in having me record complex narratives than in talking about what I took to be their 'life history." "68

Voice of Fire ${ }^{69}$, the controversial, towering blue and orange stripes, seized Bobby's attention into the gigantic white room. Julie, just as quickly, stole his attention back, "At their insistence, I continued on their terms, and it was only later when I came to see how they were using these narratives as reference points to talk about their life experiences, that I was able to appreciate the complexity of what they were doing. These narratives - about a boy who went to live in the world of salmon; about a girl who married a bear; of men who traveled to the 'other world' in search of a lost sister; or of women who went to live with the stars.",70

Bobby grinned at this, as Tom told him he would. "These stories sound so mythical and unusual; they do," he faintly whispered to himself.

"Actually these stories provided pivotal philosophical, literary, and social frameworks essential for providing young and not-so-young people with ways of thinking about how to live life appropriately," Julie quickly corrected Bobby. "The stories erased any distinction between 'story' and 'life.' They were embedded in social life and, in the words of one master storyteller, Angela Sidney, provided guidance about how to 'live life like a story." 71

"I see," Bobby meekly responded, a little alarmed by Julie's sharp remark.

"Simply a misunderstanding Bobby. Now let me end by sharing this story with you. This particular story was told to me by Angela Sidney in 1974, and is about a heroic

\footnotetext{
${ }^{68}$ Cruikshank, "The Social Life of Texts," 100.

${ }^{69}$ Barnett Newman, Voice of Fire, 1967.

${ }^{70}$ Cruikshank, "The Social Life of Texts," 100.

${ }^{71}$ Cruikshank, "The Social Life of Texts," 101.
} 


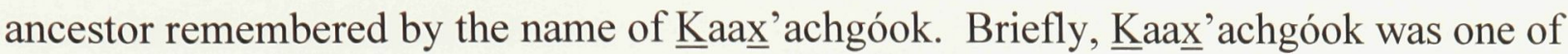
the famous Tlingit ancestors of the Kiks.ádi clan. One autumn, he went hunting sea mammals with his nephews but soon received a sign that seal hunting was now dangerous for him and that he should return home. Reluctantly, he destroyed his spears and returned to his winter village, but eventually it became unbearable to him that his wives had to beg for food and that they were treated with disrespect. Setting out to sea once again with the same nephews, he was blown off course and became lost. Eventually, the crew washed ashore on a small island. Kaax'achgóok spent the following months devising ways to feed himself and his nephews, and perfecting a way to plot the sun's trajectory as it moved north, stopping at summer solstice. At precisely the day it reached its zenith, he set sail for home, using the sun as a navigational guide to chart his direction. Despite his successful return, he faced the difficult business of acknowledging how much life had changed during his absence.

"When Mrs. Sidney first told me this story in 1974, we were both primarily interested in transcribing it in a way that she considered accurate. It subsequently appeared in a booklet by Mrs. Sidney and two other storytellers. In elementary social studies classes it was sometimes discussed with references to summer solstice, and in high school literature classes teachers sometimes compared it with The Odyssey.

"Several years later, 1980, I was visiting Mrs. Sidney one day when her son, Peter, and his wife arrived. The conversation moved to Peter's experiences as a veteran of the Second World War. He was stationed overseas for a period and Mrs. Sidney began to speak about how she had missed him, how she and her husband had bought their first radio so they could listen to news and learn 'where the troops are,' and how happy she 
was when the war ended and they received a telegram announcing his return. The remainder of her story concerned the plans she made to welcome her son back when he returned home after the war, hosting a community feast and publicly giving him the most precious gift she could - the song $\underline{\text { Kaax}}$ 'achgóok sang when he returned home after his long absence - a song she then referred to as 'Pete's song' for the rest of her life.",72

Julie paused ever so slightly, noticing how the sun accented the otherwise quiet room Bobby and she had descended into. The skylights far above allowed the light to shimmer off the water far below. Caught between earth and sky, in a room as peaceful as the Yukon landscape.

Slowly coming out of her slight reverie, she began again, "she went on to tell a third story about this story - the social processes set in motion by her gift. No sooner had she publicly given her son this song in 1945 than she was formally challenged by the elders from her father's Dakl'aweidii clan who disputed her right to sing it - much less give it to her son. They argued that it was the property of the Kiks.ádi clan and that her Deisheetaan clan had no right to use it. The remainder of her account is the story of how she proceeded with her own research to prove that her use of this story was not thoughtless appropriation but rather a carefully considered decision. She traveled to Skagway, Alaska, to visit Tlingit elders and interviewed them about an incident many years earlier in which a dispute between Kiks.ádi and Deisheetaan clan members was resolved when Kiks.ádi agreed to give this $\underline{\text { Kaax}}$ ’achgóok song to the_Deisheetaan. Her story about the story confirmed, to the satisfaction of her elders, that she had acted appropriately. Being able to tell this story almost forty years later, 1980, in the presence

\footnotetext{
${ }^{72}$ Cruikshank, "The Social Life of Texts," 105-108.
} 
of her son (who knew the story well and was a character in it) and to his non-Tlingit wife and to me (both of us familiar with the written text of the narrative) reconfirmed her competence in using stories in a socially significant way - and in fact extending her audience once she could make people understand (through her written version) the connections between a narrative, a song, a gift, and her own ethnographic authority.

"A fourth telling was performed for a very different audience, most of them familiar with Mrs. Sidney and her role as a master storyteller, but only a few knowledgeable about this particular story. When a college was opened in the Yukon Territory in 1988, Mrs. Sidney was asked to be part of the opening ceremonies. This was a thrilling event for many Yukoners because the college means that students can complete part or all of an undergraduate education without having to leave the territory. At this ceremony, Mrs. Sidney decided to tell the story of Kaax'achgóok. As she described the events to me later: 'The reason I sang this song is because that Yukon College is going to be like the Sun for the students. Instead of going to Vancouver or Victoria, they're going to be able to stay here. We're not going to lose our kids anymore.

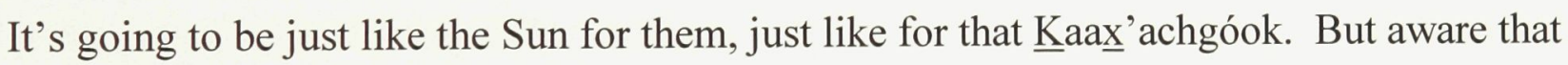
her diverse audience was probably not able to make this connection, she suggested that we should again make available a transcription of the text. We submitted this to the College's journal, The Northern Review, so that the text with her commentary could be accessible for anyone in the community interested in understanding the connections she was making." 73

${ }^{73}$ Cruikshank, "The Social Life of Texts," 105-108. 
"Do you have any questions, Bobby?" Julie changed tone, leaving the persona of the story for a few seconds. "You're very quiet."

A soft smile reassured Bobby's attention. She continued where she left off.

"Very carefully, then, Angela Sidney was able to show how a single story can 'do' several different things. She also constructed an important link between an ancient story she remembered, her various written versions of that story, and three distinctly different social occasions - the return of a son, the demonstration of her own deepening knowledge during the 1940 's, and the opening of a college in the 1980 's. In other words, she was able to edit, in performance, a written version of a narrative that she used as a reference point from which to translate particular meanings to her different audiences. In effect, her work challenges the idea that texts can be 'collected,' because no telling can be separated from the setting, the audience, and the life stage of the narrator." ${ }^{, 74}$

As Julie was telling her story, Bobby couldn't help but reminisce how this related to architecture. Could one common story, a story needed to be told in several cities throughout North America, be established as a 'point of reference' to familiarize a culture in the urban context? Like Mrs. Sidney, would the variation of the story depend on place and audience? How would architecture articulate such a story?

As the sun ascended out of the courtyard that serene afternoon, Bobby couldn't help but recognize the little Aboriginal man's stories absorbed in Julie's tale.

"I know that one," Bobby replied after a few moments of recollection had passed between the two of them, "the one about changing stories. The little Aboriginal man living in my backpack, Tom King, told me that one. 'There is a story I know,' he often

\footnotetext{
${ }^{74}$ Cruikshank, "The Social Life of Texts," 105-108.
} 
begins. 'It's about the earth and how it floats in space on the back of a turtle. I've heard this story many times, and each time someone tells the story, it changes. Sometimes the change is simply in the voice of the storyteller. Sometimes the change is in the details. Sometimes in the order of events. Other times it's the dialogue or the response of the audience. But in all the tellings of all the tellers, the world never leaves the turtle's back. And the turtle never swims away., 75 ",

Bobby pleasantly quoted the man in his backpack, as Tom and Julie listened encouragingly.

\section{Program, Urban Design, and Architecture}

With the program underway, it was time to look at the existing urban context in Saskatoon. This should determine some of the initial urban design moves, or so Bobby thought. Either way, Yves stressed the importance of urban studies. Bobby knew of the typical mapping exercises, modeled after Kevin Lynch, ${ }^{76}$ and similar other sociological techniques. He had used these throughout his schooling in various forms. The struggle now seemed to be how to associate these studies with Aboriginal culture. Was there a way to identify these maps from an Aboriginal perspective? To his advisor he went. "Perhaps you should create two maps and compare them. One from each phenomenological view, Aboriginal and non-Aboriginal," Yves suggested.

\footnotetext{
${ }^{75}$ King, The Truth About Stories, 1.

${ }^{76}$ Lynch, The Image of the City.
} 
From the little understanding Bobby was gaining of phenomenology, he was beginning to question whether he should be using a Western-based philosophy to describe the view of Aboriginal peoples. Then again, because he grew up in the Westernbased world, could he relate to the Aboriginal perspective from any other viewpoint? Besides, the basis of phenomenology is to place oneself outside the problem, set aside all preconceived notions, and look at the problem from a fresh perspective. Perhaps this was as close as he was going to get without being reborn into an Aboriginal community. Oh, the dilemmas of modern philosophy! Either way, Bobby knew it was time to visit the train again.

"Well, hello Bobby," greeted Mr. Norberg-Schultz as he prepared his fold-out table,

which fit very nicely between the facing seats,

for tea and biscuits. "Could I offer you a cup of tea?"

"Christian it is always a pleasure to see you," Bobby began as he made himself comfortable amongst the several commuters who shared Christian's home. "I have a few questions about phenomenology and architecture to query you about. I'm having doubts about phenomenology's role in Aboriginal philosophy. Aboriginal philosophy is as complex and explorative as phenomenology is. Am I dealing with two phenomenological perspectives, or one phenomenological perspective and one Aboriginal perspective?"

"Let me tell you a story," Christian replied as he poured some tea. "The Germanborn American architect, Gerhard Kallmann once told a story which illustrates how 
people become familiar to place. Visiting at the end of the Second World War his native Berlin after many years of absence, he wanted to see the house where he had grown up. As must be expected in Berlin, the house had disappeared, and Mr. Kallmann felt somewhat lost. Then he suddenly recognized the typical pavement of the sidewalk: the floor on which he played as a child. And he experienced a strong feeling of having returned home.

"The story teaches us that the objects of identification are concrete environmental properties and that man's relationship to these is usually developed during childhood. The child grows up in green, brown and white spaces; it walks or plays on sand, earth, stone and moss, under a cloudy or serene sky; it grasps and lifts hard and soft things; it hears noises, such as the sound of the wind moving the leaves of a particular kind of tree; and it experiences heat and cold. Thus the child gets acquainted with the environment, and develops perceptual schemata which determine all future experiences."

Bobby briefly pondered this over. "The way you grow up determines your interpretation of place," Bobby thought aloud, "and the stories you grow up believing often shape the way you live. Daniel, the fine philosophical guide that he is, once mentioned during our explorations, 'Learning comes early in indigenous institutions, not through lectures but through experience: customs, habits, and practices. The primary lesson learned is and was that knowledge and understanding come from our relatives, the other 'persons' or 'beings' we have relationships with and depend on in order to live. And it is through these relationships, physical and psychological, indeed spiritual, that

\footnotetext{
${ }^{77}$ Norberg-Schultz, Genius Loci, 21.
} 
human beings begin to understand who, why, and even to some degree what we are; ${ }^{78}$ anyway, something like that."

Bobby continued, "I realize that Aboriginal peoples grow up with an acknowledged relationship to the land and all the relatives that belong to it. Perhaps the urban landscape could be perceived as this new landscape that now needs to be observed, learnt from, and adapted to. It is a question of combining the Aboriginal philosophy in the modern context. One must deal with the Western philosophy, all urban centres in North America belong to this, including Saskatoon, and allow the Aboriginal philosophy to exist within. Between the two cultures, there would be different interpretations of the same thing, depending on the metaphysical belief. In this sense, the Aboriginal philosophy would be their phenomenological perspective, that which is naturally and culturally derived from place."

A moment of silence filled the train as people blankly gazed at one other absorbing what was just said.

"I must also note that most people feel 'lost' when they are moved to a foreign landscape," Christian continued the conversation. "It is well known that people of the great plains easily suffer from claustrophobia when they have to live in a hilly country.",79 "I noticed that when I traveled to Australia," Bobby mentioned as he thought back to the warm, sunny beaches, "I really missed the snow."

Christian got up to refill his cup. The train conductor passed by for what seemed the millionth time.

\footnotetext{
${ }^{78}$ Deloria and Wildcat, Power and Place, 33.

${ }^{79}$ Norberg-Schultz, Genius Loci, 48.
} 
"Don't you get bothered by the fact this train doesn't go anywhere? It makes four stops, the conductor goes to the other end of the train, and the cycle is repeated over and over again," Bobby questioned out of curiosity. Christian appeared not to have heard the question, as he continued fussing over his tea.

The Carleton stop was coming up quick again, so Bobby thanked Christian for the lovely conversation, and gathering his thoughts he mused:

"Perhaps one way to deal with this urban design issue is to map out the city using Western techniques (keeping with the overall 'belonging' theme of Saskatoon) and allow the Aboriginal philosophy to interpret the findings accordingly. Their response to what exists will be different from the non-Aboriginal interpretation. Besides, observation is a substantial part of the Aboriginal philosophy. Daniel, that wise one, mentioned, 'It is at the level of experience that our traditional and ancestral indigenous scholars have left us the richest legacy - insights of the processual, interconnected, and interrelated nature of the phenomenal world. ${ }^{80}$

"Vine mentioned shortly after, 'Indian accumulation of information is primarily observation. ${ }^{81}$ The urban centre is relatively new to Aboriginal folk. Western peoples like Mr. Lynch, however, have observed the urban environment for some time. It would only make sense then, from the Aboriginal perspective, to learn as much as possible from these observations. At least until Indigenous people have had enough time to generate their own observations, some might say stories, regarding cities;" all this as he waited for his stop.

\footnotetext{
${ }^{80}$ Deloria and Wildcat, Power and Place, 14.

${ }^{81}$ Deloria and Wildcat, Power and Place, 27.
} 


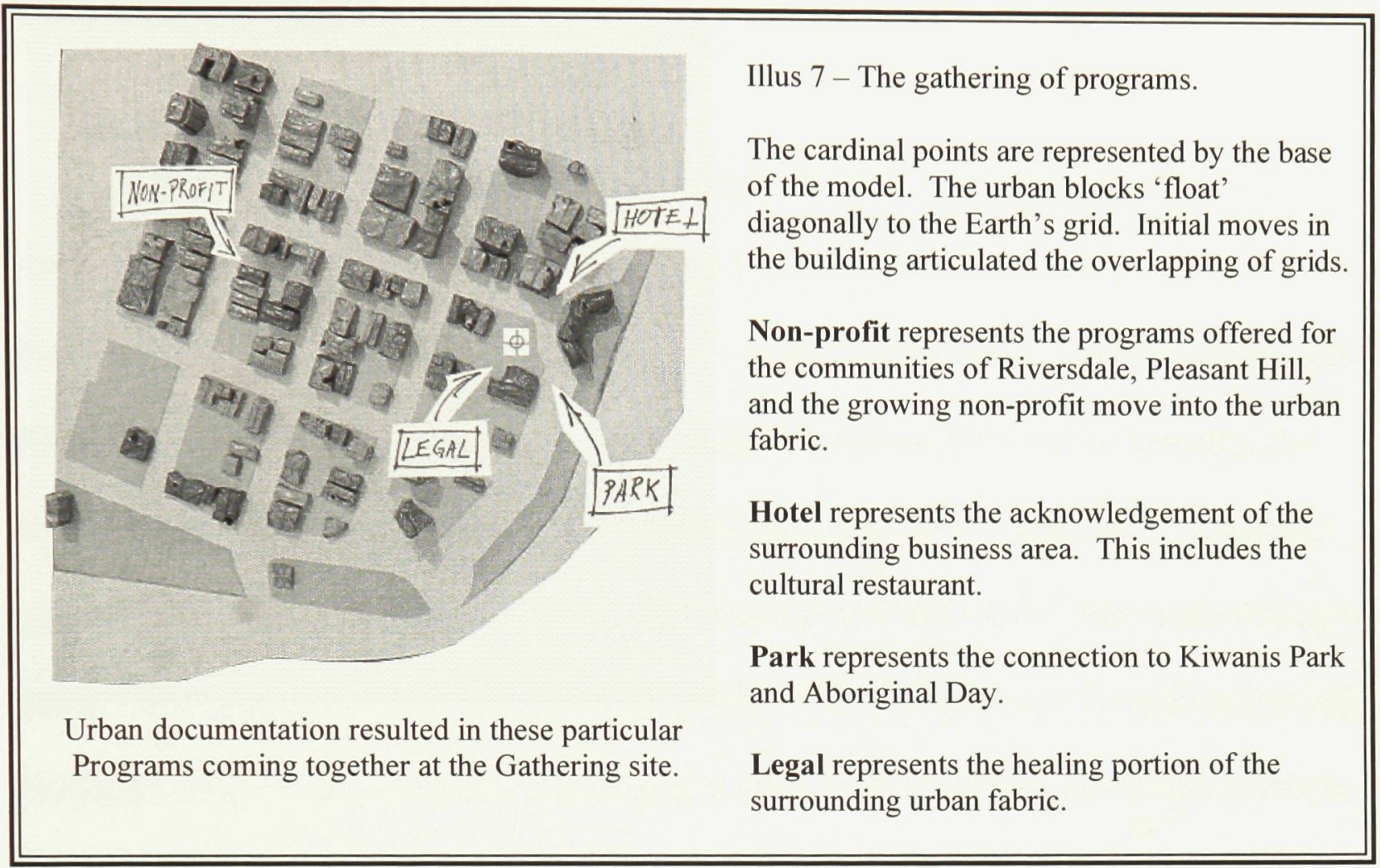

"Yes, there is an importance of the natural environment, but simultaneously one stresses man's ability to 'respond' and shape his world. Man does not obviously only 'build' nature, but also builds himself, society and culture, and in this process he may interpret a given environment in different ways, ${ }^{982}$ Christian reminded.

"The Western belief to dominate over nature and the Aboriginal belief that they are part of nature is a classic example of those different interpretations, ${ }^{83, "}$ Bobby briefly mentioned as he stepped off the train. "Thanks again for the visit Christian. I'm sure I'll be seeing you soon again."

\footnotetext{
${ }^{82}$ Norberg-Schultz, Genius Loci, 168.

${ }^{83}$ Deloria and Wildcat, Power and Place.
} 


\section{In the Land of Stories}

The walk over the Inter-Provincial bridge was one of the highlights of every week. Approaching the Museum of Civilization was Bobby's favourite part of the building. The way the winding walls reflected on the Ottawa River, as if limestone cliffs cascading stories in the distance. As one meandered through the exterior grounds, the museum revealed several perspectives of the monumental Ottawa skyline. The exterior gardens were distinctly Native, each sharing specific stories for those who were willing to listen. The totems that framed the exterior Grand Hall rippled across the water adjoining landscape with architecture. The building appeared to be an extension of that landscape, banking the river rushing by. Several images filled the mind as one approached and wandered around the museum. As Derek often reminisced, the slow trickle of water that flowed the length of the exterior front steps, indeed marked the life that was the building. Bret often mentioned buildings were living organisms; this museum was living proof.

The voyage only became more vibrant as Bobby moved further into the land of stories. Slowly more stories would reveal themselves one tale at a time. Bret's father had embedded so many within it. This was not a First Nations building by name, however the process and experiences initiated by the building would argue otherwise. Bobby walked this path every week, when Derek and he gathered to discuss stories.

"I am here to meet with Derek Smith, a professor at Carleton, who also works here at the museum," Bobby told the security guard. "He usually meets me in the lobby." The security guard directed Bobby to a small bench where he could wait upon Derek's arrival. 
After a few minutes Derek came hurriedly through the security doors, where Bobby greeted him with a cheerful smile. Derek's enthusiasm was amazing. As distressed as he appeared at times, he never ceased to astonish. These weekly visits were soon becoming a beacon, shining at the end of that wondrous weekly voyage. And as Bobby's increasingly growing appreciation for oral tradition matured, so did their conversations. Sharing knowledge and wisdom, establishing relationships between disciplines.

"How was your week," Derek asked as he led Bobby into the depths of the museum library.

"I've been talking to Richard. ${ }^{84, "}$

"Good, good. Has he been talking to you about the physical world and how it is transformed for some festivals."

"Yeah. How physical environments are transformed to allow for the performance of particular oral traditions."

"He is a theatre director you know."

Bobby nodded, "he spent a lot of time researching and observing Ramlila in Northern India."

"The month festival held to re-enact the life of Rama."

"Yes, Richard has mentioned that Derek."

"Richard was interested in making connections between theatre and anthropology. He understood well that rituals and stories were performances that included audience, ..." "place, storyteller, and physical actions."

\footnotetext{
${ }^{84}$ Schechner, Between Theatre and Anthropology.
} 
"You must have read carefully..."

... listened attentively when Richard Schechner and I met in the little café just east of the Market in Ottawa.

"I assume you are Richard," Bobby politely asked, after twisting through the busy café to where the lone man sat.

Richard's receptiveness was recognition enough.

"Thanks for meeting with me," Bobby spoke as he seated himself across from Richard. "A professor of mine tells me of your expertise with processions, spatial organizations, and the physical performance of stories."

"Ramlila to be specific. Ramlila is environmental theatre on the grand scale. The environment as a whole and individual environments for each lila are at the core of the narrative, from the level of the Ramayana and the Ramcharitmanas to the level of the maharaja of Benares. That is, all of the various themes of Ramlila from epic literature to contemporary politics are stated spatially. The environments not only set things in the theatrical sense, they iconosize in the mythic-religious sense: the struggle publicly observed by the incarnated King Rama versus the demon King Ravana - a struggle publicly observed by the present King Vibhuti Narain Singh; the maharaja and his city versus the not-yet-civilized countryside; the love of the sophisticated palace life versus the simple life of the peasants, the tribals, and renouncers." ${ }^{\prime 85}$

The conversation was forced to stop for a brief moment as the waitress brought them drinks.

\footnotetext{
${ }^{85}$ Schechner, Between Theatre and Anthropology, 178.
} 
"The social organization of space allows for certain stories to be recognized," Bobby responded, desperately trying to make connections back to architecture. "The relationship between king and peasant is articulated by the relationship within the festival environment. These 'programs' were situated in such a way as to allow for a dialogue between the one experiencing the festival and the performer. Therefore, allowing both to become part of the performance. The spatial organization allows for such tensions or associations to exist."

"Movement through this organization is also important. The audience at Ramlila takes naturally to a performance that includes procession." 86

Procession was already a popular word in Bobby's vocabulary.

"May I add," Richard interrupted Bobby's thoughts, "the very geography of Ramlila of Ramnagar echoes with very ancient pre-Hindu and Hindu references. And the geography of Ramlila - its hilltops, rivers and river junctions, cities, temples, caves, trees, wells, and paths - are models of actual places that carry and emit bundles of significance." 87

"Good, this ties stories back to place. Christian and Julie will be pleased. Stories are deeply embedded in clan and community, you know. ${ }^{88}$ Interpretation of these stories is also important."

"Well, as so many know, the force of the performance is in the very specific relationship between performers and those-for-whom-the-performance-exists.

\footnotetext{
${ }^{86}$ Schechner, Between Theatre and Anthropology, 179.

${ }^{87}$ Schechner, Between Theatre and Anthropology, 174.

${ }^{88}$ Cruikshank, The Social Life of Texts, 98.
} 
Performers do not have an independent life: they are related to the audience that hears them, and that sees them." 89

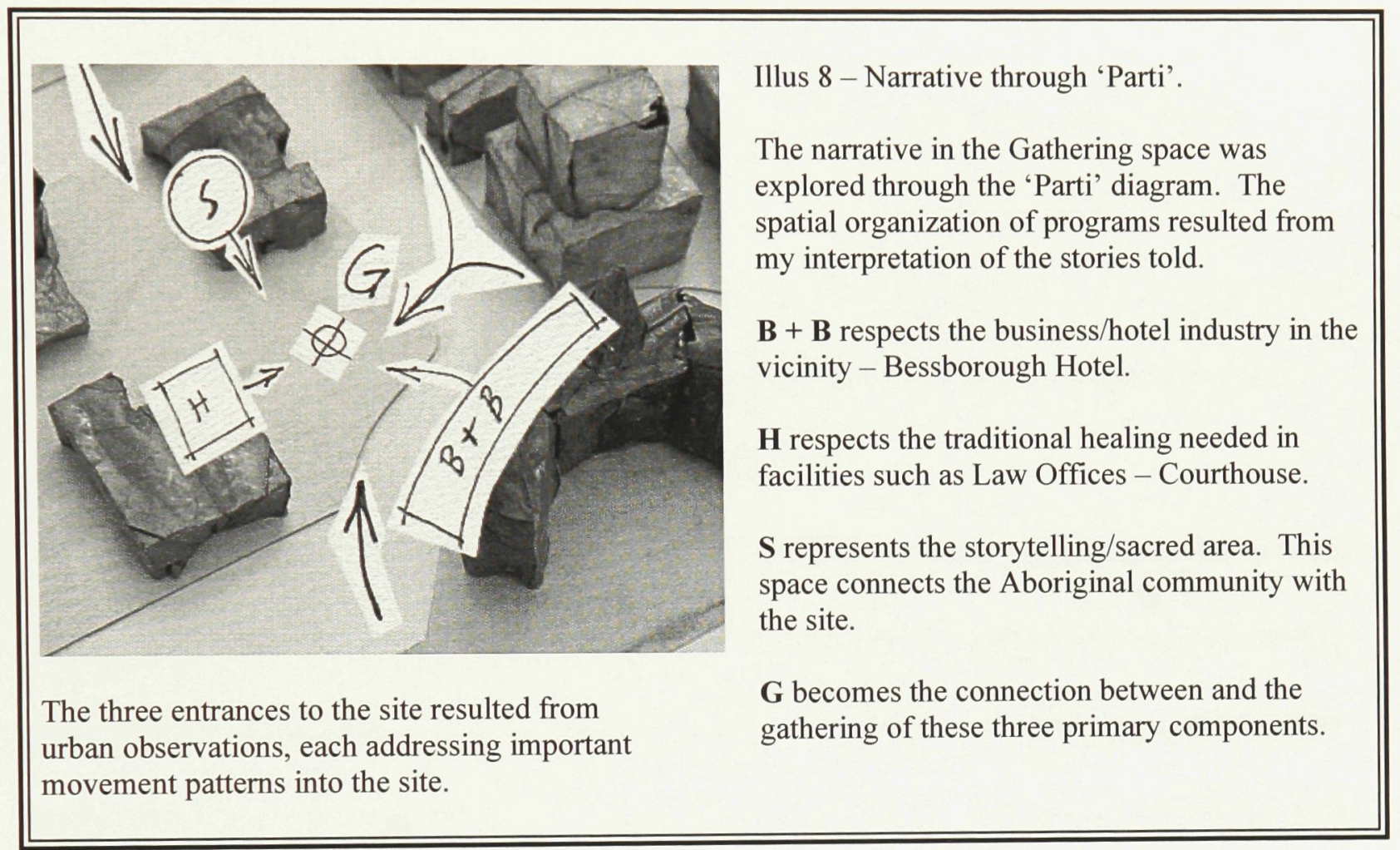

Derek listened as Bobby described his meeting with Richard. "Sounds like the two of you talked about a number of important issues, if I'm interpreting this right. It is important to understand how stories exist in real time. Richard knows all about this, or at least the physical side of it; procession; spatial organization. The continual dialogue between teller and listener is another important issue the two of you touched upon. Michael Ling, a student of mine, wrote a thesis on just this."

"Yeah, I’ve briefly talked to Michael," Bobby replied. "He mentioned, '(text and reader) are always to some degree very individual and contextualized. ${ }^{90}$ This is very

\footnotetext{
${ }^{89}$ Schechner, Between Theatre and Anthropology, 6.

${ }^{90}$ Ling, "Between the Tongue and the Teeth," 53.
} 
important in understanding how stories are lived, embodied things. Michael also mentioned, 'the process of reading and writing becomes one of incubating the experience created from the interaction of one's own life-world...

Christian would be impressed with this talk about experiencing one's life-world. ... with those offered in the ethnography itself. Such an interaction evokes a new, or perhaps at least a latent, set of experiences which emerge from the oscillation between the reader's experience and understanding of something, and that of the writer. 91 ",

"Very important indeed. The writer and reader, or teller and listener, have some degree of the performance and embodiment in storytelling. Interpretation keeps stories alive and allow for new stories to develop. Roland Barthes talks about this, how writer and reader combine as co-authors. ${ }^{92}$ Anyway, it is much too nice outside to be stuck in here. Let's go and I'll introduce you to a few of the stories surrounding this building."

Derek led Bobby into the surrounding landscape of the museum. The water trickled the length of the exterior steps, guiding the two into the gardens draping the river's edge.

"These trees and vegetation are all native to Canada. It is amazing what one will learn from each of these, if you listen carefully and recognize the story each is trying to tell," Derek enlightened.

\footnotetext{
${ }^{91}$ Ling, "Between the Tongue and the Teeth," 53.

92 Barthes, "Introduction to the Structural Analysis of Narratives," 56.
} 
"And it is only through generations of observing these beings, that one catches a glimpse of understanding," Bobby added, quite amused with catching himself refer to Vine.

"You are certainly becoming a master of quotes, my dear Bobby. You rattle one off after another," Derek said, as he paused to smell a little flower along the path leading to his parking stall.

Bobby often floated around the vast, and at times sporadic, world that was his mind, completely unaware of Derek's last comment, "Vine told me, "the best description of Indian metaphysics was the realization that the world, and all its possible experiences, constituted a social reality, a fabric of life in which everything had the possibility of intimate knowing relationships because, ultimately, everything was related. ${ }^{93}$

"Well, I'm beginning to see some relationships between stories and architecture. The way spatial organization of programs could initiate stories that need to be told. How movement and procession transform physical environments allowing stories to be told. I still don't know how dialogue will interact with architecture however."

"Only time will tell Bobby. Here, smell this wonderful flower." Derek was romantically entranced within the beautiful Ottawa summer day. "Walking around this building and within the gardens is my favourite part of the museum too."

\footnotetext{
${ }^{93}$ Deloria and Wildcat, Power and Place, 2.
} 
Program, Urban Design, and Architecture

"Before you wander back to Saskatoon, I think your program should be at least eighty percent done," Yves suggested, "that way you can get some important comments and reactions from the people you interview in Saskatoon."

Two weeks later, Bobby found himself in Yves's office with a stack of handwritten notes.

"I've organized the program into four specific parts," Bobby began. "The Friendship Centre, responding to the needs of urban Aboriginal peoples. A Bed and Breakfast / Cultural Restaurant that accommodates the tourist industry present in the area. There will be a Legal Aid, Walk-In Clinic, and Elder's office that deal with the issues of traditional healing in the legal and medical professions. The Legal Aid is also site specific, referring to the Federal Courthouse next to the site. Finally, there will be an Education and Communication department modeled after the Cultural Centre.

"Each program is specifically chosen due to cultural significance. I've justified each program according to initial urban context and cultural representation."

"Are there any precedents for this building?" Yves immediately asked, preparing Bobby for future conversations.

"Each component of the program exists on its own, however, I don't know of any one building accommodating the entire program. Actually, Bret has dealt with all these programs in one form or another."

"The specific urban context is enough justification for your program. You have chosen a large site, across from the most respected and dominant building in Saskatoon. 
Your building has to respond to this, and as discussed earlier, this can be resolved through the addition of program."

"Perhaps the people I interview in Saskatoon will provide enough reassurance about program."

"I think you will also have to do some urban studies while you are back in Saskatoon. This will determine the nature of the building and some of the decisions to be made in the future."

"I met recently with Christian and we discussed how to go about the urban design. I feel that it is appropriate to use Western observation techniques, those established by Kevin Lynch, and allow for an Aboriginal interpretation of this."

Bobby continued to fill the room with a few of the tales he heard while exploring with Vine and Daniel. It was a splendid account, and Yves had no choice but to listen. This was Bobby's discovery, and even though the process seemed abnormal at times, Yves supported and guided encouragingly.

"So you see, Yves," Bobby was now coming to an end, "Aboriginal peoples have spent very little time in the city compared to Western society. Perhaps the observations established by Western people like Kevin, would allow for a foundation for the Aboriginal culture to build their own observations and interpretations of the city. The city will be the new landscape for Aboriginal peoples."

Yves nodded in understanding. "Well then, what about the Aboriginal Day stage and Aboriginal gardens we've talked about before?"

"The stage will still be designed in Kiwanis Park, across from the site. I think the gardens should exist around the pathways along the river. I see the gardens as being 
relatively natural, and the river bank would supply the most natural setting possible. It would also be nice to connect the communities, Riversdale and Pleasant Hill, with the site. The river paths would allow for this, as they connect the two already. The deciding factor will probably be observing who, if anyone, actually uses these paths at the moment. These two elements are important connections to the Aboriginal relationship with the natural landscape. They supply important urban public spaces."

"You're right, public space is very important for urban interaction. Well, enjoy Saskatoon and the Aboriginal Day celebration."

It was searing outside when Bobby left Yves's office in Gatineau that summer afternoon. Across the Ottawa river towered Parliament Hill, defining the picturesque Canadian capital skyline. The sun glistened off its great copper roof. The Parliament library, being renovated at the time, was wrapped in a gigantic white sheet that contrasted the natural stone as if Christo ${ }^{94}$ wrapped it himself. An immense display that spread itself across the horizon. And there rising ever so quietly amongst the trees and shrubs of a neighbouring little island, was the lone tipi. ${ }^{95}$ How out of place it looked, yet so eloquent and natural on the shores of the great Ottawa river. A small whisper from a culture, apparently overshadowed by the monstrosity of Western civilization. "How appropriate," Bobby thought, as he crossed the bridge back to his Market home.

\footnotetext{
${ }^{94}$ Reference to Christo and Jeanne-Claude's art exhibits.

${ }^{95}$ The tipi assembled each summer on Victoria Island in Ottawa.
} 
In the Land of Stories

"Tom, I think I need to hear a story," Bobby coaxed the little Aboriginal man out of his backpack.

"I thought you and Dan were at the Odawa powwow with Dan."

"I was, but now I'm back and feel like talking about it."

The Odawa powwow ${ }^{96}$ was an annual event held in the Nepean campground, on the west side of Ottawa. It was a natural setting that provided the perfect urban backdrop for the day's events. Dan, a thesis student working on a similar project as Bobby, shared the pleasure of attending the singing, drumming and dancing. Two white guys attempting to represent a culture they did not belong to; a struggle to say the least, but both were now embedded in this culture, the difference being, however, place. Dan's Friendship Centre, ${ }^{97}$

and yes, they were both designing a Friendship Centre, was in Ottawa, the organization sponsoring the powwow.

The event proved to be a wonderful gathering. People of all nations were there. Bobby and Dan representing only one of the many. Bannock and Moose filled the air with a strikingly familiar smell. The earth's rhythm was accented by the vibration of distant drums, as vibrant colours flashed through the crowd before them. The ground was prepared for dancing, the only way the Grass Dance knew how. Little booths spread

\footnotetext{
${ }^{96}$ Odawa Powwow held annually in Ottawa by the Odawa Friendship Centre.

${ }^{97}$ Daniel Smith, Carleton architecture thesis on Aboriginal issues, 2003-05.
} 
throughout the perimeter circle, sharing a little piece of themselves with the world. A gathering was happening and the people there sensed it.

"Are you done?" Tom asked patiently waiting for Bobby to quit narrating his story.

"Sorry Tom, now where was I? The Odawa powwow was splendid. It's interesting, I've been to several powwows in the past, but there were so many little details that stood out this time around. Even the entrance to the dance circle was from the East. The performers moved around the dance circle with their right hand to the inside. I suppose I never heard these stories before, so they were unfamiliar to me. It is strange how stories reshape one's perspective. The way we look at things, especially the things we feel we are somewhat familiar with."

"What have I told you, stories are powerful and wondrous things. ${ }^{98}$ Remember what Leslie Silko told us, 'I will tell you something about stories / They aren't just entertainment / Don't be fooled / They are all we have, you see / All we have to fight off / Illness and death. You don't have anything / If you don't have the stories. ${ }^{99,}$

"You and so many others lately," Bobby smirked. "Dan and I noticed something interesting in a booth there. There was a shirt with an image of Native braves on it. Underneath this, it read, 'Fighting terrorism since 1492.' A different perspective of the same story."

"And a funny one at that."

Tom prepared himself for an educational story, but aren't they all.

\footnotetext{
${ }^{98}$ King, The Truth About Stories, 9.

${ }^{99}$ Silko, Ceremony, 2.
} 
"Like I've said through a character in Truth and Bright Water, 'The problem with the world are whites ... only because they got no sense of humour. ${ }^{100}$ Have you heard of Basil Johnston? In a speech he gave entitled, “How do we learn language?' for a conference regarding editing Aboriginal oral texts ..."

"I know the conference. Julie Cruikshank spoke at that one," Bobby politely interrupted, the only way he knew how.

"Yes she did. Yes she did. As I was saying, Basil had said, 'listeners loved to laugh as much as they loved to reflect. First laughter than thought. ${ }^{, 101}$ This is reflected in all oral traditions."

"For example," Tom continued, "the Columbus story has been played with often in Native culture. Even I had some fun with it. Take my, A Coyote Columbus Story. Boy, that Coyote is one silly Coyote. You got to watch out for her. Some of Coyote's stories have got Coyote tails and some of Coyote's stories are covered with Scraggy Coyote fur but all of Coyote's stories are bent."102

"I'm familiar with Coyote and her Columbus story. Coyote believed the Western version of the Columbus story, but you quickly told her another story, you did. One of your own, depicting the Western version from another perspective. Coyote realizes her true self, a naïve trickster. One definitely has to watch out for Coyote stories."

\footnotetext{
${ }^{100}$ King, Truth and Bright Water, 91.

${ }^{101}$ Johnston, "How do we learn language," 45.

${ }^{102}$ King, "A Coyote Columbus Story," 123.
} 
"Ahh, how I like Coyote stories though. ${ }^{103}$ You got to be careful with those Coyote stories. When I tell Coyote stories, you got to stay awake. You got to keep those toes under that chair. I can tell you that. ${ }^{104,}$

Bobby quickly checked that his toes were securely under that chair. He knew all about these characters in Aboriginal storytelling. When a Coyote story came about, one familiar with Native storytelling knew to be careful. You never know what will happen.

"Basil spoke of other wise things during that conference you may want to think about," Tom carried on, "I heard him say, 'A word is elastic. It changes form, it changes mood, it changes tenses. It even changes its own structure by adding to itself and sometimes by subtracting from itself., ${ }^{105}$ Take Coyote for example. I also heard Basil say, 'According to the tribe, the best that a speaker can do and the most that the listener can expect is not absolute truth but the highest degree of accuracy. Besides, one's sense may be easily beguiled and even deceived by bushy tails. It is better to say that 'it appears to be;' or 'it is said;' or 'the probability is high that;' as the old people use to do. 106,

"Thanks for the stories, Tom. You better get some rest. We are off to Saskatoon again and it shall be a busy couple weeks for sure."

\footnotetext{
${ }^{103}$ King, Truth About Stories, 122.

${ }^{104}$ King, "Coyote and the Enemy Aliens," 159.

105 Johnston, "How do we learn language?" 47.

${ }^{106}$ Johnston, "How do we learn language?" 47.
} 
Program, Urban Design, and Architecture

Saskatoon was cool for the beginning of summer; the sun had not revealed itself in days. The farmers were discontent, not sure whether to be happy about the early summer rain, or lack of sunshine. Saskatoon had been dry for several summers past, however it did not resemble itself, the sunniest place in Canada. It was mid-June when Bobby and Tom arrived, a week before the Aboriginal Day celebration was to be held.

There were several people Bobby had arranged to meet while he stayed in Saskatoon. Some were professors at the University of Saskatchewan, although Jim Waldram was away at a conference. Most of the professors had done, or were currently doing work in Riversdale and Pleasant Hill, dealing with the Aboriginal populations living there. One professor had even helped program the White Buffalo Lodge on $20^{\text {th }}$ St., in the heart of Riversdale, the tipi that stood amongst the quaint Ukrainian facades, a vibrating character in one of Saskatoon's most culturally rich areas. This didn't mean people visited there. Most avoided Riversdale and Pleasant Hill. Most were afraid of the 'other side' of downtown.

Of course, another visit to the Friendship Centre was to be made, along with the Aboriginal Day festivities. It turned out that both, the White Buffalo Lodge and Friendship Centre, were hosting the June $21^{\text {st }}$ event. Obviously then, the communities of Riversdale and Pleasant Hill would to some degree partake on a small voyage into the business district of Saskatoon for that day. It would be curious to see who would come. 
He had also arranged a meeting with Darlene Speidel. ${ }^{107}$ Darlene was the director of the Cultural Resource Development and Publication at the Saskatchewan Indian Cultural Centre, the same Cultural Centre that was to become part of the project. Bobby visited the Cultural Centre during his last visit, when the staff told him he should speak to Darlene. They had stressed, 'If there is someone to talk to at the Cultural Centre, it is Darlene.' She was of Lakota Sioux First Nations, and held dear her ties to the traditional spiritual and educational values. Lakota Sioux were a Central Plains culture, who relied on a similar environment as the Plains Cree and Blackfoot to the north. The conversation was to discuss the programming offered at the Cultural Centre. As Darlene enlightened Bobby though, the conversation moved away from this.

"The circle is undeniably symbolic," Darlene paused for a moment recollecting her thoughts, "but not very practical in the building sense."

Bobby began by explaining his project to her. The program, the site, the urban context, and some of his initial concerns about representing cultural identity.

Darlene continued, "I have worked in buildings that were shaped as a circle. It was very awkward. There was an incredible amount of wasted space. Often symbols and circles become complicated when constructed and this affects their longevity. This is not sustainable. There are ways of using the square to the same cultural effect."

Bobby listened attentively. This was already questioning a cultural preconception on design.

${ }^{107}$ Darlene Speidel was interviewed by the author in person on 15 June 2004. Darlene is a respected Aboriginal women who advocates First Nations self determination and governance. She is of Dakota Sioux First Nations. 
"Traditionally, in my Sioux camps, because these are the stories I'm familiar with, permanent camps tended to use square forms to live in. The nomadic tipi became the circular home away from home. Tipi does not refer to conical form, but a place to live. Actually, tipi is already plural for it refers to places (community) to live." Darlene was amused by the misuse of tipi, often made in the English language.

She glanced over to the side of the room where a couple of plotted plants stood. "Yes, respect for the environment is also important. Elders stress this constantly, how we no longer respect our relatives in nature. They often come in here and shake their heads at those plants. 'These poor plants suffering in that little pot,' they say, 'where is the respect.' And taxidermy...well." She paused, half-amused by the stories she had now evoked.

Bobby couldn't help notice the way Darlene was conducting their conversation. She was careful as to what she said. She would pause often while speaking. She waited for a response at times from him. Above all, he recognized her sense of humour. There was a lightness in what she said, even though she felt so strongly about what she was talking about. This humour reminded Bobby of the same humour he was growing accustomed to in the little Aboriginal man.

"I've been told orientation is very important in Indigenous buildings," Bobby persuaded Darlene, "such as the main entrance from the East."

"Most Prairie cultures (Aboriginal) enter from the East. This is practiced primarily today in Sweat Lodges and Sun Dance ceremonies. Traditional openings into the camp were also from the East, as were gatherings such as powwows. Directly across from the entrance, or at least in my Lakota culture, the home of the chief or holyman was 
located. Most buildings today designed for First Nations do not follow this." She went through several buildings that she was familiar with in Saskatchewan and beyond. "They don't even think about it, however it is something that should be acknowledged and respected."

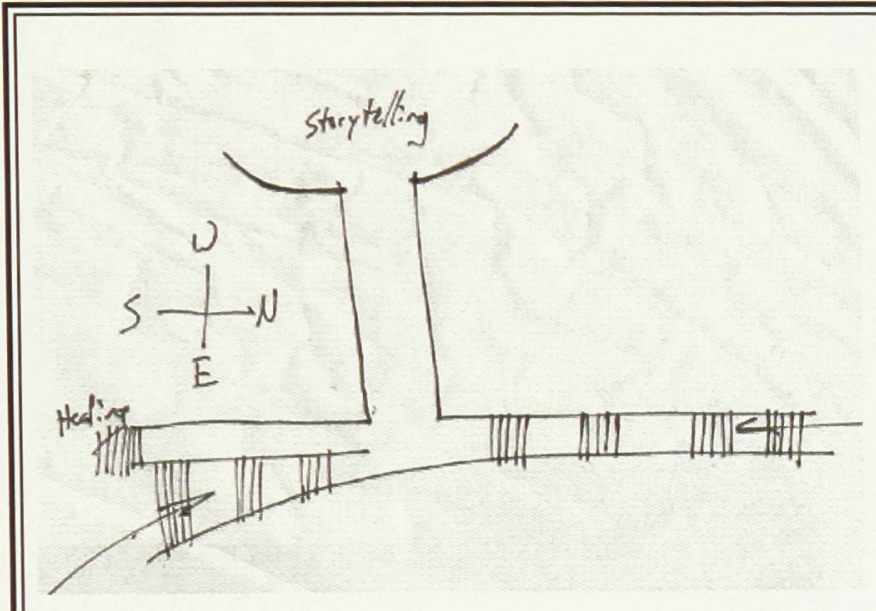

Illus 9 - Breathing life into the program: Entrance into the Building.

During the studies with Derek, entrance into the ground plane of a traditional building was discussed. Bret and Darlene verified this, especially relating to ceremonial spaces. Entry into the ground plane is sacramental. The entrance brought people into the ground plane and into the storytelling area, the centre of the building. All stories in the building resonate out of the storytelling area.

The three main entrances, responding to the three major pedestrian paths, meet in the centre where they proceed into the storytelling area from the East. The axis of the building is turned at this moment to accommodate the Cardinal points. This was also represented on the exterior of the storytelling area. This is the only component that contradicts the grid of the city while accommodating the Cardinal points.

"Another orientation to be respected is movement in the clock-wise direction," she continued. "The right arm should always be to the centre, when moving through a room. Also, upon entering one follows the perimeter to their place, even though it may lay directly right of the entrance. One must never touch anything while moving around. Once again respect. It is important for our people to get back to the basics and follow 'the way' again." 


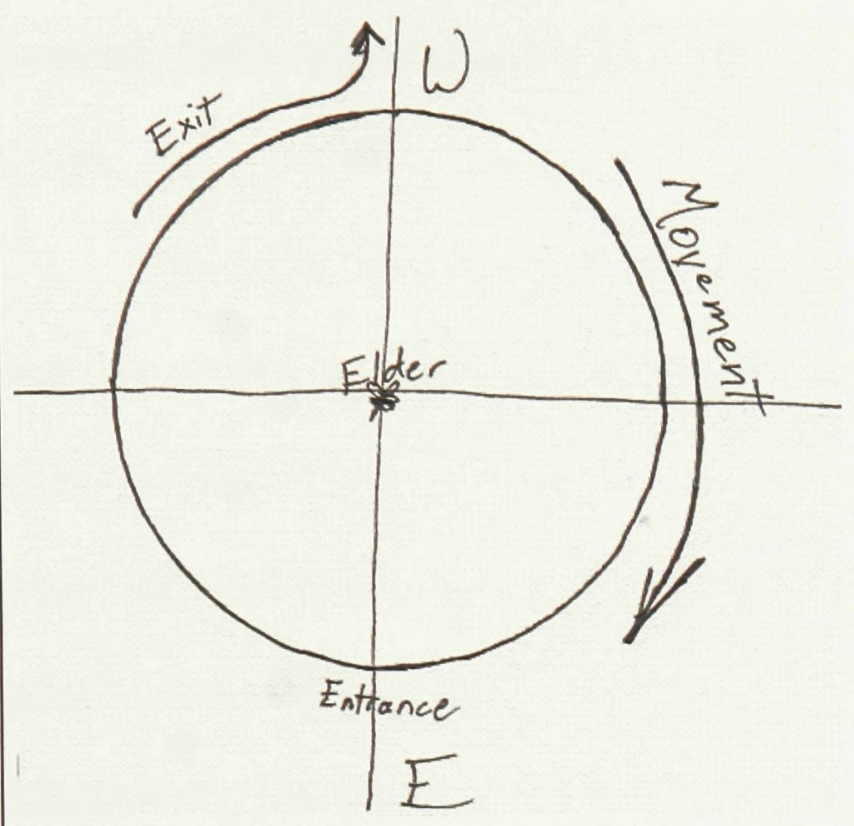

Illus 10 - Breathing life into the program:

Storytelling/Sacred space

The storytelling space captures the traditional movement and entry patterns of First Nations culture. The space was designed in the shape of a circle, but the circle doesn't become recognized as symbolic until the space is occupied. Procession, movement to the right (stairs servicing the building), and the constant rise of smoke (central to the telling of any story), begins the journey through the building and the narratives to follow. This space is occupied consistently as it serves as the entrance (from the East), movement up into the building, and as an exit out of the building. It is the central component of the Gathering space.

Bobby recognized this as a story that needed to be told. Vine and Daniel spoke of belonging to 'the way' and following traditional customs so often. ${ }^{108}$

"And materials, Darlene?"

"Wood is an obvious choice. Rock and stone are traditional as well. I suppose as long as it comes from the Earth. That is what is important. Traditionally, the poles for tipi came from large trees. As you may have observed growing up in the Prairies, trees are not plentiful, especially those needed to make poles. Often, great distances were traveled, even as far as the Black Hills, Cypress Hills, and Rocky Mountains, to find suitable trees. As one might imagine, these trees were highly respected. They were taken care of and lasted a long time." 
Darlene was again talking about sustainability. This was very important indeed, however, Bobby knew he had to direct the conversation back to the program and Cultural Centre.

"Seeing in four directions is a difficult thing to do," Darlene replied. "If one direction of understanding is altered or obscured, a person is no longer in complete control of themselves. They are ill. The doctor's office, legal office, and elder room, well, I see connections this way. There are four specific ways of understanding and perceiving everything. One needs to see clearly from all four directions. This should be emphasized in education as well."

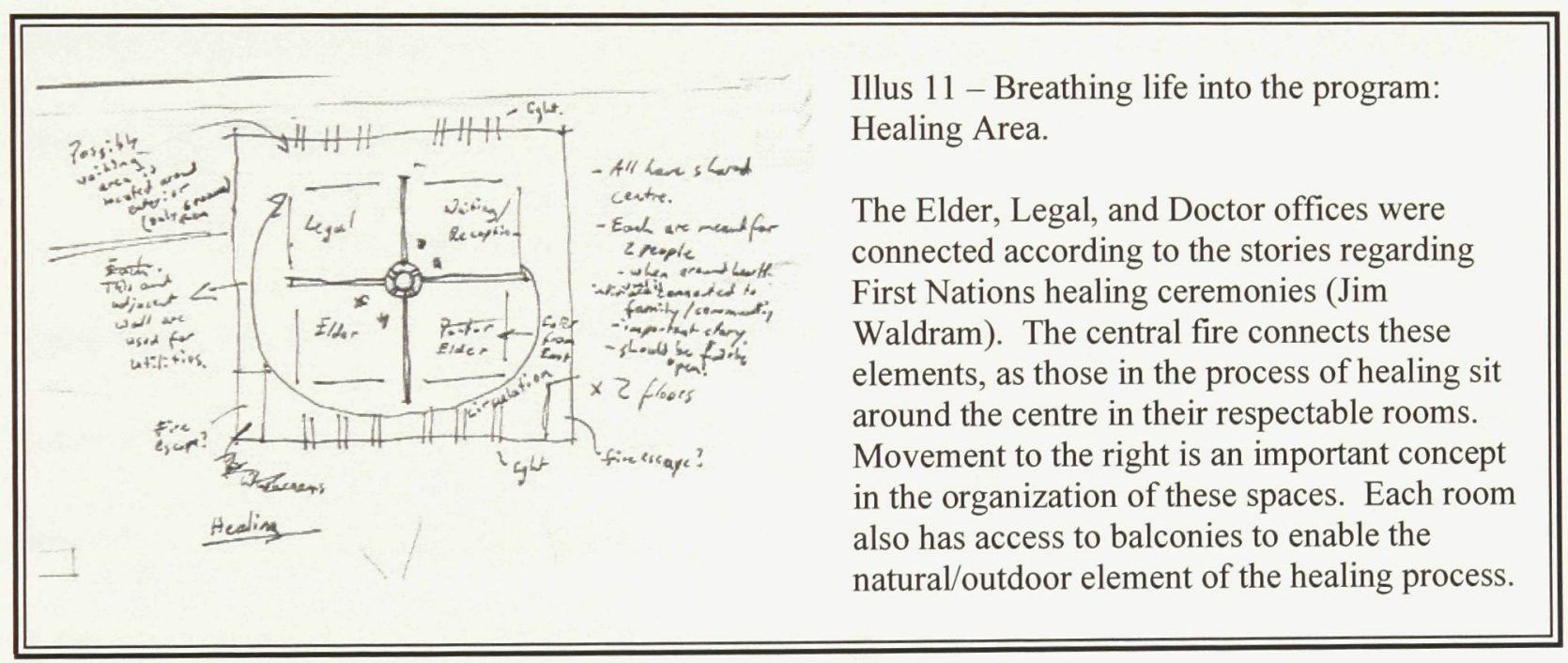

She continued, "What we do here at the Cultural Centre is very unique. Our way of thinking and learning is very different from Western ways. Education is a significant tool for bringing young people back to traditional Indigenous thinking. Courses cannot be simply and randomly placed within Western schools. They need to be respected and taught accordingly." 
Darlene was not alone with her views. Indigenous leaders have been saying this for some time, Vine being the ambassador. He had been stressing traditional values for several decades now, and was obviously nowhere near finished. 'Indian education must certainly begin within the Indian community, be it reservation, small town, or urban setting. ${ }^{109}$ Indians who come from traditional homes have considerable difficulty assimilating the practices and beliefs they learned as children with the modernist attitude of science. ${ }^{110}$ One needs to always remember that education in the traditional setting occurs by example and not as a process of indoctrination. ${ }^{111}$, The number of times Vine raised these issues during their expeditions was incalculable to Bobby. How could one count, if that was all that was talked about? Indian education in North America is and always will be a dominating feature in the survival of Native culture, another important story to be told and retold, again and again.

"Elder's warn youth and adults alike, that they need not forget traditional ways," cautioned Darlene. "Elders counsel about future days when people will not have the luxuries they have today. Youth need to prepare themselves for such days. This would include everything from food, understanding, to traditional making and survival. We, as a people, must keep our philosophies, ways of understanding, and teachings to prepare for the future."

To keep your stories, Bobby thought to himself. Darlene appeared to be reflecting upon their conversation, as well.

\footnotetext{
${ }^{109}$ Deloria and Wildcat, Power and Place, 82.

${ }^{110}$ Deloria and Wildcat, Power and Place, 59.

${ }^{111}$ Deloria and Wildcat, Power and Place, 45.
} 


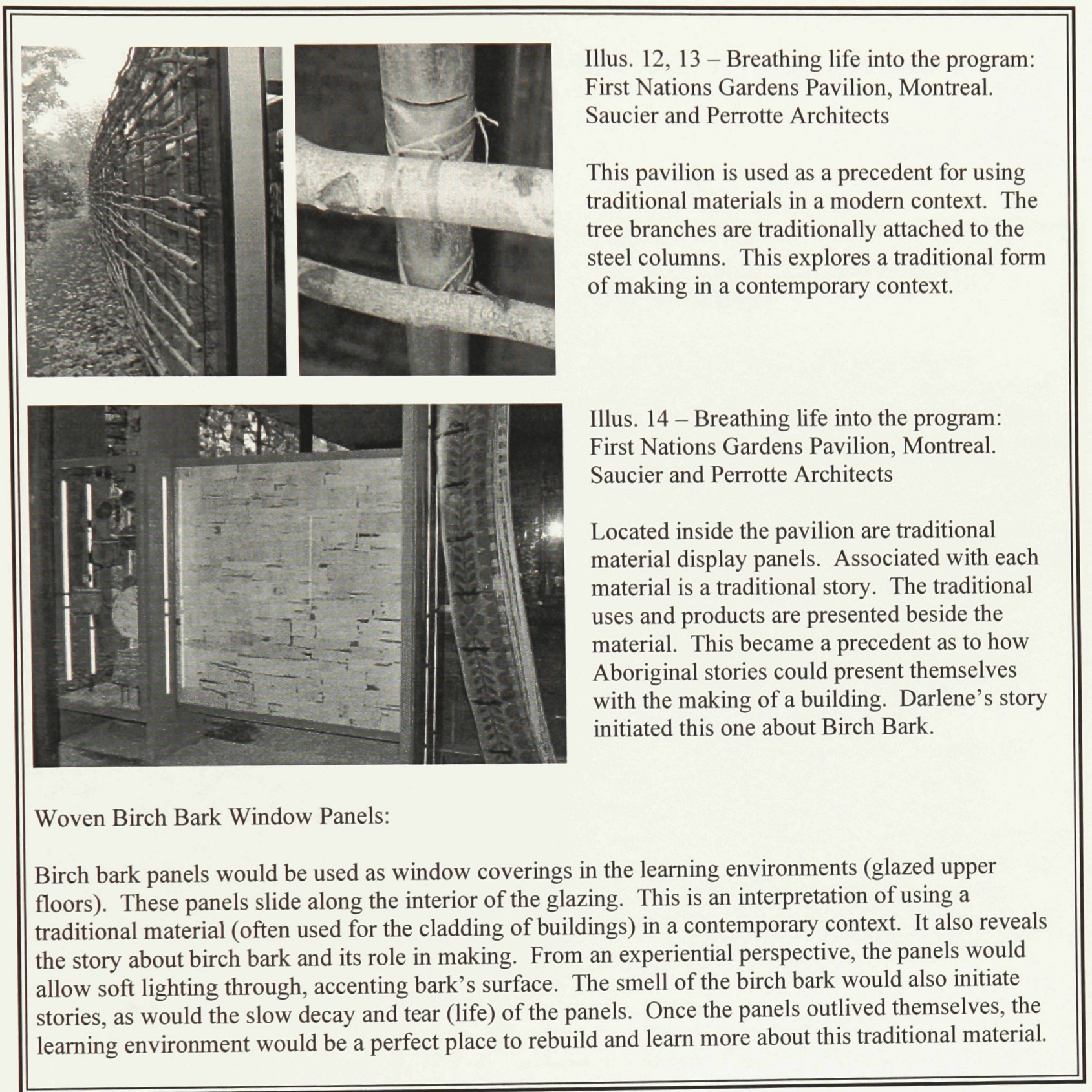

"I would like to talk about healing again for one moment, if you don't mind,"

Darlene tentatively began again. "Healing is achieved through the individual.

Healing must also occur in the family.

Finally, healing is essential in the community.

If all three divisions are not well, then the healing process will fail. One lost soul

in a community can disrupt the entire healing practice." 
Darlene stressed this to such a degree. It was a story that traditional Indigenous philosophies were based on. The individual, family, and community were inseparable components in Aboriginal belief.

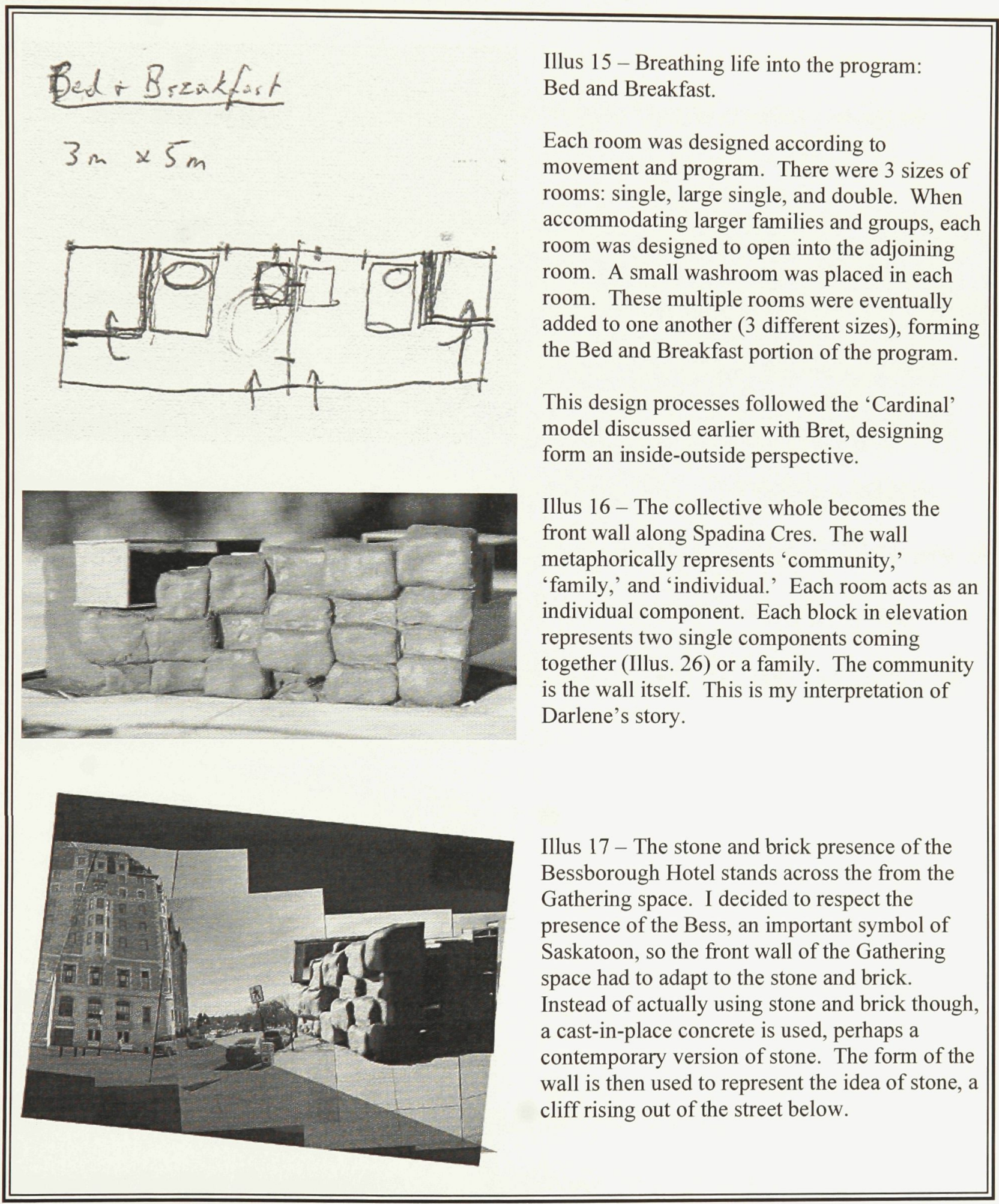


The conversation had come to an end. Bobby thanked Darlene for sharing so much. "I don't feel I've been of much help to you though. One has to ask the right question to get the right reply." She chuckled as she said this.

Well, one realizes she has helped when a chapter has been written about her.

"I do have a few comments regarding site before you leave," Darlene continued. "I feel it may be difficult to attract both Aboriginal and non-Aboriginal peoples to the site you have chosen. It is doubtful they both would come. Would the city even allow a Friendship Centre to be built there? What Aboriginal people are you trying to attract? Personally, I don't feel the people using the Friendship Centre, or the White Buffalo Lodge facility, would come to that site. It is located in the business side of downtown. A Friendship Centre would enhance a community like Confederation, with a growing Aboriginal population and no centre to accommodate them. Your program will have to further clarify itself if your site is to be successful."

Bobby left the Cultural Centre with a great deal to discover and reflect on.

\section{In the Land of Stories}

It was six days before Aboriginal Day when Bobby met with Renato Rosaldo, next to that familiar site, across from the great hotel in downtown Saskatoon. The city 
centre was vacant, businesses closed, and the hard-working folk of Saskatoon home for the evening. In this silent city evening, Bobby found himself waiting outside the icecream bus that occupied a tiny piece of the project's site; the Aboriginal man by his side. As quiet as the city was, this ice-cream bus seemed to be attracting a constant crowd, one lone destination for those enjoying that peaceful summer evening. "How strikingly odd," Bobby thought, “after six O'clock the city's downtown life depended on a London, double-decker bus selling ice-cream."

Renato was an anthropologist that Derek knew Bobby would find helpful. Renato's experience with Ilongot storytellers, the Northern Philippino Indigenous culture, led him to associations between story and experience. He promised he would share a story with Bobby, revealing the nature of dialogue, repetition, and other linguistic techniques used in oral traditions.

"I usually tell this story as it was recorded on tape, however I think it might be educational if we orally perform the dialogue this time," Renato said upon finding Bobby. "There are three parts, I, the narrator; you, the interlocutor; and a listener."

"Tom, would you mind helping us and read the listener's part," Bobby asked the little Aboriginal man. A response wasn't needed, Tom loved stories, and participating in them was his favourite part.

"This story, an account of the long tailed people-eaters, was initiated by a tale of floods caused by a South Philippine hydroelectric project." Renato described the context to the story. "The flooding displaced over 9,000 people. During the description of the floodwaters and rumoured plans to inundate another homeland, the narrator of the story interrupted, saying, 'La, now we'll be like the long-tailed ones.' When asked what the 
remark meant, she proceeded to tell two stories, both relating to flooding as the topic of conversation. We will be re-enacting the second story. ${ }^{112}$

"Briefly then, the story's protagonists are three: a group of men who went on a headhunting raid and got lost after the flood; the raiders' wives who stayed behind; and the long-tailed monsters who customarily hunt people with dogs and then eat them. The story begins in medias res. As we enter this tale without a beginning, the lost headhunters have by now found their way home and lurk in the background, hoping to trick the long-tailed monsters and avoid becoming their next victims. The monsters have just instructed the women (ie, the headhunters' wives) on how to prepare and cook the human victims they have brought with them to eat. They tell the women not to chop up and cook their victims' vaginas and penises because eating them makes even monsters drunk to the point of passing out."113

There was slight commotion from the ice-cream eaters as Renato was articulating himself a little too enthusiastically.

In the voice of a monster addressing the head hunters' wives, Renato began the story, ignoring the small crowd now forming around him, " "Don't go and get their vaginas.'"

"Ugh." Bobby imitated the written dialogue.

" "And their penises.

Uh, they'll make us drunk.'

That's when, they say, friend, they chopped away,

\footnotetext{
${ }^{112}$ Rosaldo, "Ilongot Hunters," 123.

${ }^{113}$ Rosaldo, "Ilongot Hunters," 123.
} 
these Ilongots did,

the ones who raided, got lost, and came upon them.

Now by stealth there they chopped them up.

Now, you, they sneaked in and chopped up their vaginas.

And their penises."

"No, it can't be," Tom broke in.

"That was to make them drunk," Renato replied,

"When they ate.

They finished then

with their chopping."

The headhunters finished their chopping and continued to cook their vaginas and

penises. The whole while though, they feared the monsters would catch, kill, and eat them.

"They cooked." Renato continued the re-enactment.

"They went faster and faster then, they say.

alas, there was

all that cooking

for they were afraid and saying,

'For pity, if we now finish this

they move on to us next.' 
Bobby interrupted then, attempting to clarify, for himself and the audience they were now performing for, if the headhunters actually ate with the monsters, and who indeed chopped the penises and vaginas.

"Did they eat with them then?" Bobby queried.

"Yes," Renato responded,

"they ate with them.

No,

they didn't eat together

so they wouldn't get drunk.

they didn't eat with them."

"Were the ones who got lost the ones who chopped?" Bobby asked his second question.

"Yes,

the ones who got lost were the ones who chopped."

"Hum.

I thought that maybe the people-eaters had chopped?"

"No, no."

With 'who-did-what' clarified, Renato picks up the storyline, where the long-tailed people-eating monsters eat their victims'vaginas and penises, and proceed to become drunk and pass out. 
Renato continued, "Now comes when they ate them, they say, then, friend. They get drunk, they say, indeed.

They toppled down, they say, really drunk it seems, uh, spread all through the house."

"Hum." Bobby listened intensely.

This being the opportune moment, the headhunters set traps to kill the monsters' hunting dogs. After retrieving bamboo, they began shaving and sharpening the ends.

"The others, they say, sneaked off to set the trap," Renato continued.

"Set the trap," Bobby wanted to clarify.

"They went, they say, for bamboo."

"Hum."

"Shaving

shaving

sharpening through the night."

"Hum."

"They sharpened and sharpened and sharpened.

They, uh,

went and whisked (magically), they say,

by stealth,

everyone in the house. 
The others went to whisk."

"Hum."

"When they had finished sharpening, friend."

"Were the ones who sharpened the ones who chopped?"

"Yes."

After sharpening, the sharpened bamboo stakes were spread out 'like a blanket' by the headhunters, the trap for the monsters' dogs.

"They left, they say," Renato emphasized his whisper,

"They left, they say.

Now, they set up sharpened (bamboo) stakes as they came.

It was the dogs they were setting up for"

"Hum."

"because they were about to hunt with dogs.

They went on setting up the sharpened stakes.

They, uh, spread them out like a blanket, they say.

The sharpened stakes

they went on setting up and went on setting up."

"Hum. Hum."

Suddenly Renato through his arms in the air while articulating loud crashes with his voice. The monsters were awakened. The headhunters had not yet finished setting up the 
stakes. The monsters knew humans were around, but not finding any, prepared their dogs for the great hunt.

Renato spoke cautiously, "They had not, they say, finished, friend, every last one, they say, that, uh, was to be set up.

They began to stir, they say."

"Lord."

"They called one another.

They said, they say,

'There are people there.

There are none.'

Over and over, they say,

'They are there.

They aren't.'

They said, they say.... Oops.

They left then.

They leashed together then, they say,"

"Hum."

"their dogs in order to hunt them with dogs." 
The dogs fortunately fell on the sharpened stakes and were killed. The monsters had to make a retreat.

"Uh, along came the dogs to that bamboo they set up and sharpened for them." Renato continued.

"So, they didn't go on." Bobby asked.

"They didn't go on because the sharpened stakes finished off the dogs. How could they hunt without dogs, uh,"

"Without..."

"Without the dogs

to catch

and bite us?"

"Hum."

"Now,

truly, they say, they left then.

And they hurried away fast, they say, poor things."

"Hum."

Although the story appears to have ended, Renato continues to the beginning to explain where the monsters made their mistake. The women had asked the monsters at the beginning about the source of the water. The monsters told them to drop a leaf in the water, and this would determine upstream from downstream, therefore regarding their where-abouts. 
"Uh, they slipped up, they did friend, by telling

the women they came upon the beginning," Renato emphasized the script.

"Hum." Bobby interrupted accordingly.

"at the house. (The women asked,)

'Where is the source of this water?'"

"Hum."

" "We're lost." "

That's, they say, when, uh, they went, friend, uh, and told the women."

"Hum."

"Let a leaf float along.

'Now the, uh, direction the leaf comes from

that's where you're from.'

That's how they learned about it.

That's what they followed."

"Did they really let the leaf float along?"

"Yes.

So then they followed, uh,

the direction the leaf came from."

"Hum."

"They didn't follow it floating downstream."

"Oh, I see." 
"They didn't follow that.

That's the end of the story, uh,

I heard them tell."

"It's yours to keep now."

"Yes.

That's the end there."

Renato concludes the story by emphasizing that he had told the story as it was told to him, and Bobby tells him it is his to keep. After which, Tom begins the vast portion of his dialogue in the story. It clarifies the floating leaf and then gradually merges back to the initial conversation on flood waters. This marks the conversation after the story. As many know, in the actual performance, stories no sooner end than they become the topic of further discussions and stories.

"Where, uh, ...

The leaf didn't float along anymore?" commenced Tom.

"It floats along," answered Renato,

"They believed them when they saw the leaf floating along because you couldn't see, they say, the current in the water."

\footnotetext{
"Water ..."

"Yes.
}

It was just like, uh, 
oozing,

I'd say."

$$
\begin{aligned}
& \text { "Seeping ..." Bobby corrected. } \\
& \text { "Seeping ..." acknowledged Renato, }
\end{aligned}
$$

"I'd say like the ocean

except for the ocean's rocking."

“Moving ..." Bobby corrected again.

"Yes.

It was just moving, they say, uh, going along a bit."114

Renato ended, as the crowd around him looked confused after the curious event. Renato did not wait long, however, before curing their confused state.

"This one of the long-tailed monsters emerges as a dialogue," Renato spoke to Bobby, Tom and the crowd, "The back-and-forth verbal play we engaged in requires a skilled narrator and an adept interlocutor, both of them cultural insiders. Far from being mere ornament, the property of dialogue deeply shapes a story's unfolding."115

Bobby couldn't help notice the crowd that had gathered. And on the very site that he wanted gathering to occur! A story was being told and people were curious of the commotion that early evening. They just needed something to initiate it.

"Actual performance does more than provide an additional voice for clarifying who is doing what and how we should feel about it during the telling," Renato persisted. "However, mood and clarification are extremely important," Bobby interrupted.

\footnotetext{
${ }^{114}$ Rosaldo, "Ilongot Hunters," $124-128$. Refers to the entire story.

${ }^{115}$ Rosaldo, "Ilongot Hunters," 129.
} 
Renato reassured Bobby by nodding in his direction, "it also infuses narrative time with an extra dimension of suspense that can best be explicated by following the storyline. ${ }^{116}$ The action of chopping is thus protracted in narrative time through repetition and iterative specification of the verb phrase. But time grows short for the headhunters, as they could at any moment get caught and be eaten by the long-tailed ones. Once finished with their chopping, the humans began to cook 'faster and faster.' Raising my pitch and slowing the tempo, I was depicting their plight, their fear, and their haste through interjections ('alas', 'for pity') and by speaking directly in their voice."'117 "Though my interruptions and clarifications, we were able to heighten the suspense and delay the story's flow" Bobby again paused Renato.

"Yes, and the suspense resumes as I echo the adverbial phrases used to describe the chopping. Protracting and intensifying the narrative through repetition, I begin shaving shaving sharpening through the night.

They are sharpened and sharpened and sharpened."118

“Again I interrupt you making sure the headhunters did both the chopping and sharpening. Of course they did. The headhunters then proceed to set-up their sharpened stakes.”

\footnotetext{
${ }^{116}$ Rosaldo, "Ilongot Hunters," 129.

${ }^{117}$ Rosaldo, "Ilongot Hunters," 130.

${ }^{118}$ Rosaldo, "Ilongot Hunters," 131.
} 
"This setting-up process becomes intensified and protracted through repetition." 119

"Hum."

"I then leave my interlocutor (Bobby) and listeners in suspense awhile longer as I twice imitate the monsters shouting that there were people there, only to shout again that there were none." 120

"It is also interesting how you change perspective by employing the inclusive first-person plural pronoun, 'us,' when identifying all of our own vulnerability to the dogs, including the audience listening to us."

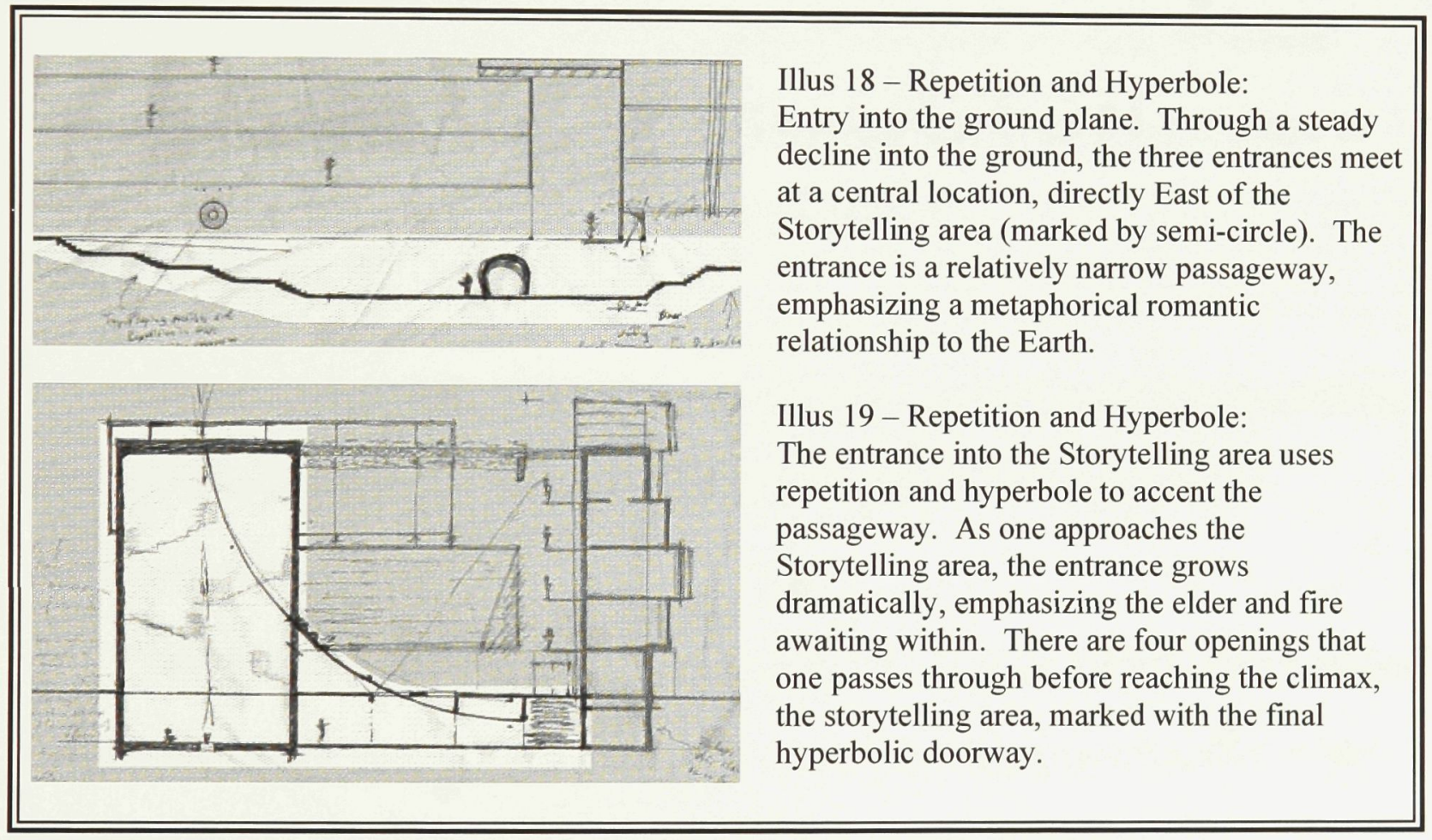

${ }^{119}$ Rosaldo, "Ilongot Hunters," 131.

${ }^{120}$ Rosaldo, "Ilongot Hunters," 131. 

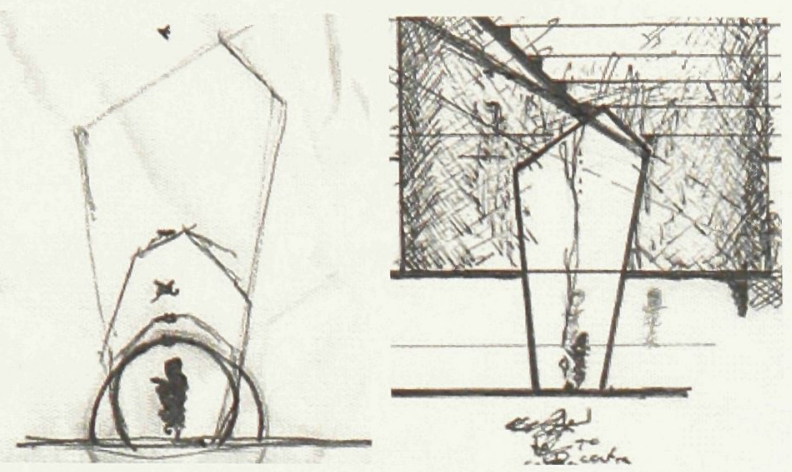

The Ilongot story remains an important introduction to understanding storytelling in Indigenous oral tradition. By understanding the nature of this story and why it was told, one may begin to recognize First Nations' oral tradition. This is important when understanding the nature of this narrative (thesis) and the stories in it.
Illus 20 - Repetition and Hyperbole:

The four openings slowly deform the initial halfembedded circle (the first opening). This gradual growth and exaggeration of the circle stresses the symbolic nature of the circle. The circle is only a symbol until one recognizes the story embedded in it. The circle is transformed, releasing it of its symbolic nature, but through procession and movement (entrance from East, movement to the right) one enters into the circular sacred storytelling area, experiencing the story in it. This was the primary attempt of using Repetition and Hyperbole as a linguistic tool, for communication and of representation, in the building. Narrative was explored as a Parti, materiality, and detail tool in most circumstances.

"Yes Bobby. Now, this myth comments on hunting by inverting the normal order and placing humans in the position of animals who are hunted down by dogs. In the end, only stealth and wile enable the humans to survive.

"I then explain where the monsters went wrong: they never should have told the women (the headhunters' wives) how to find their bearings in the disorienting, undifferentiated floodwaters.",121

"Much like the floodwater that initiated the story in the first place," one of the icecream eaters replied. Bobby continued, "This is marked by the discussion at the end of the story. As Tom puzzled over the leaf, you, Renato, turn from the leaf to the water. How the water flows without current, 'oozing,' 'seeping,' 'just moving,' and 'going along a bit.' Similar to the Ilongots confronting hydroelectric projects and loss of land,

${ }^{121}$ Rosaldo, "Ilongot Hunters," 132. 
the headhunters faced the unfamiliarity of a once-recognizable world, now covered by virtually motionless water."

"This portrays the human struggle to resist fatal interruption, dissolving into the environment, and utterly ceasing to exist. Yet it is through such near escapes that Ilongots can recover a story that in telling leaves their traces above the unendingly still and uniform waters, ${ }^{, 122}$ Renato concluded.

"As with our stories," Tom spoke, about to reference the Aboriginal writer, Leslie Silko, "we don't have anything, if we don't have stories. ${ }^{123}$ Someone has to tell our stories. ${ }^{124}$ Our stories need to float above the flooding waters of assimilation. Therefore, the need for places where these stories can be shared. Like the ones about Coyote. Oh, how I do like those stories."

Bobby wanted to clarify one more thing with Renato, "Aboriginal oral story editors, Nora Marks and Richard Dauenhauer, have remarked, 'the question arises: what is a 'good' or 'best' version of an oral tradition.' They continue, 'Outsiders tend to find the versions with the most explanation and detail to be the most satisfying and coherent. From the Indigenous point of view, the best versions are the most laconic. ${ }^{, 25}$ This would allow for the maximum freedom of the listener to interpret and make sense of the story for him-or-herself."

\footnotetext{
${ }^{122}$ Rosaldo, "Ilongot Hunters," 133.

${ }^{123}$ Silko, Ceremony, 2.

${ }^{124}$ King, The Truth About Stories, 151.

${ }^{125}$ Dauenhauer and Dauenhauer, "Editing on the Page," 7.
} 
"This is why I gave a small background to the story, and emphasised the original story was told to a fellow Ilongot and was caught in its actual cultural performance,",126 Renato replied.

"Well, this would explain the constant narration by the narrator of this story," Tom commented with a grin. "To those of you reading it right now."

\section{Program, Urban Design, and Architecture}

Bobby had arranged several other meetings during the two weeks he was to spend in Saskatoon. Darlene, who happened to be the first conversation, turned out to be very critical. Her warnings regarding program and site would resurface in the opinions of several others Bobby would talk to. The program, primarily the preconceptions associated with the Friendship Centre, seemed contradictory to the location of the site. These being the same issues that Jim Waldram brought to Bobby's attention months earlier.

"Perhaps it is as simple as renaming the centre. People often initially associate a building through its name, especially if there are preconceived notions of what exists behind the walls of that name. Renaming might eliminate several of the connotations that the program suggests." Evelyn Peters, ${ }^{127}$ a geography professor at the University of

\footnotetext{
${ }^{126}$ Rosaldo, "Ilongot Hunters," 122.

${ }^{127}$ Evelyn Peters, professor at the University of Saskatchewan, interviewed in person by the author on 18 June 2004.
} 
Saskatchewan suggested. She was associated with studies reflecting urban Aboriginal statistics in Saskatoon.

Evelyn was one of two professors Bobby would visit at the U of S, Georgia BellWoodard the other. Georgia was a professor in the Community Health department. Both professors were non-Aboriginal, but they had spent time associated with the Aboriginal communities of Saskatoon. Georgia also worked on city planning committees, and was associated with the programming team for the White Buffalo Lodge. When Bobby met with Georgia, Blaine Kinniewess, an Aboriginal man working with Georgia on community projects and associated with the White Buffalo Lodge, was able to attend. ${ }^{128}$

"This is not a location for a Friendship Centre," Georgia responded.

"I would have to agree." Blaine also expressed his concern. "By allowing social issues to cross boundaries, one would likely see pan-handling outside the Bess. The existing Friendship Centre focuses on poverty, AIDS victims, money management and other social urban issues. These people will not come to the $\mathrm{CBD}^{129}$ of Saskatoon. This would be a difficult thing to introduce and make work."

This was becoming all too familiar for Bobby. If he was to design a Friendship Centre, he may have to change sites. The heart of the project though, still existed in Aboriginal Day and gatherings. Perhaps the program would have to begin to accommodate.

${ }^{128}$ Georgia Bell-Woodard and Blaine Kinniewess, interviewed in person by the author on 23 June 2004.

${ }^{129}$ CBD - Central Business District in Saskatoon. 
"What exactly are you trying to do with this building and program?" Georgia asked a little concerned. "I think this is the biggest problem I have with the project, the lack of clarity in program."

"It sounds like you are planning to do everything in this building," Blaine commented to Georgia's question. "Mixing programs doesn't necessarily work. Any elder would probably tell you, 'You would not go to a doctor for legal advice.' I do like the Bed and Breakfast and Cultural Restaurant. They fit into the site and respect the urban area you are proposing to design within."

Both agreed that a gathering space would also work in the proposed site. That was reassuring.

"Legal Aid is important," Blaine continued, "especially due to its location. Remember though, there is a long history of not so good connotations associated with the courthouse for Aboriginal peoples."

"I also really like the idea for the Aboriginal Gardens," Georgia added. "That would be a beautiful introduction to the river paths, especially between Kiwanis and Victoria Park, which also borders Riversdale. I truly believe the neighbourhood of Riversdale would use this, especially if allowed to harvest certain plants for personal use."

Blaine nodded in agreement, "It would provide an interactive and hands-on learning environment. One's respect for nature would respond to the vandalism and over-consumption that may occur." 
"I think you have to rethink your program again. A Friendship Centre simply will not fit in this part of Saskatoon. It is needed in the communities," Georgia confirmed her original opinion.

Blaine wanted to add one last comment. "First Nations are promoting sharing and coming together. Elders are now telling the youth it is time to share knowledge and cooperate with other cultures. You may want to address these issues in your programming."

This was the way Bobby left every meeting in Saskatoon, rather disoriented and unsure of his project. His initial moves in the project were drifting further away, and at this rate the communities he was attempting to attract would only have further to go. Was the great divide between Aboriginal and non-Aboriginal cultures only to grow further apart? Perhaps the perspective he was attempting was too drastic and idealistic. Bobby couldn't help being the extreme social idealist that he was. It wasn't naivety, only the strong unconditional faith in people. Daniel and Vine agreed, referring to the traditional Aboriginal "way of living that found lessons on humility, generosity, and hope in the world - hope not for something in the distant future but hope in the sense of acting with confidence and expectation that something good will happen."130 Others also shared this optimism.

"One place where all peoples gather and share stories. To bridge that divide. Wouldn't that be nice. Could this actually be done in one building though?" Mel Auten

${ }^{130}$ Deloria and Wildcat - Power and Place. Pg. 13. 
showed a little wonder at the thought during a visit with Bobby that week. ${ }^{131}$ He was a resident of Saskatoon and knew the separation between cultures as well as anyone. He worked for the Correctional Service of Canada in Saskatoon, and had recently worked on several projects dealing with First Nations' correctional facilities. While working on these projects he met a couple individuals that he generously directed Bobby to. Both persons were non-Aboriginal and faced similar struggles as Bobby. They had to establish foundations with an unfamiliar culture before starting their voyages as well. Besides, correctional facilities were similar to some of the programs associated with the current Friendship Centre and the Courthouse. Perhaps these two could advise him how to work with the program he had established.

"Across from the Bessborough Hotel is no place for a Friendship Centre," Roger Schindelka ${ }^{132}$ boldly confessed. Roger was the vice-president of planning, research, and development at the Saskatchewan Indian Institute of Technology (SIIT), which was located only a half block from the 'chosen' site. He worked with Mel on the programming for the new Fire and Police Training facility to be built on the Sioux Reserve just south of Saskatoon. Mel loved the idea of non-Aboriginal people moving to the reserve to attend training. "It completely reverses the scenario," he mentioned a couple evenings earlier.

"Actually, most of your programs do not belong there," Roger continued to be honest. "The CBD is built around financial wealth, and currently is host to businesses, tourism, and festivals that exceed these financial expectations. Student housing for SIIT

\footnotetext{
${ }^{131} \mathrm{Mel}$ Auten, interviewed in person by the author on 18 June 2004. He also described several Correctional Services Aboriginal projects.

${ }^{132}$ Roger Schindleka, interviewed in person by the author on 22 June 2004.
} 
is completely out of context for the current downtown housing situation." Bobby had only recently added student housing to his program. "Besides, the communities of Riversdale and Pleasant Hill supply all the low-income housing that one will need, and it borders downtown. Health Care and traditional healing, like the Friendship Centre, belongs in the community. I did enjoy the Aboriginal Gardens suggestion though. That is an interesting addition to the river valley, and would attract both tourists and Aboriginal peoples.

"Overall, I think you have to be sensitive to the downtown vicinity and the programs that already exist there. Your program should respond accordingly. The Cultural Restaurant is a nice addition.

"Finally, as a suggestion referring to your gathering theme and the Aboriginal Day celebration, perhaps a gathering area would justify so many programs belonging in one building. At the moment everything seems separated and distant from the other, and it appears that something should tie them together."

The second person Mel directed Bobby to was Gerry Cowie. ${ }^{133}$ Gerry led several committees dealing with Aboriginal correctional facilities. Most of these buildings dealt with healing ceremonial spaces.

"So you know Jim Waldram then," Bobby replied, surprised when the connection came up.

"We have used his studies when determining how to approach program and design," Gerry reassured. "You have to definitely understand a culture if you are to work

${ }^{133}$ Gerry Cowie, interviewed in person by the author on 22 June 2004. 
with them. First Nations peoples think very different from non-Aboriginals. This has to be acknowledged.

"First Nations' philosophies and beliefs are very important to understand. Cardinal points, entrance, and movement, as you have mentioned, are essential. Often our designs take the shape of symbolic bodies in nature."

"Such as tipi and eagles?" Bobby asked.

"Yeah, have you seen the White Buffalo Lodge?"

Bobby couldn't understand how the entire city of Saskatoon loved this building. He had to respect the renovation; it used to be a grocery store. However, it was as if the architect slapped a tipi on the front façade, drew a door from the West, and called it First Nations, without any idea of the culture itself. The programming was fantastic. The facility was tremendously used by the community. They had well-needed health services, youth activities, and relations back to traditional beliefs. Programmatically, they balanced both worlds, urban and traditional, beautifully. Literally representing symbols in architecture had to be questioned though.

Most of the correctional facilities existed in natural settings, therefore responding to a much different landscape than that of the CBD in Saskatoon. There were no other buildings to respect, no other cultures to respect, and definitely no urban segregation and preconceptions. Only trees, lakes, and a sky that never quit. Perhaps an eagle truly belongs in nature. And perhaps enough tipi will congregate into the urban centre, creating a new place to respect. Either way, this was not the case for the parking lot across from the Bessborough. He had to focus on 'belonging,' and attempt 'familiarity' 
through other building characteristics. Literal representation wasn't even an option. There were several different ways of representing culture, without literally representing symbols. Bret knew this. Darlene encouraged it. And an entrance from the West; the architect didn't even get that right. Perhaps this was a story Bobby felt needed to be told. "Yeah, I know that building," he replied.

"I want to briefly comment on your program," Gerry continued enthusiastically, "I cannot see it being feasible to put the Friendship Centre in the CBD. Wouldn't you agree that it would be more useful within the communities themselves?"

"Yes, I'm beginning to," Bobby politely smiled, as aggravation wrenched through his tormented little mind, belligerently fighting to escape.

"I love your Bed and Breakfast and Cultural Restaurant. Tourists would love that. I also feel the Legal Aid is extremely important to your site."

The powerful wind (the wind was always powerful in the Prairies) swept away the Friendship Centre off into the sky's horizon. Now, this is a tremendously long way away in Saskatchewan. Bobby could only silently watch it blow beyond the day's reach. It was obviously time to start believing in a new story, perhaps one strictly about gathering as suggested. One to replace the story about healing the urban Aboriginal. They would have to find their own healing story, Bobby could only offer them something recognizable once they did. The people visiting this building may not be from Riversdale and Pleasant Hill; not at first anyway. There was no going back now, the Friendship Centre was far beyond the horizon, lost in the great mountains to the west, crashing with 
the intensity only a two-story building could create. It was time for a change. How would May, and the people at the Friendship Centre, those who were so generously helping him, react to this change?

\section{In the Land of Stories}

The bus ride to the CBD was extra long that early morning. Perhaps it was simply the early morning that had always tended to exhaust itself endlessly. The bus was empty, thankfully. Bobby couldn't imagine talking this early morning. It always bewildered him how people chose to strike up conversations with him instead of the numerous others sharing the bus. It had to be the eye contact. It was a strange connection he had with people. He needed them; could not live without them. There was not much he enjoyed more than observing this curious race. The way people respond to their environment, to the things within that environment, and to each other. They never ceased to amaze Bobby, in all their stupidity and utter brilliance. This early morning, however, interaction had to be from a distance. The day was shaping into its name, the longest day of the year. And he was on his way to Friendship Park, where interaction with the people was unavoidable, considering he was a volunteer.

The festivities were across the CBD from the bus stop. He decided to walk; not that there was any other choice. The crazy people of Saskatoon drove everywhere; there was no need for a better bus system. Too bad, too sad for those poor folk who decided to 


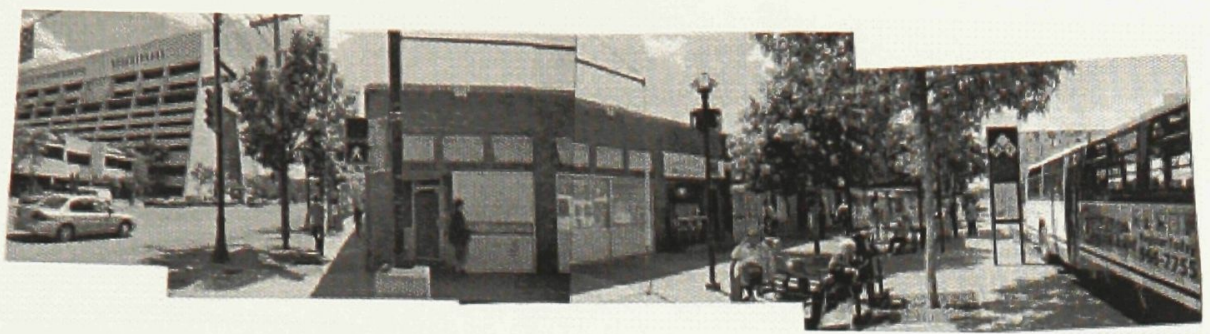

Illus 21 - The bus stop in Saskatoon's CBD (Central Business District).

walk, because

everyone could own a car, or oversized truck. Bobby loved the people back home. 'The most friendly people in the world, those Prairie folk,' he would say. At times though, home was too much. He pondered this love-hate relationship as the streets of Saskatoon eased him through the flat terrain. It was

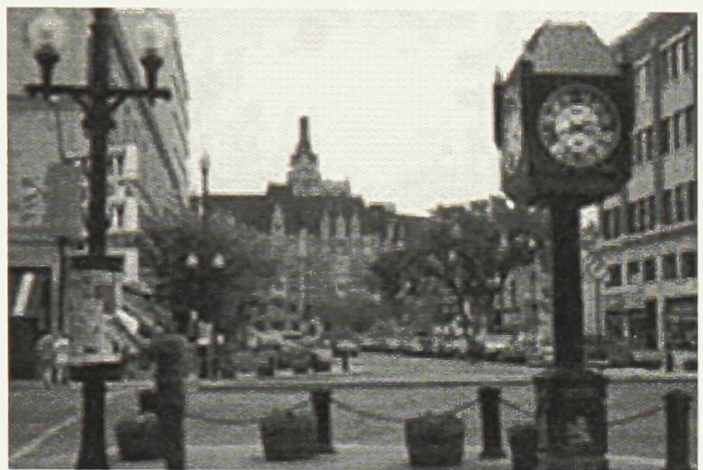

Illus 22 - The Bessborough Hotel from $21^{\text {st }}$ Street. hard to believe rivers flowed at all in

Saskatchewan, let alone swiftly. ${ }^{134}$ And behold, there it was, the lone building that Saskatoon should be proud of, the Bessborough Hotel. The Chateau face, a fiery brick and stone façade, etching itself into the endless sky. The

base stapled to the ground, a fortress never to be removed. The gothic roof pointing to the heavens as if to mark its holy presence. Yet it was inviting. How could one not want to pass its mighty doors and open the elegance that waited inside. Above all, these railway hotels were one of those few Canadian ties that spread themselves wide, connecting the vast Canadian landscape, much like the blanket of snow that kept Canadians warm during the winter. All views, paths, nodes, everything seemed to refer back to the Bess, as Saskatonians enjoyed calling it. It was the heart of the city, literally. It reserved a special place in the heart of all of those who called Saskatoon home.

\footnotetext{
${ }^{134}$ Origin of the name Saskatchewan - the name means 'river flowing swiftly'.
} 
Across the street was a parking lot filled with cars. Some of the cars were bright and pretty. Some big black trucks too. How did nothing exist there? Only the beloved ice-cream bus. The site was screaming for people to occupy it. He crossed the empty

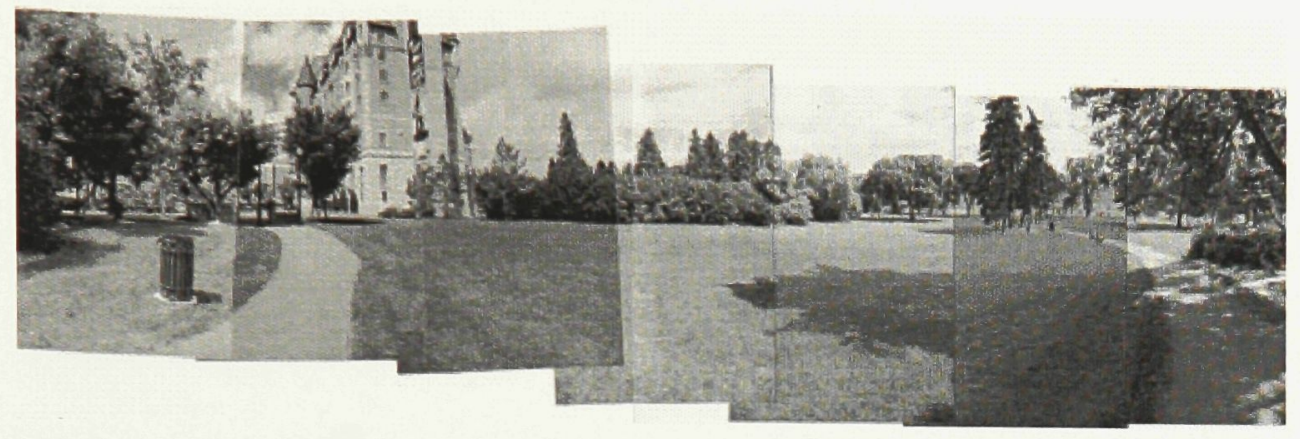

Illus 23 - Kiwanis Park on Aboriginal Day, 21 June 2004. parking lot, then

the street, passing

into Kiwanis

Park, so vacant

and desolate.

Where was this treasured Jazz Festival? The same Jazz Festival that caused the city to forbid Aboriginal Day celebrations in the park. A banner spanned four stories of the Bess, towering the dates, June 25 - July 4. Four days away, obviously not enough time to clean out the debris left by Aboriginal Day. Yet, there was no sign, except the gaudy banner, that Jazz Fest even existed.

This was the centre of the city, and still no sign of a gathering taking place. It was hard to believe that two thousand or so people were congregating only two blocks away. The silent summer breeze wept by unnoticed. Bobby moved through Kiwanis Park, east toward the river and away from his site. The river appeared peaceful, somewhat softening that early morning; no people in sight, only a long paved path running the length of the city. The Meewasin Valley controlled the waterfront, making sure greenery would always remain on either side of the river's bank. As he wandered south toward the Broadway bridge, that main entry point into the city, he noticed the vast natural vegetation growing there. This continued for most of the next few kilometres. 
It occurred to Bobby that the number of Indigenous people would be large at the festival he was slowly approaching. It was never easy attending events that one felt out of place in, or unfamiliar with, especially alone. Even though he didn't want to talk to anyone that early morning, he felt fortunate that he had volunteered. There was some comfort in knowing that, as a volunteer, in a small way he belonged to the event. $\mathrm{He}$ knew the event would be miraculous, a gathering like no other. People of all nations coming together to celebrate a humble, yet resonant culture on the one day when each city throughout Canada recognized the vibrancy and life of Aboriginal peoples. Yet, Bobby couldn't help wonder how many non-Aboriginals would actually come, this being, after all, Saskatchewan, where the only genuine river that existed separated the two cultures. A lone bridge lay further in the distance. Preconception was Coyote herself, always looming about, never knowing what mischief she will get herself into next. He wondered if it was actually possible to rid oneself of preconception. Probably not. Then, it should be respected, as any elder would tell. "How would we manage a universe in which the attempt to destroy evil is seen as a form of insanity?"135 Tom had often asked. Evil should not be destroyed, but respected and accepted, ${ }^{136}$ a life lesson very difficult to comprehend for the Western-raised mind; a story that doesn't quite make sense. It walks beside sense, but not quite the same path. Under the bridge, the path he was following continued, squeezing through the other side, at which time Friendship Park revealed herself. She was a small park, protected by a bridge on each side, full of trees and shrubs, a Louis Riel statue, and today, Aboriginal peoples.

\footnotetext{
${ }^{135}$ King, The Truth About Stories, 110.

${ }^{136} \mathrm{King}$, Momaday, and Silko examine good vs. evil issues in their literature.
} 


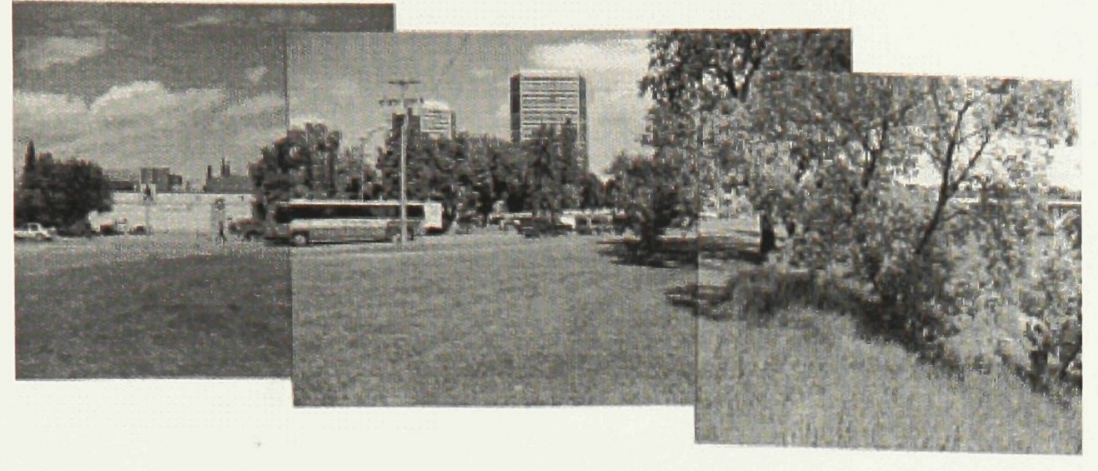

Illus 24 - Friendship Park viewed from the Meewasin walkway.

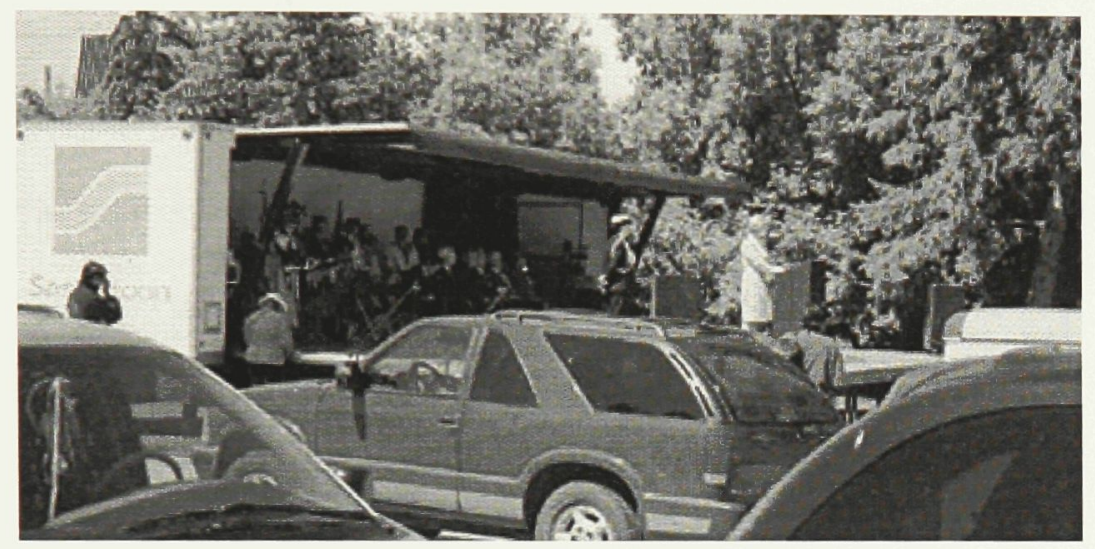

Illus 25 - Aboriginal Day celebrations, 21 June 2004.

The single event that

Bobby built his thesis

around; the choice of site, the

Friendship Centre, a

gathering, all owed respect to this single day. He was tired; no exhausted, from the last two weeks. It took all his energy, that early morning, to enter the festival alone. He was looking for May, possibly Ashley, just

someone he knew. He noticed the entrance, a set of stairs, located on the East side of the stage; something he recognized. A young schoolchild sat alone on the stage. He noticed the child was in full dress, obviously awaiting the Grand Procession. The child's feathers introduced the sun to him that early morning. It had always been shining; he just didn't recognize it. The child's smile is what caught him off guard though. That early morning blew off into the horizon, landing somewhere near that Friendship Centre from the days before. That afternoon reminded Bobby why he was in Saskatoon. 
"Did you enjoy yourself at Aboriginal Day yesterday?" May asked when Bobby arrived for their tri-monthly conversation. ${ }^{137}$

"It is the reason I'm doing this project. It was nice to be part of such a gathering. More are needed," Bobby replied as he sat down in May's office, a place he was becoming familiar with. "There were so many non-Aboriginal people as well. It was very nice to see. Perhaps Saskatchewan is slowly growing up."

"It was a very good day indeed."

"I especially enjoyed the break-dancing."

"It has become as much a part of urban youth as anything else today. It was fantastic to watch. The whole crowd appeared to have stopped and watched at that moment." May was extremely proud of the event.

Bobby didn't know where to start. How was he to tell her the altered direction of his project.

"I think I have to focus on gathering for my program," Bobby began, not able to look at May. "The building will not belong to anyone but rather to everyone. It will be designed according to a First Nations' perspective, or rather their stories, be they Cree or Pan-Indian. It will attempt to attract all peoples. Yesterday was inspirational." May listened attentively.

Bobby continued, "I have come to believe several of the programs offered at the Friendship Centre do not belong in the site I have chosen. From the beginning, my

${ }^{137}$ May Henderson, third interview in person by the author on 22 June 2004. 
objective was to focus on a place of gathering and sharing cultures. Aboriginal Day is an example of this. The original Friendship Centre's objectives were an example of this. However, time has caused these objectives to share their home with the needs of the urban communities. A new Friendship Centre belongs in the community, not downtown, where the people will not come."

"I've always been critical about the fact they never combined the Friendship Centre with the White Buffalo Lodge when they were programming it," May revealed her understanding. "Still, one of the primary goals of the Friendship Centre is to create situations where all Aboriginal peoples can share their culture with all others. Aboriginal Day and Folkfest are examples of this. This is why we remain in the centre of the city, hoping to attract people from all communities, not only one."

As Bobby left the Friendship Centre, he walked toward MidCity Plaza, the old train station. It had been renovated into a mall, however the front façade remained authentic. May had eased Bobby's troubled mind. This trip to Saskatoon opened his eyes to the complexities of cultures and their inherent urban context.

He was leaving tomorrow for Ottawa. How things had changed. The clientele he envisioned using this project probably wouldn't use it. The best he could hope for was the gradual progress into downtown Saskatoon by the residents of Riversdale and Pleasant Hill. His building would be there, awaiting with familiar and open arms, if the Indigenous people ever made the difficult transition. For now, it would accommodate the 
people who participated yesterday. This was also an important population in Saskatoon, and should not be overlooked. However, these people already interacted with nonAboriginals.

As he walked, he noticed the distinctive motif of the train station, marking one end of the dominant axis in Saskatoon, the Bess the other. Downtown Saskatoon thrived around this axis and always would. Instead of taking $21^{\text {st }}$ Street however, as everyone did, he decided to take a quieter route to the site.

He turned into the back alley and proceeded down it. As expected, there was little

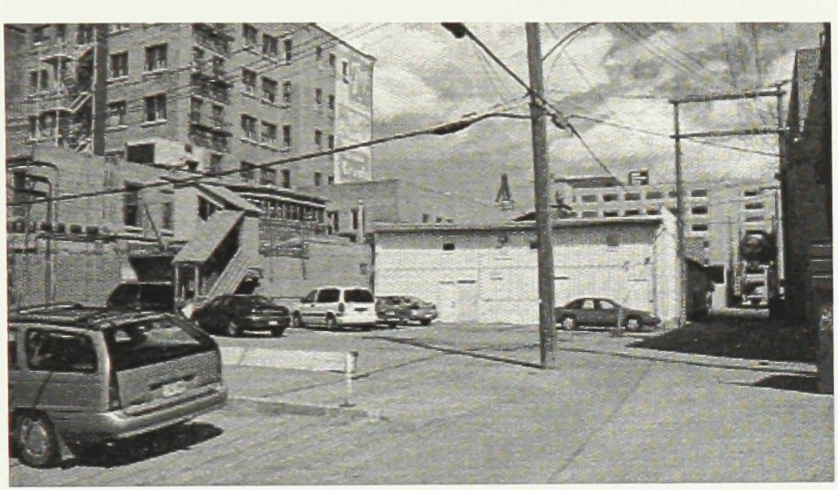

Illus $26-\ldots$ and the alleyway opens.

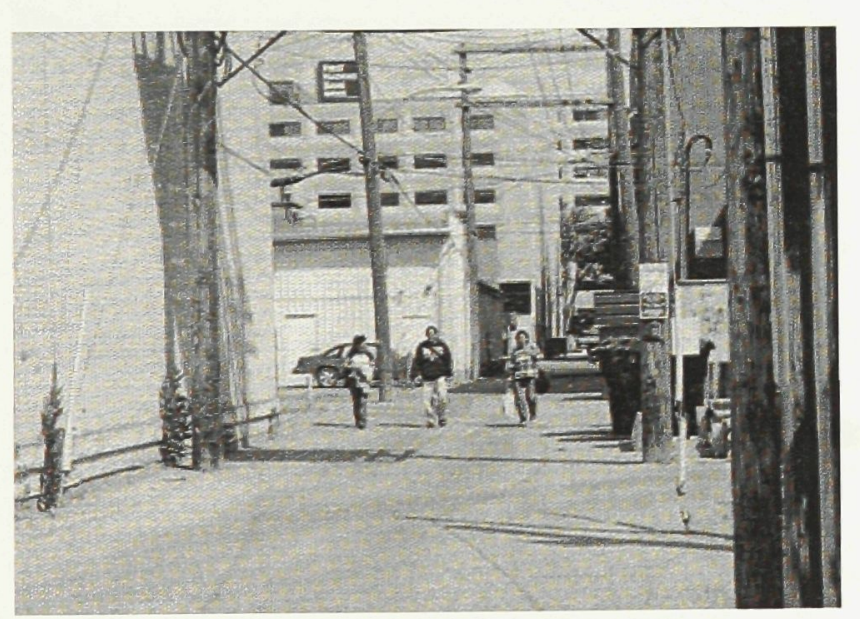

Illus 27 - Aboriginal peoples walking in alleyway. The First Nations Bank is in the distance. commotion. Graffiti was sprawled along a brick wall bordering his voyage. The alleyway abruptly ceased the procession of graffiti, as it opened into basins of parking and building disposal.

Strikingly though, these spaces were intimate, isolating the busy city life from its interior; a peacefulness that one could only experience. In the distance Bobby noticed three people walking toward him. As they soon passed, he couldn't help notice these people were of First Nations descent. 
$2^{\text {nd }}$ Avenue broke the alleyway's transition, reminding him that he was still downtown. Cars interrupted the silence he was so enjoying. Crossing the street proved difficult, but once the endless promenade of vehicular commotion passed, he continued

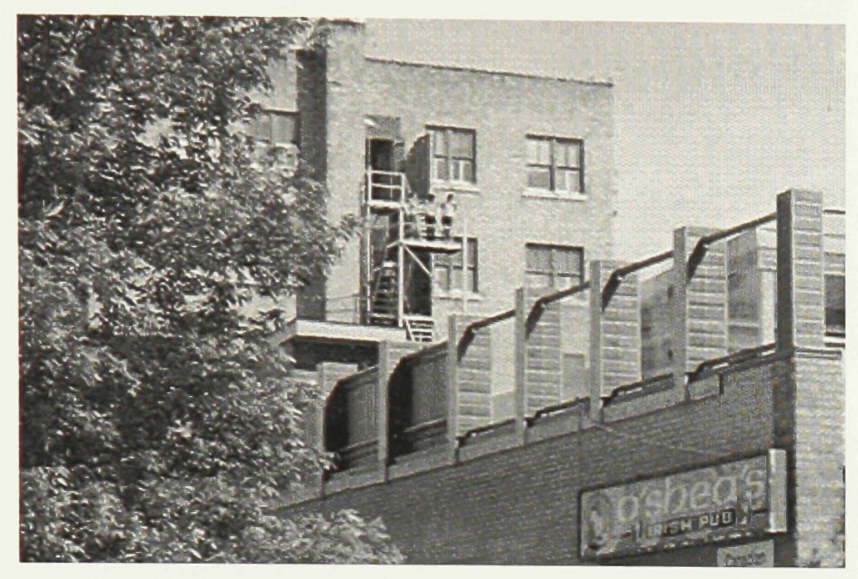

Illus 28 - Children on the $5^{\text {th }}$ Storey balcony.

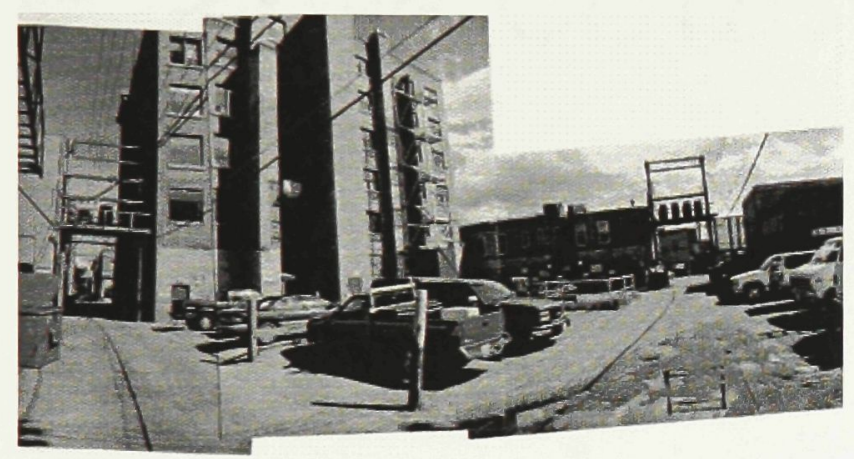

Illus 29 - Low-income residential complex/SCYAP. his journey. He noticed a few children on the fire escape of a five-storey building in front of him. He eventually approached the building, now very curious as to what occupied it. He turned right onto $3^{\text {rd }}$ Avenue to try and enter the building from the front. There was no apparent front entrance, only a sign in one of the commercial windows advertising apartments for rent. The rental price gave a relatively good idea of the level of housing. If low-income housing existed

only a block from his site, there was a chance other related activities did as well.

He didn't have to go far to find it. At that moment, the front entrance to the building was revealed; he entered into it. The small entrance led him into a two-storey loft, filled with teenage youth. They all held paintbrushes and the walls were plastered with layers of paintings. After inquiring where he was, he was escorted toward the office of the art director for the Saskatoon Community Youth Arts Programming (SCYAP) centre, a small non-profit organization. 


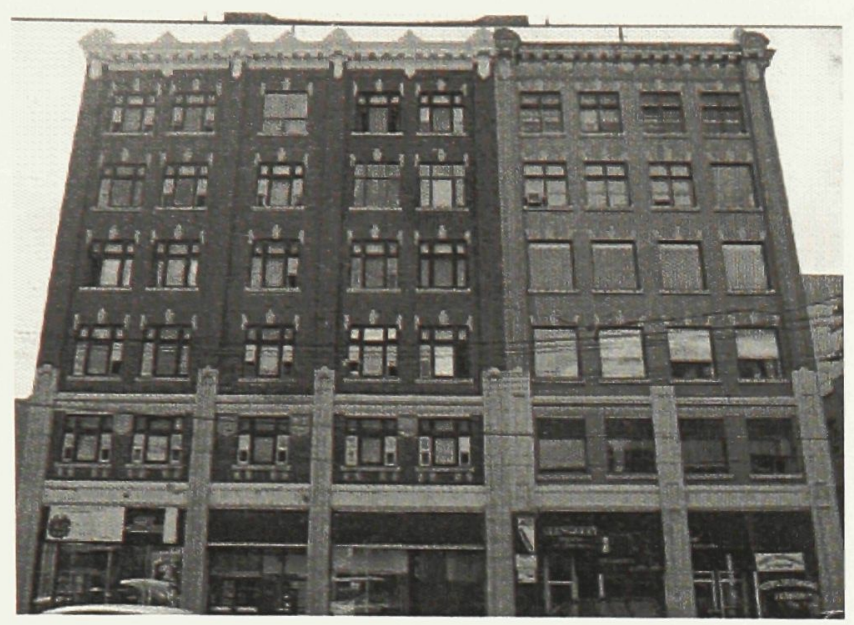

Illus 30 - The SCYAP, low-income housing above.

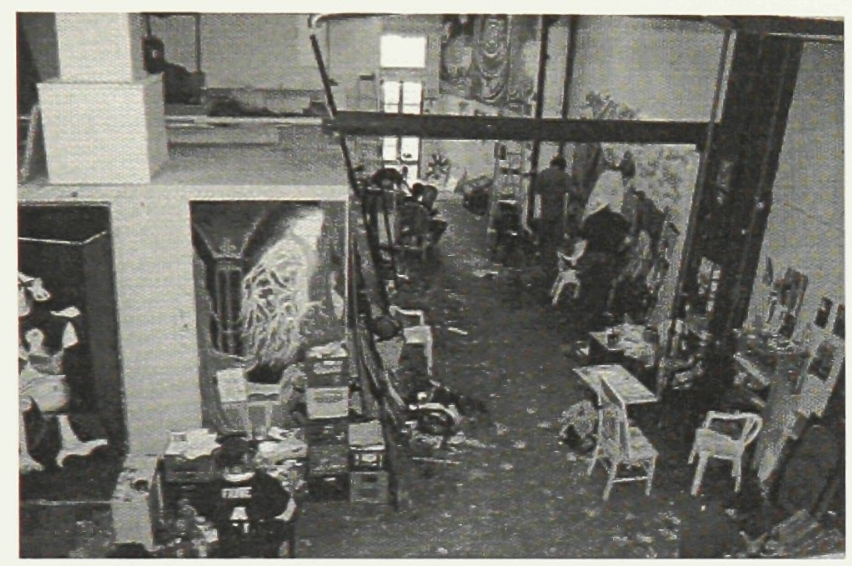

Illus 31 - The SCYAP art studio.

"We've only been at this location three months," Bevin Bradley, the nonAboriginal director, began explaining. ${ }^{138}$

"We used to be located outside the downtown area, but since coming to this building, our participants have generously increased. We primarily deal with 'street kids,' who have an interest in painting, and have often vandalized city surfaces using this interest. The youth learn to use these skills and often repay the victims through painting. Several youth are Aboriginal, so the man who brought you to me is an Aboriginal painter working here."

"And what is upstairs? Housing?" questioned Bobby. The curiosity was killing him.

"There are 50 apartments constrained onto three floors. Very low-income housing. There is talk about changing it into transitional housing for Aboriginals moving into the city. It would probably still be considered low-income though," Bevin answered.

Bobby's eyes glistened, “Are there several non-profit organizations downtown?"

"There is the theatre company, gymnasium, low-income housing in Riversdale..."

${ }^{138}$ Bevin Bradley, interviewed in person by the author on 23 June 2004. 
Bobby interrupted this lovely art director. He couldn't have imagined stumbling upon a more pleasant surprise. He continued to explain the project to her, just so she would lose that puzzled look on her face, the one she had from the time the two were introduced. His spontaneous questions must have seemed a little unexpected that afternoon, not to mention the pure, uncontrollable enthusiasm he was radiating throughout the studio. Another enthusiastic nut with a camera dropping by unexpectedly only to rattle off questions. It probably happened all the time.

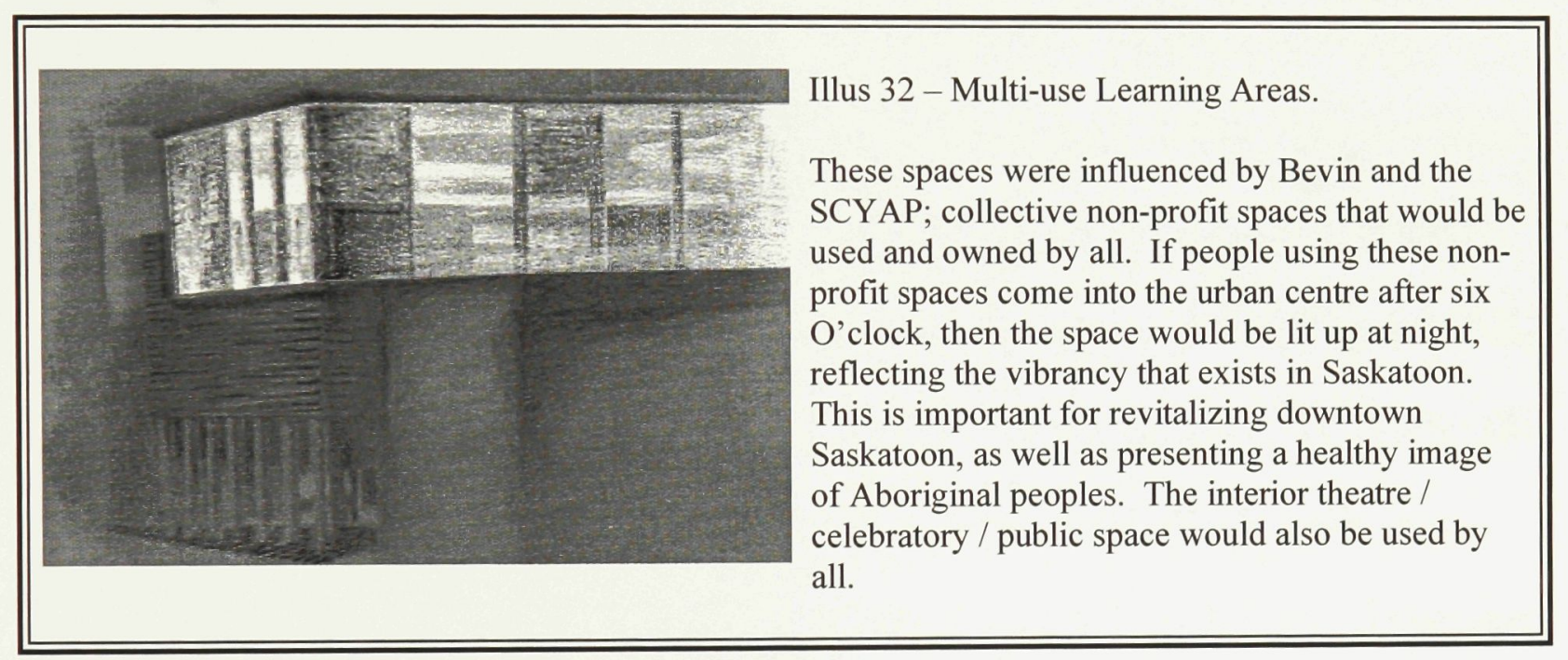

She began to smile, now understanding the purpose of his questions, "I think it is important for non-profit organizations to move into the city. It would be interesting to have a place that several existing organizations could use periodically. Something used and owned by everyone, yet no one actually occupied it permanently."

Who was she? She had touched on the essential heart of his project. The transition into the city may not be complete for the Aboriginal communities struggling with urban life, but it had begun. Whether the city of Saskatoon was ready for this 
transition or not, it was here and there was no turning back. Those preconceived notions may as well permanently visit the Friendship Centre and that early morning, beyond the horizon, in the great mountains out west. Aboriginal peoples were here to stay, and it was time for change.

He thanked her for the time she spent with him, the conversations they shared, and the new hope he had found. It was time to start designing.

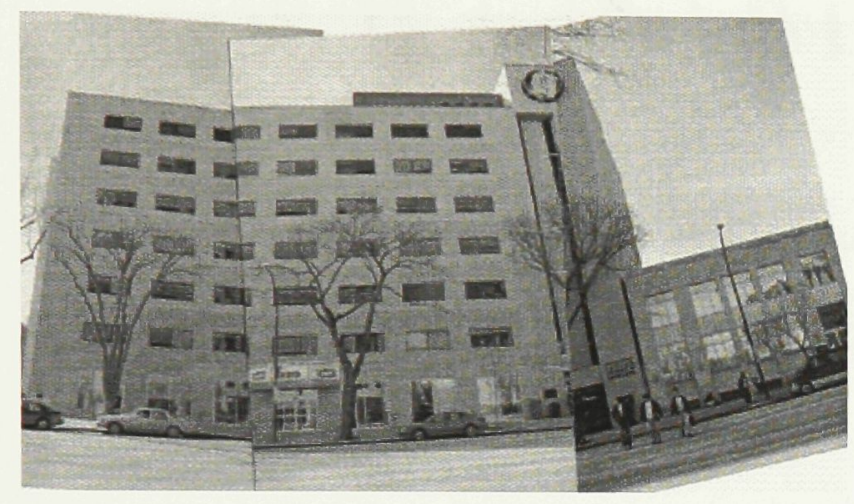

Illus 33 - Aboriginal peoples walking in alleyway. The First Nations Bank is in the distance.

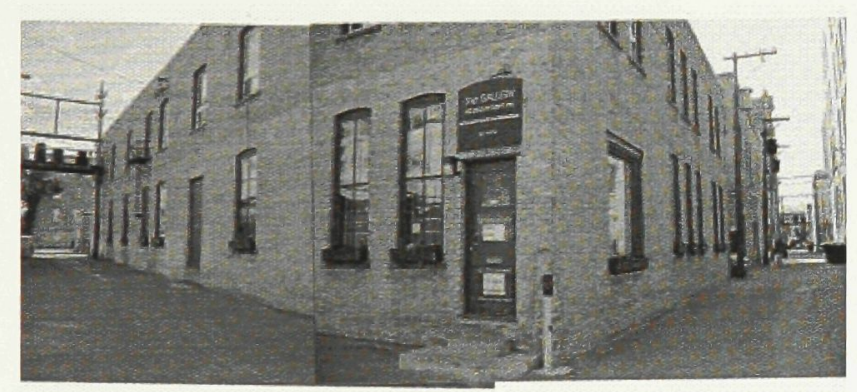

Illus 34 - The Gallery, an art store opening onto two alleys. Directly behind the SIIT.
He continued down the new path he fortunately wandered into. The alleyway soon revealed a few more Aboriginal people. They happened to be emerging from the Saskatchewan Indian Institute of Technologies (SIIT), only half a block from the gathering site. For some reason, Aboriginal peoples used these paths to move around the city. There was a life in the alleyway that resonated. Even an art store made the alleyway its front entrance and home.

As the back alley came to an end, he found himself at the back entrance of the gathering site, the urban entrance, as it would later be called. It only made sense to continue this path into the site and connect the urban environment with the Gathering space. There had to be an entrance on $21^{\text {st }}$ Street, addressing the axis that thrived so vibrantly with businesses and people, however, who says there need only be one entrance 


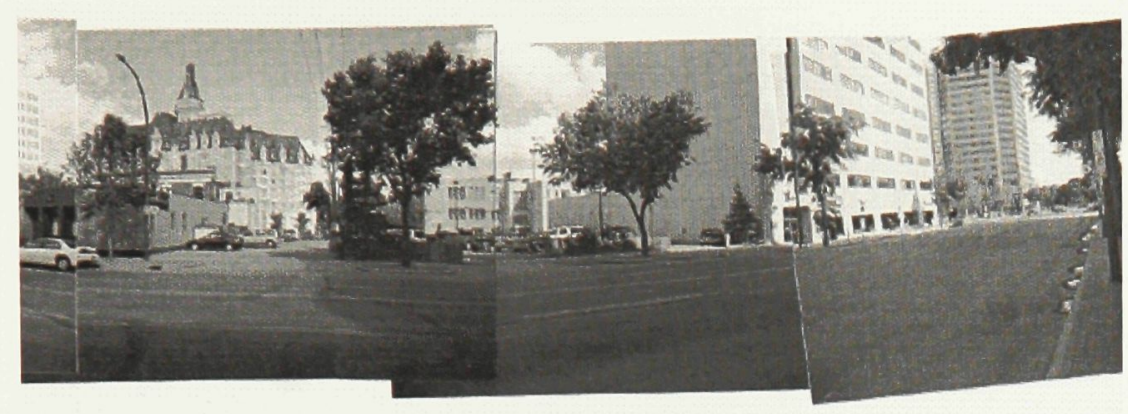

Illus 35 - The alleyway continuing into the site. The First Nations Bank is on the right, directly across from the SIIT. to any single building?

This site had a new

importance; it had to reveal the vitality of First Nations culture. It had to bring all peoples together, a meeting

point of several paths. Introducing the Friendship Centre, as it was, would not be appropriate for the site or the city. It belonged in the communities, where it would give people strength to continue the transition into the urban fabric. The journey would not be an easy or short one; looking in four directions at the same time is not an easy thing to do.

The building had to show the culture that existed. The culture that had always existed. Yves would later comment, "The Bessborough Hotel is the best Western culture offers Saskatoon, architecturally speaking. The site across from it must show the best Aboriginal people can do." Bret would also add, "This building has to show that Aboriginal peoples have always been here, are still here, and are not going anywhere." 


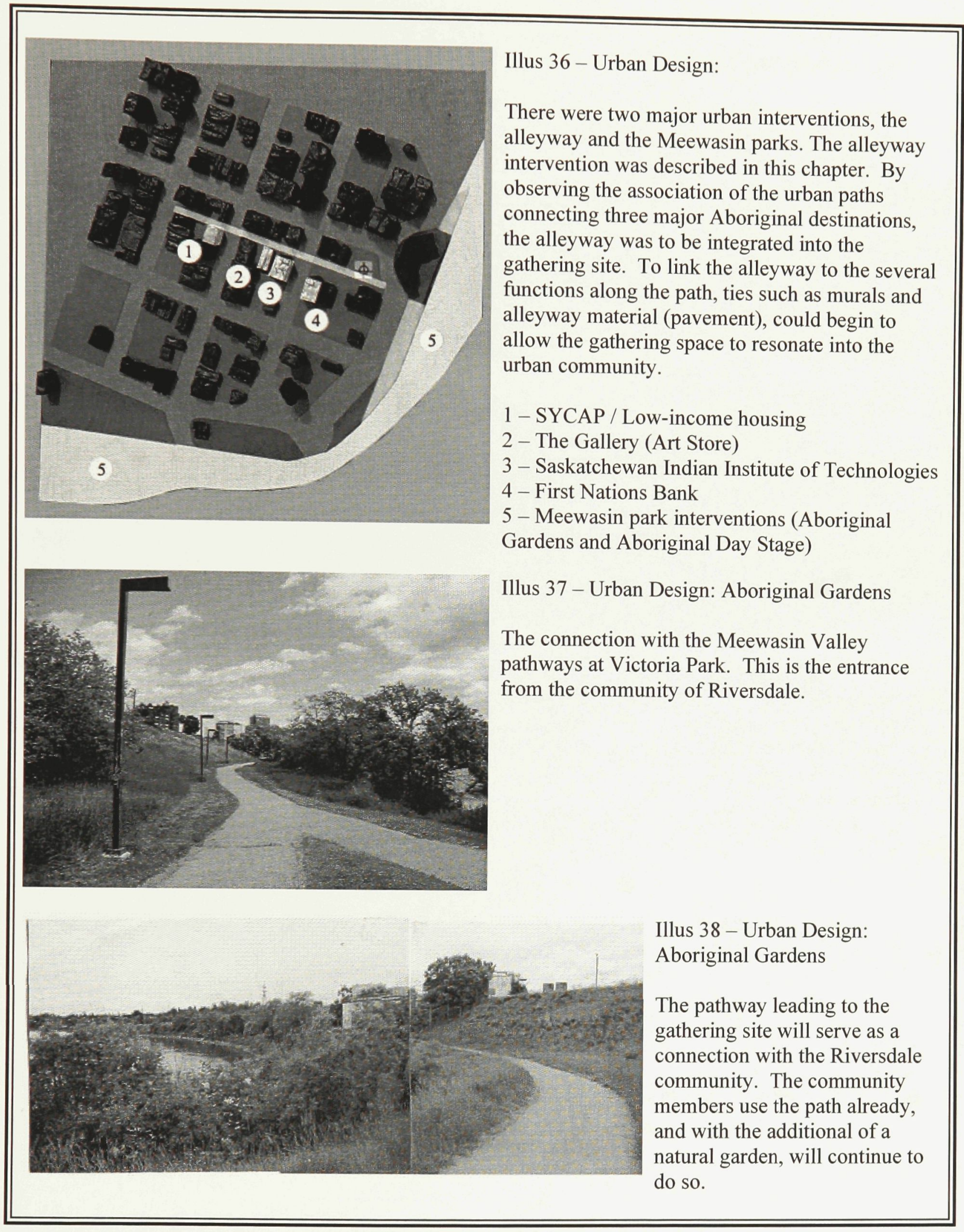




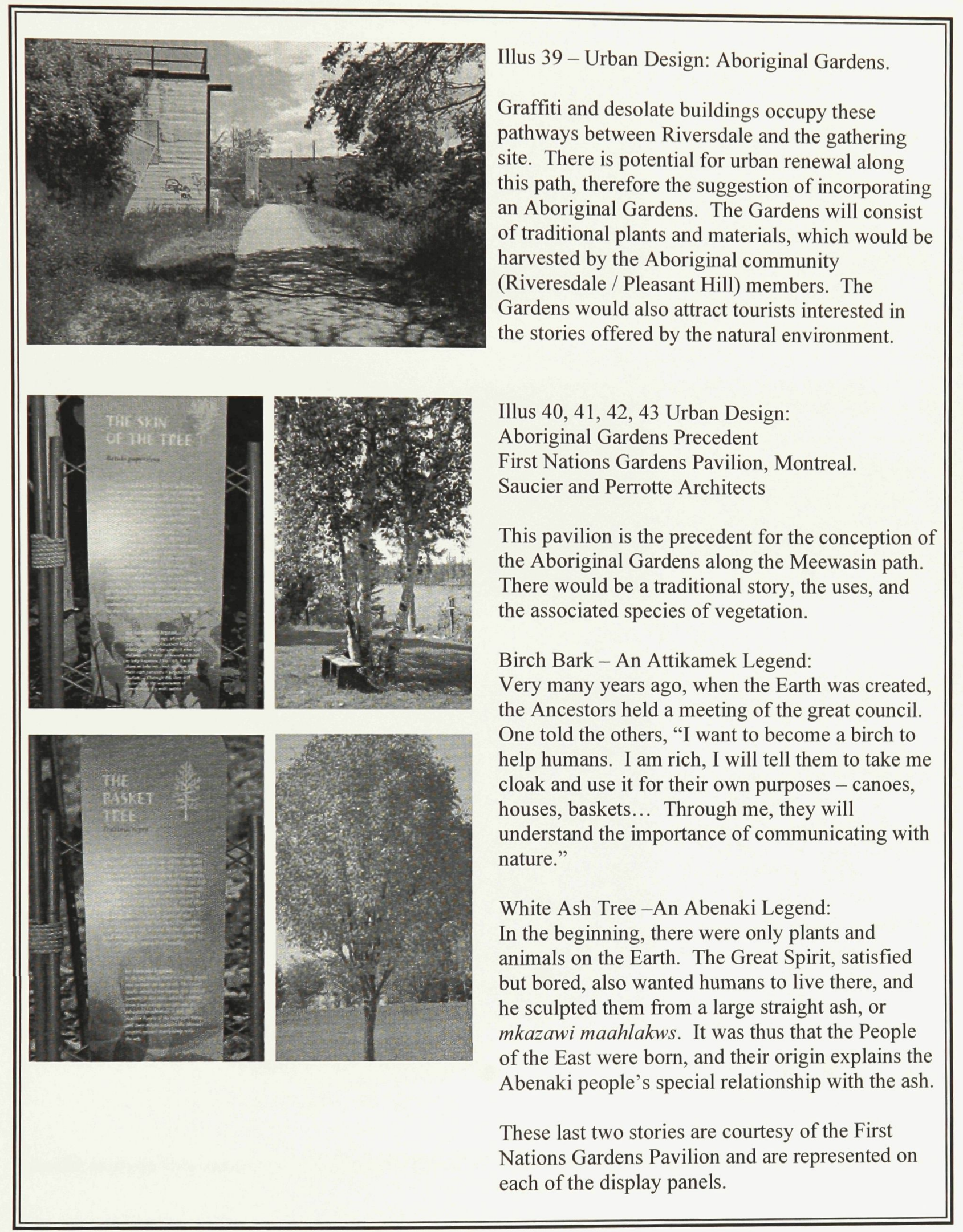




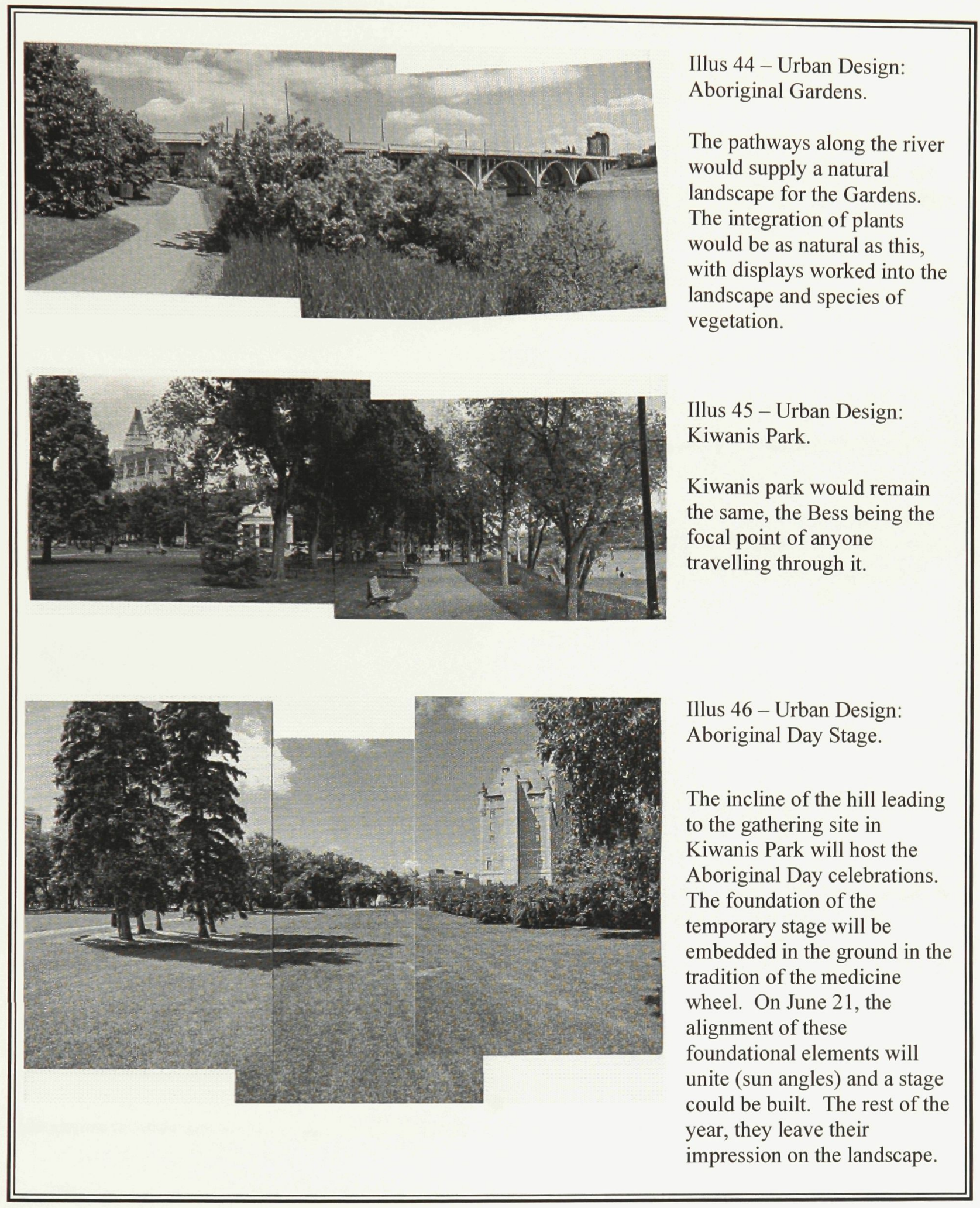




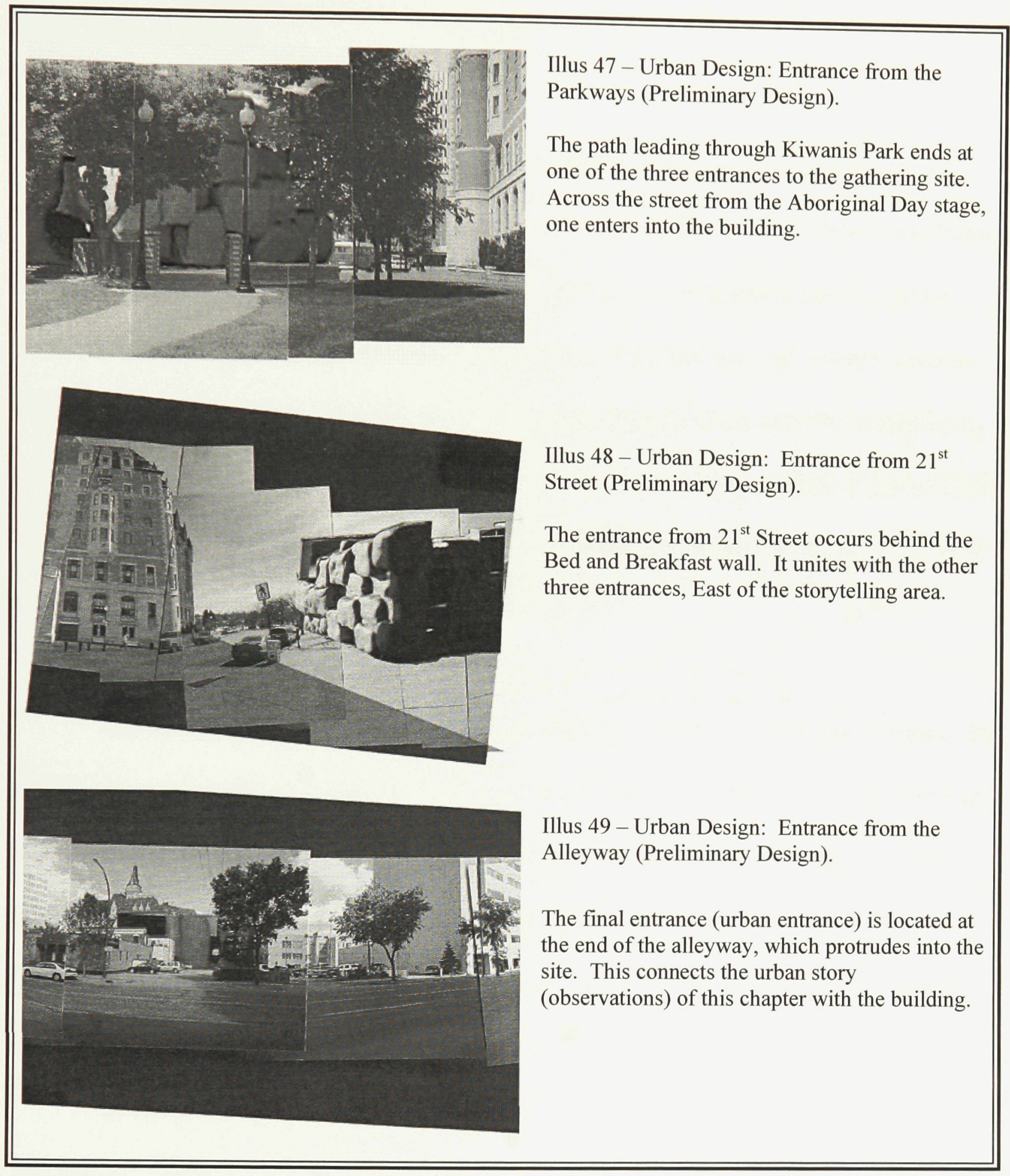




\section{In the Land of Stories}

Every explanation is a text that requires interpretation, and it is in this way we achieve understanding. Neither explanation nor understanding - they both are, implicitly, 'interpretations' - is an exact, total, unalterable account or comprehension of a given thing. Explanations and understandings are always partial and they are always to some degree or other 'personal.' We take from them something of what was left behind by a previous writer (or reader/traveler) and we in turn leave something behind, a faint outline of ourselves where we have paused for a moment, a deposit of sand from our shoes, and in the process carry away new sand to someplace else. ${ }^{139}$

The words of Michael Ling ran through Bobby's mind as he pondered stories. He had learnt so much about stories over the last eight months, since Tom's arrival. He had conversations with so many vital people regarding stories over the past eight months. Where did architecture fit into this? As he saw it, there were two routes he could go. Either the Gathering space would be a place where stories were told or the architecture itself would tell the story, but he knew these were two completely different creatures.

"I have a few stories that I would like to share with you," Tom said, sensing some frustration. "They are about Native writers creating a Native Universe. For N. Scott Momaday, the answer, in part, was to write a novel in which aspects of an unfamiliar

${ }^{139}$ Ling, "Between the Tongue and the Teeth," 23. 
universe stood close enough to parts of a known world so that the non-Native reader, knowing the one, might recognize the other."140

"Momaday, he was the author of House Made of Dawn, no?" Bobby clarified. Tom nodded in agreement, "What Momaday and other Native writers suggest is that there are other ways of imagining the world, ways that do not depend so much on oppositions ..."

"The good versus evil dichotomy," Bobby interrupted again.

"as they do on co-operations, and they raise the tantalizing question of what else one might do if confronted with the appearance of evil."141

"This being one example."

"Of course. Native writers are engaged in much more than a literary debate over the nature of good and evil. Gerald Vizenor borrows traditional figures, such as the Trickster, ..."

"Coyote, one has to be careful with those stories."

"Re-imagines them within a contemporary context, and sets them loose in a sometimes modern, sometimes post-apocalyptic world. James Welch looks at the question of identity, of place, and the value of names. Lee Maracle and Jeannette Armstrong show how traditional wisdom and customs can suggest ways to conduct oneself in the present." ${ }^{, 142}$

"To name only a few, I'm sure."

\footnotetext{
${ }^{140}$ King, The Truth About Stories, 108.

${ }^{141}$ King, The Truth About Stories, 110.

${ }^{142}$ King, The Truth About Stories, 111.
} 
"Back to good versus evil. Native writers aren't arguing that evil isn't evil or that it doesn't exist. They're suggesting that trying to destroy it is misguided, even foolish; that the attempt risks disaster."143

"It is tough for non-Native peoples unfamiliar with this way of thinking to understand, let alone accept this," Bobby expressing some of his own frustrations.

"It's lucky for me that literary analysis is not about proof, only persuasion. In our cynical world, where suspicion is a necessity, insisting that something is true is not nearly as powerful as suggesting that something might be true."144

"Basil Johnston mentioned that." He was referring to a previous conversation with Tom, where a similar subject came up.

"I once told you about Porcupines and China Dolls. I suspect that many people who come to this book will leave it annoyed and/or puzzled and/or bored by the novel's biting satire, by its refusal to resolve the tensions that it creates, and by a narrative style that privileges repetition, hyperbole, and orality as storytelling strategies. ${ }^{145}$

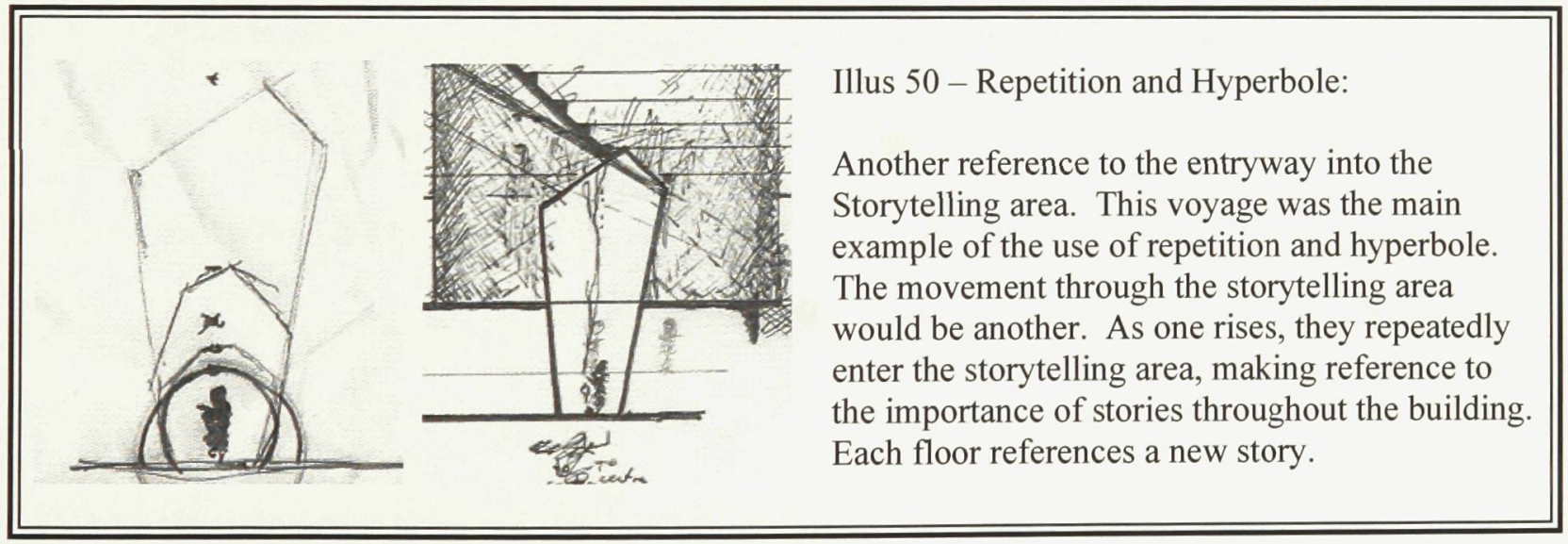

${ }^{143}$ King, The Truth About Stories, 111.

${ }^{144}$ King, The Truth About Stories, 115.

${ }^{145}$ King, The Truth About Stories, 117. 
"Well, there is a delightful inventiveness in tone, however, a strength of purpose that avoids the hazards of the lament and allows the characters the pleasure of laughing at themselves and their perils. For the Native reader, these continuing attempts of the community to right itself and the omnipresent choruses of sadness and humour, of tragedy and sarcasm, become in the end, an honour song of sorts, a song many of us have heard before. ${ }^{146}$

"Now, at the beginning and the end of Porcupines and China Dolls, James puts the barrel of a gun in his mouth and pulls the trigger. And in the novel, as in life, whether he lives or dies depends on which story he believes."147

Tom was suggesting that people live their lives through stories, just as Julie Cruikshank had suggested months earlier. Through the stories people choose to 'tell' themselves; through the stories they choose to believe; and the understanding that every story possesses several interpretations.

By hearing a story, it becomes a part of you, and the way you live is often determined by the interpretation you have chosen. This thesis is an example of this. The narrative is translated into the building, existing as one. These narratives and translations are supplied as an initial context for another story or narrative to begin. This is the dialogue that the building creates.

"This is what Julie must have meant when referring to stories being "deeply rooted in the clan and community, ${ }^{148, " ~ B o b b y ~ t h o u g h t . ~ " S t o r i e s ~ a r e ~ e m b e d d e d ~ i n ~ h u m a n s ~}$ 
and the places they live. Stories are told, never to end, only to begin again, through the retelling thereof. Stories only initiate new stories, shaping the way people live."

He realized what Michael was saying. Interpretation results in new variations of the same story. Interpretation determines how stories shape the way one lives. "This still doesn't help me with architecture's role, though. Does it tell the stories or allow for stories to be told?"

It was too late to ask Tom. He had already crept back into the backpack, probably now dreaming about stories.

\section{Program, Urban Design, and Architecture}

A little west of Carleton campus, just across the canal, Bobby walked in the Fletcher Wildlife Garden, full of its share of maple trees. Approaching fall, the leaves were slowly cycling on their annual voyage to the ground, the colours vibrant, yet revealing their vulnerability. Leaves were an excellent reminder of life, of all its beauty and eventual fatality, the cyclical timeline that Indigenous people hold so dear. Vine spoke of this often along their voyages. "Being interested in the psychological behaviour of things in the world and attributing personality to all things, Indians began to observe and remember how and when things happened together," Vine had said. "The result was that they made connections between things that had no sequential relationships. Indians were well aware that when a certain sequence of things began, certain other elements or

${ }^{148}$ Cruikshank, "The Social Life of Texts," 98. 


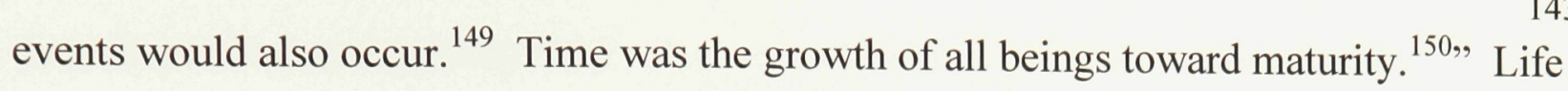
in all its forms, never feared, only respected and observantly understood. Like any other environment, Bobby knew the city had a life too.

Urban centres grow, change, adapt, and even pass away. It is common to see a city breathe, in all its physical senses. Buildings themselves also have lives. A building doesn't have to be old to be vulnerable to old age. A poorly programmed building resembles the dried leaf's brittle state as much as any other. Without people breathing life through its walls, a rehabilitation of program is needed, otherwise it slowly withers and deteriorates away, no matter its age. The art studio (SYCAP) is a fine living example of this. As with anything that lives, a building is an organism and should be respected as so. Several of these organisms, or people if you will, congregate in one area, forming the urban centre. As the forest grows, changes, breathes, and eventually dies and replenishes itself, so does the city. A new natural environment, or landscape, that Aboriginal peoples will have to grow accustom to, in his or her own special way.

Bret had discussed on several occasions the importance of his father's 'organic design.' How it was Indigenous, or in the words of Daniel, 'to be of a place.' ${ }^{151}$ How it reflected his culture, and the importance of acknowledging what it created as a living organism. "Buildings live and breathe," Bret would say, "they consume and dispose of, they are born, slowly deteriorate and grow old, all the while sharing special stories. A young building is full of life, whereas an old building shares history and the several stories, time embedded within it." The 'organic buildings' shared stories as well. One

${ }^{149}$ Deloria and Wildcat, Power and Place, 26.

${ }^{150}$ Deloria and Wildcat, Power and Place, 25.

${ }^{151}$ Deloria and Wildcat, Power and Place, 31. 
story in particular, regarding form. The 'organic buildings' oriented themselves 'naturally' or 'logically' without attention given to form, yet they appeared as if siblings, sharing a common father.

The circle was the common gene in all these children. They all possessed it in one form or another; some relied on it, others accented it more subtly, nevertheless it was present. These were the dominant precedents for Indigenous buildings in North America, besides the vast number of turtles and tipi. The process was as much Indigenous as the physical building was. The 'organic designs' themselves were living beings.

The inefficiency of the circle was a problem however. How could one look away from the cautionary advice given by the wise Aboriginal lady in Saskatoon. ${ }^{152}$ Formal explorations could not determine the Indigenous quality of the Gathering centre. This was known; the acceptance of buildings as living beings would do so; the programs situated inside would do so; how these parts were put together would do so; and how all of these components came to be would determine how the building would be interpreted. The stories are embedded within it. Would this be enough to familiarize Aboriginal peoples using the building? It may have to be. The site was rectilinear. The city was rectilinear. The buildings, for the most part, were rectilinear. To maintain place, the Gathering centre had to respect this. It is a well-known tale in the Aboriginal culture; the importance of respecting one's environment. "We do not worship nature. We are part of it," $" 153$ one wise storyteller said.

Yves had plenty of experience with respecting urban observation. He knew $21^{\text {st }}$ Street had to address pedestrians. The ice-cream bus could not be eliminated; slightly

\footnotetext{
${ }^{152}$ Referring to the interview with Darlene Speidel.

${ }^{153}$ King, The Truth About Stories, 114, quoting Beth Brant.
} 
moved, yes, but not shut down. He also recognized the opportunity to develop an important link with urban Aboriginal communities using the back alleys. These observations had to be respected and learnt from. Indigenous urban identity relied on it. The vitality of Saskatoon relied on it. The main artery connecting the train station with vintage French chateau, could not be punctured. The smaller, less traveled veins, alleyways as they were, revealed unexpected opportunities where life hid in the shadows of the great heart. The Gathering site happened to be where these two paths collided, connecting cultures and lives. Saskatoon is a living creature, as any centre is, and this life, like any environment, should be respected as such. This realization is what Vine and Daniel meant as being Indigenous; how one belongs to their environment. ${ }^{154}$

When dealing with life, sustainability is as important an issue as any. Sustainable has several friends, one must know, all respected as contributing to her success. One of those friends is a Trickster however, always transforming shape, never staying put. This friend, technology, and all of his theologies, abducted sustainable one day, not wanting to share her. In all the commotion, several stories regarding sustainable were forgotten. Stories that are no longer shared.

One of those stories goes like this:

It was a warm sunny day when sustainable decided to take a walk.

"Where are you going this fine day?" asked the White Birch.

"I'm off to find my friend, Adaptable," replied Sustainable.

\footnotetext{
${ }^{154}$ Deloria and Wildcat, Power and Place, 31.
} 
"I don't think I've ever met Adaptable," coaxed the curious White Birch.

"Ah, Adaptable has been very quiet these days. Not many have heard from her," Sustainable went on. "Most people only know my friend Technology."

"Oh, I know that one!" the White Birch excitedly replied, pleased that he recognized one of Sustainable's friends.

"Technology is not always a good friend," cautioned Sustainable, "one has to watch out for technology, that is for sure."

"Why so?" questioned the White Birch.

"Well you see, Technology does not always respect all four directions. Often he chooses one or two and fails to see the other consequences of his actions," Sustainable said.

"I know all about the four directions," the White Birch responded.

"Then you know how important it is to see in all directions. If one direction is hazy, one's entire perspective is thrown off. As is the case with Technology," Sustainable continued. "More so, Technology can be a bully and try to convince you that he is your only friend. That you should forget about all your other friends."

"That's not very nice," replied the White Birch.

"That is why one has to be careful around Technology. He is a tricky one."

"Just like Coyote. One has to beware of her stories," said the White Birch.

"Yes, Technology can be a tricky one. This is why I need to find Adaptable."

"On your way you must be then," said the White Birch. 
Sustainable carelessly walked the country lane, enjoying the warm summer sun. It certainly was a nice day for a walk.

"Where are you going?" asked the Sharp-tailed Grouse.

"I'm off to find my friend Adaptable," replied Sustainable.

"Oh I know her. She finds new uses for spaces when nothing else can," the Sharp-tailed Grouse responded.

"That is her, for sure," Sustainable said, now excited she might find her friend. "Have you seen her lately?"

"No. I haven't seen Adaptable in a very long time. Technology was hanging around lately though."

"One has to be careful around Technology. He is a tricky one, he is."

"How so?" questioned the Sharp-tailed Grouse.

"When he tries to help, often things just get worse and more complicated," warned Sustainable. "Oh, how I wish I could find Adaptable. She always knows what to do when Technology is up to his mischievous self."

"Good luck then," said the Sharp-tailed Grouse, and Sustainable was on her way.

Sustainable felt the warm sun beating down onto her back as she merrily strolled down the country lane. The sun certainly shines often here, Sustainable thought to herself.

"Where are you going?" asked the Scurrying Gopher.

"I'm off to find my friend Adaptable. Have you seen her?" Sustainable asked. 
"No, who is this Adaptable person you speak of?" questioned the Scurrying Gopher.

"She finds things to do in spaces when they no longer can be used. She likes to modify and alter things, so they become useful again," Sustainable proudly replied. "Oh how I miss my good friend."

"Have you heard of Longevity? I've seen her lately."

"Oh she is another great friend of mine," Sustainable's eyes lit up with excitement. "Her spaces last the longest of all spaces. They are enjoyed by so many people and are such beautiful spaces. When she takes something from the environment, one knows it will be taken care of. It is not often she has to come out this way."

"We do like Longevity out here," agreed the Scurrying Gopher, "so much more reliable than Technology. He is a tricky one."

"I'll say. Well, I must really be on my way and find Adaptable before it gets dark. Bye Scurrying Gopher."

Sustainable walked for sometime before noticing the country lane was nearing the city. As the country lane was approaching the city, it was slowly turning into a river path.

"Where are you going?" asked the Orange Tiger Lily.

"I'm looking for my friend Adaptable. Have you seen her?" questioned Sustainable.

"I believe she went into the city with Change," replied the Orange Tiger Lily. "Oh good. Change is the another close friend of mine," replied Sustainable. 
"Change is a beloved friend of us grassland people too," assured the Orange Tiger Lily.

"Without Change, there would be no need for my other friends and I," Sustainable said. "Change is the way we choose to live in the world. ${ }^{155}$ Change keeps us all in focus. With Change, my friends and I see in all four directions."

"They are very important, those four directions," the Orange Tiger Lily agreed. "I must hurry though, my friends and I are to meet at a new site in the city, where gathering is to take place." With that Sustainable hurried off.

Sustainable walked along the river path that ran the length of the city. Across from the French castle is where Sustainable found her three friends, waiting in the warm sun of the empty lot. Change was there, as was Longevity, and of course, Adaptable.

"Where is Technology?" asked Sustainable. "My four friends must all be present if I'm to perform at my full potential."

Technology was on his way. He crossed the grassy park and entered the empty lot from the East, greeting the others who were already there.

"Technology, you are a tricky one. Almost not showing up like that. I have to be careful around you," warned Sustainable.

${ }^{155}$ Deloria and Wildcat, Power and Place, 34. 
The warm sun shone on them. Sustainable knew she was complete. She needed all her friends if she was to see clearly. Looking in four directions at the same time was not an easy thing to do, and she needed all the help she could get. She had to be careful around Technology though. He was truly a tricky one; never know what mischief he will get himself into. ${ }^{156}$

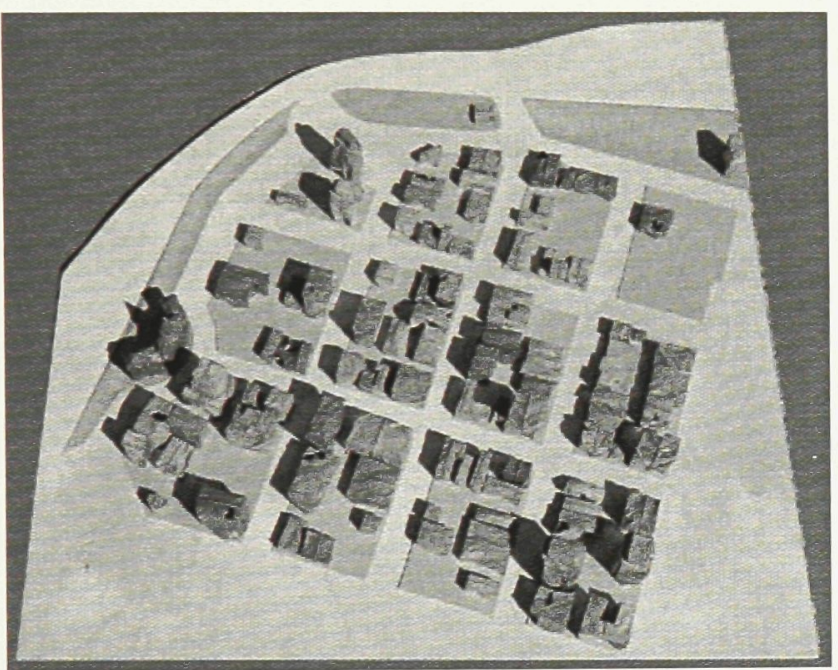

Illus 51 - The massing model made of leaves became the conceptual introduction to the project.

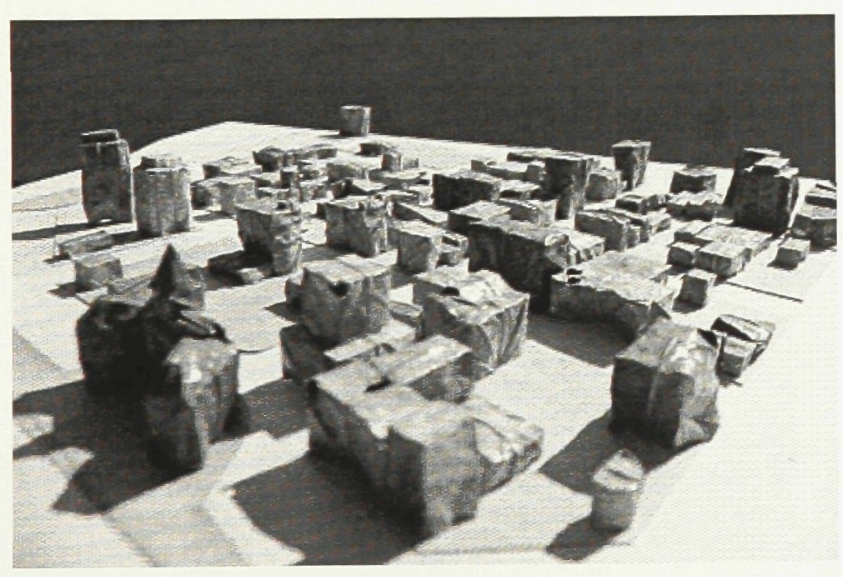

Illus 52 - Leaves reveal the life of the urban centre.
Bobby selected a few maple

leaves from the ground in that park, across the canal, just west of Carleton. Some had already turned the magnificent yellow, red and orange, that indicated Autumn. Some were summer green. Others a metallic purple. A few had been snacked on by some little bugs. In all, these leaves depicted life, in every form of the word. Wouldn't these leaves make great buildings, Bobby thought to himself. The urban centre as a living organism was a story that needed to be told.

\footnotetext{
${ }^{156}$ Story by author, referencing his six years of architecture education.
} 
They were finally approaching Toronto. Dan, Tom and Bobby were on their way to Planet IndigenUs, where Tom was to tell a few stories. The public event was the first time Bobby would see Tom speak in front of several other people. Tom would become the charismatic author and storyteller he was.

Toronto was growing. It was easily Canada's largest urban centre, showing no signs of losing that stature. People moved around as if they had somewhere to go, or even more ridiculous, somewhere to be. The sleepy city life of Saskatoon would have been trampled by the millions constantly treading through Toronto. There was no country air, no open skies, and definitely no silence, only towers of commotion, insanity, and people; there were so many people.

Toronto turned out to be an interesting experience for Tom and the two university boys; a run-in with an overly-large, crazy, bearded man on the subway; an interview with an extremely possessive urban designer dealing with urban Aboriginal issues; a night on the town. Dan, Tom and Bobby had a few stories of their own from that weekend. It was Tom's stories, those stories Bobby knew so well, that brought them to Toronto though.

Planet IndigenUs ${ }^{157}$ was held at Habourfront Centre along the shores of Lake Ontario. It was a festival celebrating Aboriginal cultural arts and Tom, being the renowned Indigenous author and storyteller he was, was asked to participate. A humid Toronto afternoon greeted the three as they made their way down to the centre. Upon

157 Thomas King read during the Planet IndigenUs festival in Toronto on 14 August 2004. 
arrival, Tom was escorted backstage, where he was to get prepared for his public performance. Bobby and Dan made themselves comfortable in the small café attached to the centre.

With only a few minutes till Tom's arrival on stage, the café was full of eager listeners, waiting the presence of the little Aboriginal man. Bobby thought it amusing, the response the audience would give, when they saw Tom literally standing on the podium. Silly folk, Bobby thought, there is no way they can be ready for the six inches of intensity I've grown so accustom to. And no matter the story, Bobby knew Tom would be entertaining. He always was. The cutting satire; the authentic imagery; and the presentation, as distinct as powerful. When the little Aboriginal man spoke, one never guessed who it was.

"May I introduce Tom King," the young Aboriginal host said with much pride. The audience began to show their utmost appreciation.

Out walked Tom, but to Bobby's surprise he had doubled in size. Bobby and Dan looked at each other, mouths agape, not sure what to make of the curious incident.

Bobby reminisced back to the day he met Tom. How could anyone be so small? How could anyone grow so quickly? 'I am whatever you want me to be,' Bobby remembered Tom saying on that day so long ago. Perhaps this was the story Bobby believed. His interpretation of everything Tom had ever told him. Right now Tom was transforming, emphasizing his charisma and storytelling nature, becoming the person everyone was to respect and listen to, that sunny Toronto day.

As Tom began to speak, he doubled once again. As he tore into the last chapter of his lecture series, a personal and emotional account of his life stories, he doubled again. 
Soon he was the towering man, glowing with vitality, that he had always been, the charisma and emotion captivating an audience already entranced by his presence. That slightly crooked grin, drenched in sarcasm, was the recognizable trait that Bobby knew so well. Never had Tom's stories sounded so good.

After the performance, Bobby waited for his friend. He was busy entertaining those who held him so dear, so close to their own personal experiences. Tom's stories worked wonders. They were transformers, encouraging one to visit the increasingly unfamiliar land of imagination. They were life as anyone might know. They captured rural Prairie towns, reserves, and the people that lived there. They spoke, as Tom so eloquently showed that day; they were both oral and written literature.

And if you know where to stand, you can hear the two talking to each other. ${ }^{158}$

"Let's go outside and talk. It is much too nice to be in here," Tom directed Bobby to the covered patio overlooking the lake. "I think you may find this to be an unfamiliar conversation from those we had before. I will attempt to talk to you about architecture." $" 159$

Bobby was intrigued. Why now, after all these months? Could this be what he was longing for? The connection between architecture and stories.

"Don’t be ridiculous," Tom smiled at Bobby. "I don’t even know where to begin with that. No, I was thinking recently about what I would interpret as 'Aboriginal' in architecture. This space, for example, is outdoors, but we are protected from the

${ }^{158}$ King, The Truth About Stories, 102.

159 Thomas King, interviewed in person by the author on 14 August 2004. 
elements. This is important. However, if I want to be completely exposed to the

outdoors, I can get up and do so. It is right there in front of me. No windows or walls interrupting that. This blurring between exterior and interior spaces I find important as an Aboriginal person.
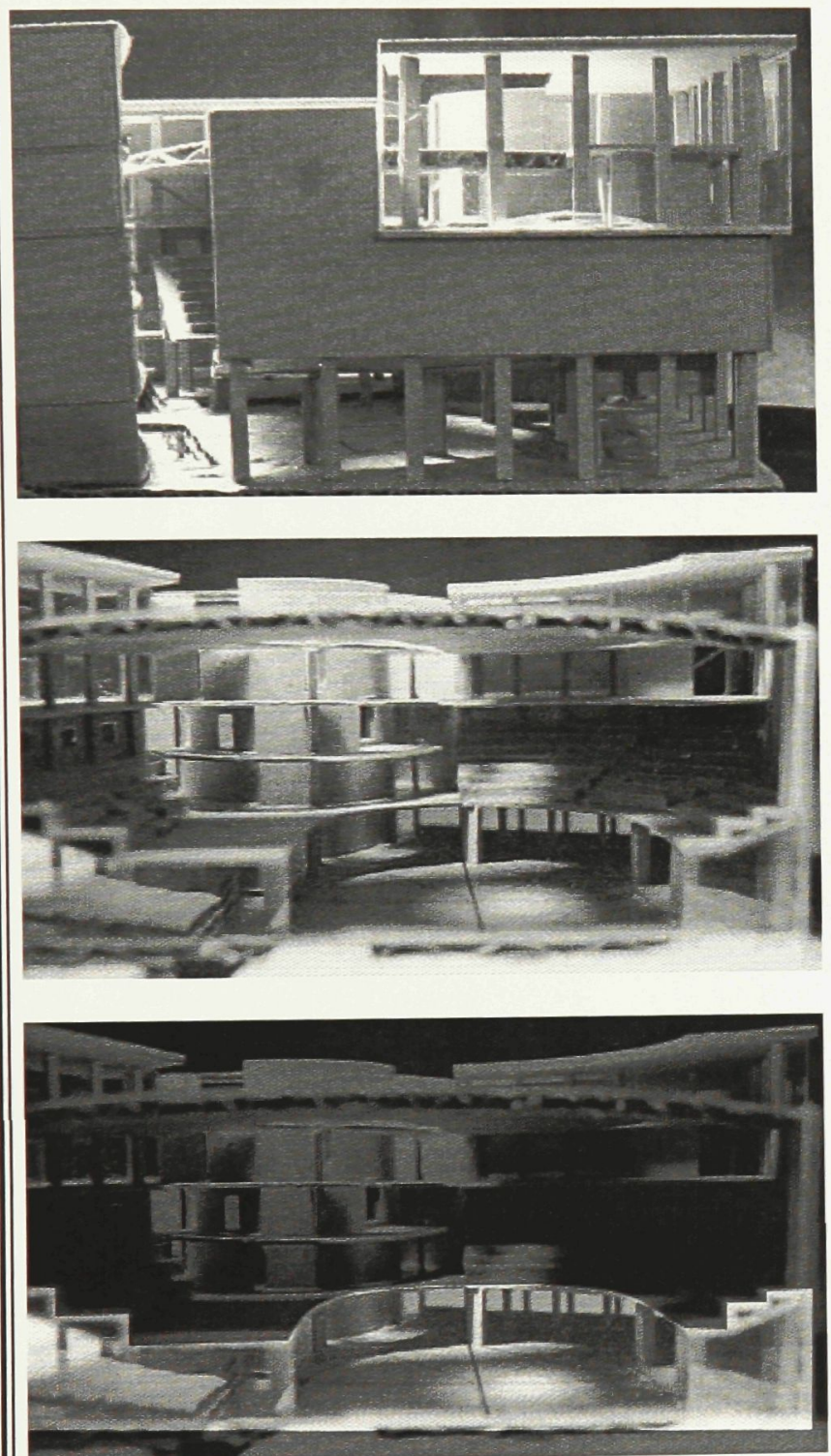

Illus 53 - Exterior/Interior

The street level of the gathering space is open to the public and natural elements. The building is raised above the ground to accommodate. The interior is also used as a theatre and celebratory grounds. The natural elements are intended to enter the interior space, similar to the space Tom and I experienced. Light enters from above, along the bed and breakfast and storytelling area. This emphasizes the parti already established.

\section{Illus 54 - Exterior/Interior}

This is the interior of the image above. There is a full roof covering this space, yet light wells (bed and breakfast, storytelling area) from above allow light inside. The street level floor was also raised to allow the dancers a clear view outside while dancing. This was a story discussed early with Bret regarding a pow wow space.

\section{Illus 55 - Exterior/Interior}

During the warmer months of the year, the street level is completely open. During the colder months there will be a wall of glass in the highlighted area. The rest of the main floor will still be open to the natural elements. The dance area has the only direct access to the rest of the interior spaces therefore it has to be closed off. 
"The openness of space is also very important. A wall can separate two rooms,

without completely closing them off to one another. It is important for me to be able to see from one side of the building to the other, a home for example."

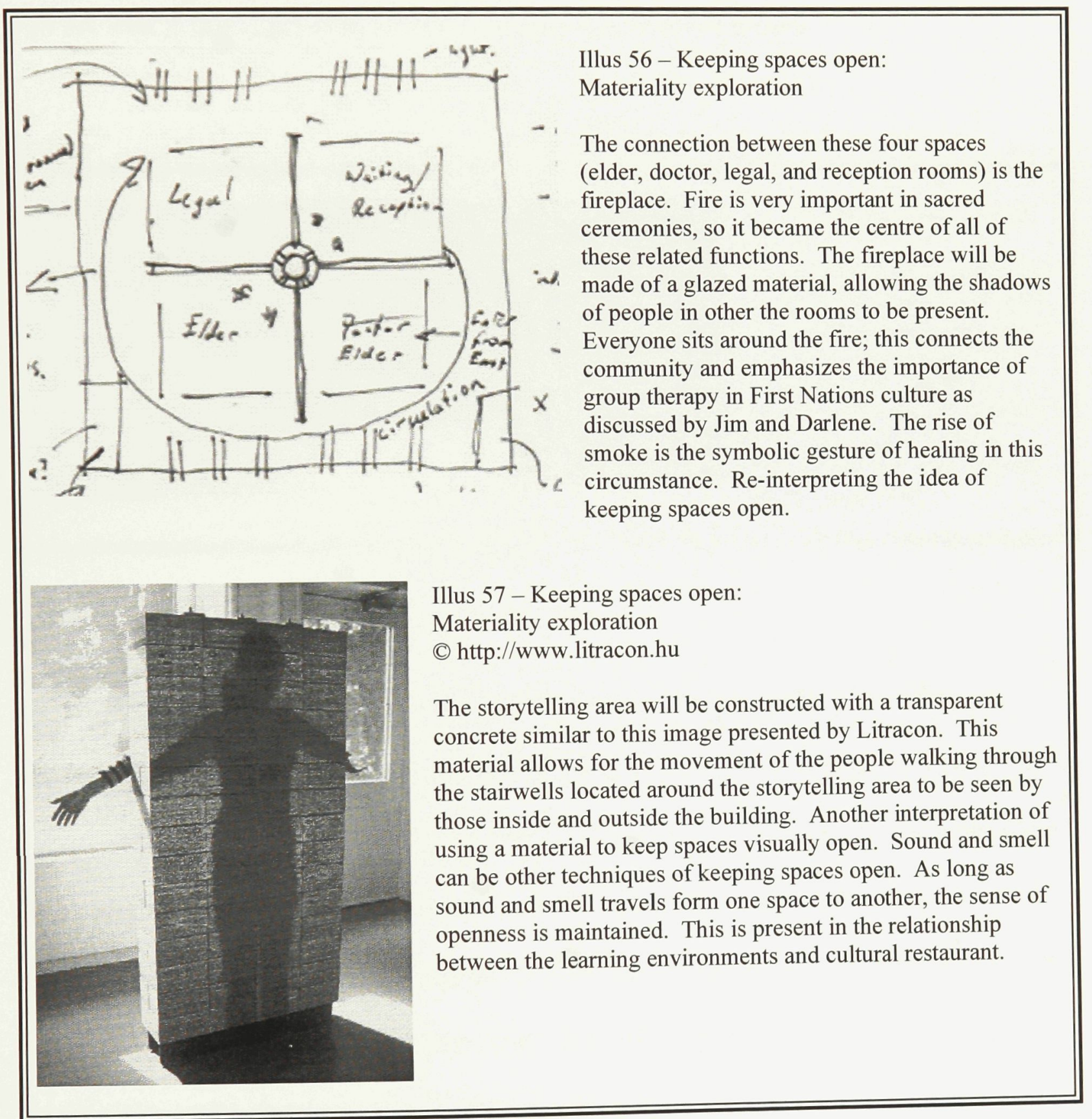

The welcomed breeze urged Tom further into the story he was telling. 
"I know you are designing a theatre/powwow space. Being a drummer and singer involved with such ceremonies, I know the power created by sitting on the Earth. By sitting on the actual Earth while performing, it enhances the connection to the environment and helps with the transforming of the ceremony itself. This is important. I'm not sure if this is possible however, in the interior of a building."

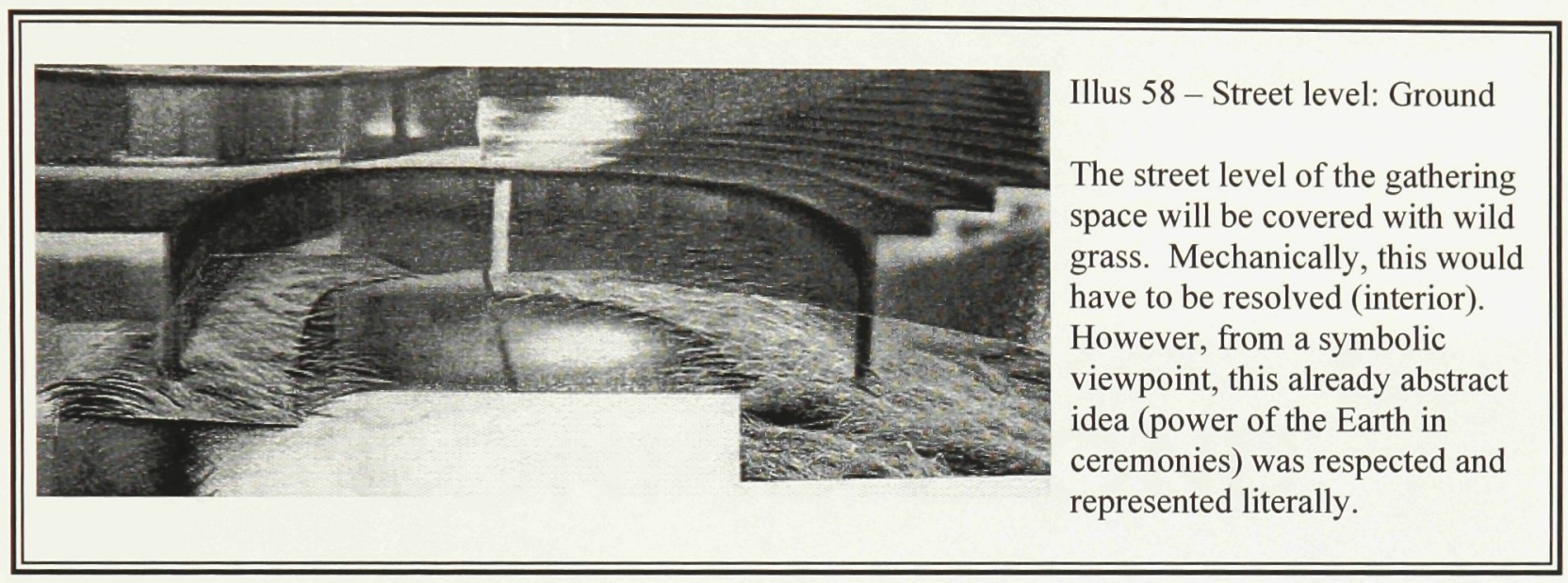

Bobby was determined to try.

"Yes, the environment is very important to us Aboriginal peoples. The relationship between exterior and interior space could be a way to design for this issue."

While Tom was explaining his connection to the land, Bobby was thinking about a connection to his project. Sustainable would be pleased to see the theatre space used for something in addition to performances. If the space had to be on the ground floor, to allow singers, dancers, and drummers a familiar surface to perform on, perhaps the surrounding walls could be opened, allowing the space to be used as public space. 


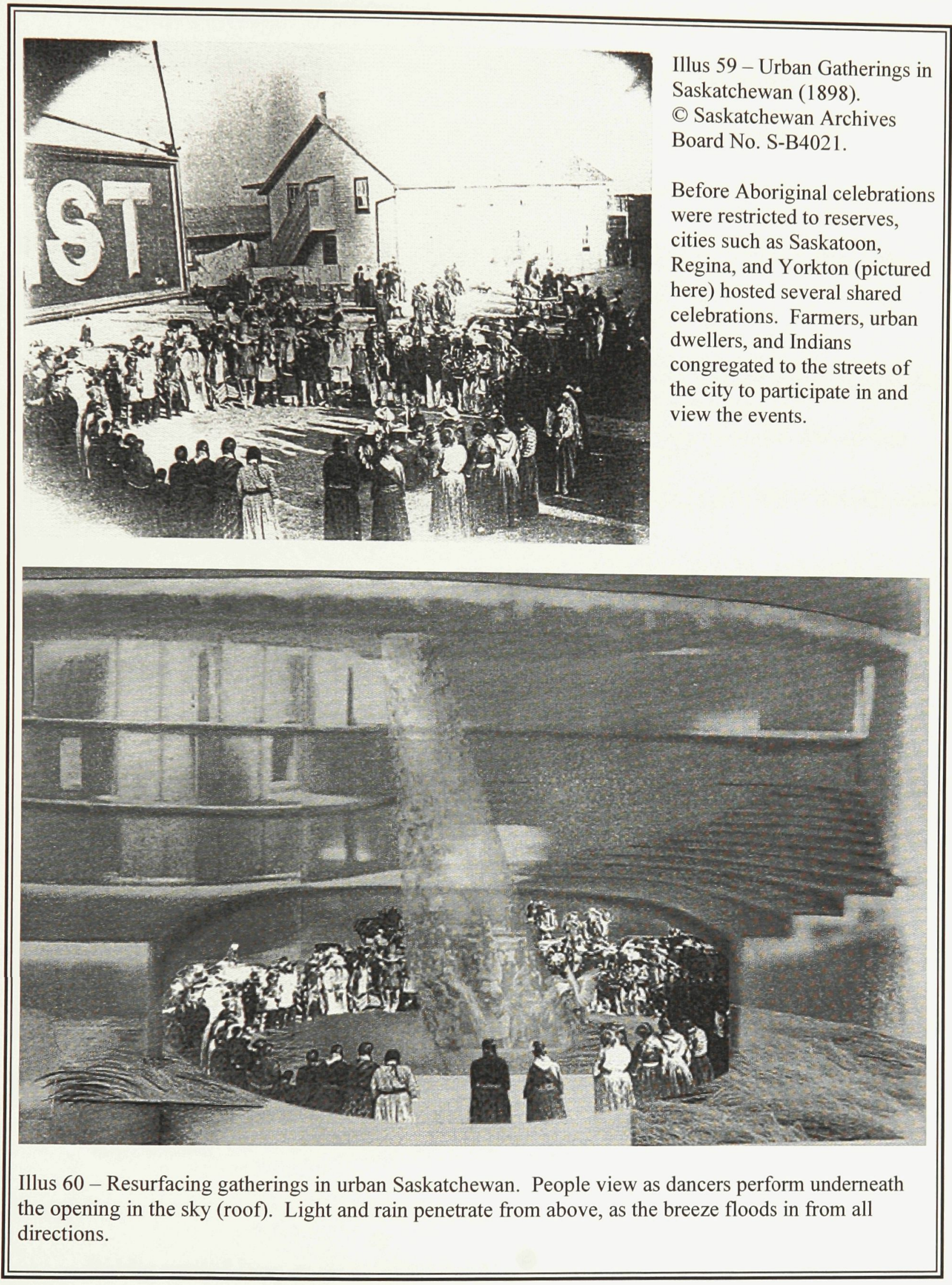


The topic of literal representation came up during the last bit of conversation. Tom was an Aboriginal artist, writer and storyteller, and his opinion on literal representation in the Aboriginal arts was an important discussion for Bobby.

"I believe literal representation should be avoided," Tom replied. "I try to write all my stories as if they are my own. I may take stories or ideas from somewhere else, but when I'm finished with them, they should have become my own."

Bobby knew just how important this was. Literal representation was a struggle he had been facing from the very beginning, and this reply may have been the end of that struggle. Tom didn't make the connections between stories and architecture that day, but he did supply a few stories that needed to be told.

They had left the Harbourfront Centre and were now walking toward the main entrance on the street façade of the building. Located to the side of the centre was a tipi, assembled for the celebrations that week.

"I did notice the entrance to that tipi was in the wrong direction, however," Tom noted casually as they walked.

"The designers did that so the entrance faced the building. That way a link is made between the two, and that space could be used in accordance. Otherwise, the opening would face the parking lot," Bobby explained the architectural reasoning behind the blatant oversight.

Tom nodded his head, "There are some things that should be represented literally though."

Bobby smiled long at this. Why would one try to abstract an idea that is already abstract? Some things simply need to be respected. 
Bobby knew this was all Tom could possibly teach him. The truth about stories is that that's all we are. ${ }^{160}$ Stories were turning into the world Bobby was now living in. Everything evolved around stories. His architecture, the cultural ties embedded in the architecture, his journey, and later the written thesis itself. The urban Aboriginal thesis was a story, a story to be shared with others. A story that needed to be shared with others.

Other storytellers would have to be found to make the connections between architecture and stories. Tom was needed elsewhere. It was time Tom was released back into that creative world of writing and storytelling. That world Tom excelled in, and always would. Indigenous stories needed to be told and carried on, that is known, and who better than Tom to do so. Bobby was simply hoping to supply the place. With that, Bobby said goodbye to the little Aboriginal man, and the two parted ways, not knowing when their paths would cross once again.

\section{Program, Urban Design, and Architecture}

Bobby found himself in Ottawa riding the O-train again. Of course, Mr. NorbergSchultz was entertaining. It had been quite some time since his last visit, and stories were now nicely floating around architecture. Bobby was hoping Christian could finally connect the two.

${ }^{160}$ King, The Truth About Stories, 2. 
"The character of a work of architecture is first of all determined by the kind of construction used; whether it is skeletal, open and transparent (potentially or in fact), or massive and enclosed." Christian was describing the ways in which architecture told stories, "and secondly by the making as such: binding, joining, erecting, etc. Those processes express how the meaning of the work becomes a 'thing.' Thus Mies van der Rohe said: "Architecture starts when you put two bricks carefully upon each other."161

"You are talking about articulation, no?" Bobby wanted to verify.

"Articulation determines how a building stands and rises, and how it receives light."162

"How it exists between earth and sky."

" 'Stand' denotes its relationship to the earth, and 'rise' its relationship to the sky, so yes."163

"This would then include the foundation, wall, and roof. Each component emphasizes how one occupies their world. How one occupies a space is often determined by interpretation. Interpretation is the result of cultural, social, and individual distinctiveness. Michael Ling -- well, almost every storyteller I've talked to, has touched on the world of interpretation."

"When a town pleases us because of its distinct character, it is usually because a majority of its buildings are related to the earth and the sky in the same way; they seem to

\footnotetext{
${ }^{161}$ Norberg-Schultz, Genius Loci, 66.

${ }^{162}$ Norberg-Schultz, Genius Loci, 66.

${ }^{163}$ Norberg-Schultz, Genius Loci, 66.
} 
express a common form of life, a common way of being on the earth. Thus they contribute a genius loci which allows for human identification."164

"And several interpretations belong to this distinct character. This would mean several distinct characters exist in any single distinct character. A town consists of several buildings, and a building of several rooms, each of which possessing an identification or distinct character. The overall unifying character being how these smaller, unique interpretations react and relate to each other," Bobby expressed his understanding.

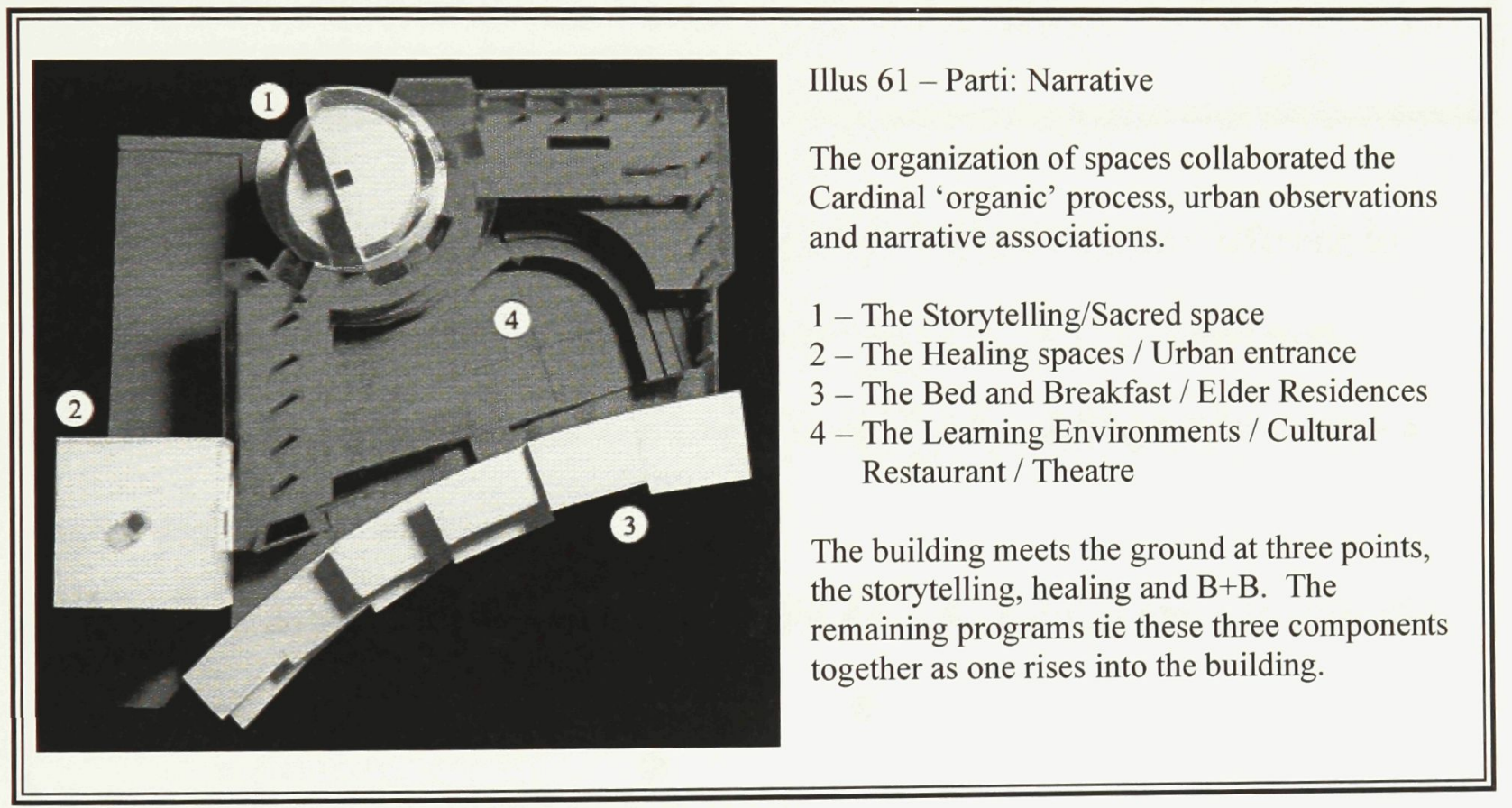

${ }^{164}$ Norberg-Schultz, Genius Loci, 63. 


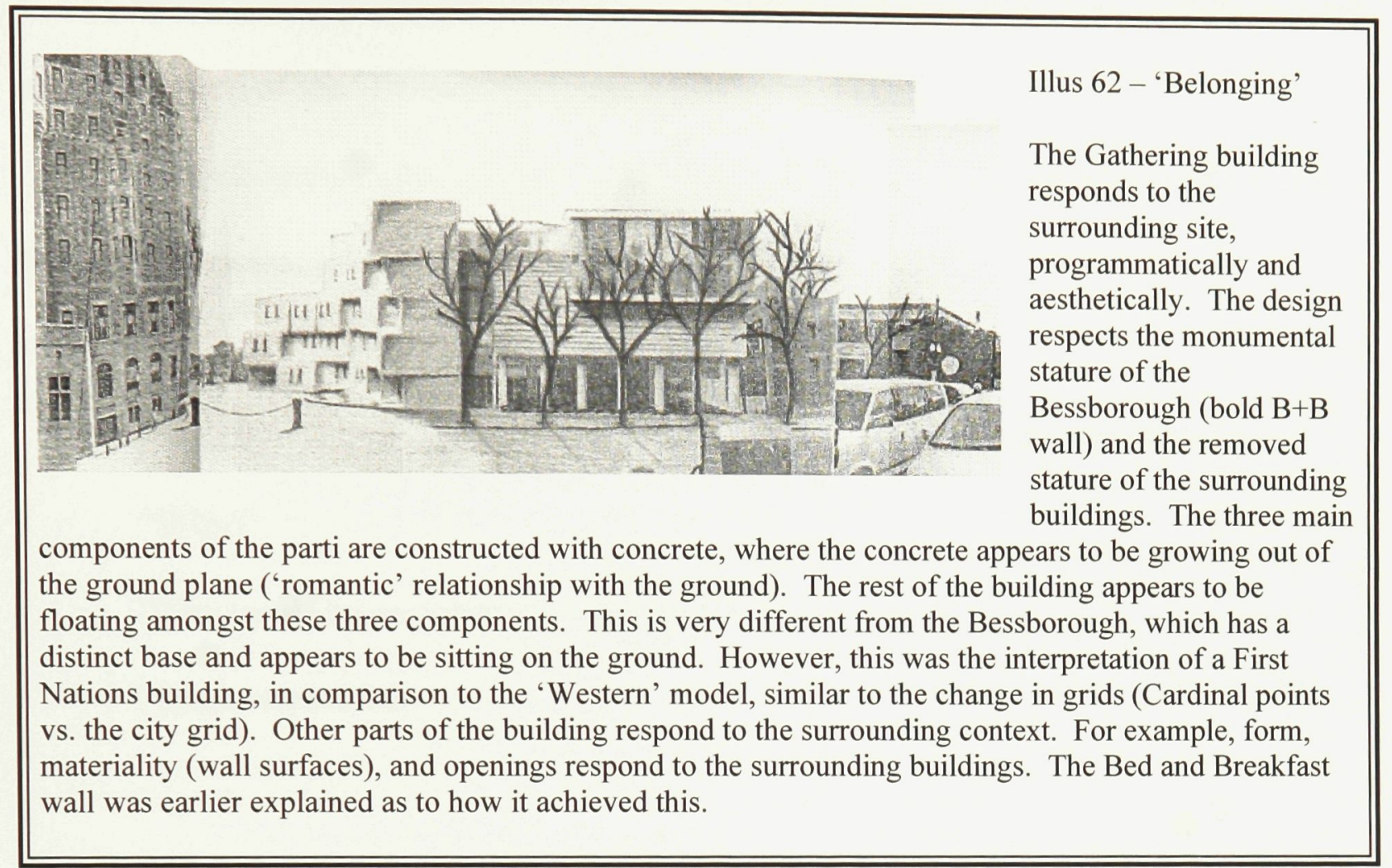

"He is starting to get the point," one passenger nudged the other, referring to Bobby's growing understanding of stories and architecture. The two passengers witnessed several of the visits between Christian and Bobby, although neither knew a single thing about architecture.

"What do you mean by that?" questioned the white bearded one to the youthful other.

"It sounds like he knows what he is talking about," replied the youthful other.

"Or so he would want you to think."

"Yes architecture is that way, isn't it?"

"What?"

"It is funny."

"Certainly is." 
Being distracted by the nonsense occurring a couple of seats over, Bobby insisted on another cup of tea. Perhaps this would calm him down.

"Would anyone else enjoy a cup of tea?" Christian was now well accustomed to the regulars riding the train everyday.

"I would," replied the youthful other.

"Watch what you ask for," the white bearded one warned the youthful other. "Why?"

"You never know what you will get." "I just wanted tea..."

"Christian, please, we must carry on with our story," Bobby pleaded.

"Yes, yes, back to architecture and stories. Where were we? Oh yeah, meaning is a psychic function. It depends on identification, and implies a sense of 'belonging, ",165 Christian replied.

This instantly sparked Bobby's attention. Those crazy voices from across the train vanished. Identification implied a sense of 'belonging.' Through urban identification, Aboriginal peoples would sense 'belonging' to Saskatoon, and through cultural identification would come that 'familiarity' that he had been searching for. 'Familiarity' being their stories.

"Man is a 'thing' among 'things,' Christian continued as Bobby listened intently. "He lives among mountains and rocks, rivers and trees; he 'uses' them and has to know 
them. He also lives with the 'cosmic order': with the course of the sun and the cardinal points." 166

How familiar this sounded! It could have been Vine or Daniel speaking during a trek through some rocky cliffs. Daniel once said, "Place or space is concrete and palpable. It is in a profound sense where one discovers his or her self, what Vine calls personality, as opposed to the casual sense of where one just happens to find one's self. Place is not merely the relationship of things, resources, or objects, it is the site where dynamic processes of interaction occur - where processes between other living beings or other-than-human persons occur."167 Bobby knew well the importance of understanding one's environment in Aboriginal culture.

"Man builds himself, society and culture, and in this process he may interpret a given environment in different ways, ${ }^{168}$ Christian added.

"Yes, the Aboriginal perspective of the environment will be much different from the non-Aboriginal one. The stories will be different, therefore representation in the man-made world will appear different. However, to respect place, as any Indigenous person knows is important, the urban characteristics must be acknowledged and not destroyed. This reminds me of a conversation we had a few months ago," Bobby recognizing the similarities.

\footnotetext{
${ }^{166}$ Norberg-Schultz, Genius Loci, 168.

${ }^{167}$ Deloria and Wildcat, Power and Place, 144.

${ }^{168}$ Norberg-Schultz, Genius Loci, 168.
} 


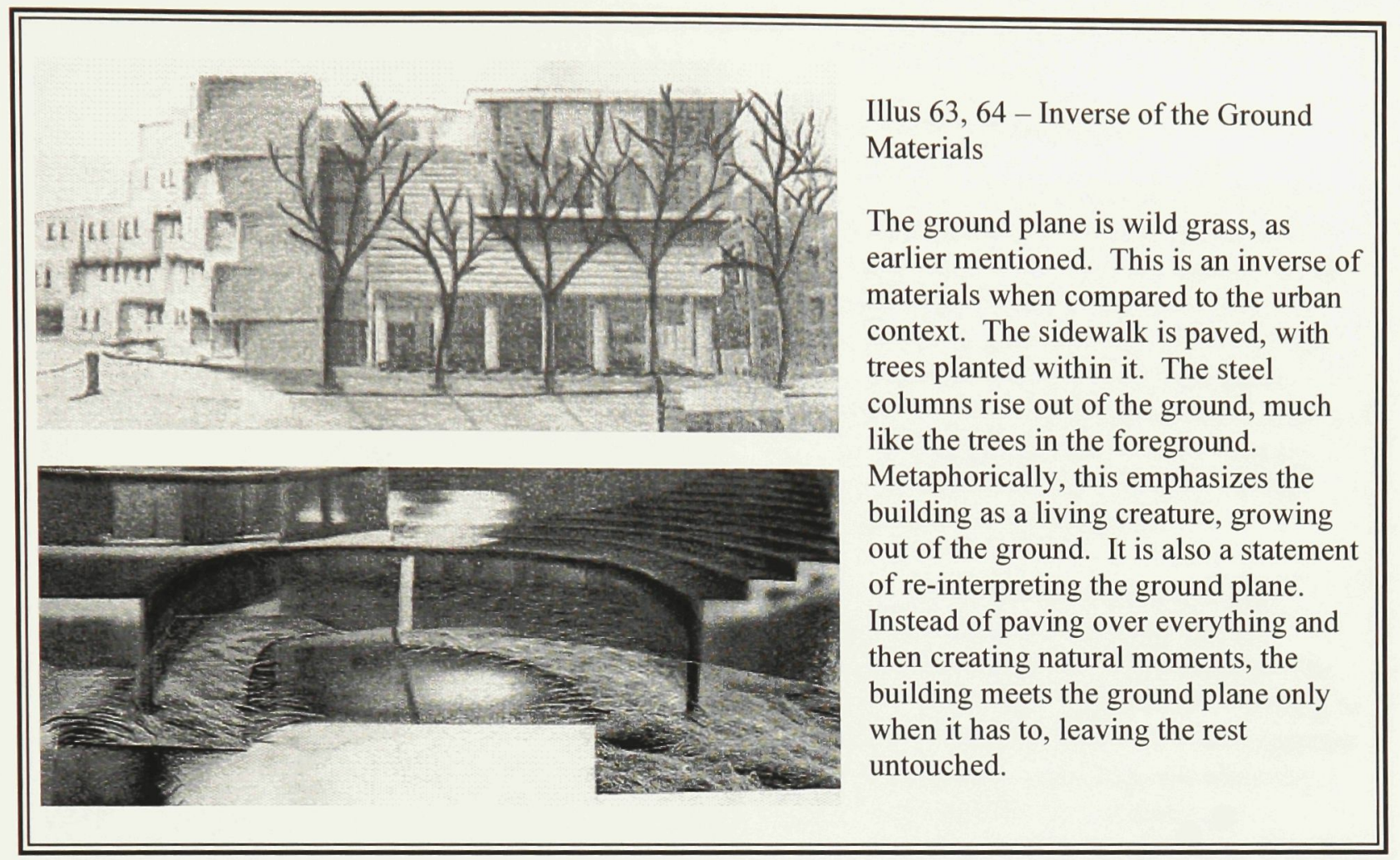

“Another cup of tea?" asked Christian.

Bobby shook his head. He was too involved with this conversation to be distracted.

Christian began to describe how buildings embody meanings,

$$
\text { or as we have come to know them, stories, }
$$

gathered by the city. "We have already shown that this embodiment depends upon how the buildings stand, rise, and open, and have mentioned that their 'behaviour' is usually condensed in motifs which characterize an urban environment as a whole. The critical parts of motifs are base, roof, corner, and opening; that is, the 'elements' which relate the building to its environment and defines how it 'is' on the earth." 169

${ }^{169}$ Norberg-Schultz, Genius Loci, 177. 


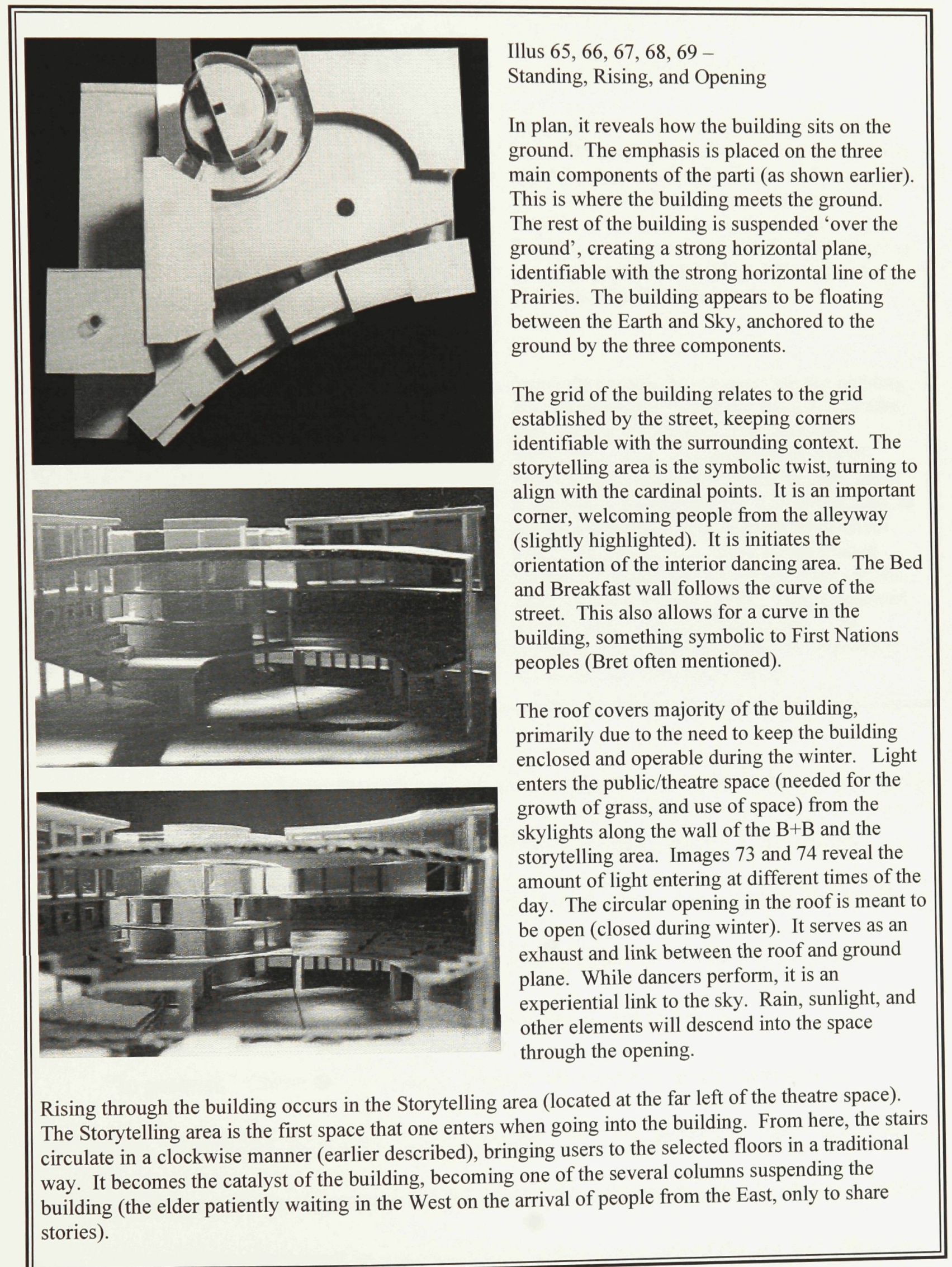




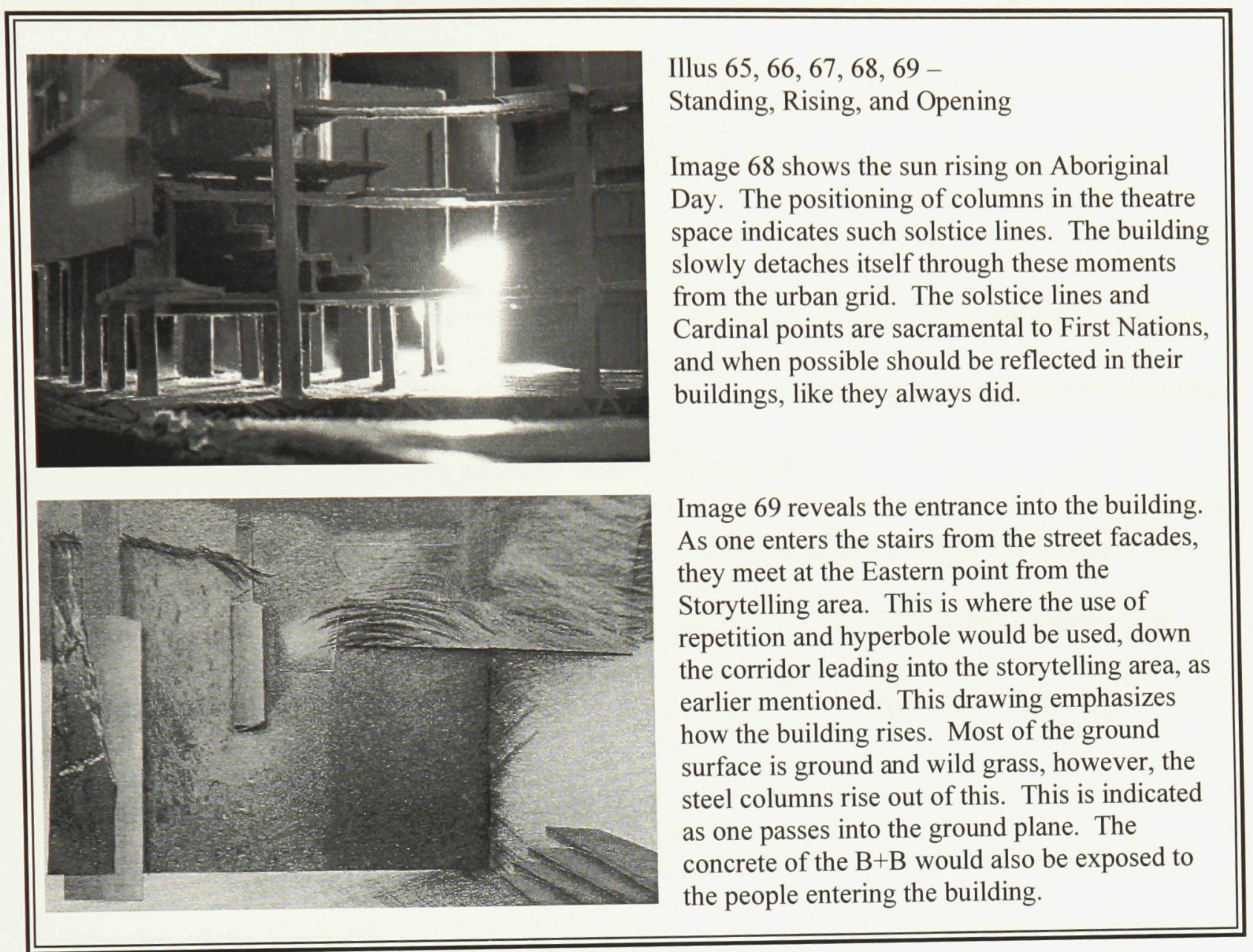

"Listen, we may learn something," Bobby overheard the white bearded one say to the youthful other. Everyone on the train was listening at this point. It wasn't that Christian's story was particularly interesting, but it was a story, and anyone listening could tell he was reaching his climax. Bobby anticipated it would not be long now, before Christian revealed how stories were embedded in architecture.

"In general," Christian continued, slightly slowing his speech to create atmosphere, "a building may stand 'in' the ground, 'on' the ground, or 'over' the ground. To be 'in the ground' expresses an intimate 'romantic' relationship to the 'forces' of the earth. It is usually concretized by making the building grow out of the ground without a distinct base. 'On the ground', instead, means that the building is set off on a base as an 
individual, 'classical' thing between earth and sky. 'Over the ground', finally, implies that the continuity of the ground is preserved; the building is placed on de-materialized stilts, and seems to exist in an abstract, 'cosmic' space.

"Now, there are three basic types of rising. Either the building is vertically 'open' and joins the sky in a 'free' and serrate silhouette, or it is 'closed' as an individual body by means of a heavy entablature or voluminous roof, or it is simply delimited by a neutral horizontal line which gives emphasis to lateral extension."

Christian briefly paused, selected his cup in a gentlemanly way, and raised it to his yearning dry lips, taking an ever so gentle sip from its rim. He held it there a few moments as the sweet aroma filled his senses, before lightly placing it back on the foldaway tray. It was then that he continued,

"the basic types of opening depend on the conversation or dissolution of the continuity of the boundary. In any case the result is determined by the size, shape and distribution of the openings. It is thus possible to create a 'romantic' interplay between exterior and interior by means of irregular and surprising transitions; or a clearly defined communication where inside and outside preserve their distinct identities; or an abstract, systematic integration where the two domains seem made of the same extended 'substance.' Among all motifs, the window is particularly important. It does not only express the spatial structure of the building, but also how it is related to light. And, through its proportions and detailing, it participates in the functions of standing and rising. In the window, thus, the genius loci is focused and 'explained.' 171

\footnotetext{
${ }^{170}$ Norberg-Schultz, Genius Loci, 177.

${ }^{171}$ Norberg-Schultz, Genius Loci, 179.
} 
"Finally, theme and variation is in fact a basic means of artistic concretization. The 'theme' represents a general complex of meanings, and the variations its circumstantial realization. Such themes may be a particular type of building as well as motifs of critical importance.

"Moreover, an interpretation is always open to individual variations. This allows for the expression of individual identity within a system of manifest common meanings." 172

"This cannot be stressed enough," Bobby responded, "Michael Ling mentioned this to me often. 'We take from them something of what was left behind by a previous writer and we in turn leave something behind, a faint outline of ourselves where we have paused for a moment, a deposit of sand from our shoes, and in the process carry away new sand to someplace else. ${ }^{173 \%}$

"That is a wonderful end to the story," said the youthful other to the white bearded one.

"Sure is," the white bearded one carefully said, "however, I don't think it was intended as an ending."

It occurred to Bobby that this conversation with Christian had led him to appreciate some of the possibilities for working with the stories offered by Darlene and Tom. Those two gave him hints as to what stories had to be told for Aboriginal peoples,

\footnotetext{
${ }^{172}$ Norberg-Schultz, Genius Loci, 180.

${ }^{173}$ Ling, "Between the Tongue and the Teeth," 23.
} 
especially those living in the city. The architectural explorations offered by Christian this evening, would allow these stories to be part of the building and the city as a whole.

\section{$\underline{\text { In the Land of Stories (and Architecture) }}$}

"Stephen, this is a grad student I am working with from the faculty of architecture," Derek introduced Bobby to his long-time friend. "He is exploring architecture's relationship with stories, and in this case, First Nations' stories. As you are a storyteller yourself, I think it would benefit Bobby to have a sit-down with you."

Two weeks later Bobby arrived at Stephen's museum office. ${ }^{174}$ Stephen Augustine was of Mi'kmaq decent, a Northeastern Indigenous culture. He was an elder, a storyteller, and a curator of ethnology at the Canadian Museum of Civilization, where both Derek and he worked.

"I've read your paper on architecture's role in storytelling," Stephen commented, referring to Bobby's paper he wrote for his class with Derek. "It has always been a curiosity of mine as to how architecture may achieve this. Being a storyteller, the place where stories are told is of great importance. I think embedding stories in architecture is also culturally appropriate. I see architecture not so much telling the stories however, but perhaps referring to them, or initiating them."

Interesting, Bobby thought to himself.

\footnotetext{
${ }^{174}$ Stephen Augustine, elder, storyteller and ethnographer, interviewed in person by the author on 3 September 2004.
} 
"Are you familiar with stories embedded in the landscape?" Stephen was about to describe a story he heard once given by Margaret Bruchac. She was an ethnographer, of First Nations descent, who had done some studies on Earthshapers and Placemakers, and their place within the natural landscape. "I will tell Margaret's story to familiarize you:

"She said, the physical landscape of Algonkian Indian homelands in the territory now known as 'North America' includes ancient mountains, rifts, and valleys; innumerable lakes, springs, rivers, and wetlands; fields and forests; and scatterings of mounds, rock piles, rocking stones and other natural formations that decorate the contours of the land. The Western Abenaki peoples call this place 'Ndakinna,' a term that defines our communal relationship to 'aki,' 'the land,' the place where the deep-time stories of the ancestors reside. ${ }^{175}$

"Now you must understand in Algonkian Indian cultural beliefs, time is cyclical rather than linear, measured in seasons and generations that do not necessarily follow a developmental timeline. Symbolic narratives and esoteric knowledge concerning the past are transmitted at particular times and places. For concrete evidence of the past, and the place of Native peoples within it, one need only look to the landscape, to see the work of mythical beings who, in ancient times, shaped significant places. This is how she began," 176 Stephen remembered the previous storytelling.

${ }^{175}$ Bruchac, "Earthshapers and Placemakers," 2.
${ }^{176}$ Bruchac, "Earthshapers and Placemakers," 3. 
A little background information, you may or may not already know:

Judeo-Christian traditions see the landscape as an inanimate world, created by one God and placed under the care of human beings. Scientific theory shows the world as acted upon by the laws of physics, and geomorphological changes over time. In Algonkian traditions, the animate and inanimate worlds, including humans, other creatures, and the land itself, exist in a constantly negotiated set of reciprocal relationships. This was the background she told. ${ }^{177}$ It was also the background told by Vine and Daniel, the philosophical North American explorers.

"One body of Native oral traditions in particular - 'earthshapers' or 'transformer' stories - references ancient events like glaciation, species evolution, and climatic change, encoding those events in mythological motifs," 178 Stephen recited. "She said, sites exist where individual and communal activities take place, and suggests continuous use of a familiar landscape over a long span of time. This allows for change and continuity over time, as people preserved knowledge of past events in local oral traditions, while adapting to a changing ecosystem and climate."179

"Learning through observing. Vine spoke of this often," Bobby needed to reassure.

"I also know of this," Stephen acknowledged Bobby's comment with a grin. "As I remember her saying, Algonkian oral traditions reflect a spiritual world that is imbued

\footnotetext{
${ }^{177}$ Bruchac, "Earthshapers and Placemakers," 4.

${ }^{178}$ Bruchac, "Earthshapers and Placemakers," 2.

${ }^{179}$ Bruchac, "Earthshapers and Placemakers," 6.
} 
with life, sentience and potential power. Within the context of a story, a character, or even a part of the natural world, might transform in both physical shape and animacy. However, under the pressure of expanding settlement, assimilation, and language loss, Indigenous stories began to suffer from the disintegration of the original community, cultural context, and performative space that had shaped them."180

Bobby knew Stephen was talking about the natural landscape.

Stephen continued as she had, "Algonkian stories that have survived resonate with, and record, historical presence, and provide the background, frame, stage, and context for the material world. Some of the oldest oral traditions, describe how ancient beings left physical traces, by marking the landscape with their footprints, reshaping natural earth formations, carving out rivers, doing battle with superhuman elementals and molding giant megafauna down to their present size. These 'transformers' and 'earthshapers,' as mythological dramatis personae, are identified with specific local landforms." $" 181$

"How storytellers told stories within a surrounding landscape. This same landscape was the one referred to in the story itself," Bobby clarified.

"Yes, yes. She then described Keith H. Basso's observations about Apache traditions. He told her, 'landscapes are always available to their seasoned inhabitants in other than material terms. Landscapes are available in symbolic terms as well, and so, chiefly through the manifold agencies of speech, they can be 'detached' from their fixed spatial moorings and transformed into instruments of thought and vehicles of purposive behaviour. Thus transformed, landscapes and the places that fill them become tools for

\footnotetext{
${ }^{180}$ Bruchac, "Earthshapers and Placemakers," 7.

${ }^{181}$ Bruchac, "Earthshapers and Placemakers," 8.
} 
the imagination, expressive means for accomplishing verbal deeds, and also, of course, eminently portable possessions to which individuals can maintain deep and abiding attachments, regardless of where they travel. ${ }^{, 182 "}$

“ 'Keith Basso's book Wisdom Sits in Places brilliantly documents the extent to which Western Apache history is less about time than places, or what might be called a sense of place, ${ }^{183}$ " Bobby remembered Daniel saying on one of their voyages. Bobby continued, "Landscape provides the context for stories to be told in. This is how the landscape initiates stories. Landscapes themselves transform into the tools generating specific associated stories to be told within it."

Stephen said, "As she said, verbal histories need not be static, unchanging fossils; when circulating freely within a Native community, they become part of a frame of reference that shapes how the community views itself in relation to the modern world. In recent decades, traditional stories have been tapped as source material for a wide variety of creative endeavours, including novels, poetry, art and film. The reanimation of stories in contemporary contexts, like the re-use of ancient objects in ceremony, ensures their survival by making them relevant to the moment at hand. ${ }^{184}$

"This is how 'earthshapers' and 'placemakers' shaped the world and how their stories are embedded in the landscape that surround their people. Lakes, mountains, rocks and rivers serve as the tangible evidence of the Native past, and these echoes of the

\footnotetext{
${ }^{182}$ Bruchac, "Earthshapers and Placemakers," 9, referring to Basso, 1988: 102.

${ }^{183}$ Deloria and Wildcat, Power and Place, 75.

${ }^{184}$ Bruchac, "Earthshapers and Placemakers," 9.
} 
Paleolithic, in reanimated form, also stand as guideposts for Native people living in the modern world. This is how she told it. This is the end of the story."185

The urban environment is this new landscape, once transformed, becomes the 'tool for the imagination, the expressive means for accomplishing verbal deeds, and eminently portable possessions to which individuals can maintain deep and abiding attachments, regardless of where they travel. ${ }^{186}$ Just as the natural landscape initiates stories, so will the urban landscape. Architecture will initiate stories.

"There are two specific stories that I feel need to be told in urban centres," Stephen was now specifically referring to the Gathering project. "These stories could be considered Pan-Indian, because they deal with issues relating to several tribes living in urban centres.

The first story is regarding the relationship between elders and youth. There is a growing separation between the two, and youth in the city need to be re-associated with the teachings and stories of their elders.

The second story deals with Aboriginal people and good diet. Aboriginal people are being affected by the unhealthy diet they are consuming. This can lead to serious health problems such as diabetes. It is important that Indigenous people are re-introduced to a proper diet. These are two stories that come to mind."

Stephen had made the connection between stories and architecture. Bobby knew now, architecture would initiate stories rather than actually tell them.

\footnotetext{
${ }^{185}$ Bruchac, "Earthshapers and Placemakers," 18.

${ }^{186}$ Basso, "Speaking with Names," 102.
} 

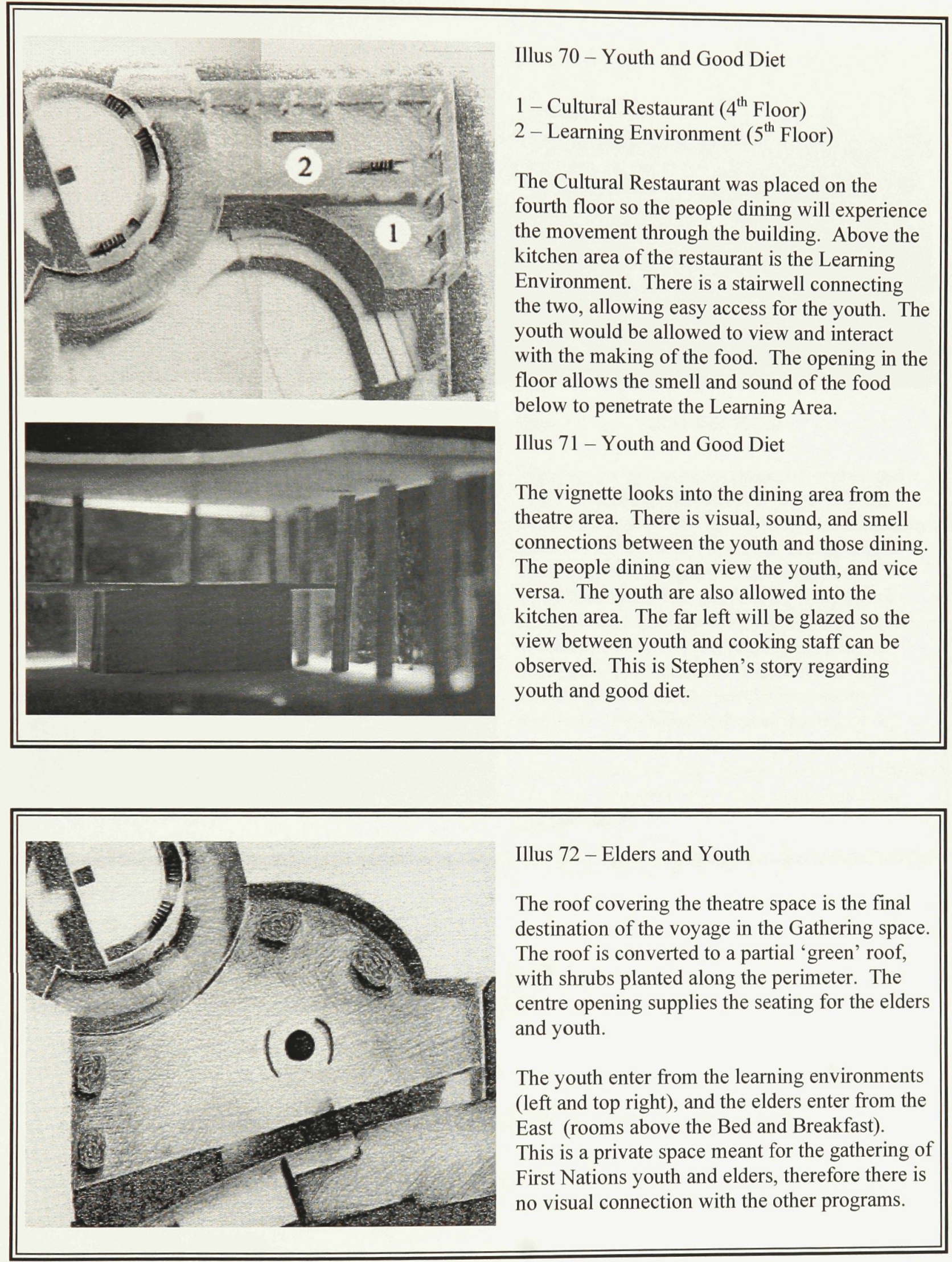


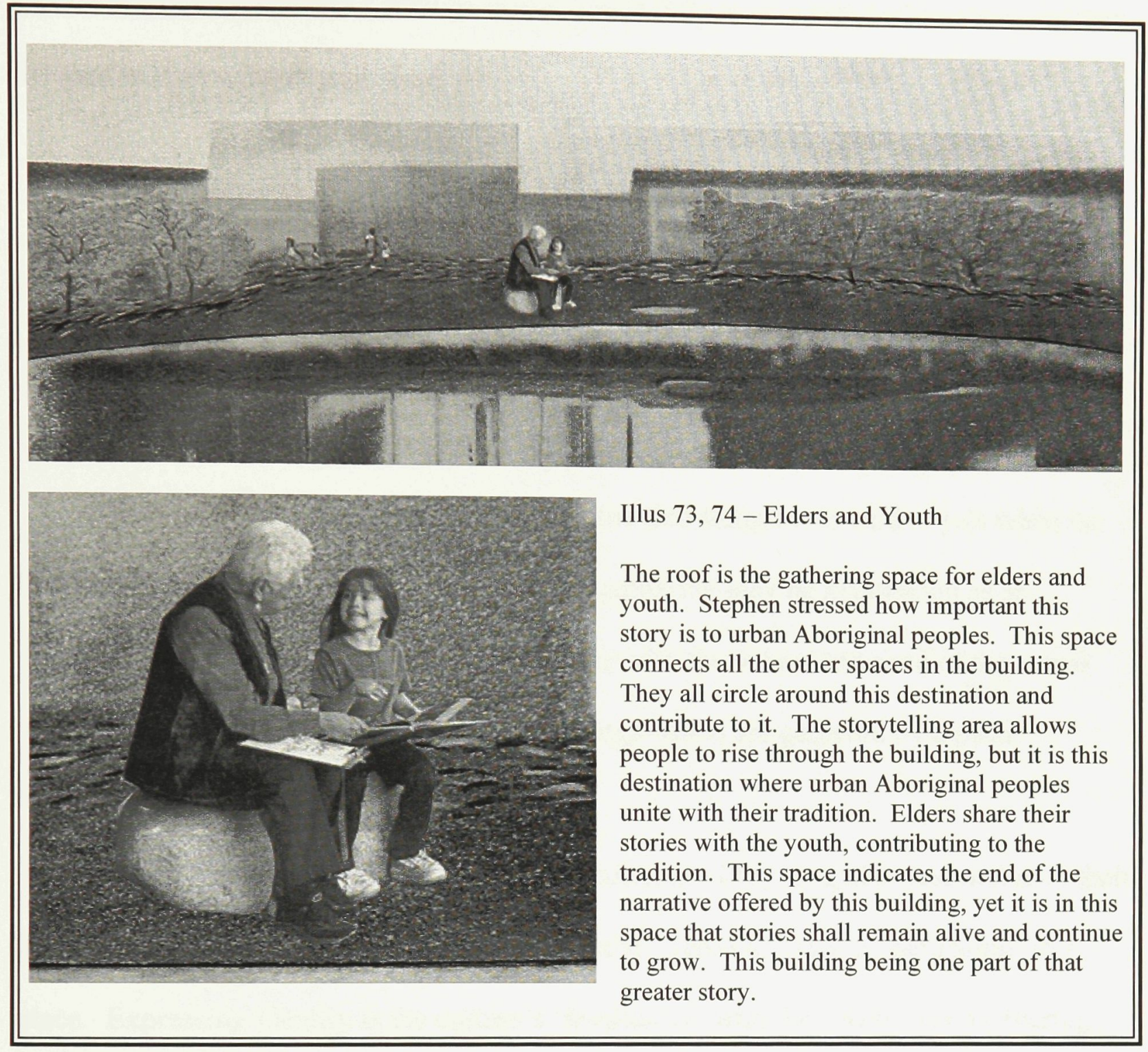

Program, Urban Design, Architecture, and Stories

"He's back," the white bearded one nudged the youthful other awake.

"So quickly," the youthful other yawned.

"I know, I know."

"Must be important this time. Always is." They were both snickering. 
Every conversation Christian hosted made little to no sense to these two, yet they listened half amusingly each time.

Christian walked up to greet Bobby as he boarded the train, purposively ignoring the two who spent too much time on the train. "Back for another story I see."

Bobby and Christian sat down, preparing for another interesting segment. Christian's stories were always interesting.

"I thought we would start by restating the first thing I ever said to you when we first met," Christian began this story. "Urban gathering may be understood as an interpretation of the local genius, in accordance with the values and need of the actual society. In general we may say that the meanings which are gathered by a place constitute its genius loci." 187

"Any urban centre constitutes several cultures. They all gather and maintain their own identity, however a sense of place must exist. Sense of place is 'belonging' to a place. Expressing identity is the culture's 'familiarity' with the space. The Gathering space will respect and belong to Saskatoon, and the stories embedded within the architecture will be First Nations in nature," Bobby clarified to himself.

${ }^{187}$ Norberg-Schultz, Genius Loci, 170. 


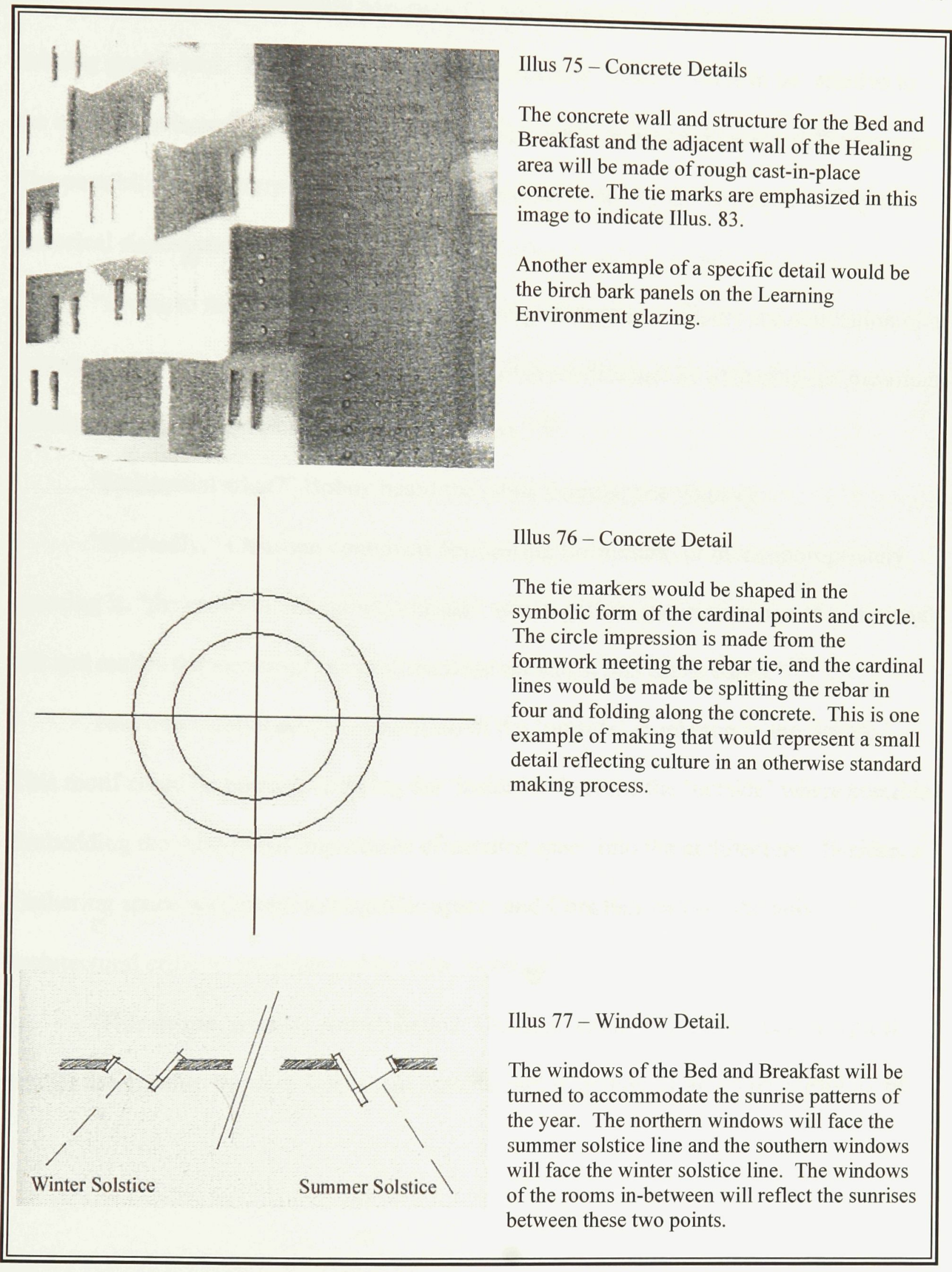


"Yes there are definitely two parts," Christian replied. "Firstly though, the existing genius loci. The man-made place has to know 'what it wants to be' relative to the natural environment. Such a correspondence can be achieved in many different ways. The possibilities of interpretation are evidently determined by the site itself and by the historical circumstances. ${ }^{188}$

'I refer to this interpretation as 'creative participation.' Firstly the realization of a private 'inside' which concretizes the identity of the individual by gathering the meanings which constitute his personal existential context." ${ }^{189}$

"Existential what?" Bobby heard the white bearded one whisper.

"Secondly," Christian continued not hearing the remark, or more appropriately, ignoring it, "the creation of a public 'outside' which gathers the institutions of communal life and makes the meanings (values) manifest on which this life is based."190

Tom had mentioned the importance of the 'outside' in relation to the 'inside.' This motif could be blurred, allowing the 'inside' to become the 'outside' where possible. Embedding the Aboriginal importance of exterior space into the architecture. Besides, a Gathering space was meant to be public space, and Christian was not the only architectural critic to associate public with 'outdoor.'

"This theme, creative participation," Christian explained, "consists in a typical spatial relationship between inside and outside, and in certain locally meaningful motifs.

\footnotetext{
${ }^{188}$ Norberg-Schultz, Genius Loci, 180.

${ }^{189}$ Norberg-Schultz, Genius Loci, 182.

${ }^{190}$ Norberg-Schultz, Genius Loci, 182.
} 
To respect the genius loci does not mean to copy old models. No, it means to determine the identity of the place and to interpret it in ever new ways."191

Saskatoon had a charm all its own. Often Saskatonians referred to it as the "city of trees and bridges'. In comparison to most places in central Saskatchewan, this was true. There were an enormous number of trees in Saskatoon, more than the Plains would have ever left known. As for bridges, it definitely had a fair few, although as some know, the landscape gets its value through bridges. ${ }^{192}$

Saskatoon was flat for the most part however, like all valleys cutting small gouges in the earth, the river offered a likewise decline in elevation. The skies were powerful, as was the wind. This was well known. The people on the other hand, were who they were, and the politics of the area often shaped them as such. With all the socialist values embedded in its people, conservative minds stood strong. The people really had no idea, simply teetering from one end of the spectrum to the other; unsure of what side of the story they wanted to believe.

In all its simplicity Saskatoon was a gem, a peaceful little place where the only big lights shine from the gigantic sky, dancing far into the North. Stories embedded in every star, field, and sunny day. Stories were the people, the landscape, the skies, the cold, cold, miserably cold winters. Everything there existed through stories; through the stories he shared in Australia; through the stories he brought home with him; even through the stories he would always carry with him, reminding him of the small Prairie town he grew up in. Stories are all any of us are, this story Bobby had come to believe.

\footnotetext{
${ }^{191}$ Norberg-Schultz, Genius Loci, 182.

${ }^{192}$ Norberg-Schultz, Genius Loci, 18.
} 
"Economic, social, political, and cultural intentions have to be understood within the natural landscape," 193 Christian continued his story. "We have to be able to 'see' the meanings of the things that surround us; be them natural or man-made. Things always tell several stories; they tell about their own making, they tell about the historical circumstances under which they were made, and if they are real things, they also reveal truth." 194

As I read this I began to smile. I knew Aboriginal peoples already knew this. This was something familiar and recognizable. All things reveal stories. All things initiate stories. Like the landscape, architecture would provide a new context where stories would be shared. An urban gathering for all, where stories from all cultures would come together and embed themselves in the heart of Saskatoon.

${ }^{193}$ Norberg-Schultz, Genius Loci, 182.
${ }^{194}$ Norberg-Schultz, Genius Loci, 185. 


\section{Part 3:}

\section{The Thunderbird House, Winnipeg, Manitoba}

The Thunderbird House is a project destined for gatherings. Considered to be a holy space, similar to any church of the Judea-Christian heritage, respect is a certainty. Tom Monteyne, an old professor of mine, describes, "soon the leaders began to dream of a place where the first people who lived in the city could gather. From the language of the Cree, they chose the word 'Neeginan' which means 'our place,' to describe their vision. The elders summoned the shaman known as Cardinal to draw two lines on the ground. He drew a circle around a fire at the centre. He made doors where the lines cross the circle. The elders were provided with comfortable seats near the fire."195

There are a few striking points regarding this story Tom Monteyne told. Firstly, it was a story about the gathering of people, 'a hopeful fable of downtown Winnipeg's rise, fall and eventual renewal with help from the city's First Nations population;" ${ }^{196}$ a likely little fable indeed, spawned by the assembly of a gathering space in the heart of the city. Sound familiar? I still remember it being built in Winnipeg. I was in my last year of architecture school there, a few months before taking off to Australia.

Secondly, my friend Dave helped Tom Monteyne write this story. Don't believe me, look at the credits on the article. Dave was one of the few Aboriginal architecture students in our class. I believe there were only two or three Aboriginal classmates. We 
were fortunate, because that was more than what most years were privileged of having, even in Winnipeg, with the large Aboriginal population that lives there, or nearby. As I've mentioned so many pages ago, David holds close ties to his traditional background. He was a good choice in supplying a cultural context for this story.

Thirdly, you may have noticed, the Cardinal team designed this building. Yes, Bret and his father created one of the first gathering spaces in North America, in one of the cities that needed it most. It is not their most acclaimed work, and there have been mixed reviews, but isn't that always the case? Form is not what is important in this building, or what I want you to be looking at. The stories embedded within it are. Like the one about the grand opening that Bret told me so long ago. It goes like this:

'The grand opening of the Thunderbird House was a funny incident,' Bret began, after I asked him about placing a constant fire in my storytelling space. 'We had to place large mechanical systems in the roof so the central fire would rise and exhaust outwards.' I knew the symbolic gestures of rising smoke, connecting earth and sky, an important story to be told. 'The smoke exhausts in all four directions, which I thought was another nice link back to culture.' Those four directions are important. 'They asked me if they could light a fire for the opening ceremonies, and of course I encouraged them, confident in the building. They began bringing in wood from outside. The first few loads I didn't think nothing of it. But they kept bringing in more and more wood and placing it over the hearth. The pile was beginning to rise extremely high, and this is when I began to get nervous. I thought they wanted a fire; not a warning signal! When they lit it, I was sure the place would get smoked out. I mean this fire was huge! Inside a building yet.' Bret was nicely shaking his head at this point in the story, remembering his outright concern 
for the safety of the people inside the building. After all, it was to a small extent his responsibility. 'Nevertheless, the mechanical systems worked fine, so unless you plan to light the building on fire, I can't see it being a problem. I still can't get over the size of that fire though.'

I finally decided to see this precedent in person, after I knew a few things about stories, that is. Downtown Winnipeg is similar to Saskatoon, however, this gathering space was located on what might be considered the 'other side' of downtown. Very few business folk made it this far down North Main. I made the trek however, one October afternoon. Main Street is the major street in the area, and all the surrounding buildings made their front entrance home to it. Except the Thunderbird House. There I am, trying desperately to get in, but the doors at that entrance were locked. Was the building closed? Why were there people inside? I tried the doors again. They were definitely locked. I waited patiently outside hoping someone would see me. It was a little cold for October, I thought. Then I saw a path leading around the circumference of the building, (circumference, because the building was a circle, remember) and just like Alice, ${ }^{197} \mathrm{I}$ followed it.

As I approached the side entrance, I saw another door. May as well see if this one is locked too, I thought to myself. It sure was. So back to the happy dirt trail I be. There were a few large rocks bordering one side of the path on this next segment of the adventure. Isn't this curious, I thought. Then it dawned on me. I suppose I didn't know those stories as well as I thought. These were the grandfather stones Bret had told me

${ }^{197}$ Referring to Alice in Alice's Adventures in Wonderland. 
about. Ancestors greeting the people as they approached the front entrance. I was trying to enter the building from the west, then the north, and of course, the next door proved to be the right one. The little dirt path had brought me around the building, my right arm always to the inside, directly to the Eastern entrance, the first stories I ever learnt on this journey.

The Thunderbird House was a gathering and holy place. Ceremonies were held there quite regularly. The building was a large, open, round room with offices bordering the perimeter. A multi-use space that Sustainable would be so proud of. Certainly she had the help from Adaptable on this one. I recognized the story behind the four entrances and windows, each located on a Cardinal point. During ceremonies, the participants must see outside in all four directions. That is known.

I wasn't particularly interested in the program of the building, or the formal expression. The Gathering space's program in Saskatoon had a very different context to respect and different people to attract. Formally, I felt the building looked too much like a Thunderbird to be of much help. I came to see how the Cardinals had used the architecture to initiate stories. Those wonderful tales embedded in that new landscape, waiting to be shared by the people occupying it, like the one about the front entrance; or about the gathering space; the one about the grandfather rocks; the one about the fire. They are yours, go experience them for yourself. Myself, I had one more story to find. In the centre of the round room was the circular floor covering, indicating the fire pit below. As I approached it, Bret's story filled my bright eyes and wide smile. I stopped at the edge of the cover, and looked way up. Yep, there they were. 


\section{$\underline{\text { Reuniting with David Thomas, Winnipeg, Manitoba }}$}

"I saw your last name on the phone, and thought who else has that last name," Dave spoke excitedly.

"I suppose my sister does," I replied, calling from her place.

Dave and I met the next day. ${ }^{198}$ He was starting his thesis on urban Aboriginals; I was finishing mine. We had a fair bit to discuss. The last time he heard from me, I was in Australia. Almost four years later he received a random phone call from an old classmate with an apparently distinct last name.

We decided to talk about architecture that day, but that is not a surprise. We also talked about Native culture, once again not a surprise. The only surprise may have been his responses to our discussion, but that really wasn't much of a surprise either. I knew Dave and the serious designer he was. He taught me so much about architecture in my undergrad years; supposedly I taught him so much about music; perhaps that was a fair trade.

Dave was working on a project for the reserve council in Winnipeg at the moment. All of the reserves in Manitoba had a representative on the committee that hired Dave to design the council building. They had asked him to design it in the shape of a

\footnotetext{
${ }^{198}$ David Thomas, Master's of Architecture student at the University of Manitoba, interviewed in person by the author on 29 September 2004.
} 
turtle. This was a great dilemma for Dave, being an architecture student and Aboriginal person. He knew the importance of the circle and symbols in his culture, but school taught him to be careful around literal representation. Tom King knew this story. Well, Dave decided to 'deconstruct' the turtle. When he was done, he had one arching wall running the length of the building, faintly representing one side of the body of the turtle. The rest of his building appeared to be a modern Patkau. ${ }^{199}$ When asked why he deconstructed the turtle he replied, "Would you make a cathedral in the literal shape of an apostle or saint?" "Good answer," I told him.

What was interesting about the building however, were the details or motifs. Dave opened the ground floor, wrapping most of the exterior walls with glass. This connected the interior with the exterior, emphasizing the connection back to nature, especially when councils gathered, an important story I am told. The materials chosen were also appealing. The majority of the building used steel, wood and glass, but the few moments when the building connected to the ground it was stone. I stressed how important these moments were, and it wasn't until I showed Dave my first proposal for the Gathering space that he understood what I meant. Even certain details (railings for example) were given special thought as to materiality.

Dave's primary goal in this building was to break away from the literal representations of Aboriginal building precedents. He was tired of seeing his culture represented so artificially; to him it was so much more than a symbol. Even Sustainable's friend Technology he veered away from. The same Technology that convinced so many other architects of its importance in First Nations' buildings. Dave

${ }^{199}$ Reference to Patkau Architects. 
felt he didn't live a sustainable life (ie. technologically speaking) so why should he focus on it in his designs. Little did he know, but living in an old 800-1000 square-foot home in downtown Winnipeg was as sustainable as anything else. He missed some important stories regarding Sustainable, I guess.

Dave was becoming the role model in Aboriginal culture that I always knew he would be. He always held those close ties to his family, even when it was difficult; that I did know. However, on that day, when we went to revisit the Architecture faculty at the University, just to see what we could find, he picked up a friend. David made that special trip to help move some studio supplies for a third year Interior Design student. She happened to be from the same reserve as him. I found out later that his parents welcomed several young adults over many years into their home, from their reserve, to help them with that difficult transition into the urban centre. The sense of community never ceased. It was only through responsibility and respect for family and community that this hospitality remained alive. I only share this to show a real example of how connected community and family are in traditional Native life.

The third year Interior Design student laughed when I asked her how she knew Dave, "Oh you mean the poster boy." Yes, I saw Dave on television and didn't even know it. He had grown his hair long, so I suppose I had an excuse. He was a poster and commercial boy for APTN, the Aboriginal Peoples Television Network. He ran into this by chance one day, bringing his daughter in for an 'extra' part; and who better? He was successful. He knew his traditional ways. He would be an influence for the several younger generations living in the urban centre, whether he liked it or not. 
Vine recognized this responsibility, as did Daniel. On one trip they told me, "We can characterize modern Indian students as fulfilling the function of scouts in the old hunting culture. They did not direct tribal activities as much as they provided information upon which the community could act. Indian education from colonial days until very recently was conceived as producing individuals who could and would lead their people into American society's economic mainstream. While many of today's programs are still phrased in those terms, they are not the conditions under which Indian professionals will be helpful to their tribes in the future." 200

Dave would always be tied to his culture, and there was great responsibility in this. He was a role-model and a professional. As a professional architect, he recognized that he had to respect what school taught him. Otherwise he wouldn't have gone. As an Aboriginal role-model, he had to be careful how to use this education; it always belonged to the community. Vine said, "The final ingredient of traditional tribal education is that accomplishments are regarded as the accomplishments of the family and are not attributed to the world around us. We share our failures and successes so that we know who we are and so that we have confidence when we do things. Traditional knowledge enables us to see our place and our responsibility within the movement of history as it is experienced by the community."201 Dave's struggles with the Council building were perhaps examples of these issues Vine was talking about. Dave had to make his people see a new way of representing themselves in this new urban landscape. It respected his people and the profession he practiced. It was his responsibility.

\footnotetext{
${ }^{200}$ Deloria and Wildcat, Power and Place, 110.

${ }^{201}$ Deloria and Wildcat, Power and Place, 46.
} 
A few days after our initial reunion of sorts, I was able to share the Gathering space with David. His response to the design and thesis would be greatly valued, considering the respect I had for him.

"It appears that your building deals heavily with program," Dave commented. He was right.

He gave several examples of similar programs that were either proposed or existed in Winnipeg.

"I also see what you mean by how a building stands and rises. These architectural issues can exist as cultural issues," Dave again responded. I told him a few of Christian's stories.

"I especially like the fact it does not resemble typical Indigenous buildings, yet it refers to several Indigenous issues. And I love that front wall," Dave continued.

I then had to ask Dave whether he recognized certain stories in buildings, the stones from the Thunderbird House for example.

"Yes, the Grandfather rocks. I know that story well."

As we prepared to leave, we began discussing tipi and turtles again. We couldn't understand why so many Aboriginal peoples encouraged such buildings. I suggested what several told me; it reflects the culture's symbols.

"Well then we have to find new symbols," Dave said as he dropped me off. It was good to see Dave again. 


\section{Introducing Kyle Kennedy, Saskatoon, Saskatchewan}

Kyle and I met in Australia. Two boys from Saskatchewan traveled to the other side of the globe only to meet each other in Sydney. I lived with Kyle and a few others during my stay in Sydney, which lasted quite a few months. We became good friends; started drinking Scotch together, and entertained English after English backpacker moving through our congested little apartment. We shared similar stories from our youth back in Saskatchewan. But we never discussed Native people back home. It wasn't until later that Kyle shared some stories about his culture back in Saskatchewan after we

returned. I believe it was the night we showed one of our visiting English friends the Northern Lights.

"I am told, those lights are my ancestors and they have come out to speak to us," Kyle replied to the English girl's question. The four of us sat bewildered by the display the sky was performing that night. The Northern Lights are still my favorite thing about home.

Kyle knew many of these stories, the stories that existed around him, the way the landscape was a storybook, waiting to be read. So it didn't surprise him when I started discussing stories embedded in the landscape. No, he knew these stories well.

"I recognize the idea of stories embedded in the places one lives, so this makes sense. I also think something needs to be built on that site. Right now it does nothing for 
the downtown area," Kyle expressed his view. "I'm not too sure about that wall though."202

The same wall Dave loved!

This was Kyle's first exposure to the project, and I needed to see how he reacted. How far could people, a culture and professionals associated with the culture continue to benefit the design process? There was a point that I had to leave the help of others behind and focus on my abilities I obtained over the several years of architecture school. However, it is people like Kyle that initiated this story, and people like Dave; Aboriginal people who bury all preconceptions, yet must live them; Aboriginal people who are finding it harder to remember those stories, stories about Sustainable and the Northern Lights; people who move into urban centres, displaced from the familiar setting they always knew. It is much more than home, it is who they are. This story is trying to recognize some of those traditional stories and introduce a few new ones; to resurface Aboriginal stories in urban Saskatchewan, the new landscape where Indigenous people now find themselves.

"The colour of that wall really doesn't fit in with the Bessborough," Kyle continued.

"The colour?"

"Yeah the colour looks out of place."

"Well, I'll see what I can do about the colour."

${ }^{202}$ Kyle Kennedy, interviewed in person by the author on 14 October, 2004. 
I was a little amused. Colour was the last thing I thought he would point out. It was nice to see Kyle react to the stories the way he did, though. Hopefully - 'hope not for something in the distant future but hope in the sense of acting with the confidence and expectation that something good will happen ${ }^{203}$ - he will decide to share those stories. Hopefully so will others, and hopefully there will be people to listen. This is my story and I hope you enjoyed.

As the wise little Aboriginal man so often told me, "Help yourself to my story, or one of the several stories inside of it. It's yours. Do with it what you will. Tell it to your children. Turn it into a play. Turn it into an architectural thesis. Forget it. But don't say in the years to come that you would have lived your life differently if only you had heard this story. You've heard it now."204

${ }^{203}$ Deloria and Wildcat, Power and Place, 13.

${ }^{204}$ King, The Truth About Stories, 119. 
Part 4:

Approaching a Place for Gathering

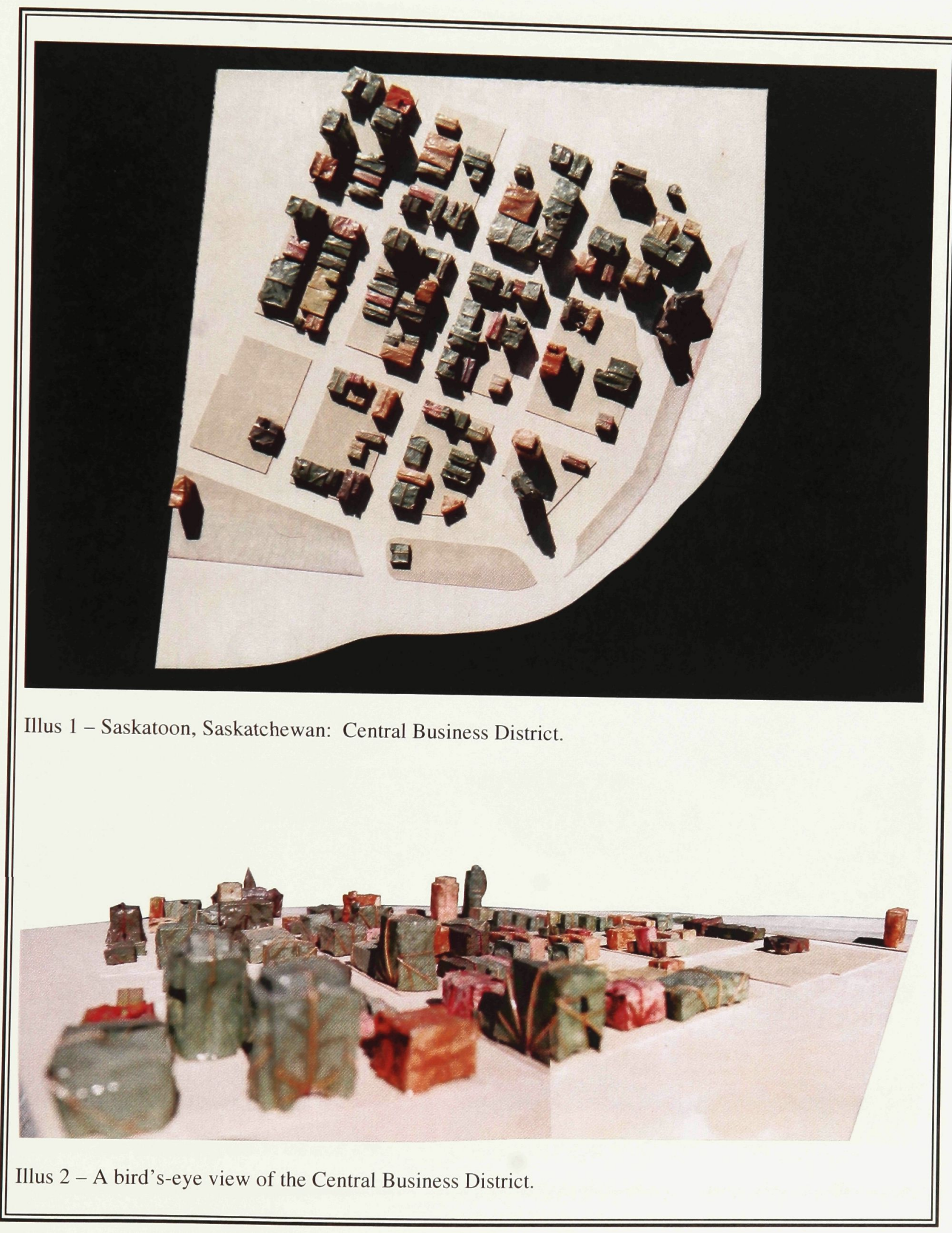




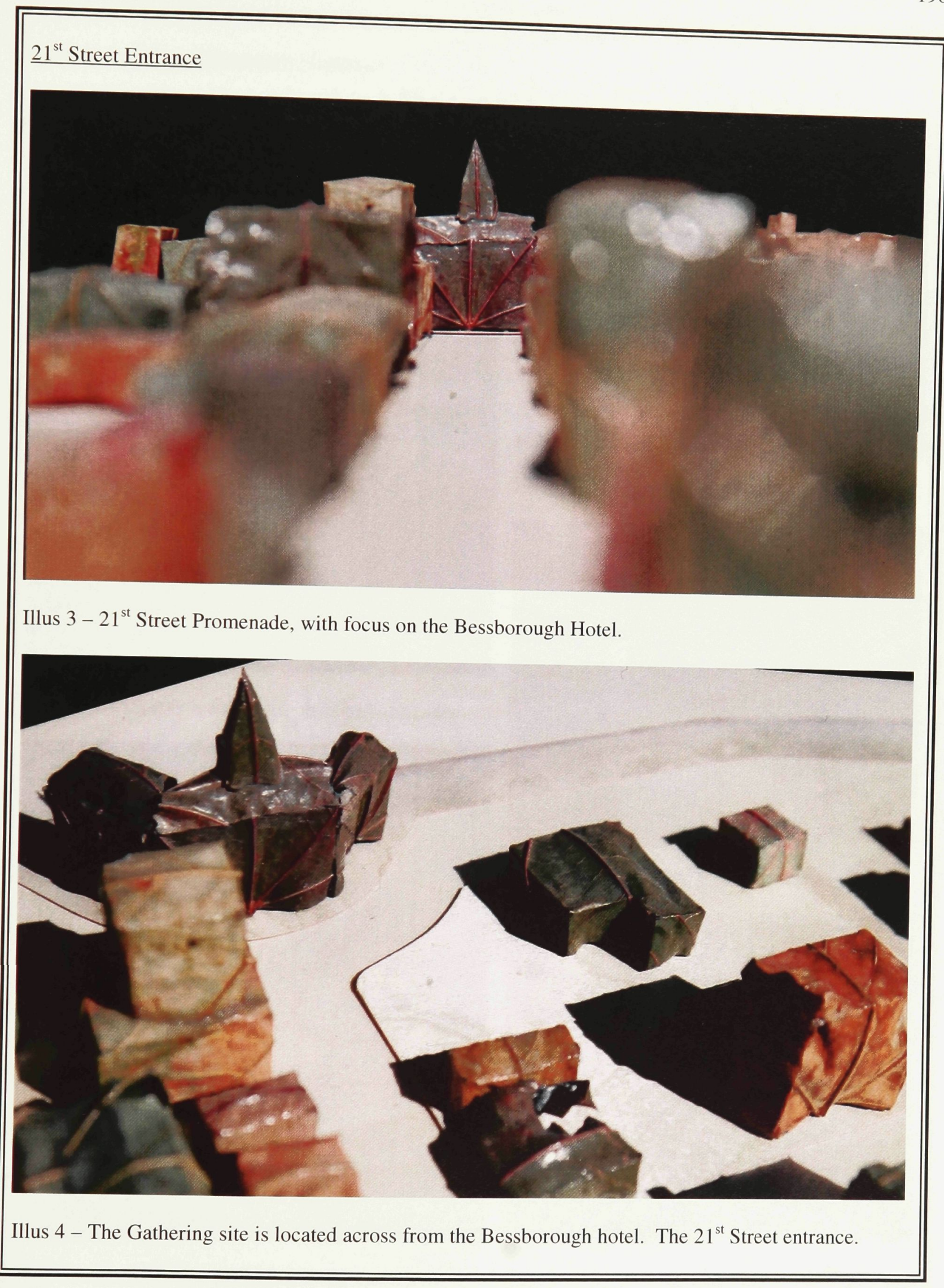


Alleyway (Urban-Community) Entrance

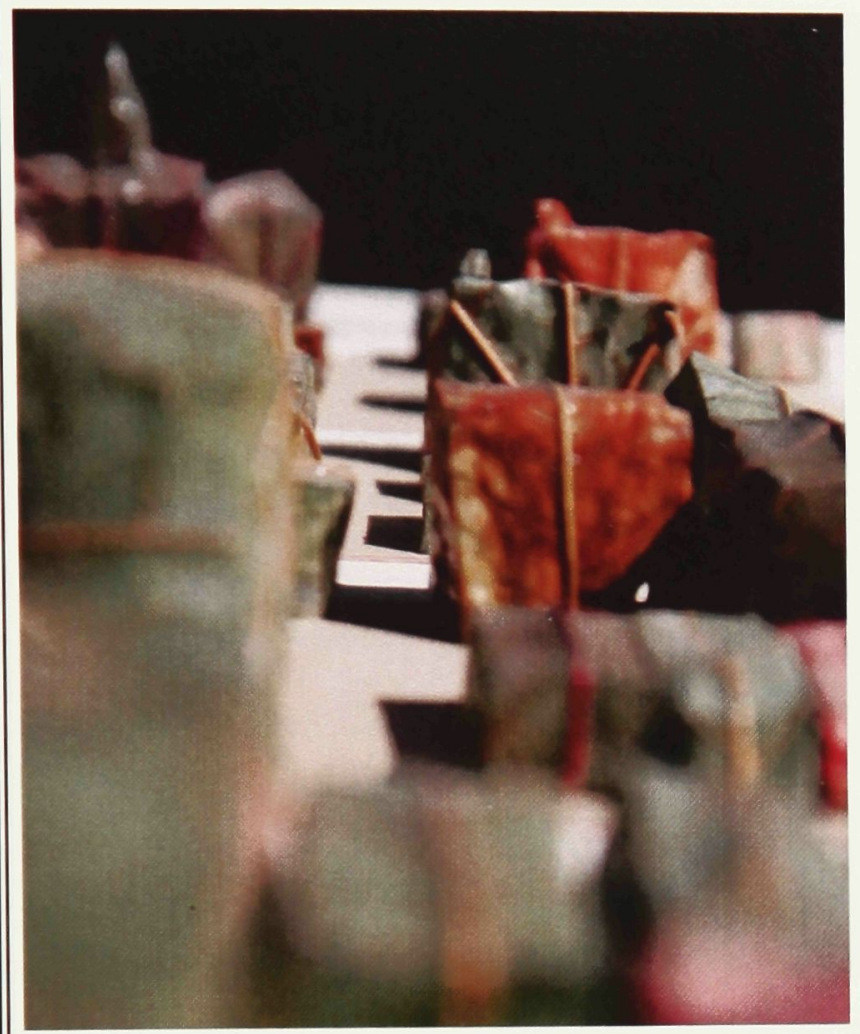

Illus 5 - Alleyway leading into the Gathering site.
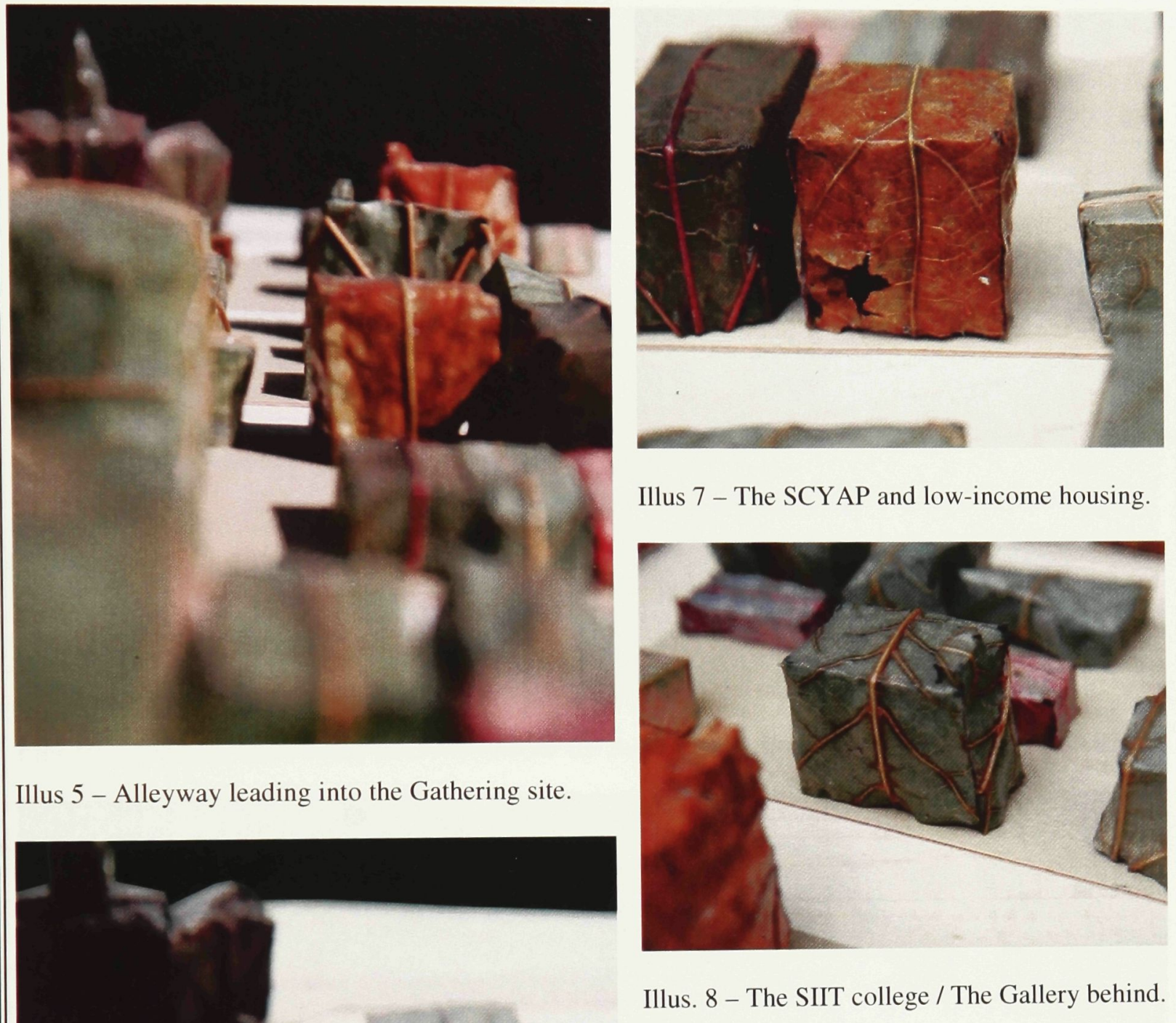

Illus 7 - The SCYAP and low-income housing.

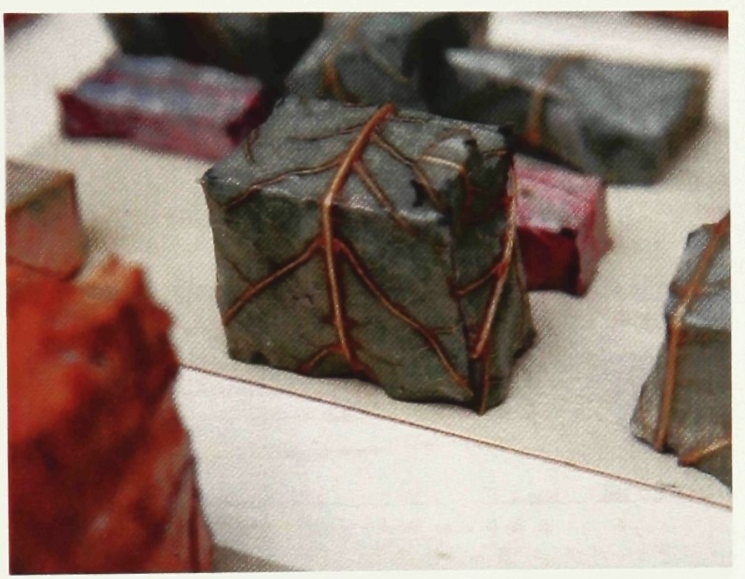

Illus. 8 - The SIIT college / The Gallery behind.
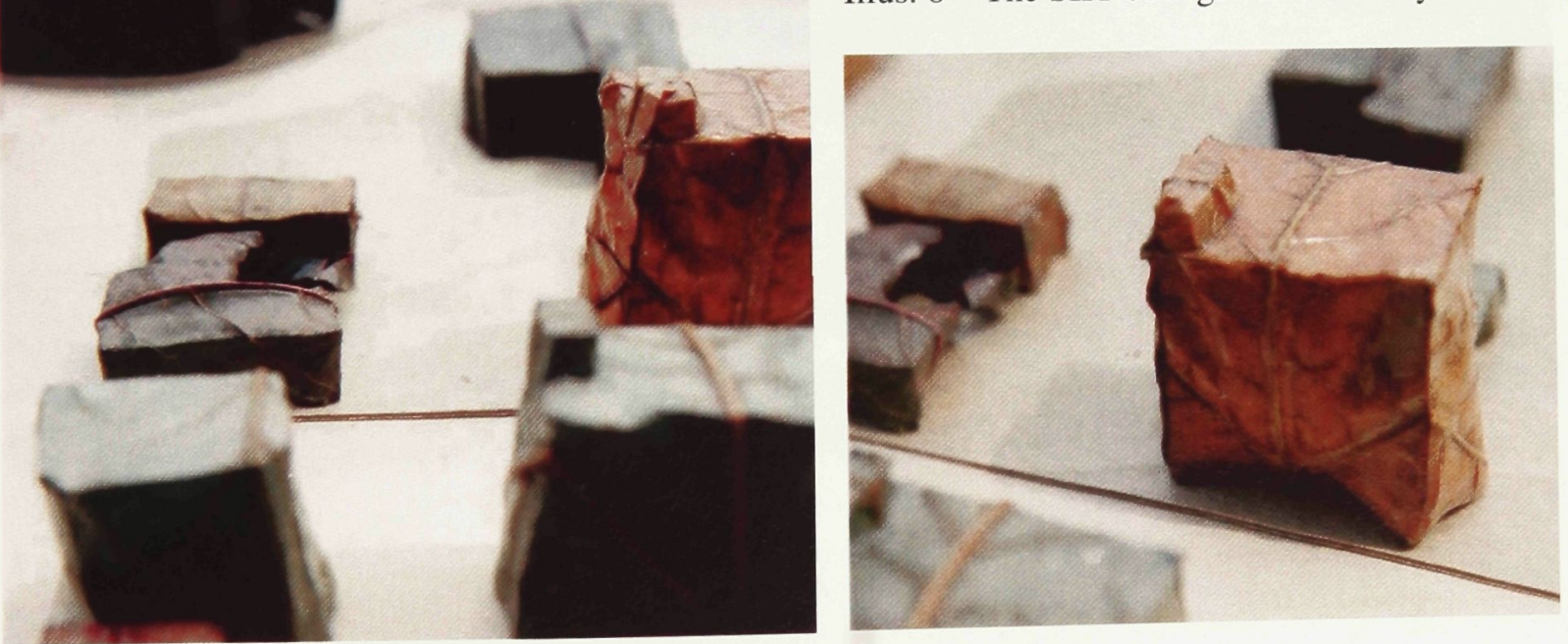

Illus 6 - The alleyway extends into the Gathering site resulting in the Urban entrance.

Illus 9 - The First Nations Bank. The Gathering site behind it. 


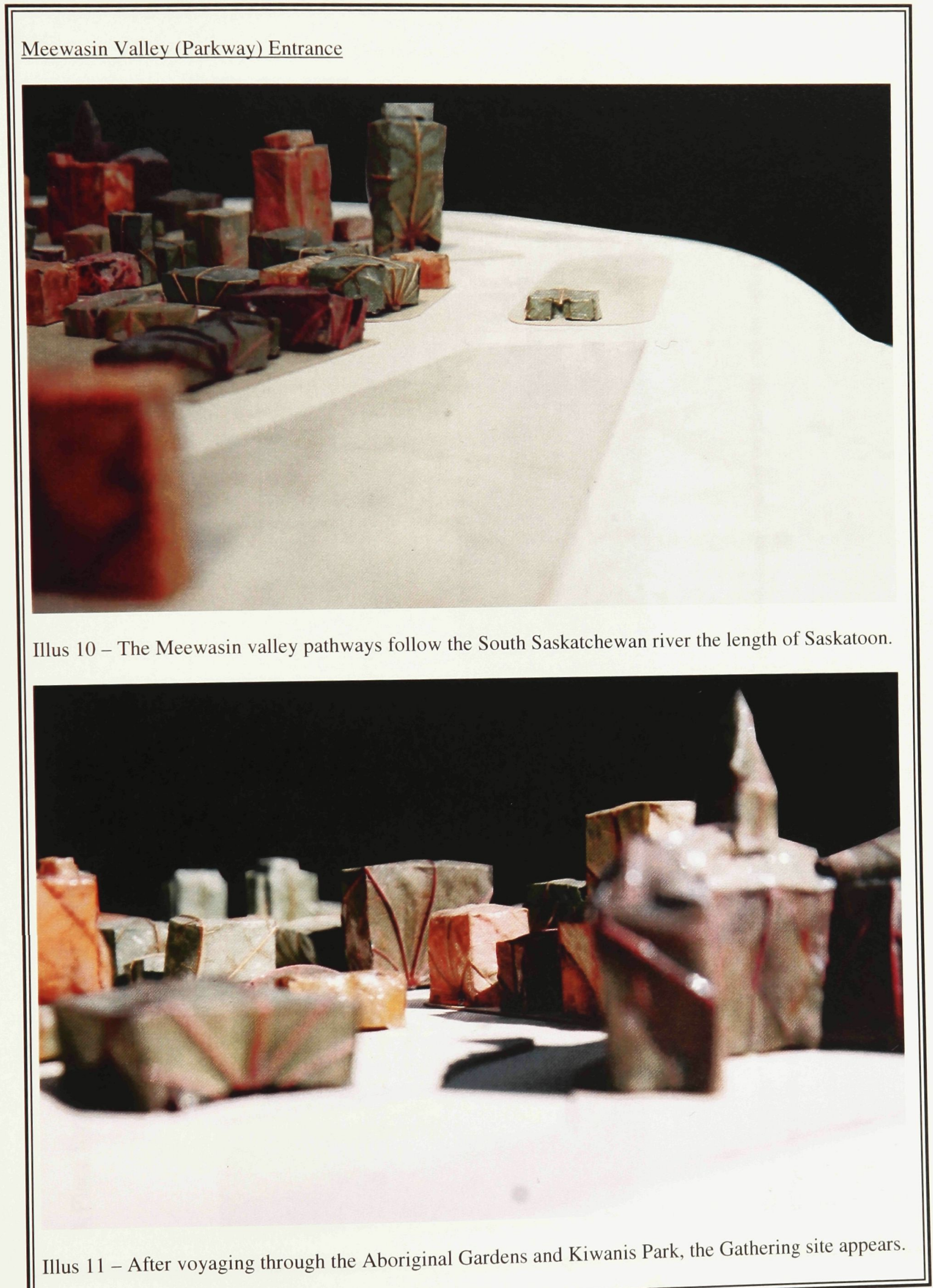




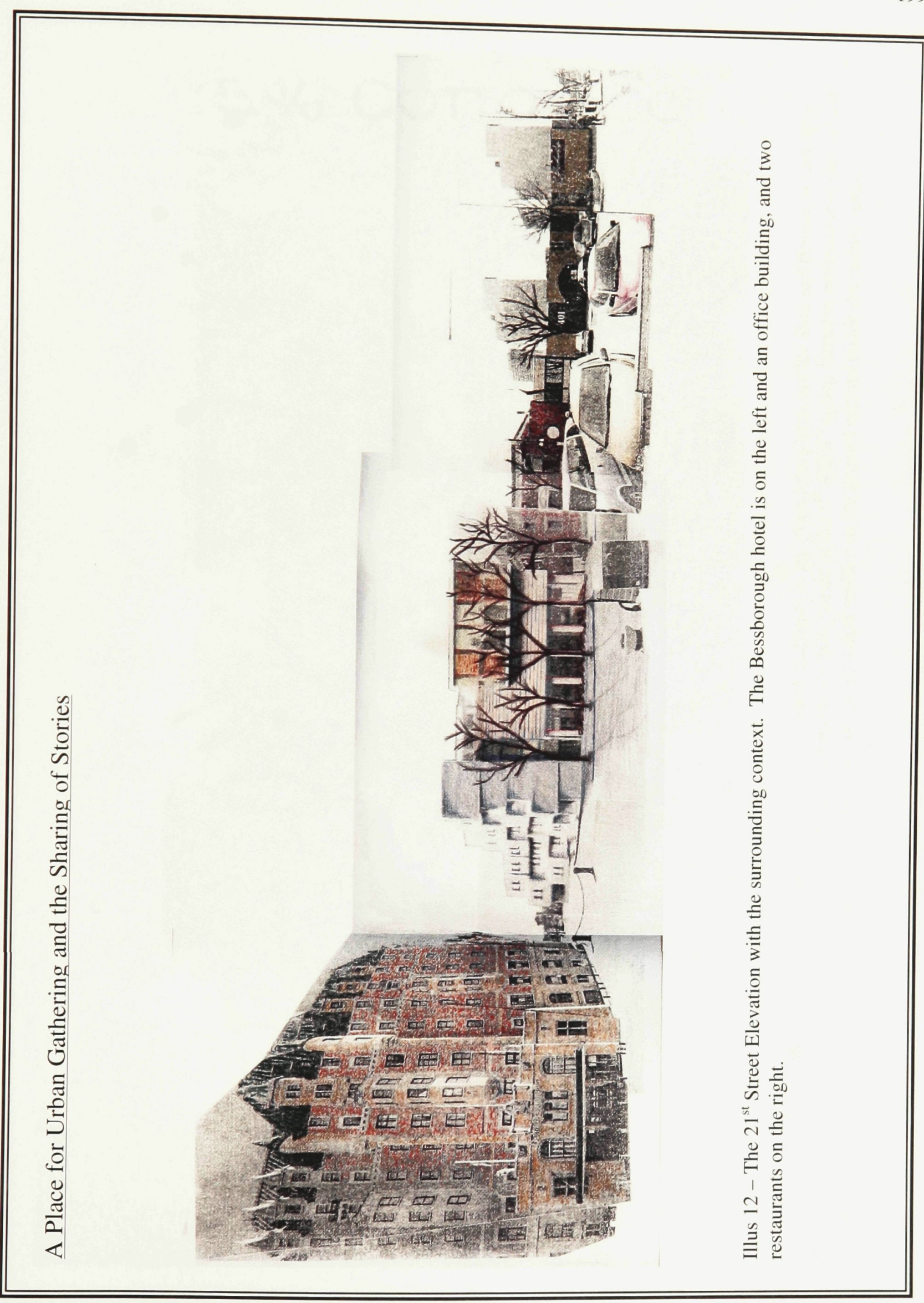




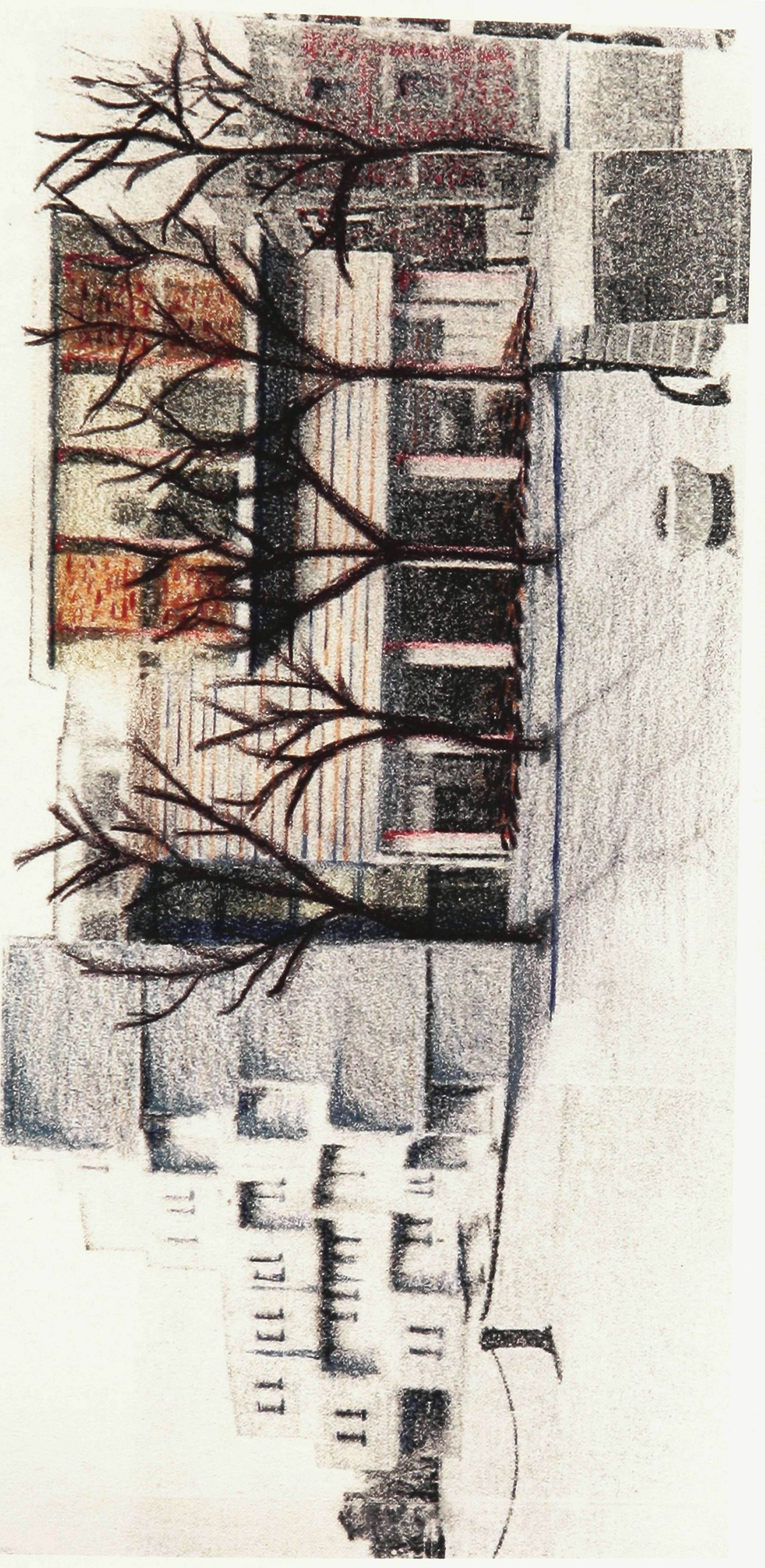

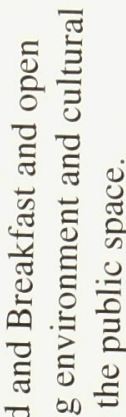

D.

$\cong$

ॠ

के के

8 in

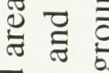

귬

$\frac{\pi}{60} \doteq$

$\Xi$.

$\Xi \frac{n}{\varrho}$

$\simeq$ ते क

.

훙

흘

\&

论

政

可它岳

훙

色

흥

है

$\stackrel{8}{=} \mathrm{D}$

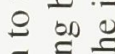

$\Xi . \Xi$

วิ을

응

ठ

产

के

$\&$ o

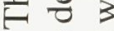

的吾

当䨔 


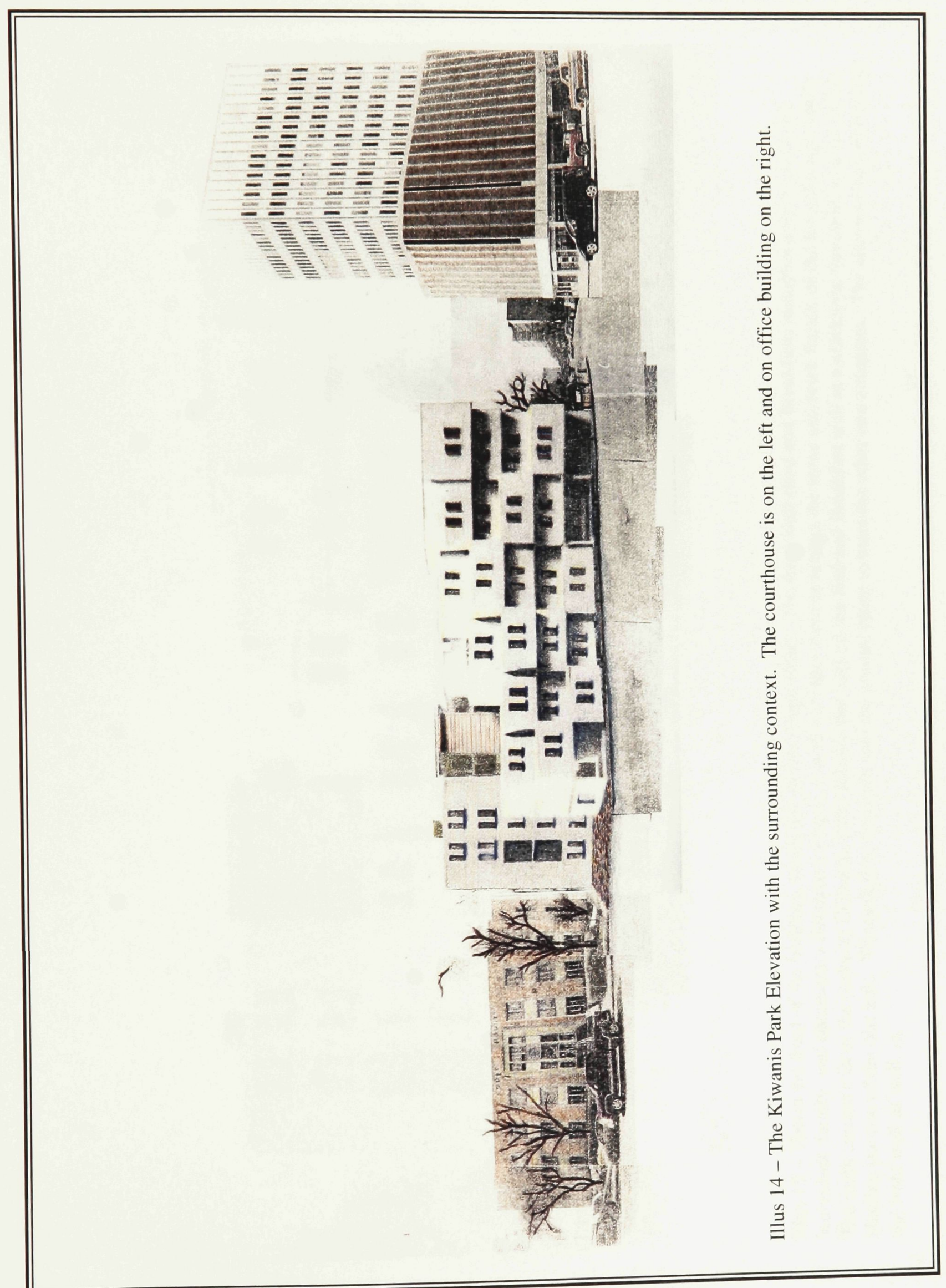




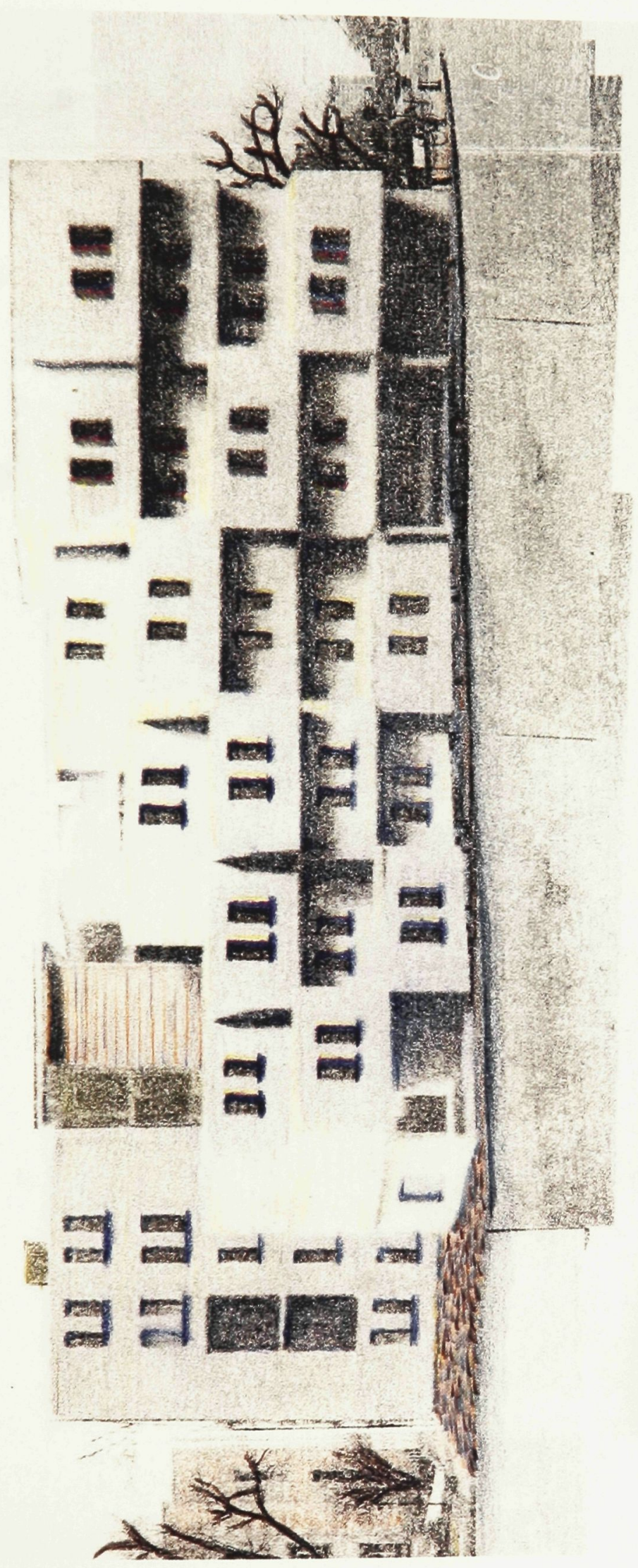

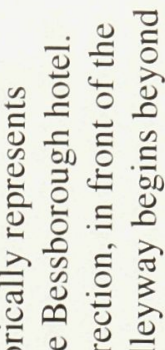

Ð. 巳

矛论

छ ะ

कิ

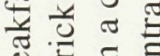

ํㅡㄹ

อ 范

它昰离

Q क क त

$\overline{\bar{\sigma}} \cong$

3 范

है के

o

F

ग 농

品苍

대요욜

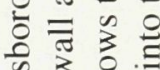

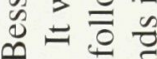

술을

on 윰

क्ष

oi 을 $\frac{3}{2}$

言造的

要需

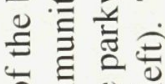

드원

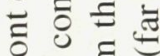

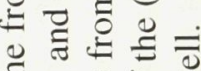

$\stackrel{5}{=} \therefore$

๓

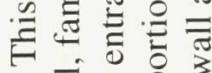

। $\bar{\Xi} \Xi$

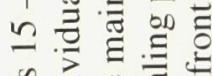

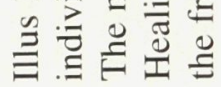




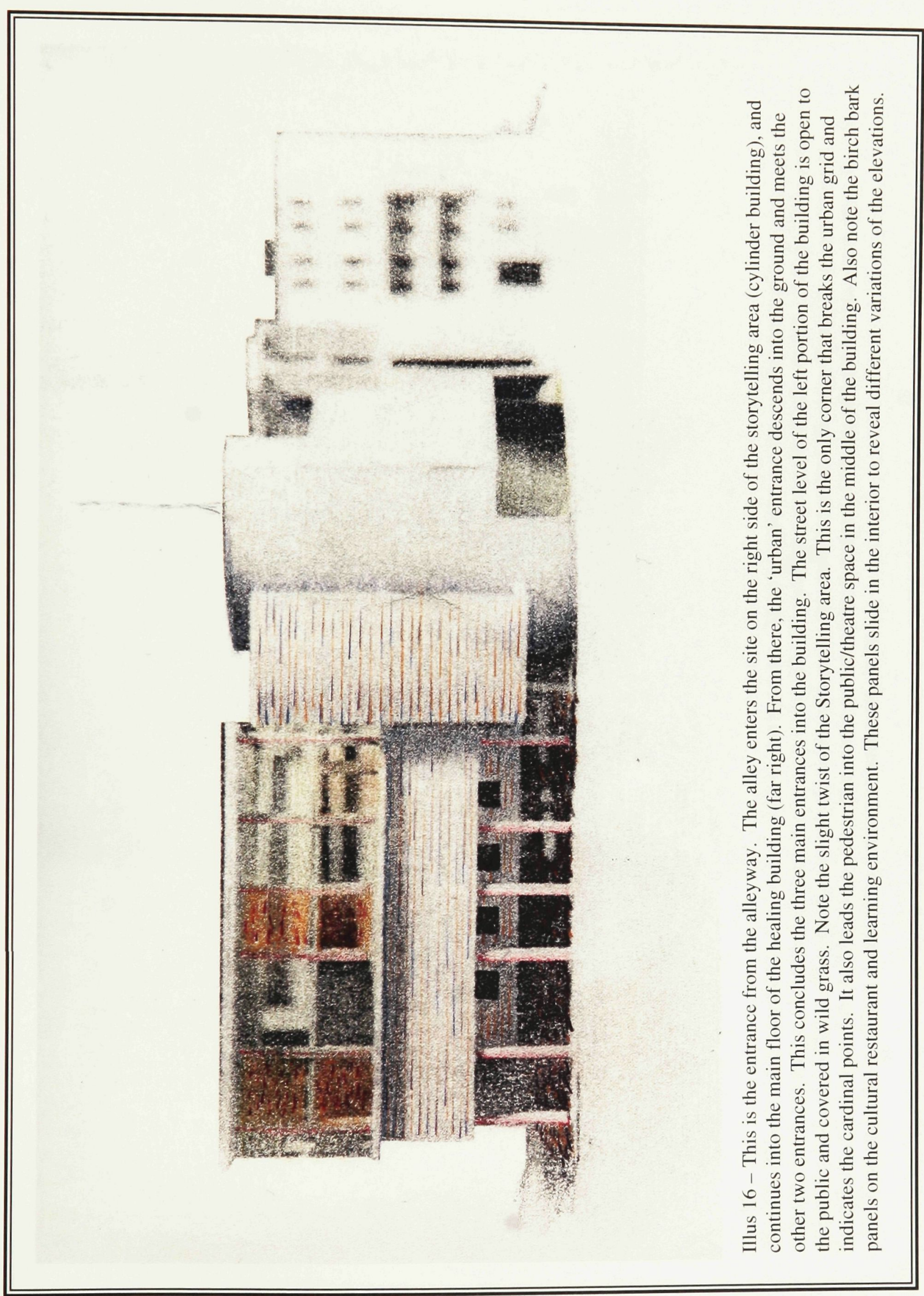




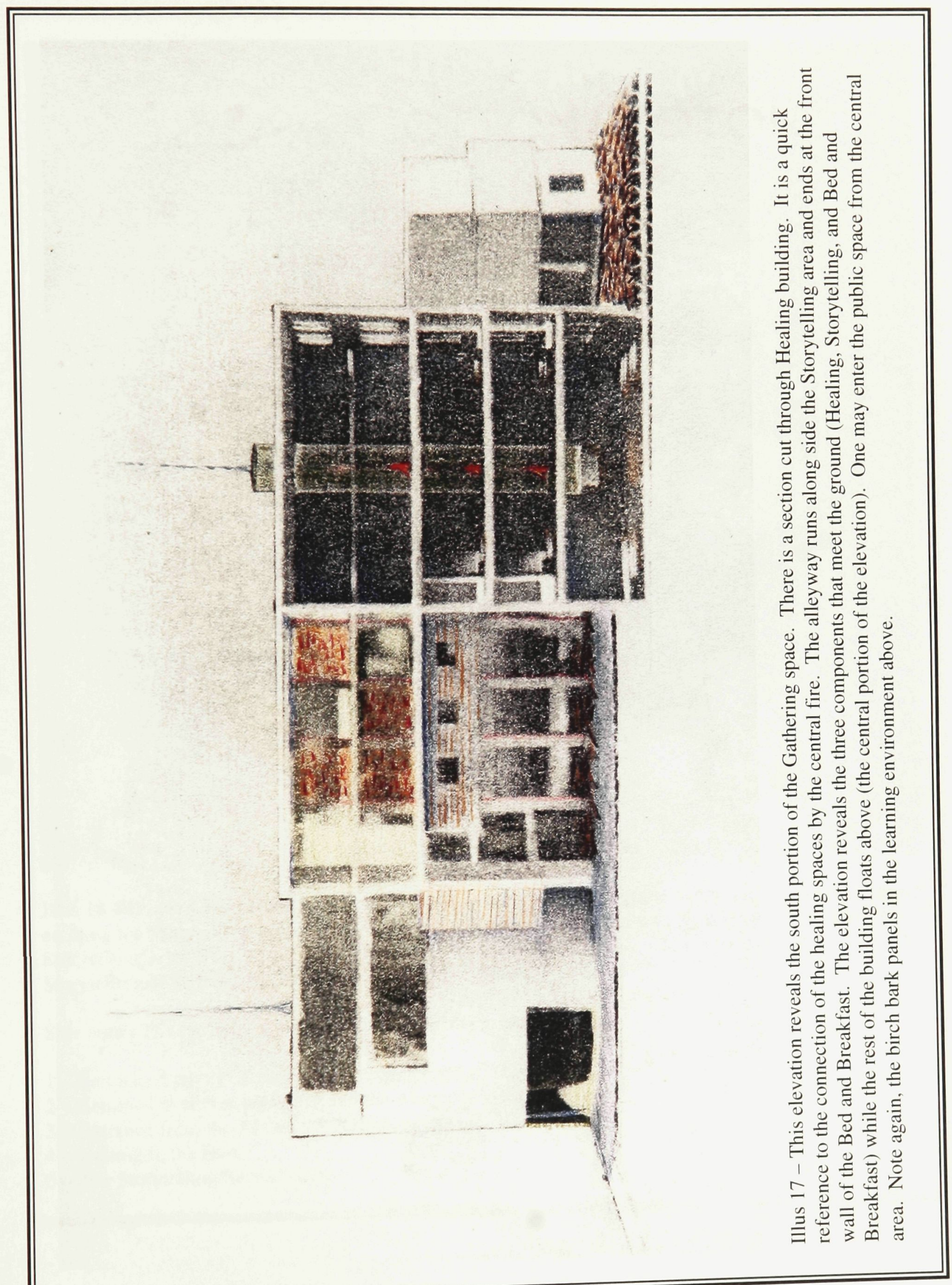




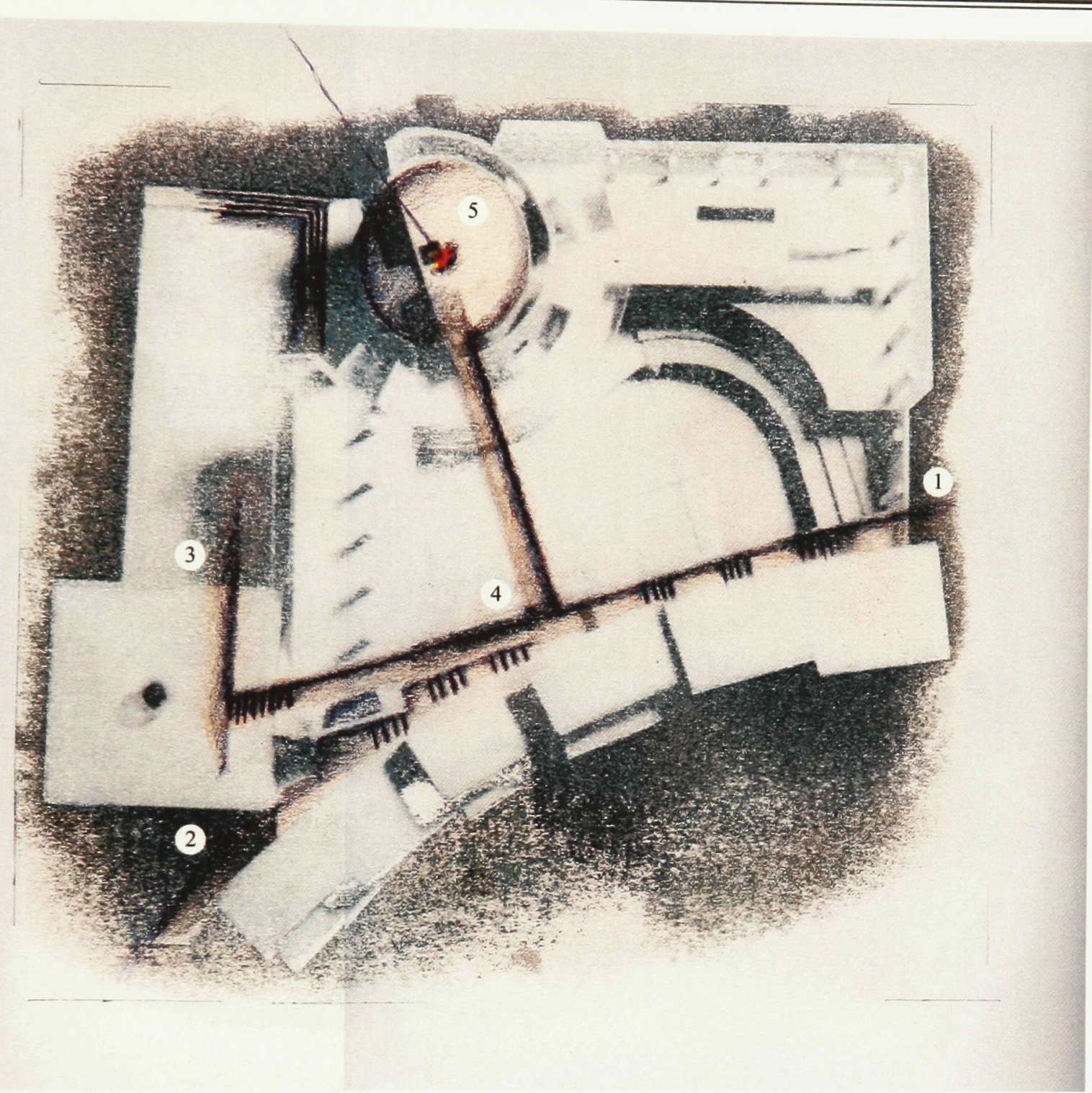

Illus 18 - Below Grade Floor Plan: Entering the ground plane from three points, uniting in the East and entering the Storytelling area. A constant fire burns while an elder awaits the initiation of stories. The Storytelling area is the 'spine' of the building. Circulation occurs clockwise around the perimeter of the Storytelling area, bringing the visitors to their destination in the building.

Side note: The elevator is located at the Kiwanis entrance (2).

1 - Entrance from $21^{\text {st }}$ Street (major commercial and pedestrian promenade).

2 - Entrance from Kiwanis Park and the Aboriginal gardens.

3 - Entrance from the Alleyways (urban entrance).

4 - Uniting in the East.

5 - The Storytelling/Sacred Area. 


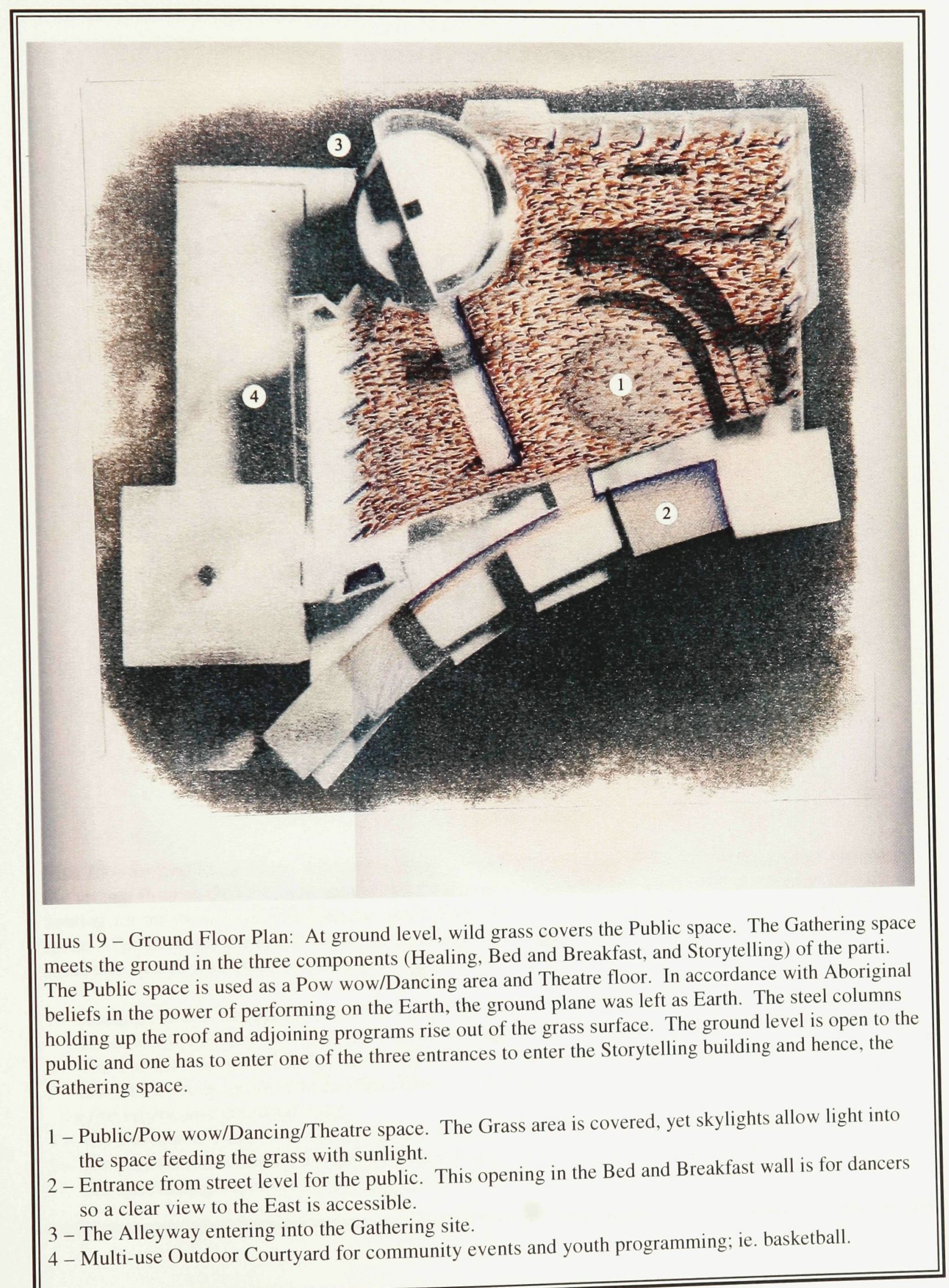




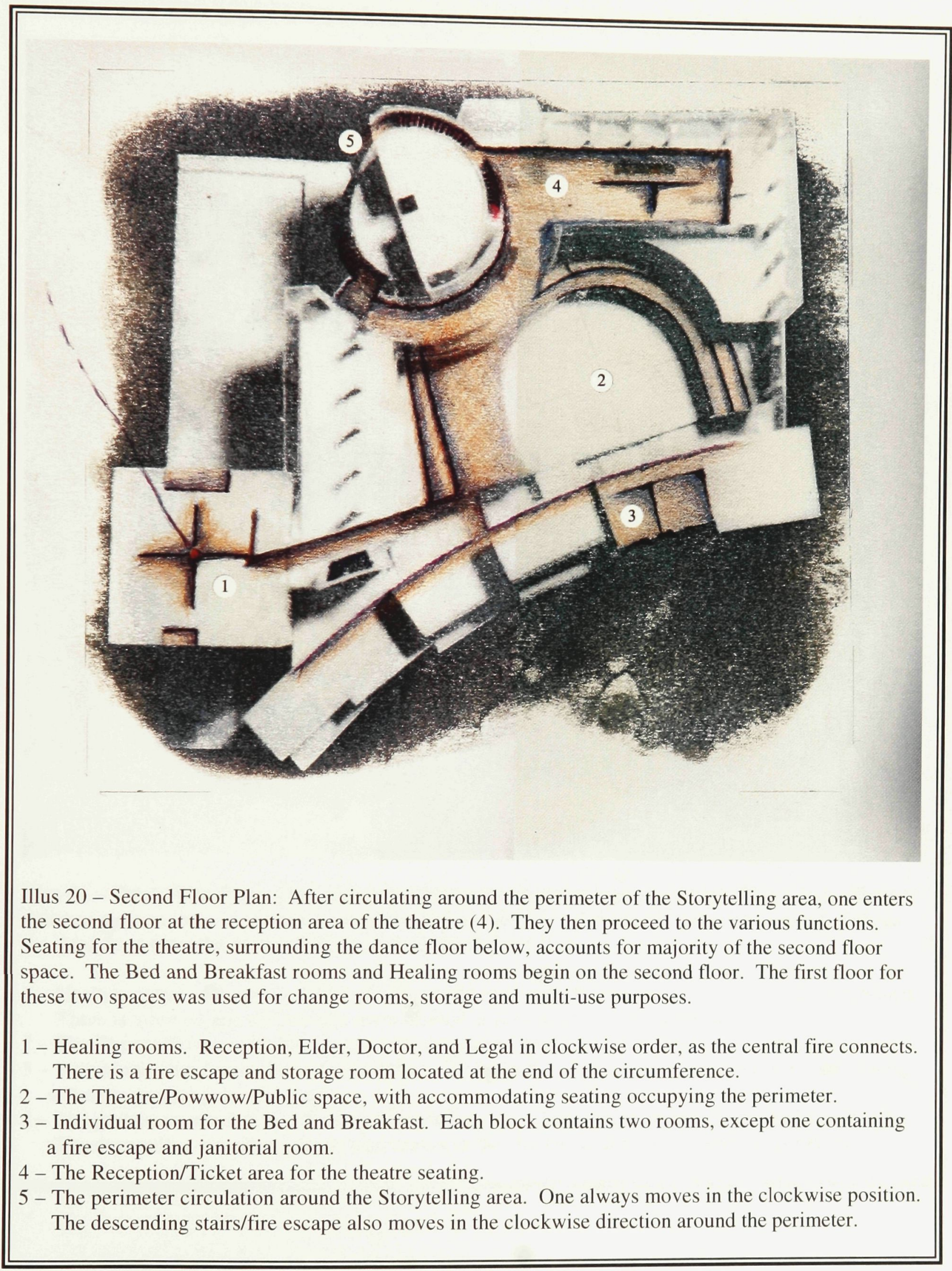




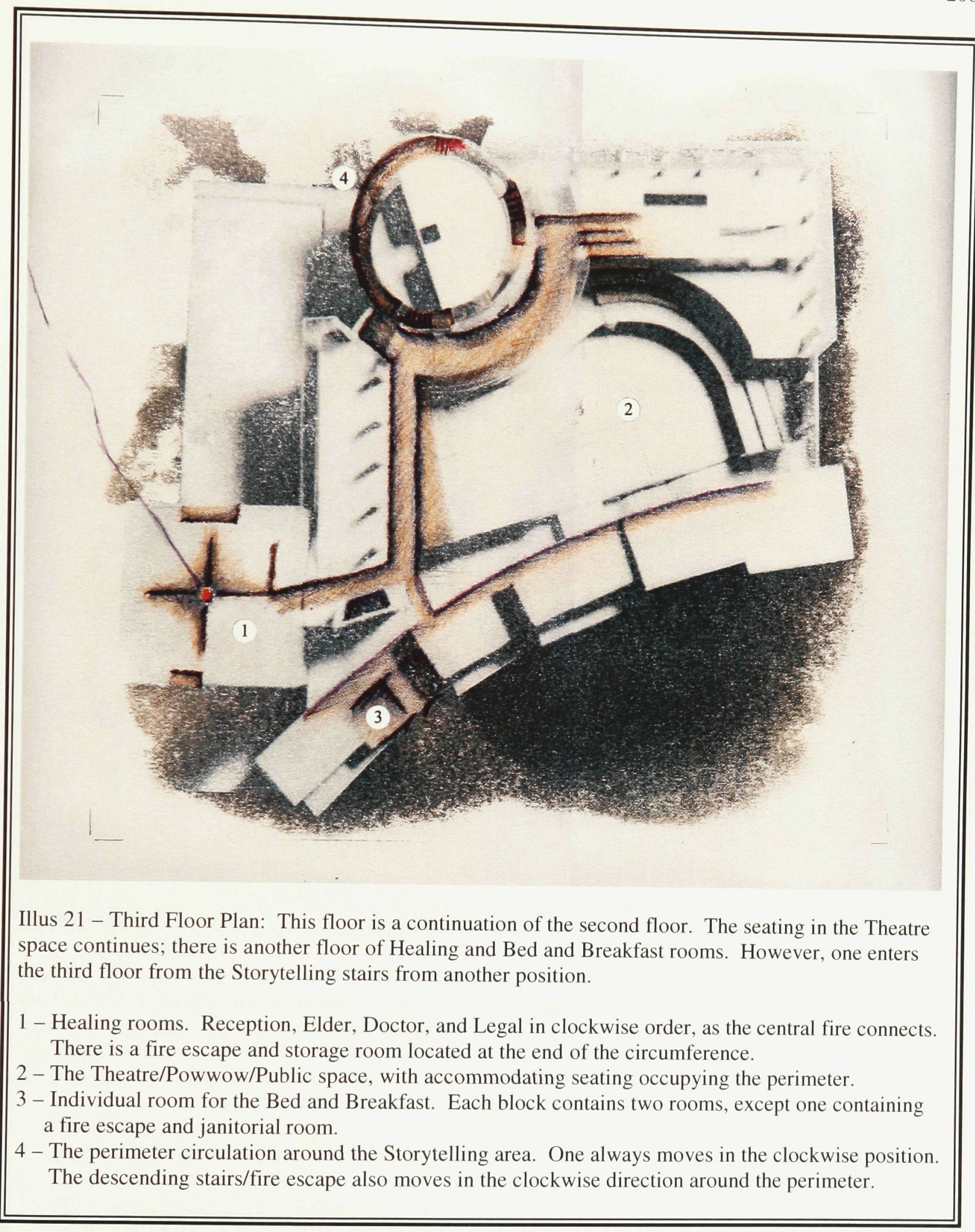




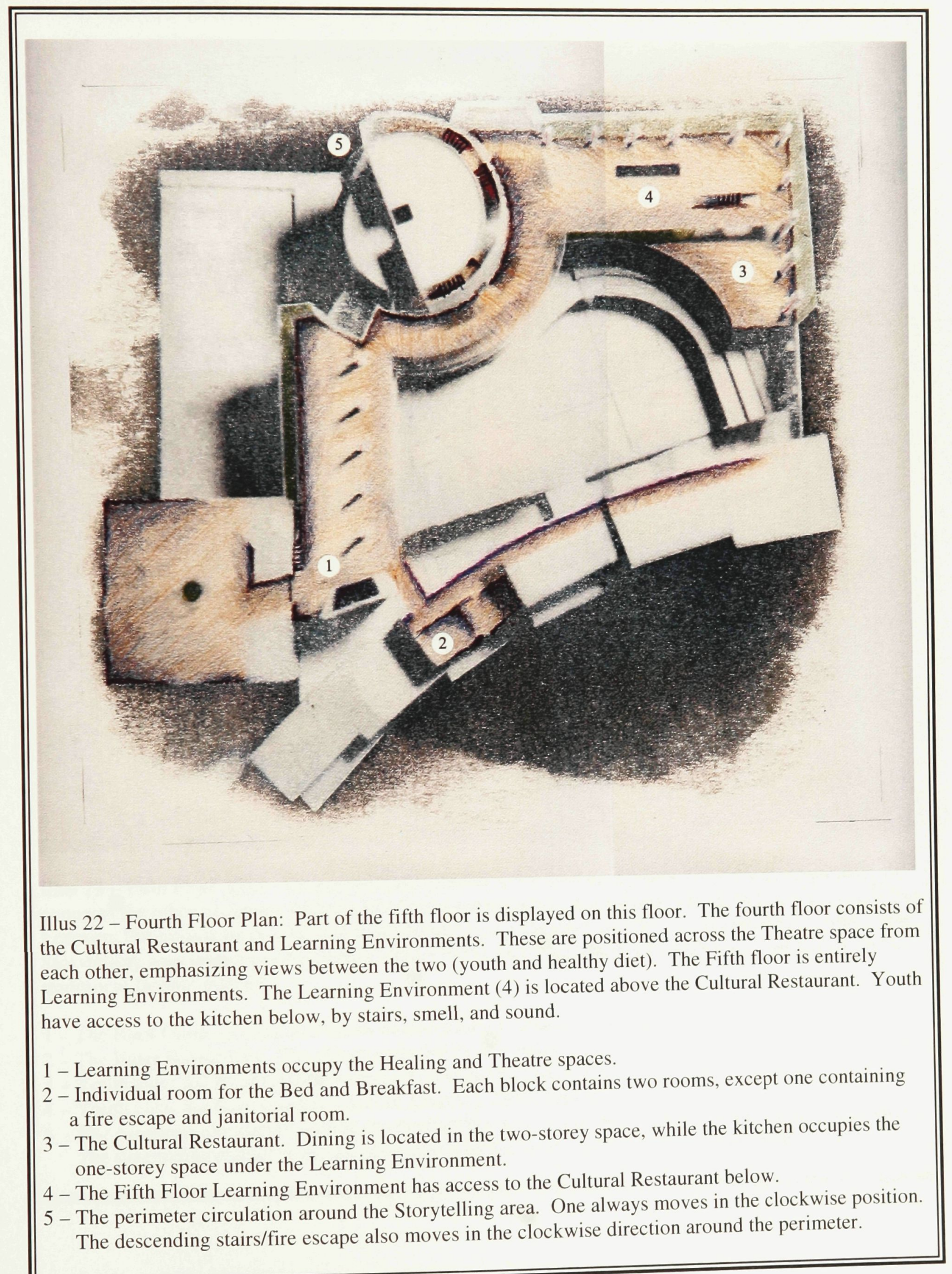




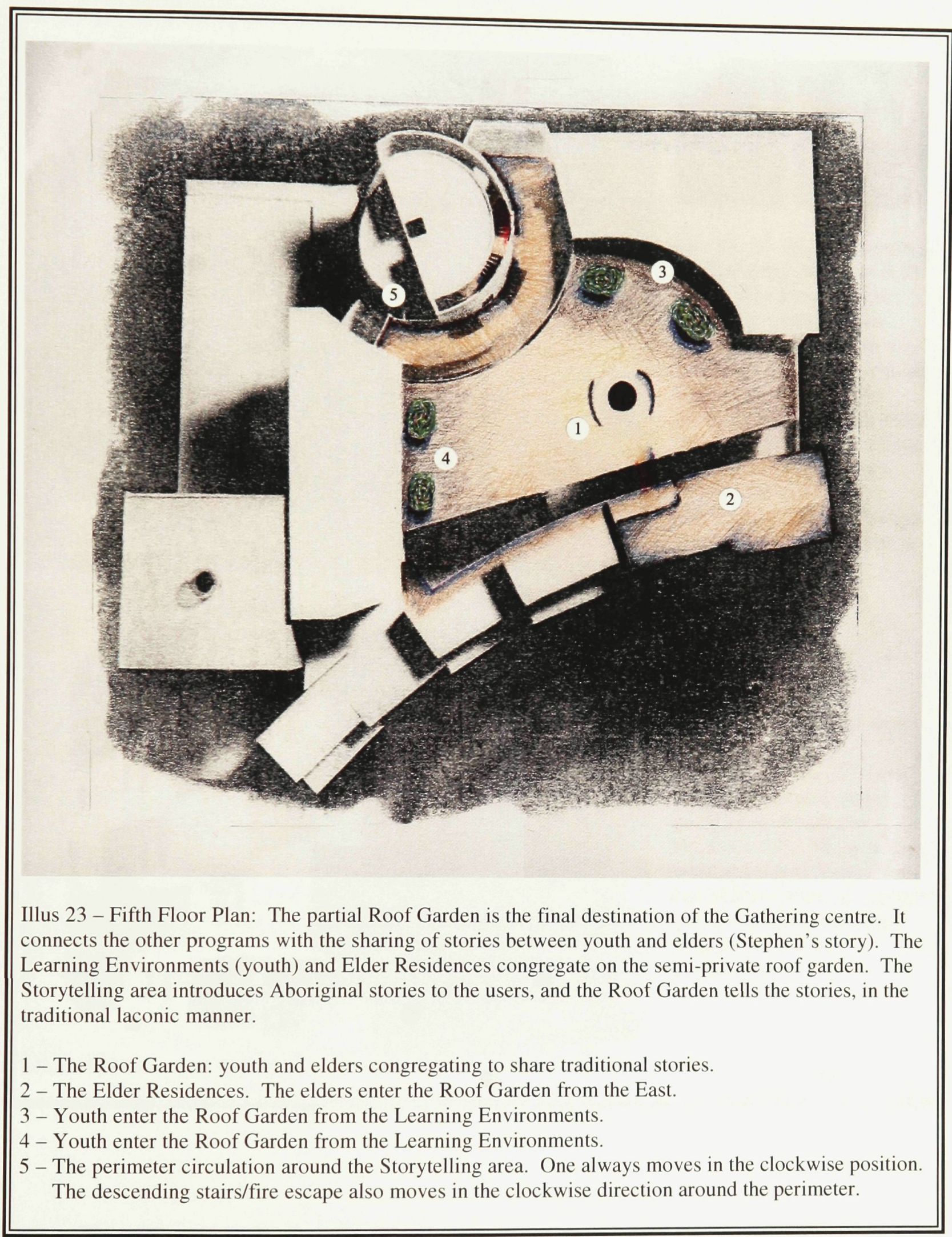




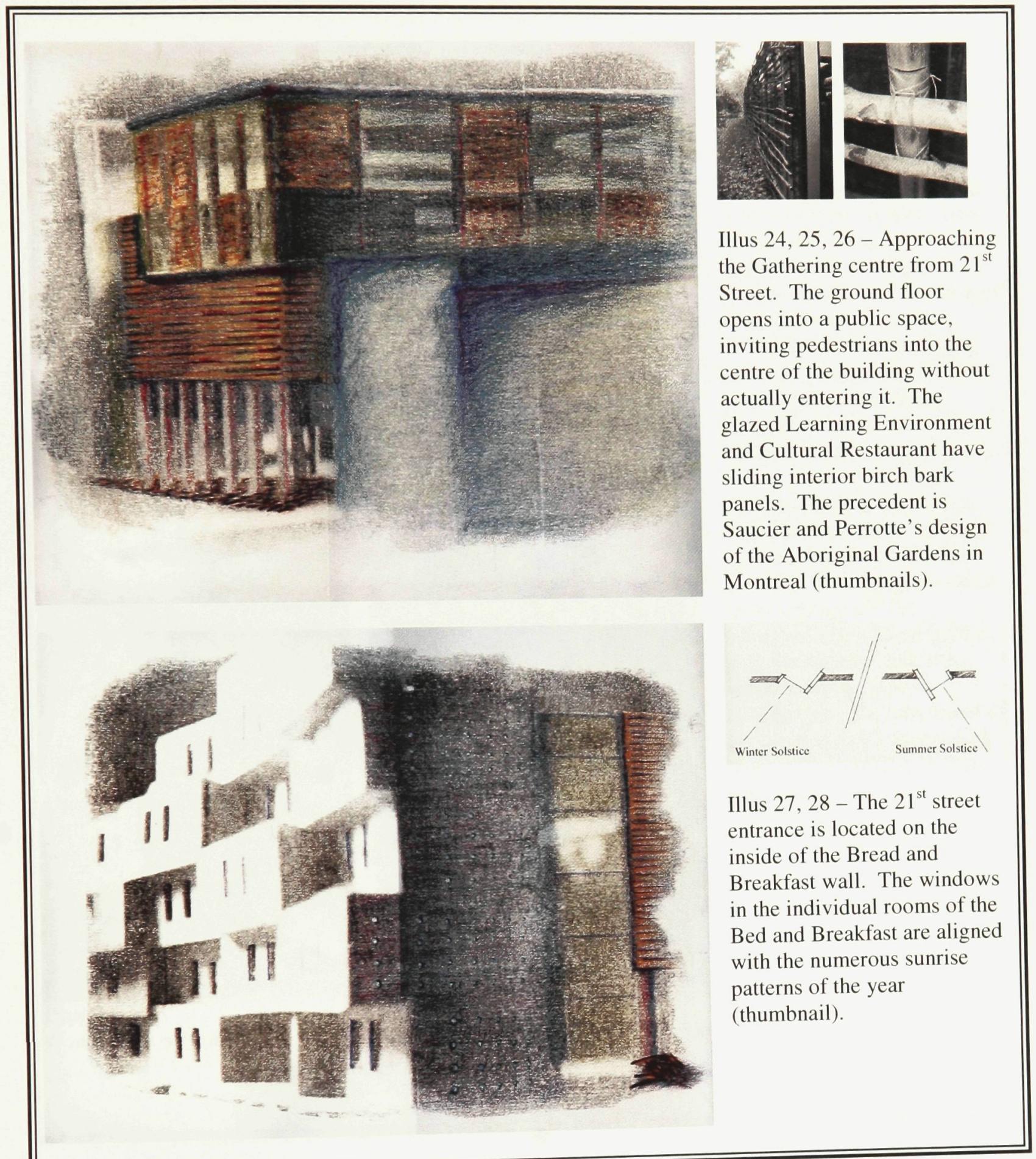




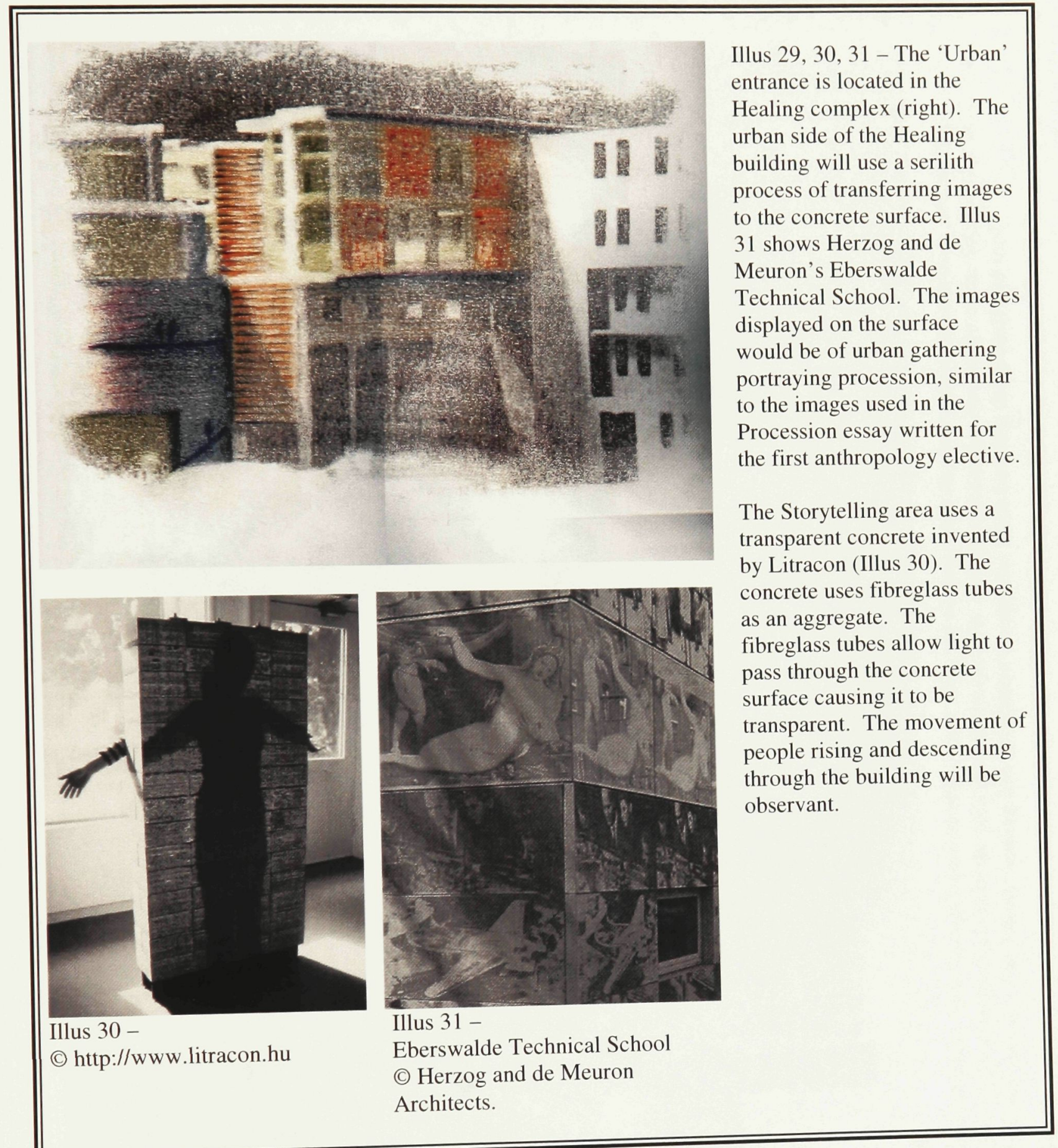




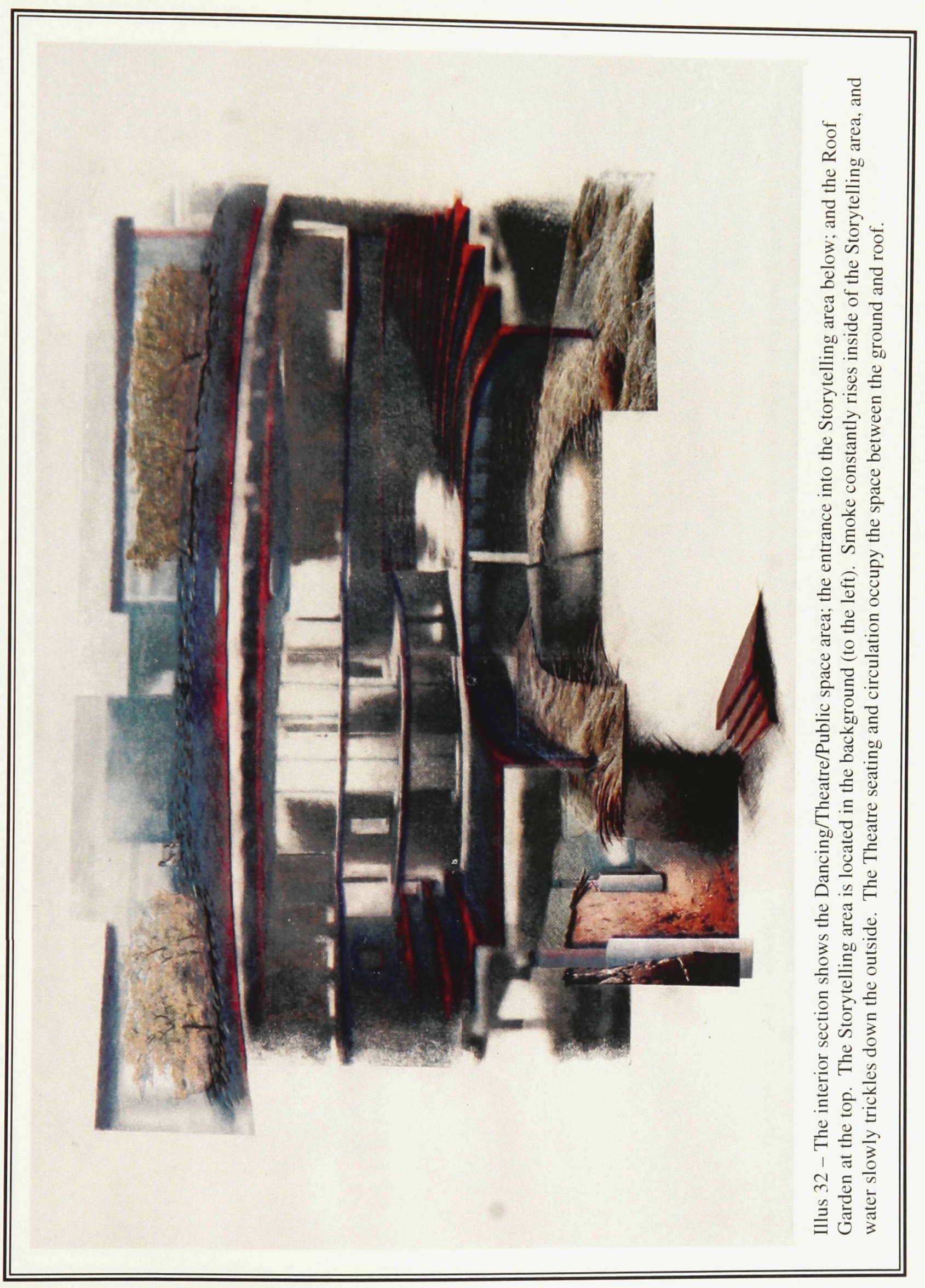




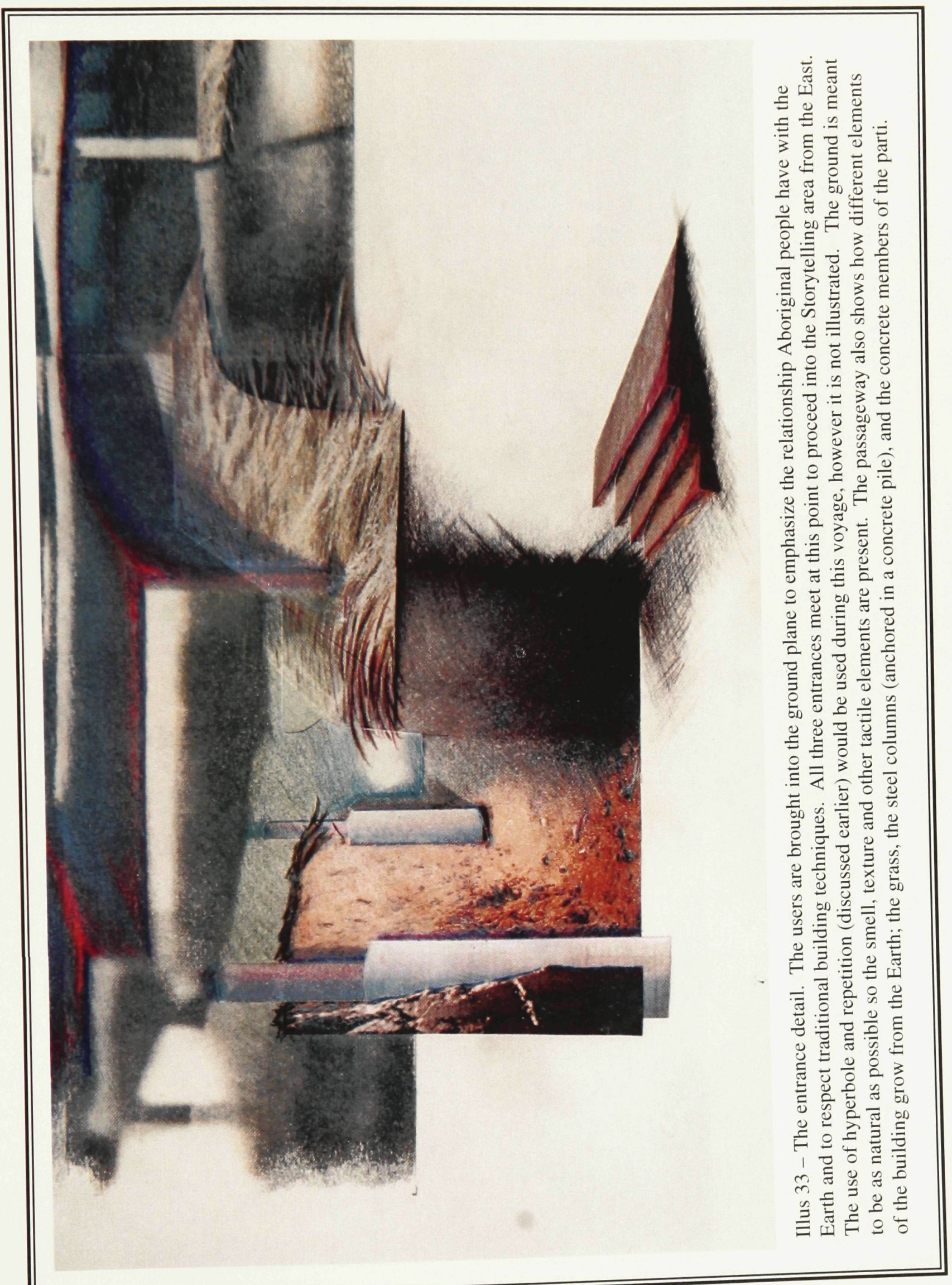




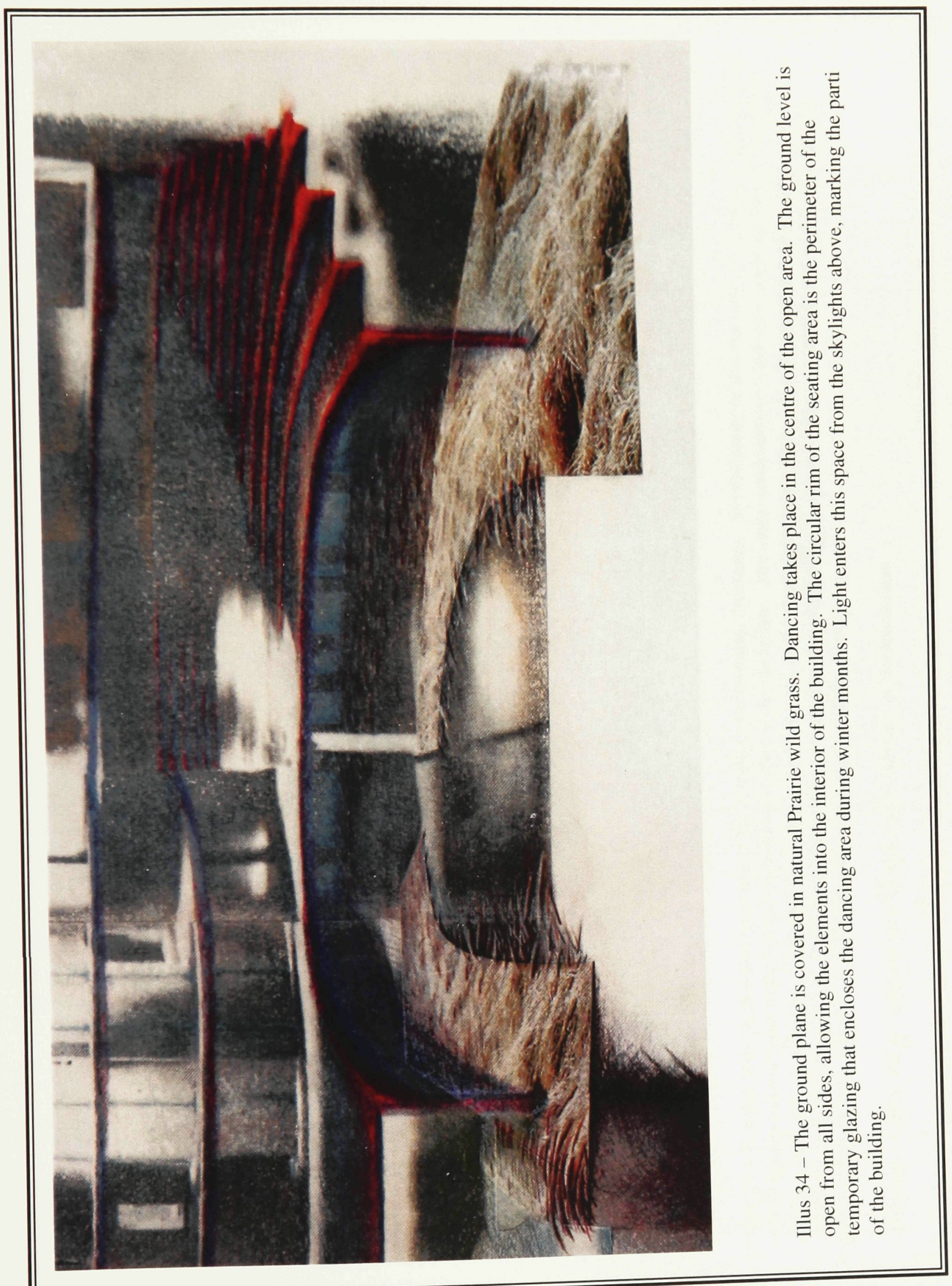




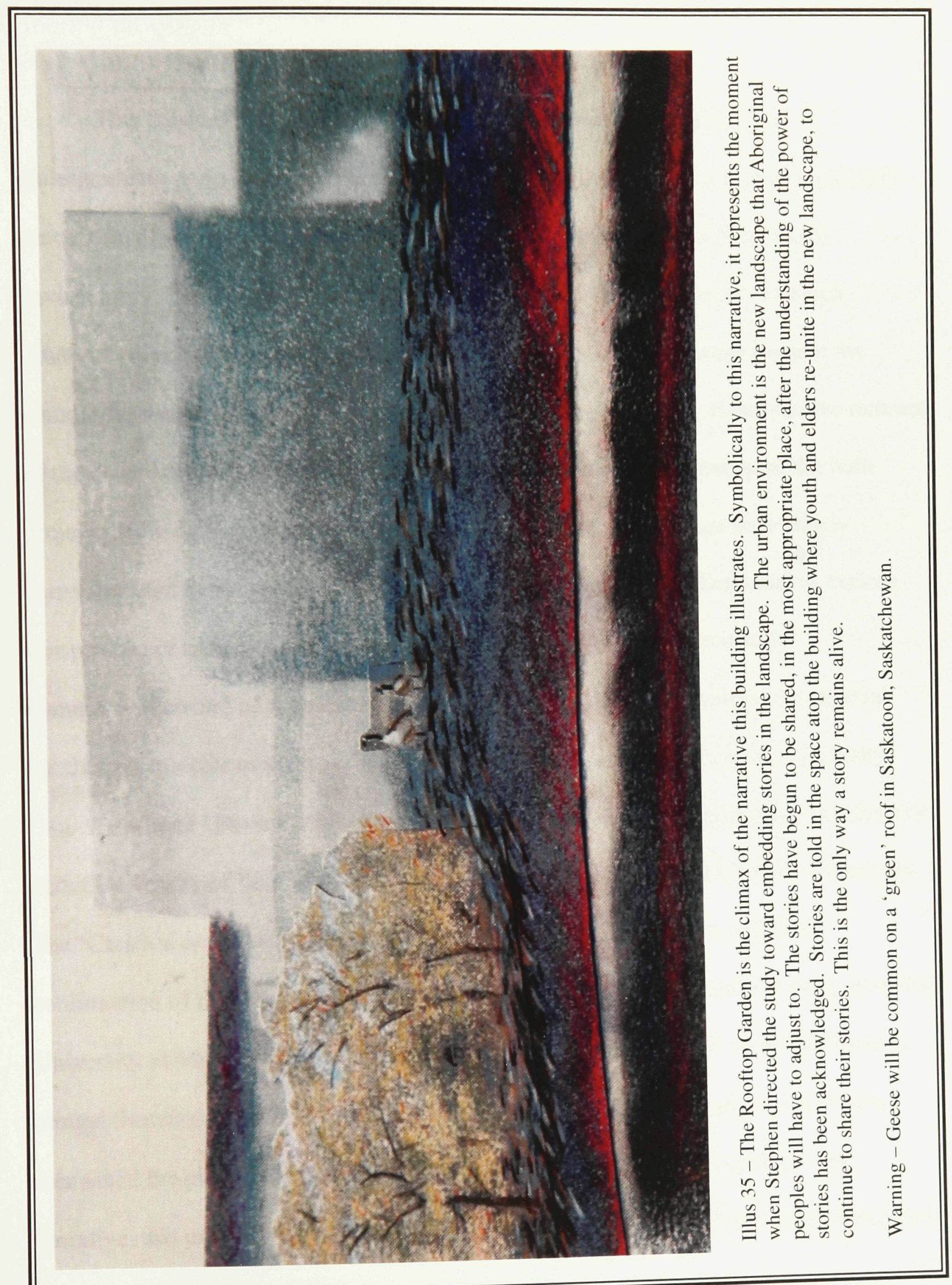


This thesis is a reflection upon six years of architecture school. The undergraduate program in architecture at the University of Manitoba initiated a design process focusing on how people associate themselves and react with their lived environment. This became the fundamental context for studio projects. Through observation, primarily structured in sociological methodologies, people became the context for design decisions, both architectural and programmatic. However, the richness of the observations was often lost in the translation to and representation of the built project. How does architecture represent these findings, and how are they clearly communicated to the people potentially being designed for? The thesis had to explore this process of social understanding, while clarifying architectural tools, for communication and of representation. To be truly rigorous, this exploration required another perspective towards architecture, hence the relocation to Carleton University.

Carleton University was an inspired choice initiated by undergraduate professors at the University of Manitoba, who were originally associated with Carleton University. The 'Carleton experience,' both professors and students, provided a refreshing continuation of the architectural explorations offered in the undergraduate program at the University of Manitoba. The Carleton architectural program tended to be structured around theoretical processes. These tools, for communication and of representation, connected the given project to the observations and context being explored. The narrative, this project's connective tool, situated the cultural and related conversations in the project context. 
The thesis also used the narrative structure of the written and documented thesis as a potential tool, for communication and of representation. Architecture is experiential, and this experience is reflected in the communication technique of the written document. The act of reading the thesis is structured as a continuation of the experience of the design process. This emphasizes the importance of the participant's involvement in the process of the project, and attempts to demonstrate a tool for communication that will be understood by these participants. The ethnography explorations provided a precedent to investigate the narrative as a tool for communicating, through the architecture and written document, with the people involved in the project. An objective of the thesis was to investigate tools for communication. The choice of the narrative will reveal its potential as, and if, the participants familiarize themselves with the final document.

To further the rigour of the process of obtaining several different perspectives of the same context, three advisors were chosen. Each advisor offered a unique perspective and established connections between the chosen peoples and their lived environment. This proved to be beneficial to the thesis. Having three advisors, two practising architects and one anthropologist, provided the process with a richness and diversity that would not have been present otherwise.

The initial involvement of participants proved quite successful. The limitation of the conversations was recognized during the architectural process. Kyle's response to the colour of the wall is an example of this. Partially due to the misrepresentation of the model, the colour proved to be the only critique of the design project. However, the recognition of the narrative's role in the landscape was beneficial to the validity of the 
design decisions. This document is the final investigation to examine communication between the designer and potential user. Kyle will eventually read this thesis, and the structure of the narrative will reveal its full potential, if any.

Dave, an architecture student, understood the architectural relevance of the wall and discussed important connections and observations in the project. He proved to be a successful participant at that stage in the project, where Kyle and the directors at the Friendship Centre could no longer benefit the architectural process. However, Dave could not have initiated the structure of the project with the same effectiveness as the directors of the Friendship Centre. When using potential users in the design process, one has to understand the limitations of their capabilities. This is an observation regarding the process of the thesis. The designer, to some degree, has to decipher the relevance of the conversations and make decisions accordingly. This also refers to the advisors and their individual criticism.

A pleasant surprise was the criticism offered by Derek, the anthropology advisor. His enthusiasm for interdisciplinary demeanour allowed for insights from a perspective outside the discipline of architecture. Apart from directing the narrative investigations and its relations to culture, Derek offered several relevant comments regarding the design. He could not have led an architectural exploration himself, but was an important contribution to the diversity of the thesis. As a note, one may be surprised at the understanding an outside perspective may have of a perception that any particular discipline thinks they know so well.

All three advisors were present during the design critiques. Their individual perspectives and observations of the design translation often differed, yet were 
compatible with each other. Bret offered a strong viewpoint, both architecturally and culturally, from his extensive experience designing with the culture. Derek offered a theoretical framework that focused on his own academic and cultural discoveries. Yves provided structure and guidance to these conversations. However, the final design decisions had to be made by the author. The advisors could only offer so much guidance. The discoveries had to rely on the process of the thesis, and how the author came to understand this exploration, in relation to his six years of architecture school.

The resultant design was a product of both, the journey into the culture and the destination. The narrative presented the connection between the two. Yves posed the question, with reference to Edmund Bacon, to consider the destination while observing the culture. The resultant design always maintained two specific objectives through the journey, to 'belong' to the existing environment of Saskatoon while providing a 'familiar' place for the Aboriginal culture. Norberg-Schultz articulates this when he wrote, "Urban gathering may be understood as an interpretation of the local genius, in accordance with the values and need of the actual society." To determine these values and needs, the journey is inevitable. It was an early position in the thesis that one must understand whom he/she is designing for if they are to represent this culture. The narrative became the appropriate design tool, by establishing a connection between what existed, what was told, and the approach, for communication and of representation.

As a final observation of the thesis, a story should be understood as never-ending. A story only initiates further stories. This thesis was a self-exploration that will continue to be pursued within the discipline of architecture. These were the interpretations and

\footnotetext{
${ }^{1}$ Norberg-Schultz, Genius Loci, 170.
} 
observations of the author. This is how he came to understand how narrative establishes itself in design. This thesis communicates architectural ideas to the world outside the school of architecture. The success of this will come from the reaction of the potential users to the finished thesis. As with any work, this thesis is intended to initiate stories, stories regarding architecture, urban design, and stories to be shared between cultures. 
Aalto, Alvar. Alvar Aalto: In His Own Words, edited and annotated by Göran Schildt. New York: Rizzoli International Publications, Inc., 1998.

Alexie, Robert A. Porcupines and China Dolls. Toronto: Stoddart Publishing Co. Ltd., 2002.

Augustine, Stephen J., Curator of Maritime Ethnology at the Canadian Museum of Civilization, Traditional Elder and Storyteller. Interview by author. Ottawa, Ontario, 3 September 2004.

Bacon, Edmund N. Design of Cities. 2d ed. New York: The Viking Press, 1974.

Barthes, Roland. "Introduction to the Structural Analysis of Narratives." In Narratology, edited by Susana Onega and Jose Angel Garcia Landa. New York: Longman Publishing, 1996.

Basso, Keith H. "Speaking With Names: Language and Landscape Among the Western Apache." Cultural Anthropology 3 (1988): 99-130.

Bell-Woodard, Georgia, Professor of Community Health at University of Saskatchewan. Interview by author. Saskatoon, Saskatchewan, 23 June 2004.

Bradley, Bevin, Art Director of the Saskatoon Community Youth Arts Programming Inc. Interview by author. Saskatoon, Saskatchewan, 23 June 2004.

Bruchac, Margaret M. "Earthshapers and Placemakers: Reflections on Algonkian Indian Stories of the Landscape." Text for Routledge Books, edited by H. Martin Wobst and Claire Smith, 2002.

Cowie, Gerry, Headed several Aboriginal Correctional Facility Projects while working with the Correctional Service of Canada Department in Saskatoon. Interview by author. Saskatoon, Saskatchewan, 22 June 2004.

Cruikshank, Julie. "The Social Life of Texts." In Talking on the Page, edited by Laura J. Murray and Keren Rice. Toronto: University of Toronto Press, 1999.

Dauenhauer, Nora Marks, and Richard Dauenhauer. "The Social Life of Texts." In Talking on the Page, edited by Laura J. Murray and Keren Rice. Toronto: University of Toronto Press, 1999. 
Deloria Jr., Vine, and Daniel R. Wildcat. Power and Place: Indian Education in America. Golden, Colorado: Fulcrum Resources, 2001.

Easton, Robert, and Peter Nabokov. Native American Architecture. New York: Oxford University Press, 1989.

Frampton, Kenneth. "Towards a Critical Regionalism: Six Points for an Architecture of Resistance." In The Anti-Aesthetic - Essays on Postmodern Culture, edited by Hal Foster, 16-30. Port Townsend, Washington: Bay Press, 1983.

Henderson, May, Executive Director of the Saskatoon Indian and Metis Friendship Centre. Interview by author. Saskatoon, Saskatchewan, 7 January 2004.

---. Interview by author. Saskatoon, Saskatchewan, 29 March 2004.

---. Interview by author. Saskatoon, Saskatchewan, 22 June 2004.

Johnston, Basil. "The Social Life of Texts." In Talking on the Page edited by Laura J. Murray and Keren Rice. Toronto: University of Toronto Press, 1999.

Kayseas, Ashley, Program Coordinator of the Saskatoon Indian and Metis Friendship Centre. Interview by author. Saskatoon, Saskatchewan, 6 January 2004.

Kennedy, Kyle, Aboriginal resident in Saskatoon. Interview by author. Saskatoon, Saskatchewan, 14 October 2004.

King, Thomas, Aboriginal author and Associate Professor of English at Guelph University. Interview by author. Toronto, Ontario, 14 August 2004.

---. Selected readings, Planet IndigenUs Festival. Harbourfront Centre, Toronto. 14 August 2004.

---. The Truth About Stories - A Native Narrative. Toronto: House of Anansi Press Inc., 2003.

Kinniewess, Blaine, Aboriginal man associated with Community Planning in Saskatoon. Interview by author. Saskatoon, Saskatchewan, 23 June 2004.

Laubin, Reginald, and Gladys Laubin. The Indian Tipi: Its History, Construction, and Use. 2d ed. Norman: University of Oklahoma Press, 1977.

Ling, Michael. "Between the Tongue and the Teeth: Conversations with a Cambodian Refugee; An Examination of Ethnography's Subject and Ethnography as Subject." Master's Thesis, Carleton University, Ottawa, 1990. 
Lynch, Kevin. The Image of the City. Cambridge: MIT Press, 1960.

Mandelbaum, David B. The Plains Cree: an Ethnographic, Historical, and Comparative Study. Regina: Canadian Plains Research Centre, 1979.

Monteyne, Tom. "The Back Page: The Legend of Neeginan." The Canadian Architect 44 (June 1999): 38.

Norberg-Schultz, Christian. Genius Loci. 2d ed. New York: Rizzoli International Publications, Inc., 1984.

Peters, Evelyn, Urban Geographer and Professor of Geography at University of Saskatchewan. Interview by author. Saskatoon, Saskatchewan, 18 June 2004.

Rosaldo, Renato. "Ilongot Hunting as Story and Experience." In Anthropology as Experience, edited by Victor W. Turner and Edward M. Bruner. Chicago: University of Illinois Press, 1986.

Rowe, Colin and Fred Koetter. Collage City. Cambridge: The MIT Press, 1978.

Schechner, Richard. Between Theatre and Anthropology. Philadelphia: University of Pennsylvania Press, 1985.

Schindelka, Roger, Vice-President of Planning, Research, and Development at Saskatchewan Indian Institute of Technologies. Interview by author. Saskatoon, Saskatchewan, 22 June 2004.

Speidel, Darlene F., Director of Cultural Resource Development \& Publications at the Saskatchewan Indian Cultural Centre. Interview by author. Saskatoon, Saskatchewan, 15 June 2004.

Stewart, David. Exploring Phenomenology. Athens: Ohio University Press, 1974.

Thomas, David, Masters of Architecture student at University of Manitoba, Aboriginal descent. Interview by author. Winnipeg, Manitoba, 29 September 2004.

---. Interview by author. Winnipeg, Manitoba, 5 October 2004.

Waldram, James B., Professor in Department of Psychology at University of Saskatchewan. Interview by author. Saskatoon, Saskatchewan, 30 March 2004. 
Secondary Bibliography:

Armstrong, Jeanette, ed. Looking at the Words of Our People: First Nations Analysis of Literature. Penticton, BC: Theytus Books Ltd., 1993.

Armstrong, Jeannie. "National Aboriginal Day Events Begin at Kiwanis Park, Culminate at Wanuskewin." Saskatoon Star Phoenix, 20 June 2003: F1.

Armstrong, Jeannie. "Kiwanis Park Site of Tomorrow's National Aboriginal Day Festivities." Saskatoon StarPhoenix, 20 June 2002: C7-8.

Armstrong, Jeannie. "Thursday, June 21 at Kiwanis Park: National Aboriginal Day Events Celebrate Youth.” Saskatoon StarPhoenix, 20 June 2001: E1.

Armstrong, Jeannie. "Celebrate National Aboriginal Day Tomorrow in Kiwanis Park." Saskatoon StarPhoenix, 20 June 2000: C6.

Auten, Mel. Interview by author. Saskatoon, Saskatchewan, 18 June 2004.

Battiste, Virginia. "Urban Natives Take Initiative for Healing." Saskatoon StarPhoenix, 22 June 1996: D15.

Bauer, George W. "Symbolism of the Plains Indians' Sun Dance." Canadian Geographic 98 (June-July 1979): 58-65.

Bloomfield, Leonard. Sacred Stories of the Sweet Grass Cree. 1930. Saskatoon: Fifth House Publishers, 1993.

Canty, Donald. “Aerodynamic School." Progressive Architecture, May 1992: 142-147.

Cardinal, Douglas J. "Architecture as a Living Process: lecture by Douglas J. Cardinal." Washington: IDB Cultural Center, 1997.

Carroll, Lewis. Alice's Adventures in Wonderland. New York: Scholastic Book Services, 1966.

Cresswell, J. R. "Folk-tales of the Swampy Cree." Journal of American Folklore 36 (1923): 404-406. 
Cruikshank, Julie. Life Lived Like a Story. Lincoln: University of Nebraska Press, 1990.

---. The Social Life of Stories: Narrative and Knowledge in the Yukon Territory. Vancouver: University of British Columbia Press, 1998.

Cunningham, Alain MacAlpine. Canadian Indian Policy and Development Planning Theory. New York: Garland, 1999.

Darnton, Robert. The Great Cat Massacre and Other Episodes in French Cultural History. New York: Basic Books, Inc., 1984.

Dupriez, Bernard. A Dictionary of Literary Devices. Trans. Albert Halsall. Toronto: University of Toronto Press, 1991.

Eco, Umberto. Interpretation and Overinterpretation. edited by Stefan Collini. Cambridge: Cambridge UP, 1992.

Erdrich, Louise. Books and Islands in Ojibwe Country. Washington D.C.: National Geographic Society, 2003.

Exner, James. Interview by author. Toronto, Ontario, 19 December 2003.

Exner, Elizabeth. Interview by author. Melville, Saskatchewan, 23 December 2003.

Gossen, Gary H. Chamulas in the World of the Sun: Time and Space in a Maya Oral Tradition. Cambridge: Harvard University Press, 1974.

Jorgenson, Joseph G. The Sun Dance Religion. Chicago: University of Chicago Press, 1972.

Kehoe, Alice Beck. The Ghost Dance: Ethnohistory and Revitalization. New York: Holt, Rinehart, and Winston, 1989.

Kehoe, Thomas F. and Alice Beck Kehoe. "Stones, Solstices, and Sun Dance Structures." Plains Anthropologist 22 (May 1977): 85-95.

King, Thomas. Green Grass, Running Water. Toronto: HarperCollins Publishers Ltd., 1993.

---. Truth and Bright Water. Toronto: HarperCollins Publishers Ltd., 1999.

---. “A Coyote Columbus Story." In One Good Story, That One. Toronto: HarperCollins Publishers Ltd., 1993. 
---. “Coyote and the Enemy Aliens." In Our Story. Toronto: Doubleday Canada, 2004

Krinsky, Carol Herselle. Contemporary Native American Architecture: Cultural Regeneration and Creativity. New York: Oxford University Press, 1996.

Krotz, Larry. Urban Indians. Edmonton: Hurtig Publishers Ltd., 1980.

Marple, Charity. "New Architectural Process in British Columbia First Nations Schools." Master's Thesis, Carleton University, Ottawa, 1998.

Mooney, James. The Ghost Dance Religion and the Sioux Outbreak of 1890, 1896.

Chicago: University of Chicago Press, 1965.

Nerdinger, Winfried, ed. Alvar Aalto: Toward a Human Modernism. New York: Prestel Verlag, 1999.

Nagler, Mark. Indians in the City. Ottawa: Saint Paul University, 1970.

O'Brodovich, Lloyd. "Plains Cree Sun Dance." The Western Canadian Journal of Anthropology 1 (1969): 71-87.

Pettipas, Katherine. Severing the Ties that Bind: Government Repression of Indigenous Religious Ceremonies on the Prairies. Winnipeg: University of Manitoba Press, 1994.

Reading, Christopher Earl. Kehawin School: The Architecture of Native SelfDetermination. Master's Thesis, University of Alberta, Edmonton, 1996.

Robinson, Eden. Monkey Beach. Toronto: Alfred A. Knopf Canada, 2000.

Schlesier, Karl. "Rethinking the Midewiwin and the Plains Ceremonial Called The Sun Dance." Plains Anthropologist 35 (1990): 1-27.

Semper, Gottfried. The Four Elements of Architecture and Other Writings, 1851, translated by Harry Francis Mallgrave and Wolfgang Herrmann. Cambridge: New York: Cambridge University Press, 1989.

Silko, Leslie. Ceremony. New York: Viking Press, 1997.

Stewart, Patrick Reid. "Designing for Canada's Native Population." Canadian Architect. Feb. 1991: 18.

Storm, Hyemeyohsts. Seven Arrows. New York: Ballantine Books, 1972. 
Summerson, John. Heavenly Mansions and Other Essays on Architecture.

New York: London: W. W. Norton and Company, 1963.

Turner, Victor. The Forest of Symbols: Aspects of Ndembu Ritual. Ithaca: Cornell University Press, 1967.

Waldram, James B. The Way of the Pipe : Aboriginal Spirituality and Symbolic Healing in Canadian Prisons. Peterborough, Ont.: Broadview Press, 1997.

Weder, Adele. "Native Intelligence." Canadian Architect 45 (February 2000): 22-26.

When the People Gather: Sun Dance of the Teton Sioux. David Zimmerly Collection. Canadian Museum of Civilization: A-V Archives, 1968. Century Theories of Architecture and the Applied Arts. 1986. 376-397. 
Appendix A:

\section{Letter of Information and Consent}

Thesis Student: Bobby Ilg

Advisor: Yves Gosselin

Secondary Advisors: Bret Cardinal

Derek G. Smith

Department of Graduate Studies at Carleton University

Faculty of Architecture (M. Arch Thesis)

This research study is being undertaken by me, Bobby Ilg as part of my requirements towards my Masters of Architecture degree. I am a student at Carleton University in Ottawa, ON. This study will examine Aboriginal identity and expression through architecture and the experiential environment. I am interested in your opinion on these matters. The project will use this interview as a way of establishing Aboriginal and nonAboriginal cultural familiarity within the existing urban context.

The potential benefits of participation include a brief understanding of how the built and experienced environment (architecture) can effect the interaction and relationship between Aboriginal and non-Aboriginal peoples. This will only be gradually understood through ongoing interviews and participation in the project or by reading the final document at the end of the project.

The interview will take between 30-60 minutes and involve open-ended questions and/or possible short design presentations. You are encouraged to participate in a series of dialogues with the researcher over the course of the thesis to follow, learn from, and nourish the progress of the thesis. If at any time you wish to withdraw from answering questions from the study you are free to do so. Should you decide to stop the interview you may decide at that time if I may use the information you have provided to that point. As remuneration for your involvement you will be offered a final thesis document.

Risks that may occur are issues regarding anonymity and security of data. There will be no video or tape recordings of the conversations, and all notes will be written after the discussions have taken place. There will be no direct quoting, only paraphrasing within the thesis document. However, you will not be given the opportunity to choose anonymity. I have selected to talk to you specifically because of your expertise in a your specific field. I feel this should be respected and acknowledged as such. Documents will be stored in locked facilities during the course of the thesis project. My advisors and I will be the only individuals with access to the data. The data will be kept in a security box after completion of the thesis for further research and publication purposes. The 
studies will be used only in the thesis itself, including any possible future publications associated with it.

Involvement in this study may be declined or revoked at any time during the course of the thesis. Should you have any questions, please contact the Ethics Committee at Carleton University, my supervisor or myself. Below is the contact information:

Bobby Ilg

Yves Gosselin

Yves.Gosselin@pwgsc.gc.ca

Prof. Antonio Gualtieri, Chair

Carleton University Research Ethics Committee

Office of Research Services

511A Tory Building

1125 Colonel By Drive

Ottawa, ON K1S 5B6

Tel: 6135202517

ethics@carleton.ca

This project has been reviewed and received ethics clearance through the Carleton University Research Ethics Committee. Should you have any questions or concerns about your involvement in this project you should contact the ethics committee chair listed above.

Bobby Ilg

I, have read the above

information and any questions have been answered to my satisfaction. I understand that my participation is voluntary and I may withdraw at any time.

Signature

Date 